Universidad de Lima

Facultad de Ingeniería y Arquitectura

Carrera de Arquitectura

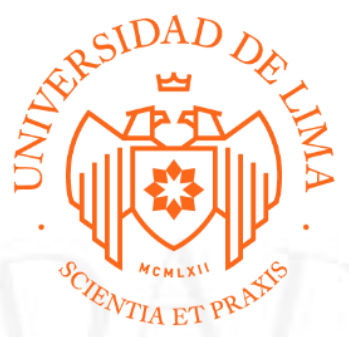

\title{
PARQUE RECREATIVO Y CENTRO COMUNAL MIRADOR DE MANCHAY
}

Trabajo de suficiencia profesional para optar el Título Profesional de Arquitecto

\section{Gustavo Alfredo Pulido Del Castillo}

Código 20110999

\section{Asesor}

Arq. Carmen Hilda Omonte Miraval

$$
\text { Lima - Perú }
$$

Agosto del 2019 


\section{MIRADOR DE MANCHAY RECREATION PARK AND COMMUNITY CENTER}




\section{TABLA DE CONTENIDO}

\section{INTRODUCCIÓN...................................................................................1}

CAPÍTULO I: GENERALIDADES......................................................2

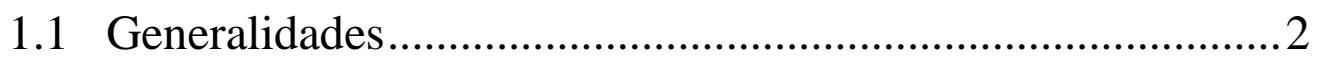

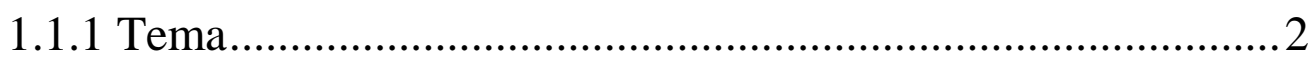

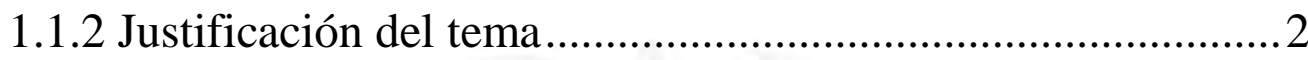

1.1.3 Planteamiento del problema................................................... 3

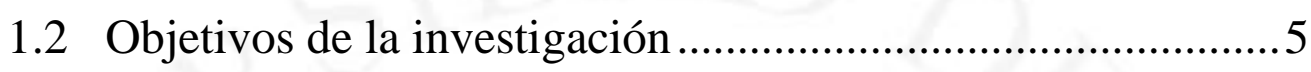

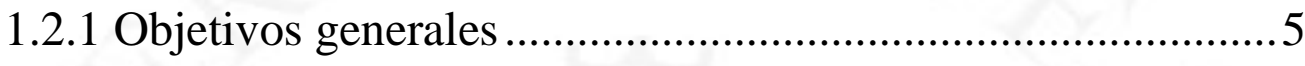

1.2.2 Objetivos específicos ........................................................

1.3 Supuesto básico de la investigación........................................... 6

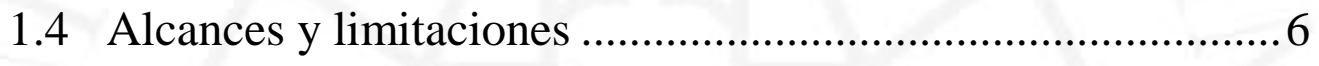

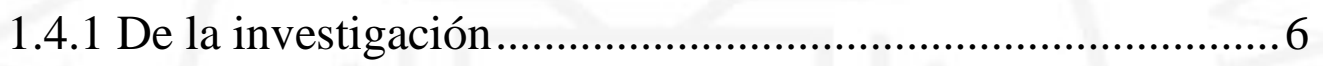

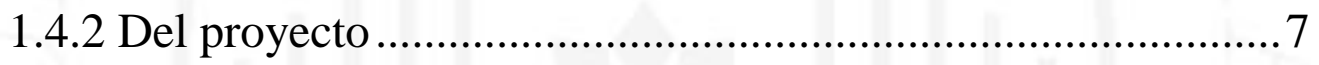

1.5 Diseño de la investigación ......................................................... 7

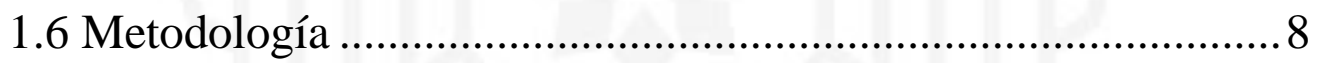

1.6.1 Forma de recopilación de la información ............................... 8

1.6.2 Forma de análisis de la información ....................................... 8

1.6.3 Forma de presentación de la información...............................9

CAPÍTULO II: MARCO REFERENCIAL ....................................10

2.1 Expansión urbana de Lima........................................................... 10

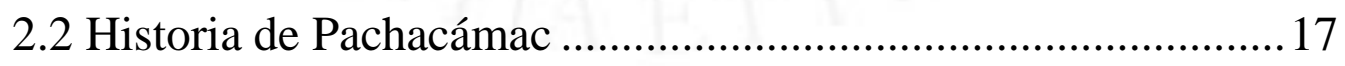

2.3 Historia de Manchay ................................................................22

2.4 Información de Pachacamac y Manchay ...................................22

2.4.1 Ubicación geográfica ..........................................................28

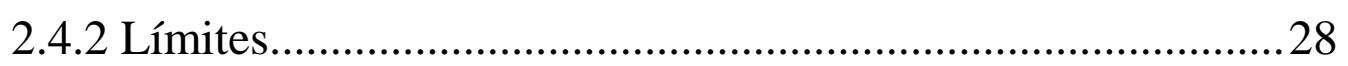

2.4.3 Extensión y Ubicación ...........................................................29

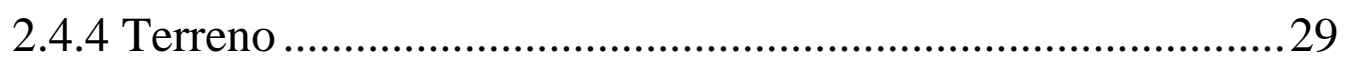




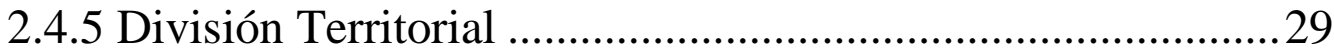

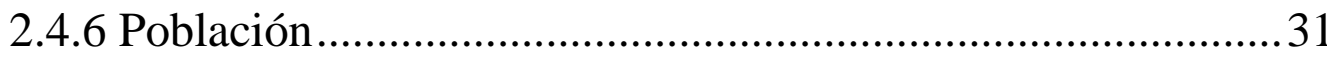

2.4.7 Aspectos Sociodemográficos ................................................... 31

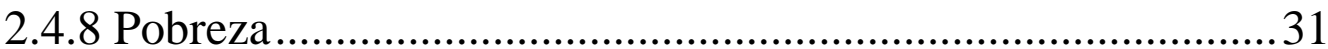

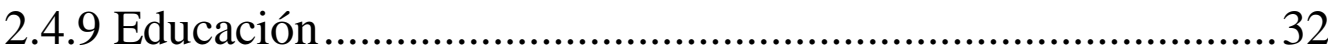

2.4.10 Población Económicamente Activa (PEA) ............................35

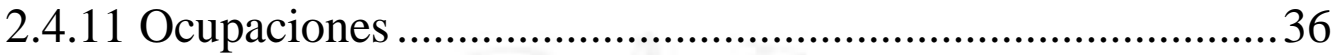

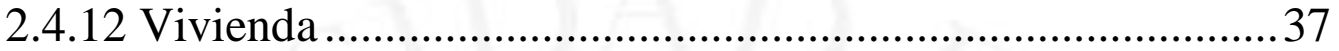

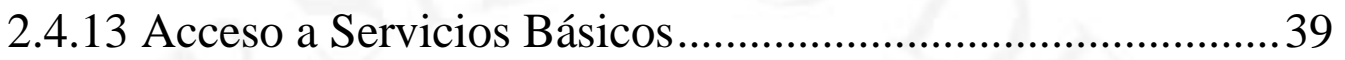

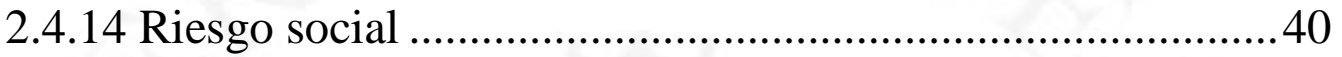

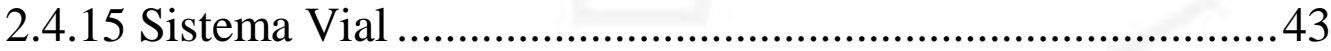

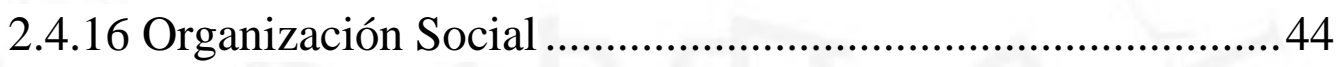

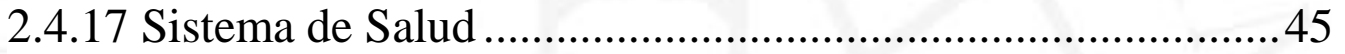

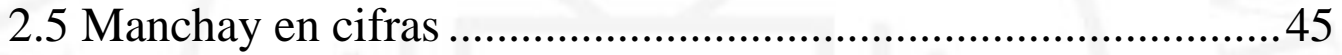

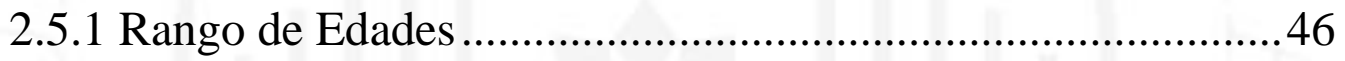

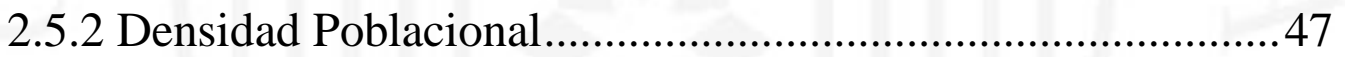

2.5.3 Crecimiento Poblacional ..........................................................4

2.5.4 Población Económicamente Activa (PEA) .............................48

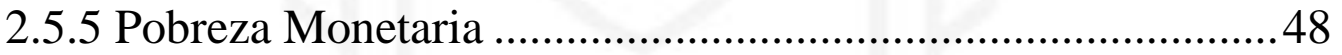

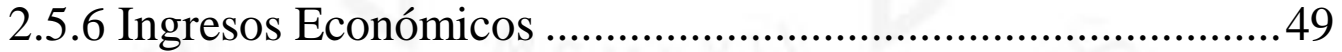

2.5.7 Población que únicamente ha alcanzado educación primaria49

2.5.8 Índice de Desarrollo Humano (IDH) ...................................50

2.5.9 Población con Discapacidad Motora ……………...................50

2.5.10 Población con Discapacidad Sensorial ..................................51

2.5.11 Zonas de Concentración de Precariedad ...............................51

2.5.12 Tipología de Vivienda.....................................................52

2.5.13 Vivienda con Estado de Tenencia........................................52

2.5.14 Áreas Verdes Públicas por Habitante ....................................53

2.5.15 Parques Públicos ...................................................................53 


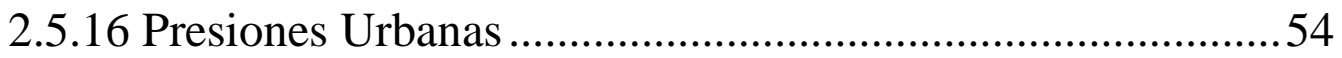

2.5.17 Equipamiento de Comercio y Abastos...................................54

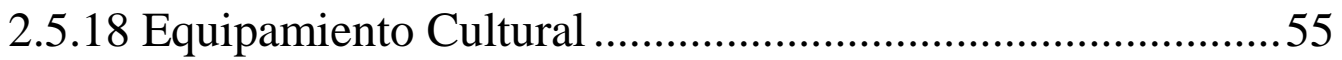

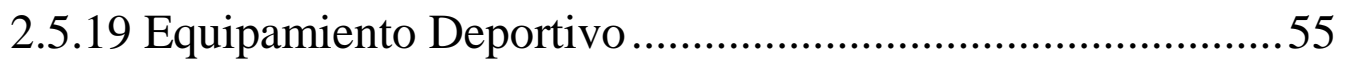

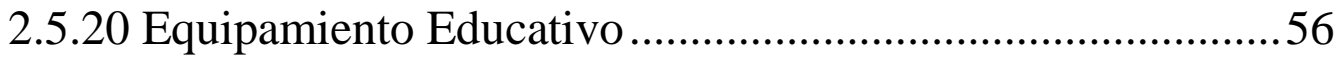

2.5.21 Equipamiento de Salud ......................................................56

2.5.22 Equipamiento Seguridad Ciudadana....................................57

2.6 Objetivos para el mejoramiento urbano según el Plan de desarrollo urbano de Lima Metropolitana (PLAM 2035) .......................................57

2.7 Estrategias de Desarrollo Municipal de Pachacamac ................58

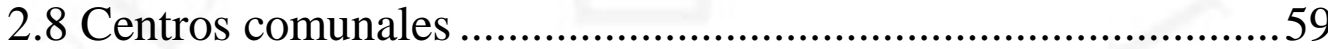

2.9 Historia de los servicios comunales y centros comunales en el

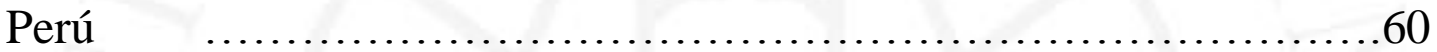

2.9.1 Sistema comunal prehispánico: Ayni .....................................60

2.9.2 Centros sociales en el Virreinato del Perú y América ............61

2.9.3 Centros y programas sociales en La República del Perú ........63

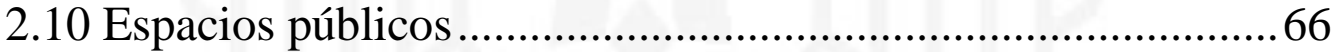

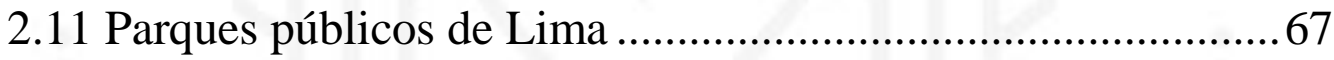

2.12 Historia de los Parques Zonales .............................................. 70

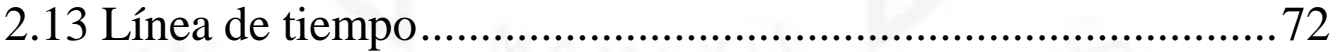

2.14 Conclusiones Parciales............................................................ 74

CAPÍTULO III: MARCO TEÓRICO ....................................................76

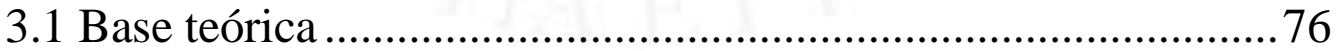

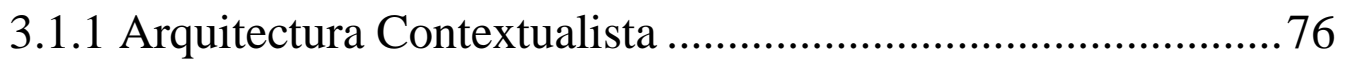

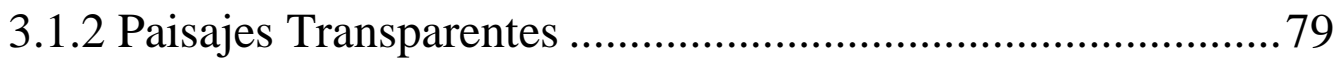

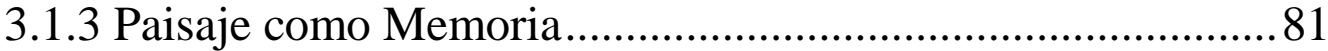

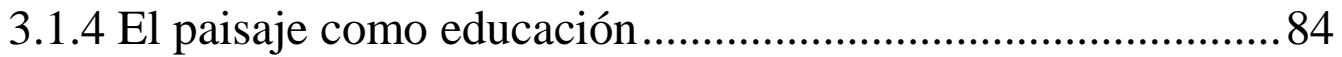

3.1.5 Arquitectura educativa del estructuralismo holandés .............85

3.2 Clasificación de Centros Comunales ..........................................8 


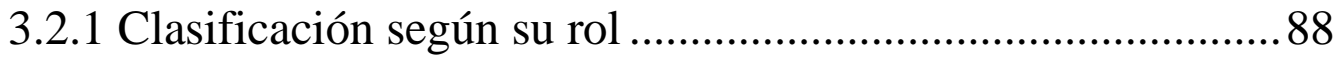

3.2.1.1 Centros comunales orientados a la educación ......................8 88

3.2.1.2 Centros comunales orientados al desarrollo empresarial....90

3.2.1.3 Centros comunales orientados a la cultura ..........................93

3.2.2 Clasificación según financiamiento .......................................95

3.2.2.1 Programas del Estado.......................................................95

3.2.2.2 Organizaciones privadas sin fines de lucro: ........................ 96

3.2.2.3 Organización No Gubernamental (ONG) ............................97

3.3 Clasificación de centros comunales orientados a la educación ......................................................97

3.3.1 Espacios educativos no tradicionales.....................................97

3.3.2 Espacios educativos que abren al exterior .............................98

3.3.3Espacios educativos móviles......................................................99

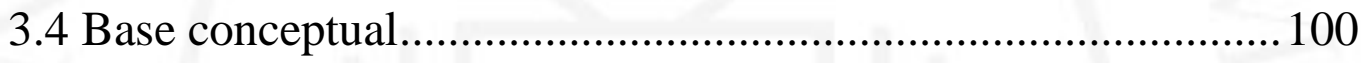

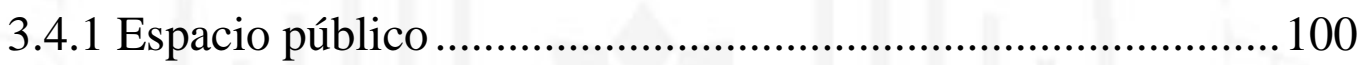

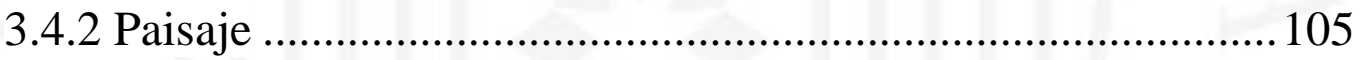

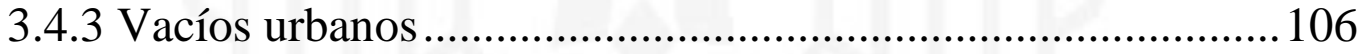

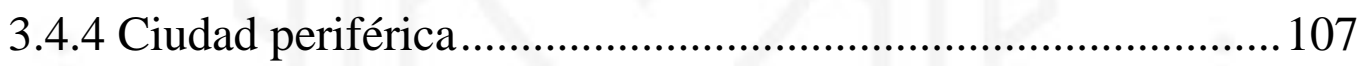

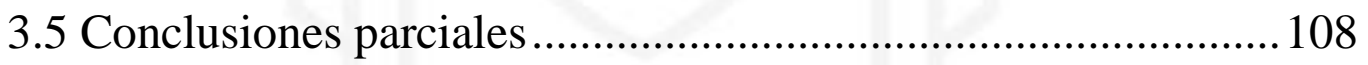

CAPÍTULO IV: MARCO NORMATIVO .............................................111

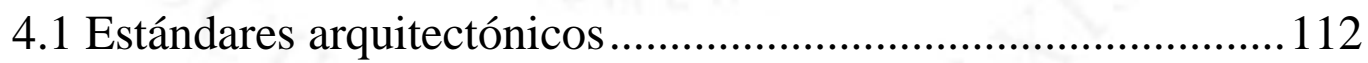

4.1.1 Norma A.090 Servicios Comunales.....................................112

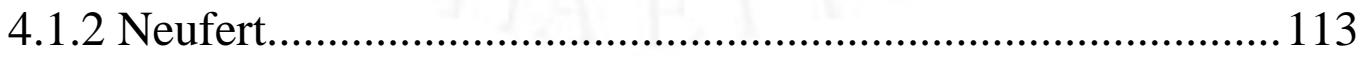

4.2 Ministerios y organizaciones locales ........................................114

4.2.1 Ministerio de Desarrollo e Inclusión Social ........................... 114

4.2.2 Ministerio de la Producción ...................................................... 114

4.2.3 Municipalidad de Pachacamac................................................ 115

4.2.4 Defensoría Municipal del Niño y el Adolescente (DEMUNA) 


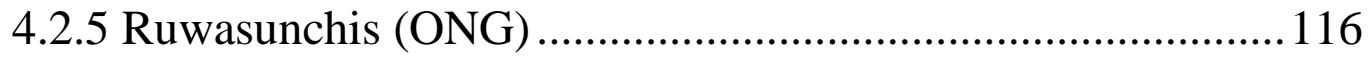

4.2.6 Los custodios de la creación (Asociación Católica) ................117

4.2.7 World Visión Perú (Organización Cristiana)........................... 118

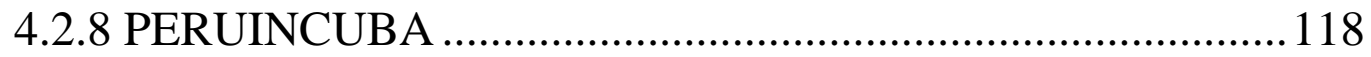

4.2.9 StarUp Perú (Programa del Ministerio de la Producción) .....119

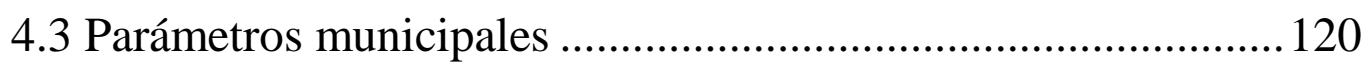

4.4 Conclusiones parciales ................................................................ 123

CAPÍTULO V: MARCO OPERATIVO ..............................................124

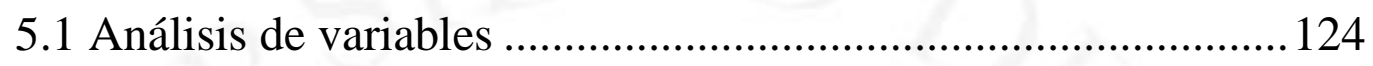

5.1.1 Ubicación y Relación con el Entorno ......................................124

5.1.2 Programa y Relaciones Programáticas ...................................124

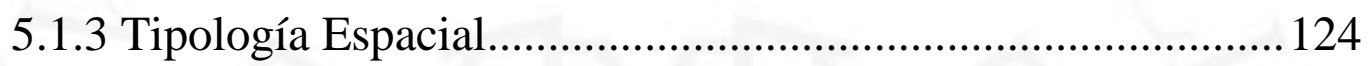

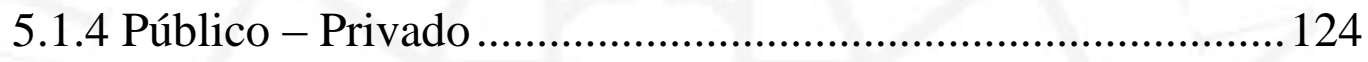

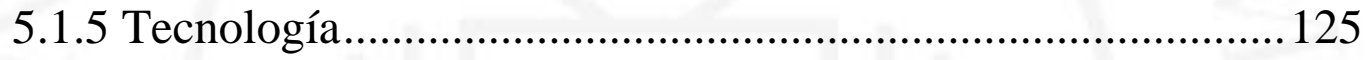

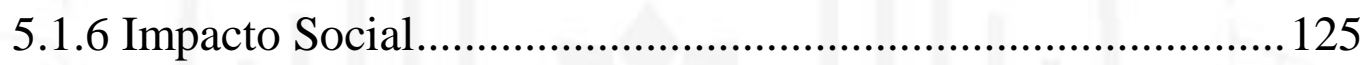

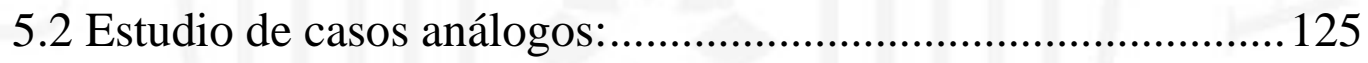

5.2.1 Centro de Recursos para el Aprendizaje y la Investigación

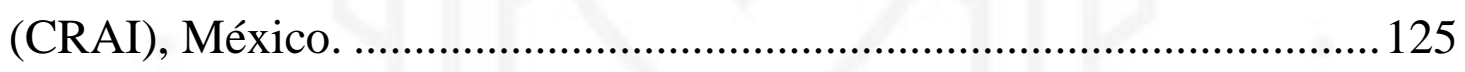

5.2.2 Parque Biblioteca León de Grieff, Colombia......................... 125

5.2.3 Centro de Cultura, Recreación y Educación Ambiental (CREA),

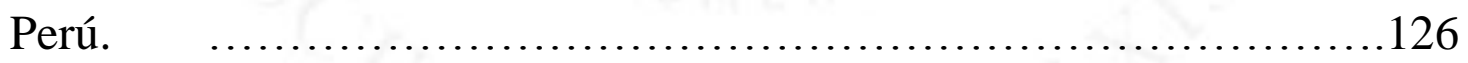

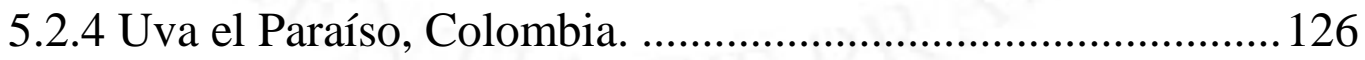

5.2.5 Proyecto: La Misteriosa Historia del Jardín que Produce Agua,

España. ........................................................126

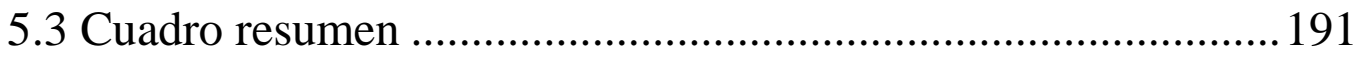

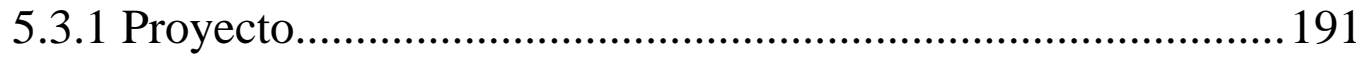

5.3.2 Ubicación y Relación con el entorno .......................................191

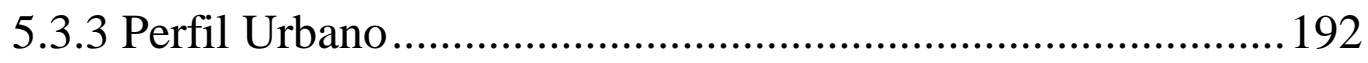

5.3.4 Programa y relaciones programáticas .....................................192 
5.3.5 Áreas

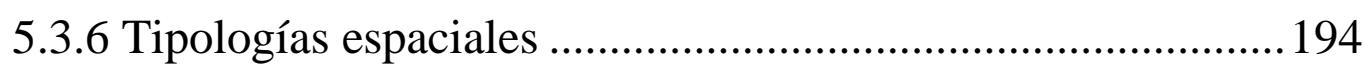

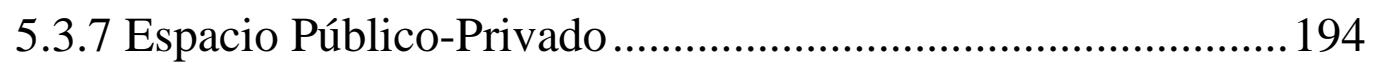

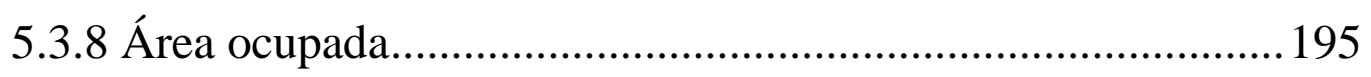

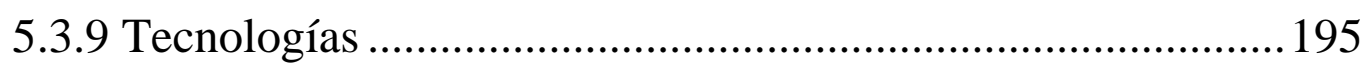

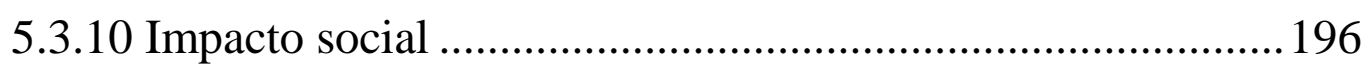

5.4 Conclusiones parciales ............................................................ 197

CAPÍTULO VI: MARCO CONTEXTUAL .........................................199

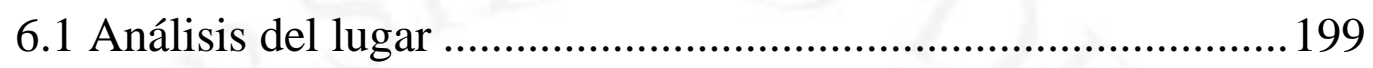

6.1.2 Criterios para la selección del terreno adecuado .....................200

6.1.2.1 Características de las Construcciones de la zona.................200

6.1.2.2 Consideraciones Ambientales .............................................200

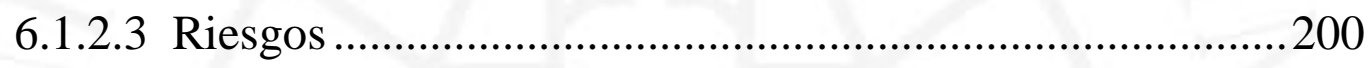

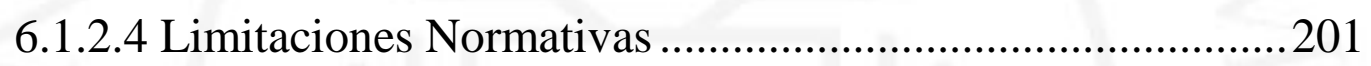

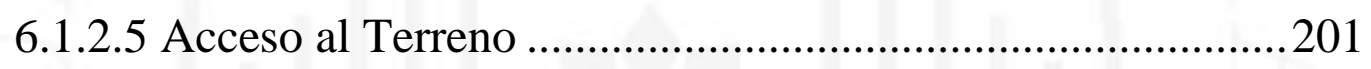

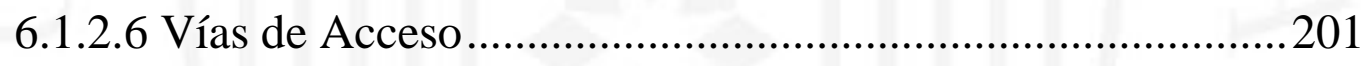

6.1.2.7 Infraestructura y servicios disponibles ...............................201

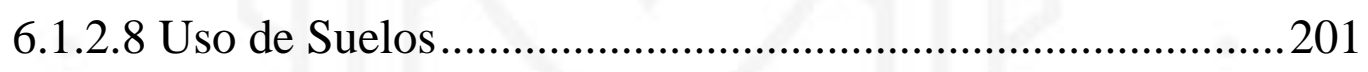

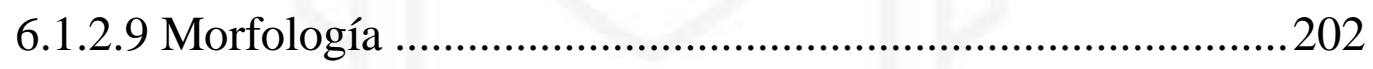

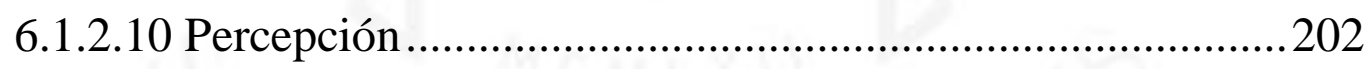

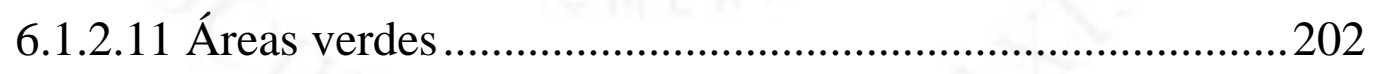

6.1.2.12 Educación y Trabajo .......................................................202

6.1.3 Análisis del lugar para obtener el terreno de la propuesta

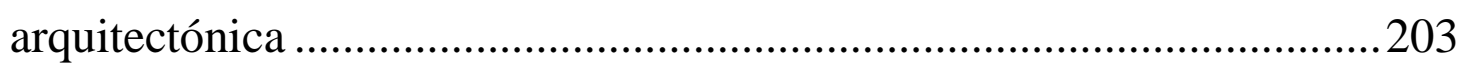

6.2 Red de equipamiento y radio de influencia .............................217

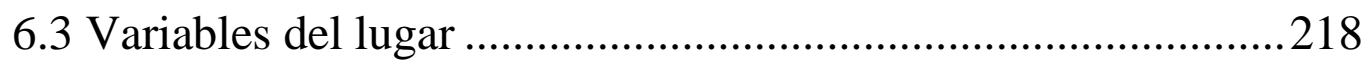

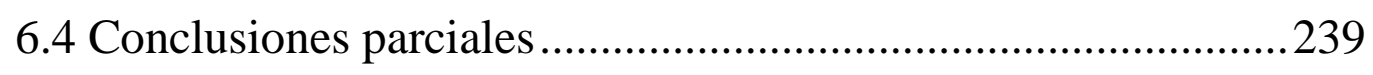

\section{CAPÍTULO VII: CONCLUSIONES FINALES DE LA}




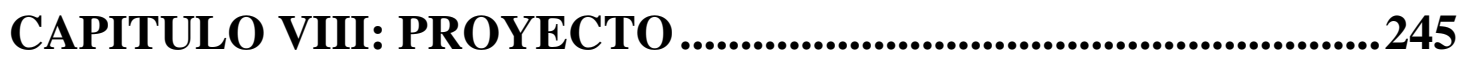

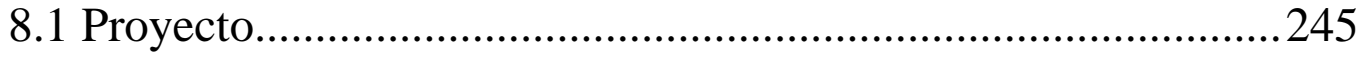

8.1.1 Toma de partida y estrategias proyectuales ...........................245

8.1.2 Diseño participativo .......................................................258

8.1.3 Programa arquitectónico ........................................................265

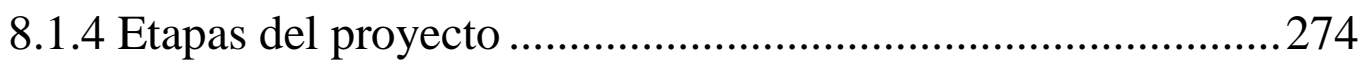

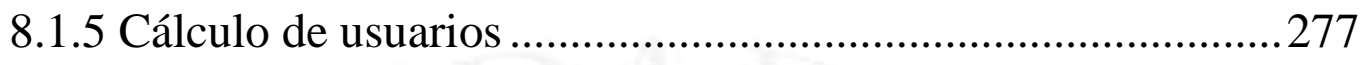

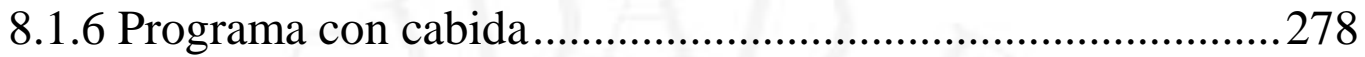

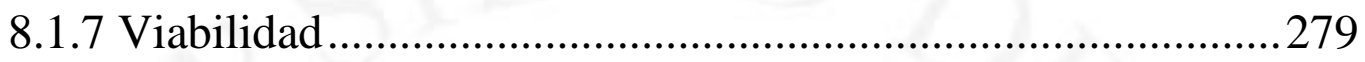

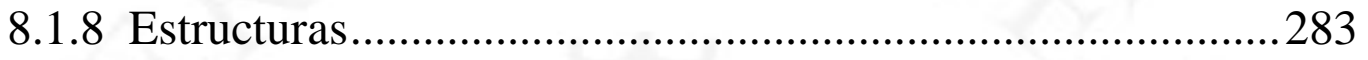

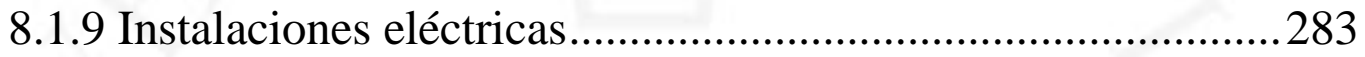

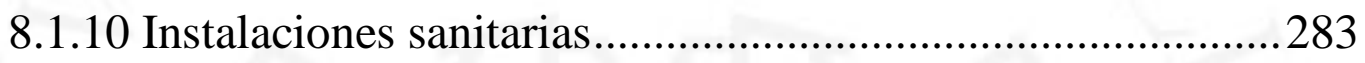

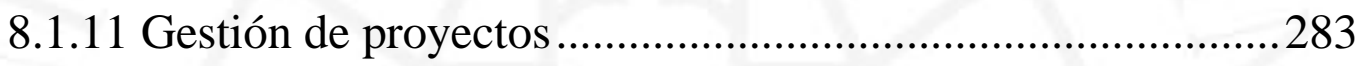

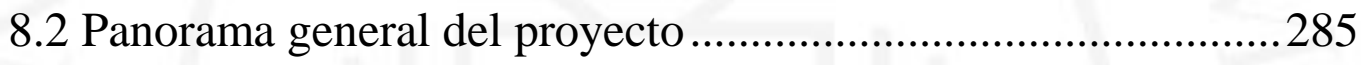

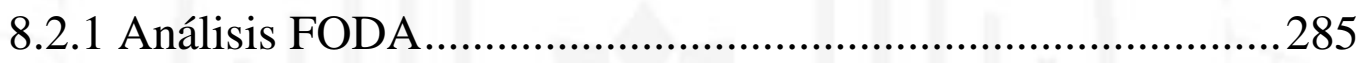

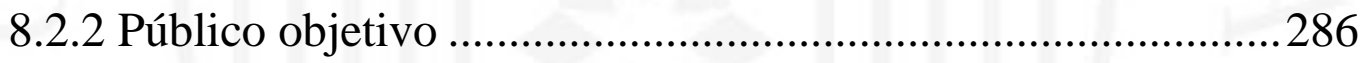

REFERENCIAS ................................................................................................290

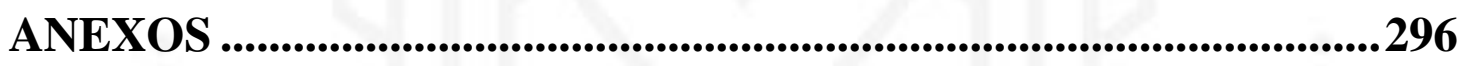




\section{ÍNDICE DE TABLAS}

Tabla 2.1 Crecimiento poblacional de Pachacamac (2012) .........................................20

Tabla 2.2 Población por edades del Distrito de Pachacamac ........................................31

Tabla 2.3 Población educada en Pachacamac (2010) ....................................................... 34

Tabla 2.4 Indicadores de Educación en Lima Sur (2007)..............................................35

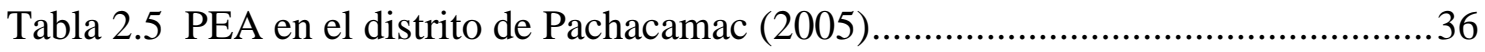

Tabla 2.6 Número de habitantes por vivienda en Pachacamac (2005) ..........................39

Tabla 2.7 Carencias en los distritos de Lima Sur, en porcentaje (2007) ...................... 40

Tabla 2.8 Acceso a servicios básicos de la vivienda en Lima Sur, en porcentaje (2008)

Tabla 2.9 Población en riesgo social en Pachacamac, en porcentajes (2005) ...............42

Tabla 2.10 Tipos de poblaciones en Riesgo Social, Pachacamac (2005) ......................42

Tabla 2.11 Distribución de edades en la Población de Manchay (2016)....................... 46

Tabla 8.1 Cuadro resumen del programa arquitectónico ..........................................266

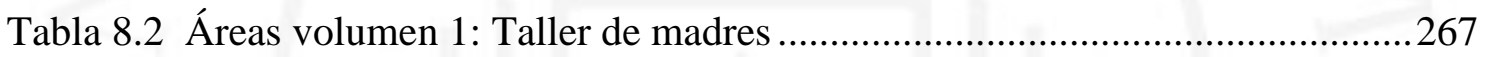

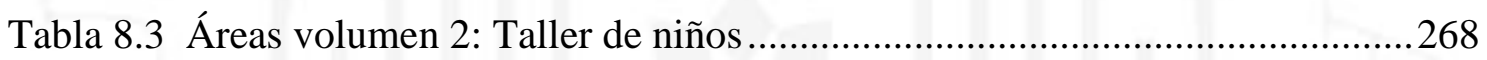

Tabla 8.4 Áreas volumen 3: Educación para niños ...................................................269

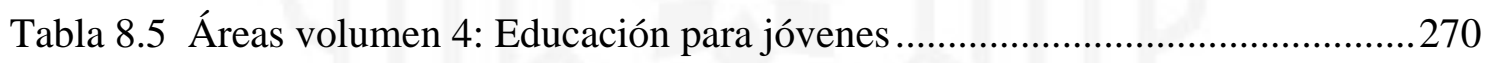

Tabla 8.6 Áreas volumen 5: Taller de jóvenes ...........................................................22

Tabla 8.7 Áreas volumen 6: Taller de emprendimiento 01 ......................................22

Tabla 8.8 Áreas volumen 7: Taller de emprendimiento 02 .....................................273

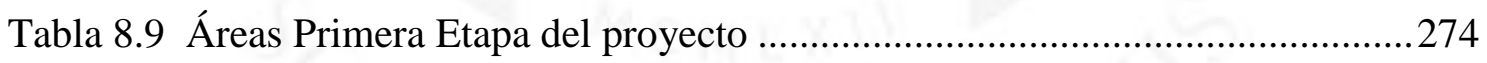

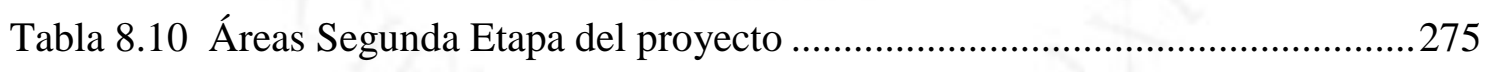

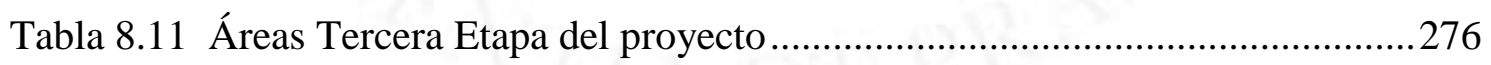

Tabla 8.12 Costos Primera Etapa del proyecto ..........................................................280

Tabla 8.13 Costos Segunda Etapa del proyecto........................................................281

Tabla 8.14 Costos Tercera Etapa del proyecto ..........................................................282

Tabla 8.15 Inscripción de madres al programa de madres tejedoras ..........................287

Tabla 8.16 Inscripción de niños a los talleres...................................288

Tabla 8.17 Inscripción de Jóvenes a los talleres................................289 


\section{ÍNDICE DE FIGURAS}

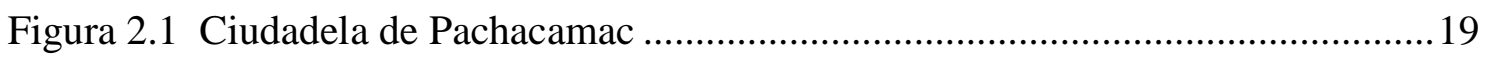

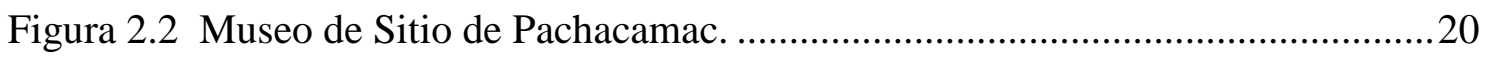

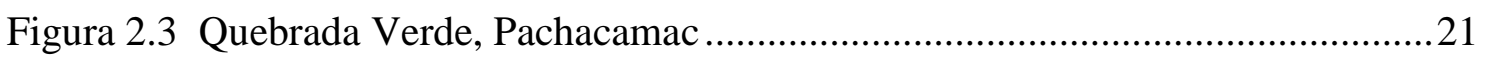

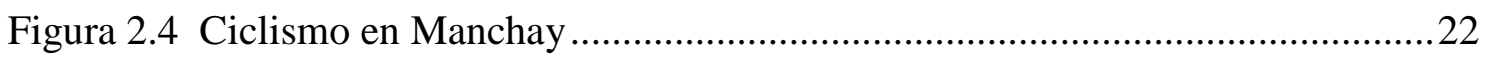

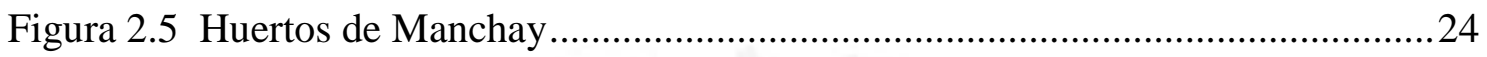

Figura 2.6 Expansión poblacional de Pachacamac......................................................25

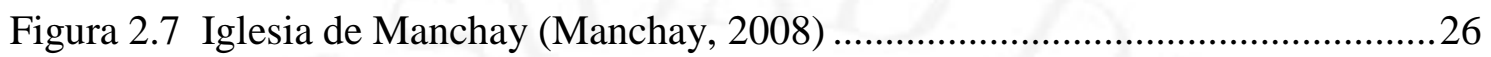

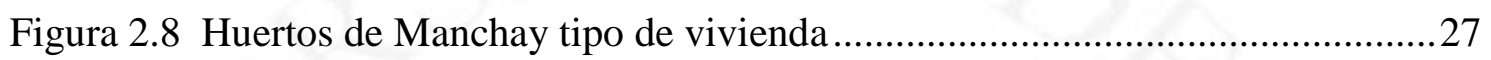

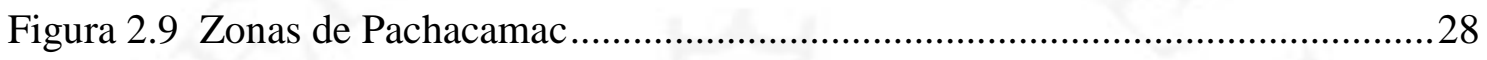

Figura 2.11 Vivienda precaria en Manchay ............................................................... 38

Figura 2.12 Vías importantes del distrito de Pachacamac ............................................44

Figura 2.13 Mapa de rango de edades en Lima Metropolitana ................................... 46

Figura 2.14 Zonas por densidad poblacional en Lima Metropolitana ..........................47

Figura 2.15 Tasa de creciemiento poblacional en Lima Metropolitana ........................47

Figura 2.16 Población Económicamente Activa en Lima Metropolitana....................... 48

Figura 2.17 Pobreza Monetaria en Lima Metropolitana.............................................. 48

Figura 2.18 Ingresos económicos en Lima Metropolitana. .........................................49

Figura 2.19 Población que únicamente ha alcanzado educación primaria ....................49

Figura 2.20 Índice de desarrollo Humano (IDH) en Lima Metropolitana ......................50

Figura 2.21 Población con Discapacidad Motoro en Lima Metropolitana.....................50

Figura 2.22 Población con Discapacidad Sensorial en Lima Metropolitana ..................51

Figura 2.23 Zonas de Concentración de Precariedad en Lima Metropolitana...............51

Figura 2.24 Tipo de Vivienda en Lima Sur .............................................................52

Figura 2.25 Vivienda con Estado de Tenencia en Lima Sur ......................................52

Figura 2.26 Verdes Públicas por Habitante en Lima Metropolitana .............................53

Figura 2.27 Parques Públicos en Lima Metropolitana...................................................53

Figura 2.28 Presiones Urbanas en Lima Metropolitana …...........................................54

Figura 2.29 Equipamiento de Comercio y Abastos en Lima Sur ..................................54

Figura 2.30 Equipamiento Cultural en Lima Sur.....................................................55

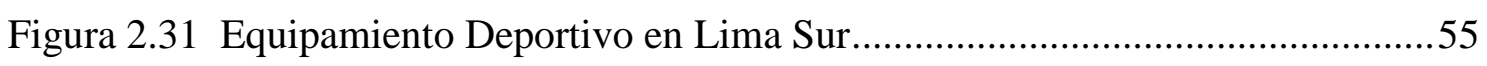

Figura 2.32 Equipamiento Educativo en Lima Sur...................................................56 
Figura 2.33 Equipamiento de Salud en Lima Sur .56

Figura 2.34 Equipamiento Seguridad Ciudadana en Lima Sur .57

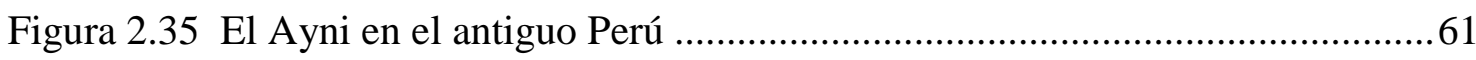

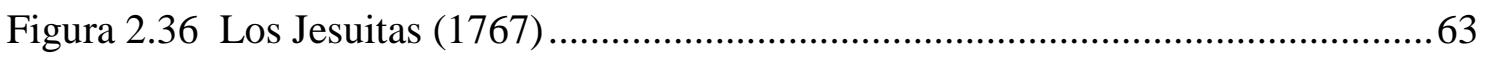

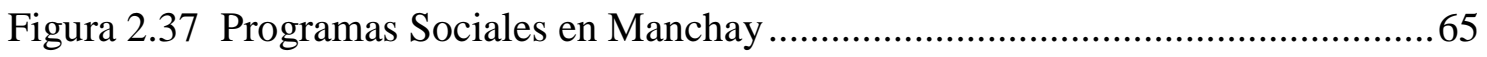

Figura 3. 1 Santa Cruz de la Serós: nueva y antigua arquitectura en una harmonía......78

Figura 3. 2 Representación de la calle Saalgasse en un grabado de 1628 .................... 79

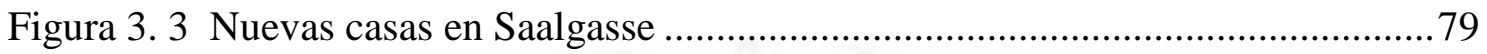

Figura 3. 4 Curso de artesanía peruana para madres ................................................. 97

Figura 3. 5 Espacios no tradicionales para el aprendizaje ....................................... 98

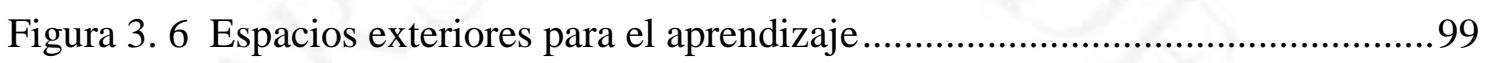

Figura 3. 7 Espacios móviles para el aprendizaje .................................................... 100

Figura 5.1 Historia del CRAI.............................................. 127

Figura 5.2 Ubicación del CRAI............................................. 128

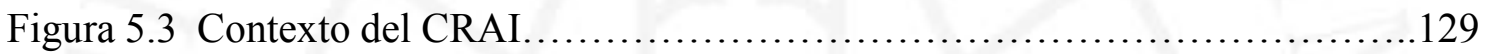

Figura 5.4 Vistas del lugar del CRAI..................................... 130

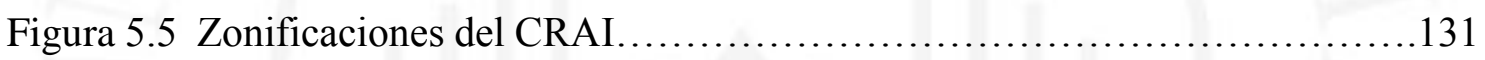

Figura 5.6 Programa Planta inferior del CRAI................................. 132

Figura 5.7 Programa Primera planta del CRAI................................. 133

Figura 5.8 Programa Segunda planta del CRAI...................................134

Figura 5.9 Organigrama del CRAI..............................................

Figura 5.10 Cuadro de áreas del CRAI..........................................136

Figura 5.11 Área libre y ocupada del CRAI...................................137

Figura 5.12 Espacio público y privado del CRAI............................... 138

Figura 5.13 Flujo de personas por hora del CRAI...............................139

Figura 5.14 Tecnologías constructivas del CRAI...............................140

Figura 5.15 Impacto social del CRAI......................................... 141

Figura 5.16 Historia del Parque Biblioteca León de Grieff......................... 142

Figura 5.17 Ubicación del Parque Biblioteca León de Grieff........................143

Figura 5.18 Contexto del Parque Biblioteca León de Grieff.........................144

Figura 5.19 Vistas del Parque Biblioteca León de Grieff...........................145

Figura 5.20 Zonas del Parque Biblioteca León de Grieff.............................146

Figura 5.21 Programa del Parque Biblioteca León de Grieff........................147

Figura 5.22 Organigrama del Parque Biblioteca León de Grieff.....................148 
Figura 5.23 Cuadro de áreas del Parque Biblioteca León de Grieff....................149

Figura 5.24 Tipología espacial del Parque Biblioteca León de Grieff................150

Figura 5.25 Área libre y ocupada del Parque Biblioteca León de Grieff..............151

Figura 5.26 Espacios públicos y privados del Parque Biblioteca León de Grieff......152

Figura 5.27 Flujos peatonales del Parque Biblioteca León de Grieff.................153

Figura 5.28 Tecnologías constructivas del Parque Biblioteca León de Grieff.........154

Figura 5.29 Impacto social del Parque Biblioteca León de Grieff....................155

Figura 5.30 Historia del CREA Parque Zonal Huiracocha.........................156

Figura 5.31 Ubicación del CREA Parque Zonal Huiracocha..........................157

Figura 5.32 Programa del CREA Parque Zonal Huiracocha.........................158

Figura 5.33 Organigrama del CREA Parque Zonal Huiracocha.....................159

Figura 5.34 Cuadro de áreas del CREA Parque Zonal Huiracocha.................... 160

Figura 5.35 Área libre y ocupada del CREA Parque Zonal Huiracocha.................161

Figura 5.36 Espacios públicos y privados del CREA Parque Zonal Huiracocha.......162

Figura 5.37 Flujos peatonales del CREA Parque Zonal Huiracocha...................163

Figura 5.38 Tecnologías constructivas del CREA Parque Zonal Huiracocha........... 164

Figura 5.39 Impacto social del CREA Parque Zonal Huiracocha......................165

Figura 5.40 Historia de la UVA El Paraíso ..................................... 166

Figura 5.41 Ubicación de la UVA El Paraíso...................................167

Figura 5.42 Contexto de la UVA El Paraíso.......................................168

Figura 5.43 Zonificación de la UVA El Paraíso.....................................169

Figura 5.44 Programa de la UVA El Paraíso.....................................170

Figura 5.45 Organigrama de la UVA El Paraíso...............................171

Figura 5.46 Cuadro de áreas de la UVA El Paraíso................................ 172

Figura 5.47 Tipologías espaciales de la UVA El Paraíso...........................173

Figura 5.48 Tecnologías constructivas de la UVA El Paraíso........................174

Figura 5.49 Impacto social de la UVA El Paraíso............................. 175

Figura 5.50 Historia del proyecto La Misteriosa Historia del Jardín que Produce

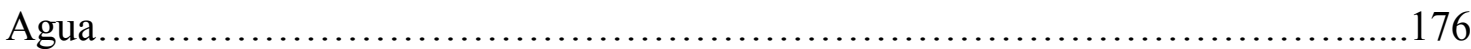

Figura 5.51 Ubicación del proyecto La Misteriosa Historia del Jardín que Produce

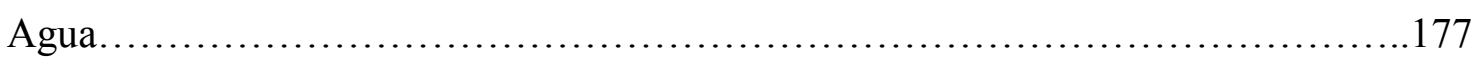

Figura 5.52 Contexto del proyecto La Misteriosa Historia del Jardín que Produce Agua................................................................ 178 
Figura 5.53 Terreno del proyecto La Misteriosa Historia del Jardín que Produce Agua 179

Figura 5.54 Sistemas del proyecto La Misteriosa Historia del Jardín que Produce Agua 180

Figura 5.55 Zonas del proyecto La Misteriosa Historia del Jardín que Produce Agua.... 181

Figura 5.56 Programa del espacio público del proyecto La Misteriosa Historia del Jardín que Produce Agua.

Figura 5.57 Arquitectura del proyecto La Misteriosa Historia del Jardín que Produce Agua 183

Figura 5.58 Programa del proyecto La Misteriosa Historia del Jardín que Produce Agua 184

Figura 5.59 Tipología espacial del proyecto La Misteriosa Historia del Jardín que Produce Agua.... .185

Figura 5.60 Espacio público y privado del proyecto La Misteriosa Historia del Jardín que Produce Agua. 186

Figura 5.61 Tecnologías constructivas del proyecto La Misteriosa Historia del Jardín que Produce Agua.... .187

Figura 5.62 Impacto social del proyecto La Misteriosa Historia del Jardín que Produce Agua .188

Figura 5.63 Cuadro resumen de casos análogos 01 189

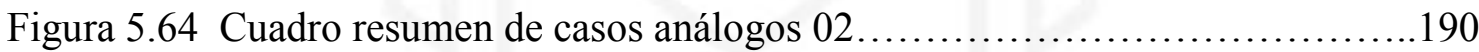

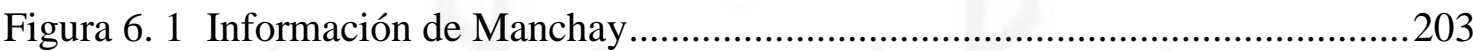

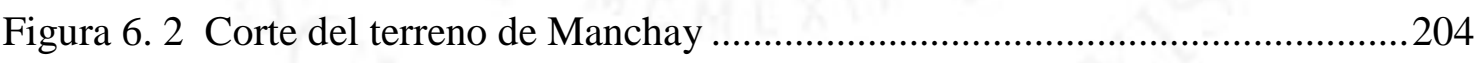

Figura 6. 3 Mapa concentración de población en Manchay …....................................205

Figura 6. 4 Mapa concentración de población económicamente activa en Manchay..206

Figura 6. 5 Mapa de concentración de precariedad de vivienda en Manchay .............207

Figura 6. 6 Mapa de concentración de servicios básicos en Manchay .........................208

Figura 6. 7 Mapa de concentración deserción escolar en población mayor de 11 años en Manchay. .209

Figura 6. 8 Mapa ubicación de parques públicos y zonas industriales en Manchay ...210

Figura 6. 9 Mapa ubicación de equipamiento urbano en Manchay ..............................211

Figura 6. 10 Mapa de zonas de riesgo en Manchay ...................................................212

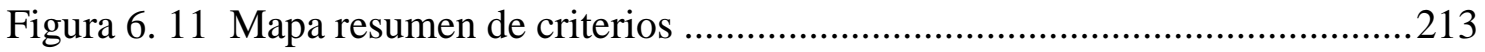


Figura 6. 12 Comparación de terrenos potenciales..... 214

Figura 6.13 Datos demográficos de la zona....................................219

Figura 6.14 Recorrido solar en el terreno...................................220

Figura 6.15 Recorrido del viento en el terreno..............................221

Figura 6.16 Topografía del terreno........................................222

Figura 6.17 Áreas verdes cercanas al terreno.....................................223

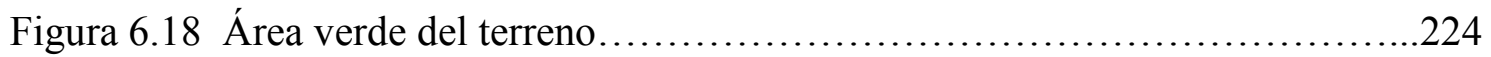

Figura 6.19 Equipamiento urbano de la zona..................................225

Figura 6.20 Equipamiento urbano cerca al terreno.............................226

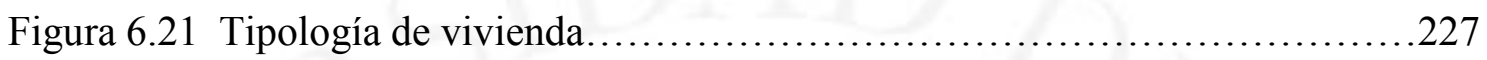

Figura 6.22 Bordes y barrios de la zona.................................... 228

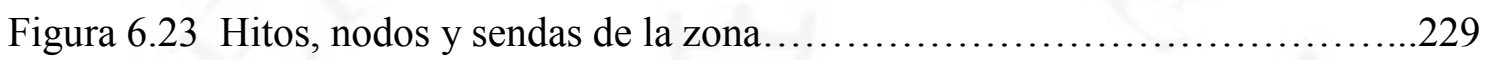

Figura 6.24 Hitos, nodos y sendas cerca al terreno.............................230

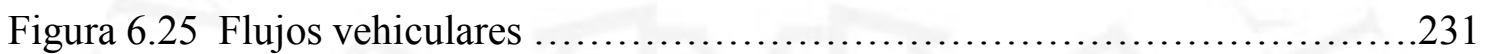

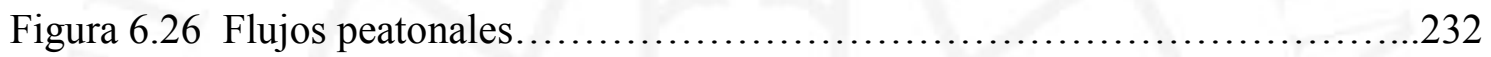

Figura 6.27 Zonificación...............................................233

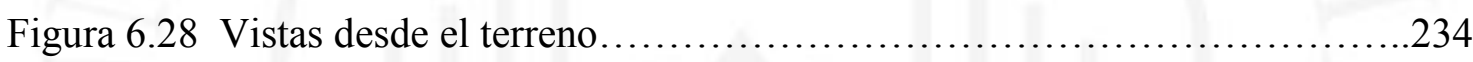

Figura 6.29 Vistas del terreno zonas de precariedad............................235

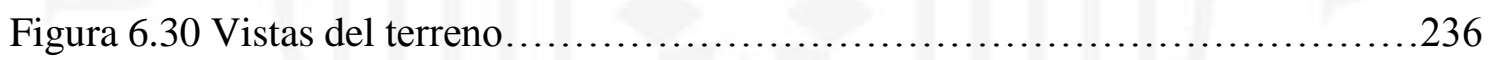

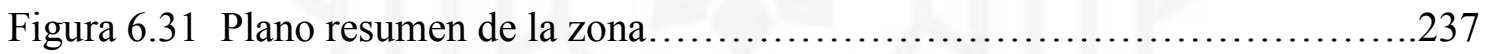

Figura 6.32 Plano resumen cerca al terreno..................................238

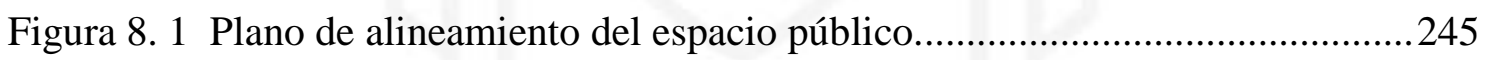

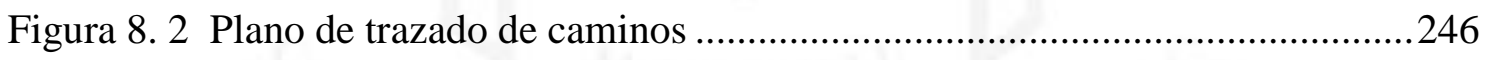

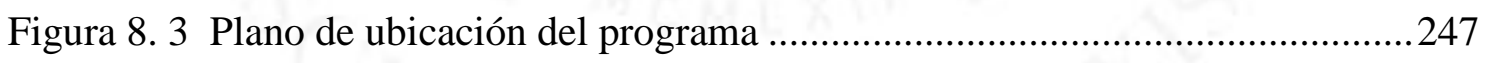

Figura 8. 4 Plano de ubicación de volúmenes arquitectónicos ....................................248

Figura 8.5 Potencialidades y problemas del lugar .................................................249

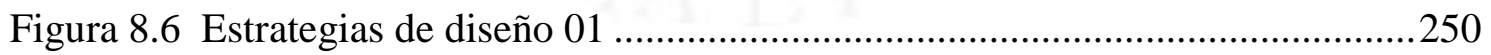

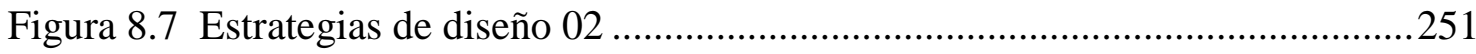

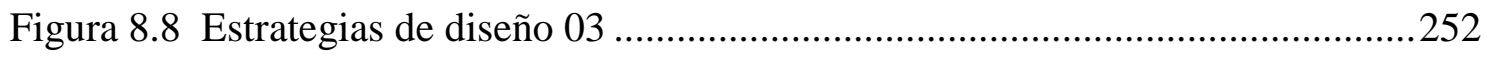

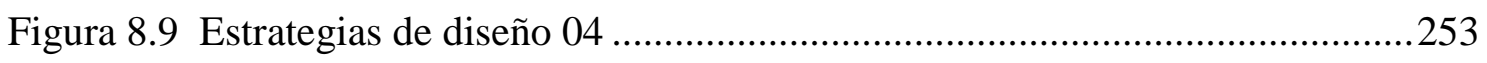

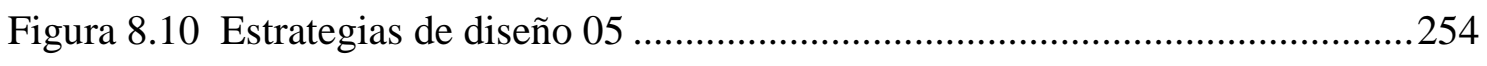

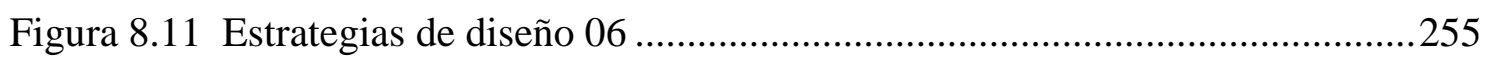

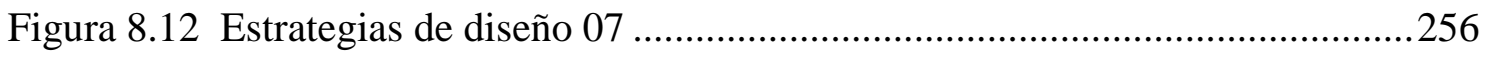

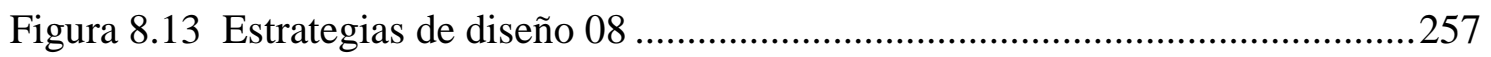


Figura 8.14 Taller de diseño participativo con los niños de Manchay .258

Figura 8.15 Taller de diseño participativo con los niños de Manchay 259

Figura 8.16 Taller de diseño participativo con los niños de Manchay 259

Figura 8.17 Taller de diseño participativo con los niños de Manchay 260

Figura 8.18 Taller de diseño participativo con los niños de Manchay 260

Figura 8.19 Taller de diseño participativo con los niños de Manchay 261

Figura 8.20 Taller de diseño participativo con las madres de Manchay .262

Figura 8.21 Taller de diseño participativo con las madres de Manchay. 262

Figura 8.22 Taller de diseño participativo con las madres de Manchay. 263

Figura 8.23 Taller de diseño participativo con las madres de Manchay. .263

Figura 8.24 Taller de diseño participativo con las madres de Manchay......... 264

Figura 8.25 Etapas del proyecto 265

Figura 8.26 Área del proyecto .278 


\section{ÍNDICE DE ANEXOS}

ANEXOS 1: RNE A.010 Condiciones generales de Diseño

ANEXOS 2: RNE A.040 Educación

298

ANEXOS 3: RNE A.090 Servicios comunales

ANEXOS 4: RNE A.120 Accesibilidad para personas con discapacidad y de personas adultas mayores. 301

ANEXOS 5: RNE A.130 Requisitos de Seguridad 302

ANEXOS 6: RNE EM.110 Confort térmico y lumínico con eficiencia energética. ....303 


\section{RESUMEN}

La ciudad de Lima está en constante cambio y transformación, algo característico de toda gran urbe. Por su parte la informalidad a nivel de infraestructura crece expandiéndose descontroladamente de manera horizontal en las laderas de los cerros de las periferias. Este crecimiento restringe la accesibilidad, habitabilidad, carencia de servicios básicos y espacios públicos en dichas zonas; además de coexistir con problemas sociales como la pobreza, la deserción escolar y la violencia.

El objetivo de esta investigación y del proyecto de suficiencia profesional es el de abordar estas problemáticas sociales y urbanas desde un punto de vista arquitectónico. Se identificó a la comunidad de San Pablo Mirador en Manchay como zona potencial para hacer una intervención urbana que afronte los problemas de deserción escolar y carencia de espacio público, entre otros. Se identificaron las características del lugar, el usuario objetivo y el terreno para proponer el proyecto de un parque con centro comunitario en donde la población y actores sociales como algunas ONG de la zona puedan trabajar en conjunto disfrutando de una buena infraestructura y espacios flexibles. Con el proyecto se espera también que las condiciones sociales cambien generando memoria, fortaleciendo la identidad y empoderando a los habitantes de la zona. ¿Cómo proponer un proyecto arquitectónico y de espacio público en terrenos con pendientes? En ese contexto, se proponen estrategias de diseño que puedan usar la pendiente como un potencial que agregue valor a la zona y enriquezca las relaciones espaciales.

Este proyecto surge debido a que existe una gran falta de infraestructura en zonas como las laderas de los cerros de las periferias y son pocos los proyectos de espacio público que intervienen en este contexto. El proyecto genera algunas estrategias de diseño que sirven de apoyo para futuros proyectos en condiciones similares.

Palabras clave: Espacio público en ladera, espacio como memoria, centro comunitario, espacios flexibles, paisaje costero en pendiente. 


\begin{abstract}
The city of Lima is constantly changing and transforming, a characteristic of every major city. On the other hand, infrastructure informality levels grow expanding uncontrollably horizontally on the peripheries' hillsides. This growth restricts accessibility, habitability, utilities and public spaces in these areas; as well as coexisting with social problems such as poverty, school dropout and violence.

The goal of this research and the professional proficiency project is to address these social and urban problems from an architectural point of view. The community of San Pablo Mirador in Manchay was identified as a potential area to carry out an urban intervention that addresses the problems of school dropout and lack of public space, among others. The characteristics of the place, the target user and the land were identified to propose the project of a community center and a park where the population and social agents such as some NGOs in the area can work together using good infrastructure and flexible spaces. The project also expects social conditions to change, generating memory, strengthening identity and empowering the inhabitants of the area. How to propose an architectural and public space project on hillsides? Design strategies that can use the hillsides as potential that adds value to the area and enriches spatial relationships are proposed.

This project arises because there is a great lack of infrastructure in areas such as the peripheries' hillsides, on top of few public space projects targeting these areas. The project unlocks some design strategies that support future projects under similar conditions.
\end{abstract}

Keywords: Hillside Public Space, Space as Memory, Community Center, Flexible Spaces, Coastal Landscape 


\section{INTRODUCCIÓN}

Lima es una ciudad de casi 10 millones de personas y tiene un largo camino histórico de consolidaciones y de expansiones territoriales a lo largo de su historia. Por su pasado prehispánico y posterior a ello, se formó como una sociedad multicultural, pero algunos problemas como la desigualdad social se van arrastrando a lo largo de la historia. Actualmente uno de los problemas que se busca erradicar es la lucha contra la pobreza, y para lograrlo se necesita afrontar algunos puntos básicos, como es la educación, el trabajo y la alimentación para formar personas preparadas para que ellas mismas tomen sus propias decisiones a formar su futuro.

Lima es una ciudad que tuvo una planificación, pero con el pasar de los años a causa de diferentes factores internos, esta planificación se fue perdiendo y la informalidad fue formando el Valle de Lurín de una manera desordenada hasta llegar a lo que es ahora una ciudad caótica, con muchas cosas desarticuladas, falta de: espacios públicos, áreas verdes, equipamiento urbano, servicios básicos y red optima vial. No todas las municipalidades tienen un plan de desarrollo urbano para los próximos años, por lo que la informalidad sigue en pie. Y los más afectados con estos problemas sociales son los más pobres porque al no contar con ingresos para satisfacer sus necesidades no pueden acudir a ciertos servicios de calidad por ello les da una desventaja con el resto de la población no pobre. Una de las estrategias para luchar por la igualdad, la participación ciudadana y la lucha contra lo pobreza es generar centros comunitarios para fortalecer al barrio y generar comunidad con la ayuda de distintas entidades, tanto públicas como privadas, se proponer programas para afrontar directamente los problemas de una comunidad, estos centros se establecen mayormente en las zonas de mayor conflicto de la ciudad con el fin de mejorar la calidad de vida de las familias y generar ciudades más justas y con oportunidades para todos. 


\section{CAPÍTULO I: GENERALIDADES}

\subsection{Generalidades}

\subsubsection{Tema}

El tema de investigación es el análisis de las condiciones de infraestructura pública urbana en las laderas de las periferias de Lima Metropolitana, ya sea para uso comunal, recreativo, espacio público y de accesibilidad.

Para el estudio, se toman puntos importantes como la calidad del equipamiento educativo y recreativo para jóvenes estudiantes de educación básica, la percepción y el uso del espacio público en zonas periféricas, las dinámicas que se viven en una ciudad dormitorio y el uso que de los recursos naturales y urbanos por parte de la población. El tema de investigación abarca de manera general Lima Metropolitana y se centra luego en la ciudad de Manchay, que pertenece al distrito de Pachacamac, desarrollando ahí un proyecto de arquitectura y espacio público que aspira ser un nuevo centro de nuevas dinámicas ubicado en la zona denominada San Pablo Mirador; teniendo como base estrategias de diseño obtenidas de la investigación inicial considerando las distintas variantes de la zona, teorías, recursos y participación de la comunidad con la finalidad de revertir los índices de deserción escolar, déficit de espacios públicos y desempleo que son problemas latentes de la zona.

\subsubsection{Justificación del tema}

Para la presente investigación es relevante visibilizar dos aspectos: El primero es uso del Espacio Público en zonas en consolidación con falta de estos lugares de encuentro. Y segundo la relación de los niños y jóvenes en edad escolar con los espacios educativos y uso del espacio público. Viendo estos dos aspectos se tendrá las bases que ayudarían a identificar otros lugares y formas de intervención bajo circunstancias parecidas. Es preciso levantar información cualitativa respecto al uso del espacio público y a la situación de los estudiantes en edad escolar, ya que en la actualidad son pocas las investigaciones desde la arquitectura respecto a esta práctica. 
Las condiciones del equipamiento urbano en las zonas periféricas son las que menos se trabajan, más aún si se trata de espacios públicos y de accesibilidad. Es importante conocer la percepción y el nivel de pertenencia por parte de las poblaciones, en especial de los niños y jóvenes que son los actores que más tiempo pasan en la zona. Teniendo en cuenta que los espacios públicos son espacios colectivos, libres, multifuncionales, integradores, cargados de sentidos, memorias y de identidad. Brindando a la población un sentido de pertenencia generando ocio, cultura, relaciones sociales, intercambio de ideas, seguridad, cooperación, movilidad, entre otros.

\subsubsection{Planteamiento del problema}

Lima es una ciudad en constante cambio y presenta una expansión horizontal llegando a cubrir laderas y cerros casi en su totalidad debido a la informalidad, la falta de recursos, el desinterés de las autoridades y la necesidad de salir adelante. Esta expansión horizontal es una característica de las zonas periféricas en vías de ser consolidadas. Las zonas urbanizadas construidas en ladera presentan problemas como accesibilidad, carencia de servicios, infraestructura, equipamiento urbano, sin contar los problemas sociales como la violencia familiar, la pobreza, inseguridad, deserción escolar y falta de identidad con la comunidad.

La arquitectura, en contextos en vías de consolidación, ha buscado identificar los indicadores para trabajar temas como la vivienda dormitorio y la deserción escolar en la población de niños en edad escolar, sobre todo secundaria. La arquitectura trabaja a través del estudio a la población objetivo para lograr un acercamiento a los usuarios y el paisajismo para poder identificar los recursos naturales y urbanos del lugar para identificar las mejores formas de habilitar la ladera. Sin embargo, en las últimas décadas como producto de la falta de estabilidad laboral e informalidad del desarrollo de la vivienda, las condiciones de vida en la ladera no han hecho posible consolidar la idea de barrio como agente de identidad y asentamiento.

En esta ciudad se cuenta con un medidor de uso de espacio público a través de Lima como Vamos, donde se identifica que existe un déficit de áreas verdes públicas (Lima Cómo Vamos, 2016). La cantidad de $\mathrm{m}^{2}$ asignado para cada habitante es de 3.25 
m2 en Lima Metropolitana, de los 9,2 $\mathrm{m}^{2}$ de área verde por habitante establecido por la Organización Mundial de la Salud (OMS) en el 2012.

Los espacios públicos son áreas de la ciudad destinadas a satisfacer las necesidades urbanas colectivas. En Lima Metropolitana, estos espacios suelen ser caracterizados por sus áreas verdes de las cuales existen 3207 hectáreas de áreas verdes públicas (Municipalidad Metropolitana de Lima, 2013). De las cuales el 52\% son parques distritales, es decir solamente 1667 hectáreas de espacios público con área verde esta destino para una ciudad de casi 10 millones de personas (INEI, 2017) y estos son los espacios preferidos por la población debido a la cercanía de sus viviendas y a la posibilidad de hacer actividades en esos lugares. La falta de estos espacios significa una pérdida de oportunidades, como generar una ciudad más inclusiva y aprovechar mejor los espacios vacíos que son de propiedad de Estado, que puedan ser de ayuda y satisfacción de la población e incluso espacios que puedan generar ingresos económicos. (Lozada, 2018).

Manchay es una de las zonas con mayor déficit de áreas verdes y públicas por habitante, teniendo menos de $1 \mathrm{~m}^{2}$ por habitante. Una oportunidad para generar nuevas áreas verdes con espacios públicos es el uso de los vacíos urbano que generan en muchos casos problemas de invasiones, insalubridad e inseguridad. Estos vacíos urbanos se encuentran dispersos por las distintas tramas urbanas, en ciudades consolidadas son tratadas como áreas recreativas, con equipamiento, servicios y áreas verdes, por otro lado en las periferias no cuentan con ningún tipo de tratamiento.

Otra problemática que se abordará en el presente proyecto de tesis son las poblaciones vulnerables, como son los niños y jóvenes que no estudian ni trabajan y las madres que se dedican al hogar. Para la problemática de la deserción escolar se plantea brindar mejores espacios para el aprendizaje y el estudio esto se llevará a cabo mediante una infraestructura comunitaria que sirva de apoyo a los colegios del distrito, ya que actualmente es una de las zonas con mayor deserción escolar de Lima Metropolitana llegando a un $35 \%$ de menores de edad (INEI, 2016). Por otro lado en el distrito el $20 \%$ de las mujeres son amas de casa y muchas de ellas no tienen educación básica completa y mucho menos estudios superiores. 


\subsection{Objetivos de la investigación}

\subsubsection{Objetivos generales}

Proponer un diseño arquitectónico de centro comunal y espacio público en terrenos de pendiente para zonas en consolidación, considerando factores como accesibilidad, recursos, tipo de suelo y necesidades del usuario.

\subsubsection{Objetivos específicos}

- Hacer una investigación para encontrar las zonas más críticas de la ciudad, partiendo de poblaciones vulnerables en la periferia de Lima Metropolitana.

- Hacer un mapeo y ubicar los puntos de la ciudad con menos espacios públicos, áreas verdes públicas y déficit de en Lima Metropolitana por habitante.

- Analizar las zonas más vulnerables de los distritos con respecto a deserción escolar, déficit de educación básica y trabajo infantil.

- Buscar vacíos urbanos dentro de la trama urbana, con el propósito de darle valor, recuperar parte de la ciudad y generar un nuevo punto de dinámicas urbanas.

- Conocer al usuario de una zona elegida, por rango de edades, sexo, ocupación e identificar sus actividades cotidianas.

- Conocer las problemáticas sociales de una zona más específica, identificar el perfil de sus poblaciones vulnerables, conocer sus antecedentes.

- Analizar el lugar potencial, sacar curvas de nivel, ver el tipo de suelo, identificar puntos de ingreso, problemáticas, riesgos y potencialidades.

- Investigar sistemas para abastecerse de recursos básicos como el agua.

- Desarrollar una lista de conceptos, definiciones y teorías en torno a espacios públicos, paisajismo y a la tipología de centros comunitarios.

- Buscar casos análogos de centros comunitarios que apoyen a sociedades vulnerables.

- Buscar diseños de parques en pendientes y en zonas áridas que se encuentren en América Latina que sean de aporte para identificar estrategias.

- Idear estrategias de diseño arquitectónico y de accesibilidad en terrenos en pendiente. 


\subsection{Supuesto básico de la investigación}

La deserción escolar en Manchay tiene un nivel muy alto, esto se debe a varios factores como falta de una buena infraestructura escolar y espacios donde los jóvenes puedan aprender y jugar debido a falta de espacios públicos o de hogares en estado de precariedad que no motiva ni facilita el aprendizaje.

\subsection{Alcances y limitaciones}

\subsubsection{De la investigación}

Los alcances de la investigación serán los siguientes:

- El análisis de la investigación abarcará el distrito de Pachacamac, y se centrará en la zona de Manchay. Siendo esta zona la que presenta más vulnerabilidad del distrito.

- Se desarrollará un mapa gráfico identificando y ubicando las problemáticas y déficit en Machay.

- Se elaborará un cuadro con las necesidades más requeridas de la zona.

- Se elaborará un programa específico en base al perfil de los pobladores y con esa misma información se basará para la propuesta del parque público.

- Para la zona de análisis se hará un estudio del estado actual de la zona a nivel geográfico, climático, seguridad, salud, vivienda, educación, viabilidad, equipamiento urbano y normativo.

- Se hará un análisis de los usuarios y actividades de los pobladores de Manchay, desde el punto de vista de una ciudad dormitorio.

- Para el diseño del parque se investigará sobre especies de árboles, arbustos y plantas de bajo consumo de agua, resistentes al sol y que puedan crecer en suelos áridos que necesiten tratamiento.

- Para un mejor panorama sobre las necesidades del usuario se harán talleres de diseño participativo con los niños, jóvenes y madres de la zona.

Las limitaciones de la investigación serán las siguientes: 
- No se desarrollarán encuestas por escrito en la zona de intervención.

- No se proyecta desarrollar una red de centros comunales, pero si dejar un precedente al respecto para que pueda ser aplicado a otros puntos de la ciudad que tengan las mismas condiciones de Manchay.

\subsubsection{Del proyecto}

Los alcances del proyecto serán los siguientes:

- Desarrollar un anteproyecto de centro comunitario con parque recreativo para la zona, mejorando la accesibilidad al terreno, generando espacios de encuentro, espacios naturales y áreas verdes.

- Para el diseño se tendrá contemplado todos los factores medio ambientales, económicos y sociales para que sea sostenible.

- Estará ubicado en una zona que requiera una rehabilitación urbana, llenando un vacío urbano y creando nuevas dinámicas para los usuarios.

- Se planteará un programa en base a las necesidades y oportunidades de la población.

- El proyecto tiene contemplado áreas de expansión para el futuro.

- El proyecto contará con un sistema de abastecimiento de agua.

Las limitaciones del proyecto serán las siguientes:

- El proyecto no presentará sistemas constructivos nuevos o experimentales.

\subsection{Diseño de la investigación}

La investigación será de tipo descriptiva porque se analizará la carencia de espacios públicos, áreas verdes y de equipamiento urbano en la zona de Manchay, así como la descripción de las dinámicas y las problemáticas sociales que pasa la población.

Con respecto al estudio de carencia de espacios públicos se analizará la situación actual de sus zonas de recreación, se medirá la cantidad de área verde que se tiene por habitante y un punto importante es la recuperación de vacíos urbanos. 
Con respecto al usuario se hará una descripción de la población, se realizará un reconocimiento in-situ y también gracias a información recaudada por otros investigadores y grupos sociales que ayudan en la zona. El análisis ayudará a identificar las dinámicas del día de una población que vive en una ciudad dormitorio.

Con respecto al diseño, las estrategias serán obtenidas de manera analítica y se emplearán teorías para diseño de arquitectura social, así como para diseño de espacio público y de paisaje.

\subsection{Metodología}

\subsubsection{Forma de recopilación de la información}

La información estadística será obtenida de material digital del Instituto Nacional de Estadística e Informática (INEI), del Banco Central de Reserva del Perú (BCRP), base de datos como Perú en Números (2018) y de investigaciones realizadas de la zona por investigadores y de ONG's que operan en el lugar como Ruwasunchis, que luego será procesada para obtener conclusiones y pensar en programas que se implementarán en la zona.

Para la recaudación de información del lugar de intervención y su entorno inmediato se realizarán visitas al lugar, apuntes sobre condiciones del lugar, se realizarán algunas entrevistas con pobladores del lugar y se tomarán fotografías.

La bibliografía de consulta para obtención de datos históricos, conceptuales y teóricos se obtendrá de bibliotecas de distintas universidad y de arquitectos.

Se usará buscadores de material digital con artículos, investigaciones o tesis con información del tema.

\subsubsection{Forma de análisis de la información}

El análisis empleado recopila la información estadística y se organiza en un cuadro comparativo y mapas gráficos. También se recopilará las ideas principales y secundarias de los materiales físicos y electrónicos para que sean sintetizadas. Las entrevistas serán transcritas y resumidas. La recopilación del material será constante para luego poder 
articularla hacia el tema, los análisis in-situ serán recurrentes para distinguir las distintas dinámicas durante el transcurso del día.

\subsubsection{Forma de presentación de la información}

La información de la investigación será presentada impresa, estructurada por capítulos de los cuales se desdoblan en subcapítulos y serán detallados en un índice en la parte inicial. Se incluirá cuadros estadísticos y mapas de elaboración propia, así como gráficos de otras fuentes de confianza como el PLAM 2035, INEI, los distintos Ministerios y entre otros. Se contempla además usar imágenes de apoyo así como mapas mentales gráficos para reforzar la explicación de la investigación. Para el análisis de la zona las fotografías serán un gran aporte para identificar las condiciones de la realidad en la que se vive. Las teorías serán representadas con esquemas gráficos y con apuntes a mano alzada. Para el proyecto se desarrollará el análisis del entorno y las condiciones geográficas y climáticas de manera gráfica. El anteproyecto se presentará en planos de manera física en las escalas requeridas.

La bibliografía y las citas bibliográficas estarán presentadas en el sistema de citación APA. 


\section{CAPÍTULO II: MARCO REFERENCIAL}

\subsection{Expansión urbana de Lima}

La Lima actual es el resultado de varios hechos históricos y sociales que fueron moldeando la ciudad actual. Durante este proceso fue adquiriendo muchos nombres que la enaltecieron como la Perla del Pacífico, la Ciudad Jardín o la Ciudad de los Reyes; sin embargo también fue adquiriendo nombres poco favorables como la Ciudad informal o Lima fragmentada. Lima ha pasado por varios procesos de estructuración física acompañado de acontecimientos sociales e históricos importantes que son importantes conocer para entender su expansión y funcionalidad.

El proceso de crecimiento y urbanización de Lima pueden ser divididos en cuatro etapas de estructuración y funcionamiento propuesta por Wiley Ludeña (2006) y Bähr \& Bordorf (2012) para entender la ciudad. Las etapas son: la ciudad colonial (1535-1820); la ciudad sectorial (1820-1950); la ciudad polarizada (1950-1990) y la ciudad fragmentada (1990-actualidad).

La ciudad colonial fue conocida mayormente como "La Ciudad de los Reyes" desde su fundación en 1535. Era la sede principal del virreinato colonial español en América del Sur. Lima obtuvo un gran poder económico cuando la corona española le otorgó el monopolio comercial de las colonias donde todas embarcaciones comerciales debían pasar por el puerto del Callao para luego ser distribuido al resto de las colonias. (Panfichi, 2004).

A nivel urbano la ciudad adquirió un modelo de damero, una ciudad cuadriculada que se distribuían alrededor de la plaza central que albergaba los poderes de la colonia como eran el palacio de gobierno, el ayuntamiento y la catedral. La ciudad estuvo amurallada de manera circular y la jerarquía social dependía de que tan cerca estabas al centro de la plaza principal y a la vida urbana. Sin embargo, en 1857 la ciudad se expandió más allá del damero. Esto fue producido por el crecimiento de los barrios fuera de la trama que se desarrollaron y unificaron gracias a las distintas iglesias, capillas, hospitales que ayudaron a consolidar este nuevo diseño. Los habitantes de las clases más pobres 
eran quienes se establecían fuera de la muralla generando una zona conocida como "El Cercado" (Panfichi, 2004).

La ciudad sectorial se inició cuando el auge de Lima colonial se desplomó junto con el monopolio económico debido a las reformas borbónicas y a la creación del Virreinato de la Plata en 1776. Estos cambios ocasionaron un cambio en la economía urbana afectando las élites de la ciudad. Esta caída de la economía estuvo perenne hasta mediados del siglo XIX cuando empezó la época de bonanza guanera. Este periodo ayudó a grandes transformaciones de la ciudad (Ludeña, 2004).

Entre los años de 1845 y 1862 parte de los ingresos obtenidos del comercio del guano se utilizó para modernizar la ciudad de Lima, como la pavimentación de las calles, la renovación de los sistemas de agua y desagüe, la iluminación pública a gas y la implementación del ferrocarril urbano. También se invirtió en el ornato de la ciudad. La ciudad siguió siendo amurallada hasta 1868 donde operaba el poder político, económico y religioso. Sin embargo durante los siguientes años hasta el último año de la Guerra con Chile (1879-1883) Lima no recuperó su liderazgo y esplendor económico, manteniéndose como centro político y administrativo de una república en decadencia. (Panfichi, 2004).

Durante el gobierno del presidente José Balta (1868-1872) se empieza la modernización de la ciudad bajo el lema "Ciudad sin límites" y comenzó por demoler la muralla (1870-1872) y se la ciudad se expandió más hacia Callao al oeste, a Chorrillos al sur y Ancón al norte. (Panfichi, 2004).

A fines del siglo XIX y principios del XX se dio un crecimiento económico importante gracias a las exportaciones de caucho, algodón, azúcar y minerales a los distintos países en vías de industrialización cerca de la región. Esto garantizó una modernización de la ciudad con la construcción de un tranvía y de grandes avenidas con dirección a los balnearios. Con estas nuevas rutas se inició la transformación de la estructura urbana de Lima desde su fundación, sectorizando el área residencial del área laboral.

En el gobierno del presidente Nicolás de Piérola (1895-1899) se fomentó esta nueva transformación urbana, donde divide al centro como el poder administrativo económico de la ciudad, y a la periferia como zona residencial para la clase social alta. A 
la salida de esta clase social del centro, estos espacios fueron ocupados las nuevas clases medias y por los migrantes.

Para el gobierno de Augusto B. Leguía (1921-1930) se consolidaron las ideas urbanas de Balta y Piérola, que más allá de las diferencias entre la Lima de José Balta, los planes de Piérola y el urbanismo de Leguía, existe una única idea de ciudad, un solo ideal que se desarrolló en distintos momentos. La idea de ciudad sin límites se caracterizó por una idea radial con ejes axiales y anillos viales que conectarían el centro de Lima a distintos sub centros y balnearios a la periferia. (Ludeña, 2004, pp.128-129)

El presidente Leguía concreta este modelo con la construcción de urbanizaciones, parques, nuevas grandes avenidas y la recuperación de Centro Histórico con la remodelación y la construcción de edificios emblemáticos como el Palacio de Gobierno, el Paseo de la República, la Plaza San Martin, la Plaza Dos de Mayo, el Parque Universitario, entre otros proyectos. Con ello Lima se estableció como base administrativa de inversiones extranjeras, producción industrial y comercial del país.

En el gobierno de presidente Óscar Benavides (1933-1936) empezó a ocurrir el fenómeno social de las grandes migraciones del campo a la ciudad, causado por la industrialización en la capital por lo que originó un incremento demográfico acelerado en la ciudad y generó las primeras barriadas a causa del déficit de vivienda. Benavides para afrontar esta necesidad de vivienda creó los primeros barrios obreros entre 1936 y 1940. A pesar de las inversiones del estado por crear estas nuevas zonas urbanas las poblaciones migrantes terminaron por tomar tierras y por consiguiente la creación de barriadas. (Ludeña, 1997)

La ciudad dualizada según Bähr y Bordosof (2012) es el producto de la tensión entre la consolidación del antiguo Centro urbano y la rápida expansión de las periferias de la ciudad que se dio entre los años de 1950 y 1990.

Durante el gobierno del presidente Manuel Odría (1948-1956) se desarrollaron distintas políticas urbanas para afrontar al fenómeno de las barriadas, donde los distintos grupos populares buscaban la ocupación de terrenos privados en litigios, de poco valor comercial y como parte de un fin político. Así se formaron grandes barriadas como Ciudad de Dios (1954). De esta manera se ofrecieron títulos de propiedad para la construcción de viviendas y la intervención del Estado para el desarrollo del crecimiento 
urbano. En 1961 se creó la Ley N 13517 Ley orgánica de barrios marginales, donde el Estado concede y habilita las nuevas urbanizaciones, ofreciendo saneamiento físico y legal a las zonas que son aptas para vivienda. (Azuela \& Tomas, 1996, pp. 45-88)

A causa de las barriadas y las invasiones se inició el desarrollo de una dinámica económica en la periferia llamado el fenómeno de la autoconstrucción. La ausencia de oferta de vivienda, recursos e intervención del Estado las poblaciones migrantes optaron por autoconstruir sus viviendas sin supervisión ni asesorías técnicas para dicho proceso.

La tendencia urbana a la expansión produjo también un crecimiento demográfico y procesos urbanos sobrepaso los planes urbanos de aquella época. Por lo cual entre los años de 1965 y 1968 la ONPU (Oficina Nacional de Planeamiento y Urbanismo) realizó un estudio a nivel metropolitano para el ordenamiento del desarrollo de la ciudad. Como resultado se identificó un déficit y falla del sistema de transporte esto causado por la falta de vías de conexión y el limitado número de unidades de transporte público que son esenciales para un plan de movilidad en una ciudad en constante crecimiento. Se propuso un ordenamiento por medio de la construcción de vías que alberguen mayor densidad vehicular para que se convirtiesen en ejes de expansión urbana a futuro. (Dorich, 1996 p.103)

Durante el gobierno militar de Juan Velasco Alvarado (1968-1975) se desarrollaron políticas para apoyar con la consolidación de los pueblos jóvenes dando títulos de propiedad y habilitando con sistemas básicos de agua, luz y desagüe a nuevas zonas urbanas. También cambio el término de "Barriadas" por el de "Pueblos Jóvenes". En los años 70 se llevó a cabo un gran proyecto planificado, donde luego se formó el distrito de Villa El Salvador. Por otro lado la ciudad seguía creciendo de manera desordenada como en la zona de Canto Grande, actual distrito de San Juan de Lurigancho. La constante formación de barriadas durante las décadas del 60 y 70 formó los denominados "conos" de Lima que se desplazaron por el norte, sur y este de la trama urbana, en su mayoría en terrenos áridos propiedad del Estado y que no tenían ningún valor comercial, generando de esta manera un triángulo urbano conformada por las zonas periféricas más grandes de Lima. (Bähr \& Bordosof, 2012)

Para el año de 1961 la población de Lima era de 1'652,000 habitantes, para 1972 la población creó a 3’302,523 habitantes y en 1981 era de 4’492,260 habitantes. (MatosMar, 1988) 
La ciudad fragmentada se da entre el periodo de los años 1980 al 2000, donde la ciudad de Lima siguió con un crecimiento migratorio constante, pero en este caso fue a causa de una época de violencia política al interior del país. Este crecimiento acelerado acompañado de los problemas internos hizo que la ciudad en Lima entre en crisis por el agotamiento de terrenos, congestión vial y colapso de servicios básicos como el agua y la electricidad. Esto alentó la preparación de distintos planes de desarrollo urbano para la ciudad de Lima.

En los primeros años de la década del 80, Lima no tenía una economía adecuada frente a las peticiones de un desarrollo urbano, por lo que se delegó algunas responsabilidades, como los procesos urbanos, a los gobiernos locales y uno de los principales problemas fue que no se trabajó con una transparencia de recursos adecuada para la ejecución de proyectos. Además un problema primordial que no se afrontaba era las estrategias de transporte y el desarrollo urbano de Lima Metropolitana, de esta manera nació el Proyecto de Desarrollo Urbano de Lima Metropolitana (1981). Cuyos propósitos eran generar transparencia en los procesos municipales en los procesos de planificación así como en la estructura administrativa y desarrollar proyectos de transporte, limpieza y de mercado para las zonas con menores ingresos de la ciudad. (Dorich, 1996)

En el año de 1986 se acepta el Plan de estructuración de Lima Metropolitana, donde identificó que los principales problemas que atravesaba Lima era el servicio de agua, energía eléctrica, transporte público y vivienda social, y que dichos servicios no podían ser cubiertos con los fondos públicos invertidos como en los años anteriores. Esta situación se afrontó promocionando y desarrollando la imagen de la ciudad proponiendo una nueva organización a la planificación de acciones por parte del gobierno provincial tomando temas de habitabilidad, trabajos industriales, obras viales y de infraestructura. Una organización de la distribución del suelo para los programas de urbanización mejorando el equipamiento urbano, implementando sistemas legales y normativos, además de implementar proyectos de vivienda y empresas populares. (Dorich, 1996)

En el año 1991 se creó el Instituto Metropolitano de Planificación (IMP), que trabajó el Plan de Desarrollo Metropolitano para el periodo de 1999 al 2010 (PLANDEMET). Que busca un reordenamiento de infraestructura vial de la ciudad conformado por cuatro áreas urbanas, creando una trama urbana con múltiples centros que mejorará la movilidad y la conexión, en él se pensó un reordenamiento vial mediante 
la Vía de Evitamiento y de cuatro anillos viales que unan las áreas urbanas. (Dorich, 1996, pp.135-158)

Con este nuevo plan de desarrollo Metropolitano hizo mejorar los ejes viles como parte del proceso de mejoramiento del espacio urbano para hacer más accesible a los nuevos centros económicos y mejorar el transporte en la ciudad, así mismo se llevó a cabo fuertes inversiones de capital inmobiliario para la construcción de grandes centros comerciales como Plaza San Miguel, Jockey Plaza, Mega Plaza, entre otros.

A inicio de los años 90, durante el gobierno de Alberto Fujimori (1990-2000) se pensó en algunas respuestas ante el problema causado por el colapso automotor producido por la recesión de los años 80. Por decisión del presidente Fujimori, el Estado dejó la posibilidad de tener una política de transporte público masivo, decidiendo por otorgar licencias de manera indiscriminada a pequeñas empresas privadas y dando la autorización a la importación masiva de vehículos de segunda mano como combis y custers al país. (Protzel, 2011, pp.101-102)

Durante la gestión del Alcalde de Lima Alberto Andrade (1996-2002) se dio la construcción y remodelación de varias obras públicas, lo cual incluyó la mejora de vías. Durante su periodo se cambió la cara de Lima gracias a la remodelación de espacios públicos de alto valor histórico y simbólico como la Plaza de Armas y la Plaza San Martín.

Durante la gestión del alcalde Luis Castañeda (2003-2010) se planteó un sistema de transporte masivo, finalizando la ejecución el proyecto del Metropolitano que uniría de norte al sur de Lima. Por otro lado durante el segundo mandato del presidente Alan García (2006-2011) se culminó el proyecto de tren eléctrico que fue iniciado durante su primer gobierno.

Para los últimos años del siglo XX, Lima presentaba tres núcleos urbanos consolidados importantes que eran el Centro Histórico, el Callao y los Balnearios del Sur. Del Callao al Centro Histórico se conectaban a través de la Av. Benavides, más conocido como Av. Colonial y que posteriormente apareció el ferrocarril del Callao al Centro Histórico. Para conectarse a los balnearios desde el Centro Histórico a través del camino a Chorrillos donde posteriormente se construyó un tranvía en 1978. Estos primeros desarrollos urbanos demarcarán a futuro un acelerado crecimiento 
demográfico en sus áreas de influencia a causa de las migraciones del campo a la ciudad. (PLAM 2035, 2014)

Luego de la mitad del siglo XX, se desarrollaron las urbanizaciones a lo largo de campos de cultivo entre los antiguos ejes urbanos, formando de esta manera los distritos de Breña, Jesús María, Lince, San Isidro, Surquillo y parte de Miraflores. En 1924 se aprobaron leyes para habilitaciones urbanas en estas nuevas zonas residenciales. Durante este periodo también se formaron las primeras barriadas, algunas se ubican cerca a las urbes como Leticia, El Agustino o San Cosme. Otras al norte de Lima como Comas y al sur como Ciudad de Dios. Esto se le suma al gran proceso migratorio del campo a la ciudad para conseguir mejor calidad de vida en la capital, de esta manera empiezan la dispersión periférica alrededor de los centros urbanos. (PLAM 2035, 2014)

Después en la segunda mitad del siglo XX, Lima pierde gran parte de su zona agrícola, por el valle del Rímac, durante esos años la población aumenta en 150,000 personas al año. En el proceso de urbanización no sólo se perdieron zonas agrícolas, también se empezaron a habitar suelos áridos, quebradas y laderas. Las áreas agrícolas dieron lugar a nuevos distritos como San Borja, Surco, Los Olivos y Pro en Comas. En los suelos áridos se originaron los distritos de Puente Piedra y Villa el Salvador. Por último en las quebradas y laderas tanto al sur, este y norte de Lima, es donde se ocupó de manera informal en condiciones de habitabilidad difíciles. (PLAM 2035, 2014)

Con el transcurso de estos últimos años las zonas centrales metropolitanas fueron transformándose de ser zonas con tipologías de viviendas unifamiliares a multifamiliares. Por otro lado las zonas periféricas mantienen un crecimiento horizontal, esto produce que más poblaciones se establezcan en quebradas y zonas de ladera en condiciones muy precarias. (PLAM 2035, 2014)

Este desequilibrio genera zonas aisladas o desarticuladas, que no cuentan con equipamiento urbano, espacios públicos o servicios básicos. 


\subsection{Historia de Pachacámac}

Pachacamac es uno de los distritos formados por las migraciones que llegaron desde el interior del país que buscaban mejores oportunidades y llegaron a establecerse al sur de Lima creciendo sobre un antiguo pueblo del mismo nombre y establecieron nuevas zonas de expansión a la periferia de manera informal como Manchay que se estableció en quebradas y laderas. Pachacamac es uno de los pocos distritos que cuenta aún con áreas de cultivo cubriendo parte del valle de Lurín.

El Valle de Lurín tiene dos distritos en su parte costera: Lurín y Pachacámac. Ambos poseen cuatro zonas diferenciadas, una urbana, la otra todavía con actividades agropecuarias, la tercera integrada por barriadas y la última por playas. (Matos-Mar, 2011, p. 475)

"Las actividades agropecuarias son tradicionales por la proximidad y calidad del suelo del valle cercano al mar. Todavía es considerado el último valle verde de Lima”. (Matos-Mar, p. 476)

Pachacamac cuenta con un largo pasado prehispánico. En la mitología del mundo andino significa soberano del mundo, señor de los temblores (Matos-Mar, 2011). Era uno de los dioses venerados en el antiguo Perú, un oráculo al que se rendía culto en famosas peregrinaciones, provenientes de todas las regiones desde tiempos muy antiguos.

En 1573 se fundó el pueblo Santísimo Salvador de Pachacámac, como todo pueblo colonial, este fue trazado en forma de damero ${ }^{1}$, en el centro encontrabas la iglesia, el ayuntamiento, la cárcel y la casa de los vecinos; así mismo todos tenían que tener puerta a la calle para que fueran aprendiendo a vivir al estilo español. (Municipalidad de Pachacámac, 2010)

Durante el siglo XIX, Pachacámac tuvo dos acontecimientos importantes. En 1856 fue creado como Municipalidad y en 1857 fue declarado como Distrito Republicano aun manteniendo su característica imagen de pueblo agrícola, con haciendas (Municipalidad de Pachacámac, 2010).

\footnotetext{
${ }^{1}$ Trazado en forma de damero: Es el tipo de planeamiento urbanístico que organiza una ciudad mediante el diseño de sus calles en ángulo recto, creando manzanas rectangulares. Típico de las ciudad coloniales.
} 
Durante la Guerra del Pacífico las tropas peruanas se trasladaron a Pachacamac para hacer retroceder al batallón chileno antes de la invasión de Lima. El batallón peruano evitó el ingreso de los chilenos por la zona de La Rinconada defendiendo la ciudad por el camino de los Lomeros, hoy llamado Huertos de Manchay. (Matos-Mar, 2011)

En 1961 existían solamente dos centros poblados: Lurín, al borde de la antigua carretera Panamericana, y Pachacámac que es un pueblo existente desde tiempos coloniales. En la parte alta se encontraban 18 haciendas y 9 fundos ${ }^{2}$, de los cuales eran dueños del $87 \%$ de las tierras de cultivo del valle de Lurín. En las partes altas sobrevivieron dos comunidades indígenas, Puruhuay y los Almácigos y se formaron 2 pueblos nuevos en la parte más alta, Picapiedra y El Guayabo. La población estimada era de menos de 10 mil habitantes. Era un valle predominantemente algodonero y Cieneguilla era la hacienda más grande (Matos Mar, Portugal et col, 1964).

Luego de la Reforma Agraria de 1969, en el distrito de Pachacámac muchos de los propietarios y sus descendientes han instalado granjas de crianza de ganado vacuno, porcino y avícola. En Lurín, Pachacamac y hasta la lejana zona de Chilca, sobreviven las últimas tierras de cultivo, fragmentos de un cinturón ecológico que funcionó en las décadas de 1980 y 1990, para evitar que sus valles fueran urbanizados (Matos-Mar, 2011).

Para 1983 Pachacámac, es declarado como primer distrito turístico del Perú según la ley $\mathrm{N}^{\circ} 23614$. y para el 2 de noviembre de 1990 fue declarado como distrito ecológico. (Municipalidad de Pachacámac, 2010)

El valle de Pachacamac esta irrigado por el río Lurín, antes llamado río Pachacamac, este mantiene sus tierras fértiles y su ubicación cerca al mar hace que sus lomas sean verdes, de esta manera se genera un alfombra verde llena de vida y atractiva a la vista.

\footnotetext{
${ }^{2}$ Fundo: Explotación agrícola de superficie más pequeña que la hacienda y mayor que la de la chacra.
} 
Figura 2.1

Ciudadela de Pachacamac

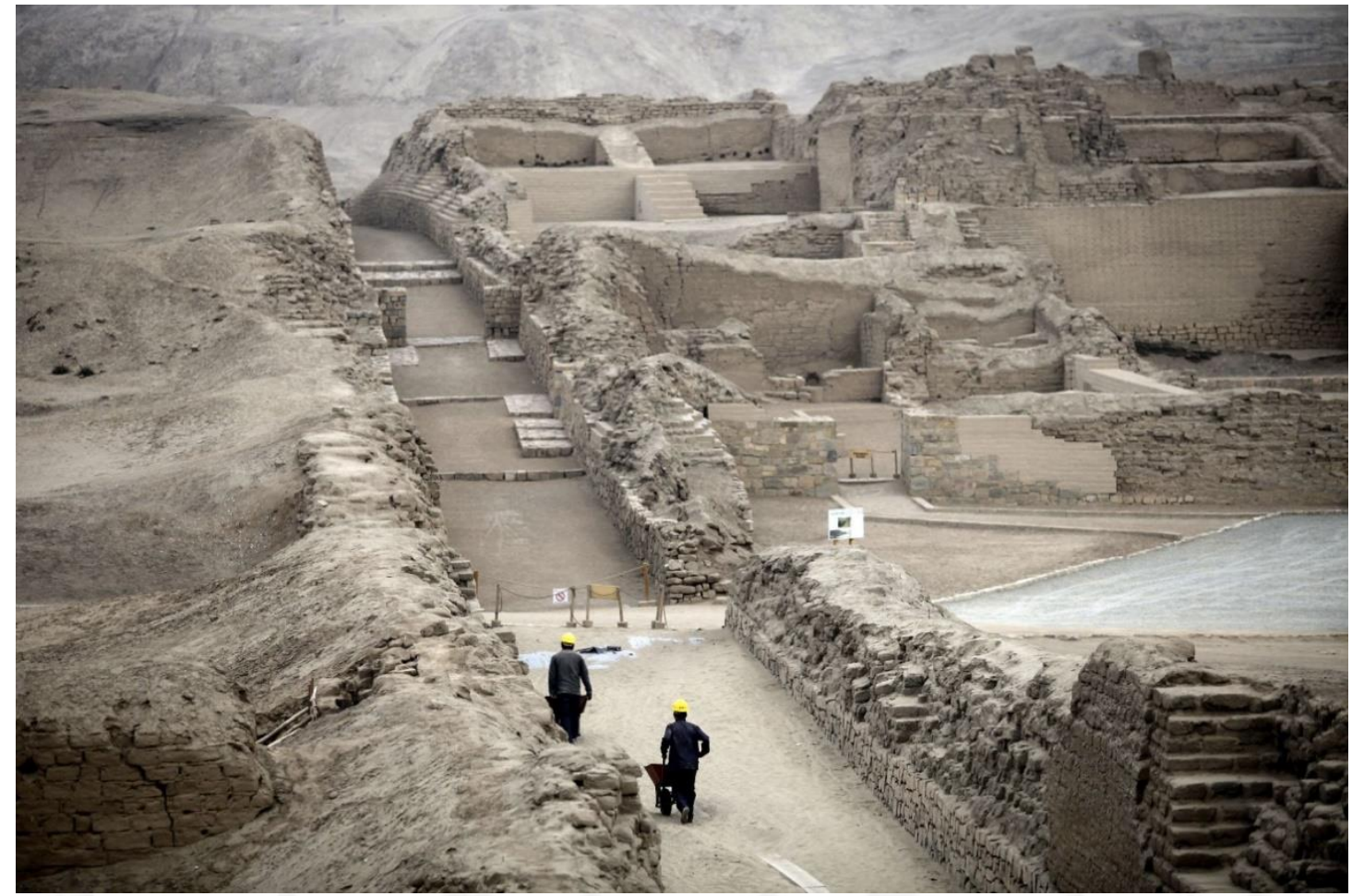

Fuente: Obregoso (2012)

El distrito de Pachacámac ha cambiado notablemente en los últimos veinte años.

$\mathrm{Su}$ capital es un gran centro urbano con notables actividades turísticas, novedosos y excelentes restaurantes, bellas edificaciones de sectores medios y altos limeños, hoteles y casas de reposo, entre sus múltiples actividades. En 1993, el distrito tenía 19850 habitantes. El censo del 2007 se registró 68441 habitantes y la del INEI del 2010 fue de 87796 habitantes (Matos-Mar, 2011, pp. 478-479). 
Tabla 2.1

Crecimiento poblacional de Pachacamac (2012)

\begin{tabular}{lc}
\hline Año & Población \\
\hline 2000 & 38882 \\
2001 & 42356 \\
2002 & 46098 \\
2003 & 50124 \\
2004 & 54451 \\
2005 & 59093 \\
2006 & 64053 \\
2007 & 69348 \\
2008 & 75026 \\
2009 & 81145 \\
2010 & 87769 \\
2011 & 94945 \\
2012 & 102691 \\
2013 & 111037 \\
2014 & 120015 \\
2015 & 129653 \\
\hline
\end{tabular}

Fuente: Municipalidad de Pachacamac (2012)

Figura 2.2

Museo de Sitio de Pachacamac.

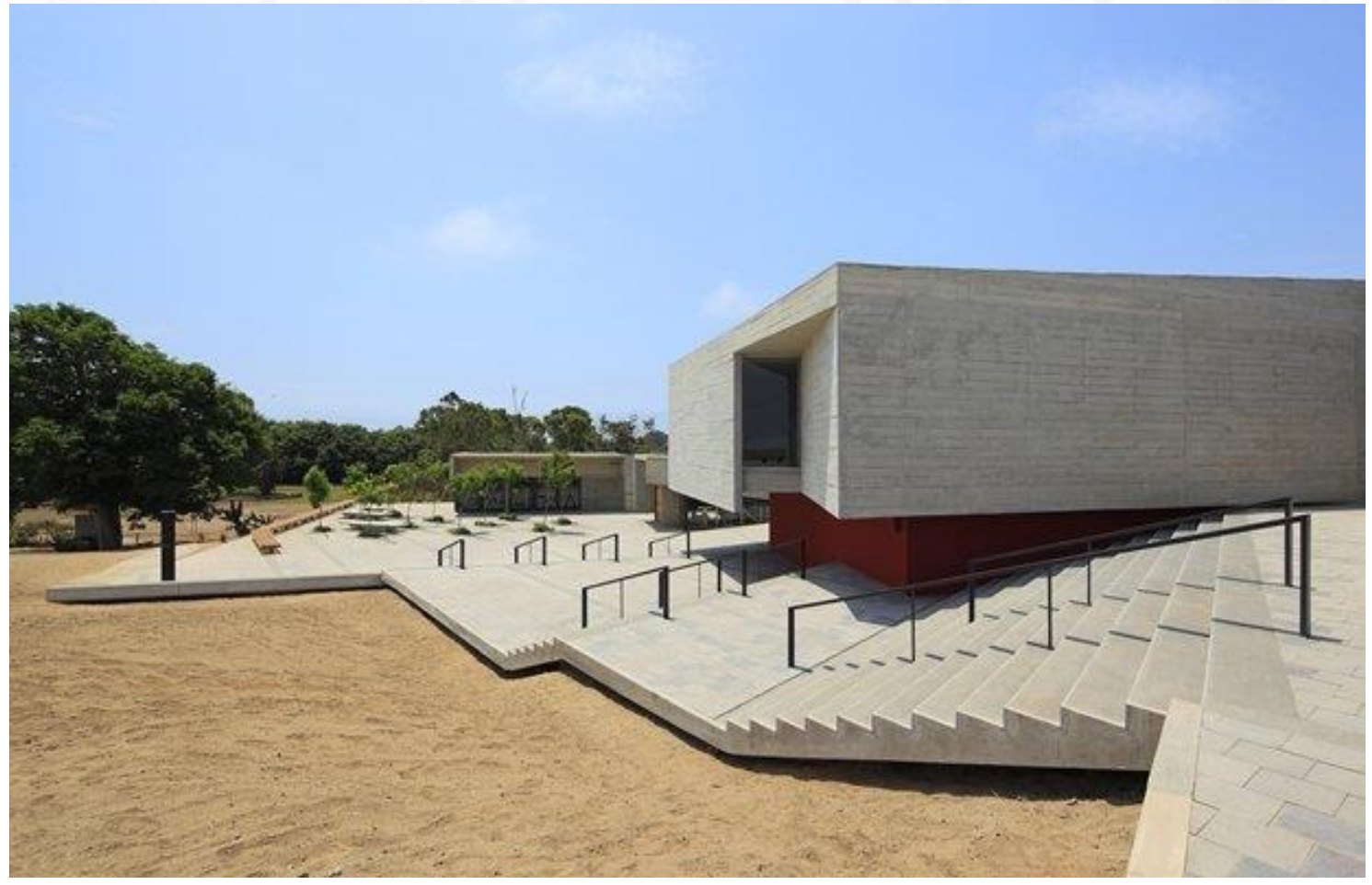

Fuente: Ministerio de Cultura (2016) 
En la actualidad junto a la ciudad de Pachacámac destaca el pueblo de Picapiedra, las barriadas Huertos de Manchay, Paul Poblete Lind, Portada de Manchay I y Portada de Manchay II, las asociaciones de vivienda Casablanca, San Fernando y Santa Anita, las cooperativas de vivienda El Oasis de la Molina y El Paraiso, los centros poblados rurales Cardal, Collanac, Curva Zapata, Guayabo, Jatosisa, La Unión, Manchay Alto, Manzano, Pampa Flores, Puente Manchay, Quebrada Verde, Santa Rosa de Malpaso, Tambo Inga y Tomina, y las comunidades campesinas Santa Rosa de Manchay y Los Almácigos. Todos juntan una población de 120015 personas. (INEI,2014)

Figura 2.3

Quebrada Verde, Pachacamac

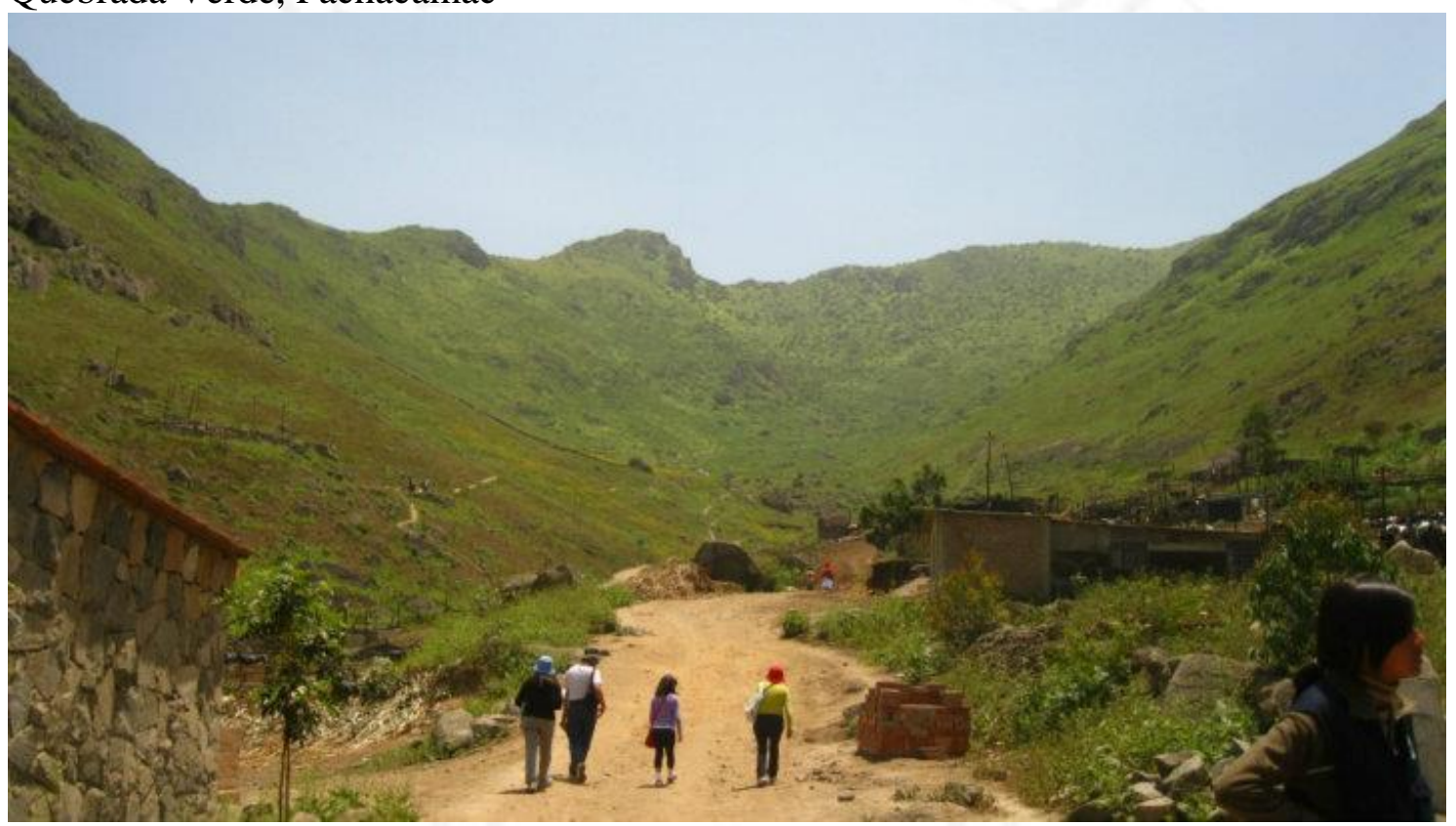

Fuente: Trochainnova (2013).

La zona más poblada de Pachacamac es la zona de Manchay que está ubicado al este del distrito en una de las quebradas que conecta al valle de Lurín. Se originó en los años 80 producto de las expansiones no controladas de Lima Metropolitana, es una de las zonas más vulnerables por su nivel de precariedad, falta de servicios y equipamiento urbano (Matos-Mar, 2011). 


\subsection{Historia de Manchay}

Manchay, en quechua significa "Miedo", es un gran asentamiento humano que ocupa una vasta quebrada de cerros pedregosos, áridos y arenosos. Surgió en la década de 1980 y se dio a conocer más en el año 2000, ya que en ese año fue considerado el emblema de la pobreza urbana y de los esfuerzos de sus pobladores por superarla. (Matos-Mar, Perú: Estado desbordado y sociedad nacional emergente, 2011, p. 478)

Era un páramo famoso porque en sus lomas secas los domingos muchos limeños jóvenes practicaban motocross y carreras de autos durante los años 60. En esos mismos años las constructoras explotaban los suelos y se llevaban toneladas de arena y piedra. Los primeros pobladores eran familias de trabajadores de construcción civil de La Molina y de Cieneguilla, posteriormente se les unieron agricultores y ganaderos que se asentaron en las quebradas de Musa para luego bajar con dirección al Valle de Lurín para vender sus productos al mercado local. Para la década de los 80, a consecuencia de la centralización, la extrema pobreza rural y la violencia terrorista interna, Manchay se volvió un punto de llegada para estas familias en busca de seguridad. (Matos-Mar, 2011)

Figura 2.4

Ciclismo en Manchay

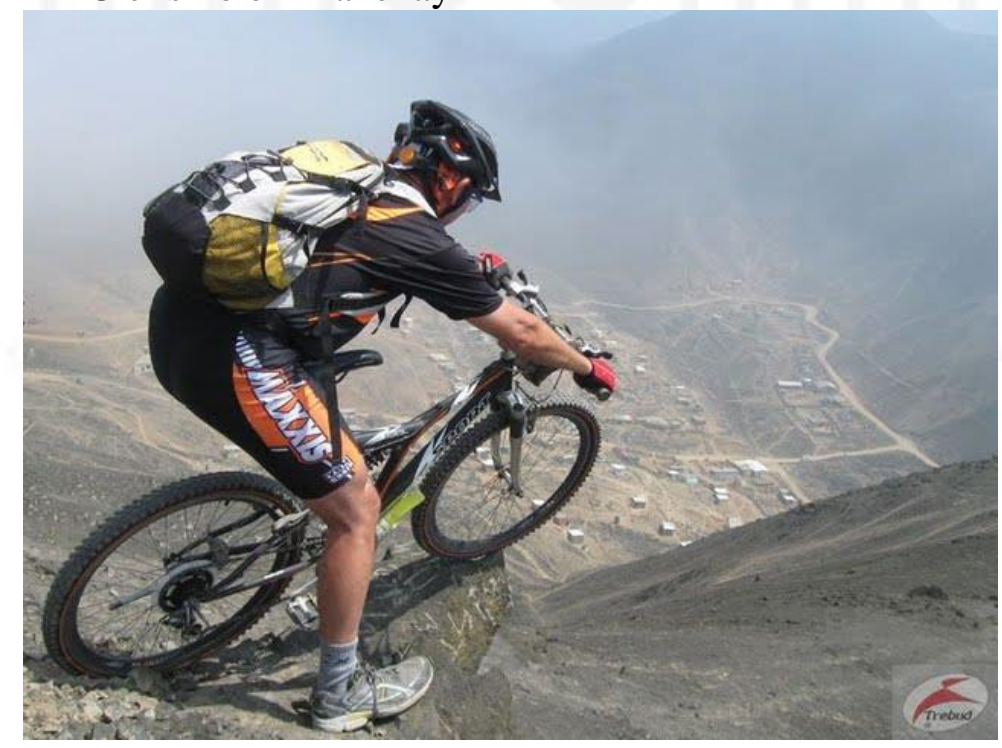

Fuente: Kerino Bike (2005)

Manchay se ubica al sureste de Lima, entre los 400 y 1000 m.s.n.m. fue denominado Centro Poblado Huertos de Manchay y creado por 13 dirigentes el 8 de marzo de 1983. Las familias vivían bastante aisladas unas de otras y cuentan los primeros 
pobladores que durante las noches corría fuerte viento y sucedían cosas extrañas, como escuchar el paso de muchas personas. El saber popular relataba que en esa zona se castigaba a los esclavos de las haciendas y que también por ahí paso el ejército chileno durante la Guerra del Pacífico y dejo muchos muertos a su paso. (Matos-Mar, 2011, p. 479)

Muchas familias llegaron a esta zona debido a los desplazamientos provocados por la guerra interna, cuando el terrorismo atacaba Huanta y Ayacucho durante la década del 80. Numerosas familias huyeron de la violencia, la muerte, la pobreza y el abandono. Las primeras viviendas fueron de esteras o de materiales abandonados en los cerros, así como antiguos tranvías que eran desechados por esas zonas desérticas. (Matos-Mar, 2011)

Manchay fue elegido como refugio de los "desplazados" por su absoluta marginalidad no solo física, porque pensaban que nadie los iba a encontrar, sino también social por el olvido absoluto en que vivían. Las familias la fueron poblando gradual y silenciosamente. En 1982, cuando empezaron a llegar más personas vivían sobre el mismo suelo seco y árido y a fines de 1983 ya eran casi ocho mil personas. En 1990 ya era un pueblo grande donde se hablaba quechua y se trabajaba para lugares más consolidados como el distrito de La Molina, pero aún ellos tenían una carencia de todo, desde servicios básicos, educación, carreteras, vivienda digna. (Matos-Mar, Perú: Estado desbordado y sociedad nacional emergente, 2011). Para esa década se otorgo documentos de propiedad a los "dueños" de las tierras invadidas, para luego brindarles servicios básicos. (Municipalidad de Pachacámac, 2010) 
Figura 2.5

Huertos de Manchay

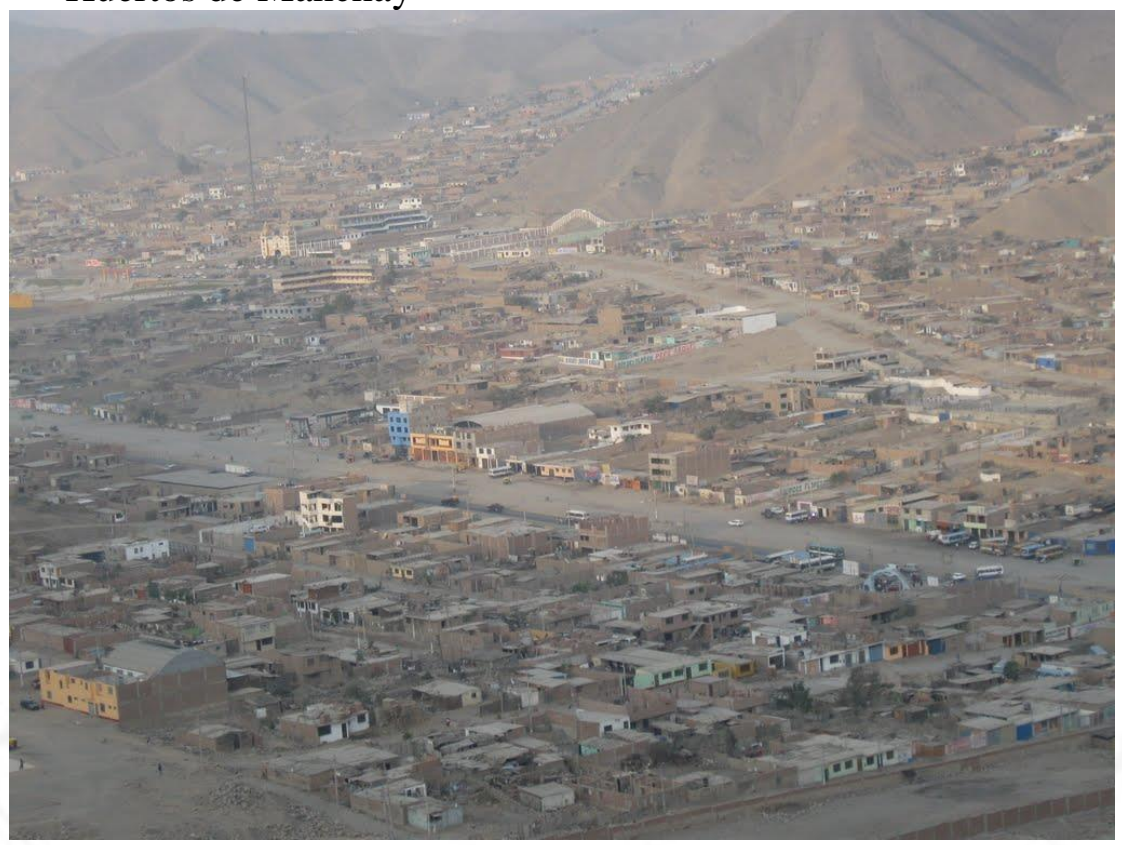

Fuente: López R. (2010)

El arenal, la escasez de agua y vegetación al igual que la pobreza extrema son las características más resaltantes de Manchay. En 1991 se podía comprar un terreno por 80 soles y para no perderlo la única condición era ocuparlo inmediatamente. No había combis, buses ni mototaxis, se debía caminar desde la urbanización de Musa, a algunos kilómetros de su terreno, cargando agua y víveres. El recorrido tomaba de 2 a 3 horas para llegar a los puntos más altos de las quebradas (Matos-Mar, 2011). 
Figura 2.6

Expansión poblacional de Pachacamac.

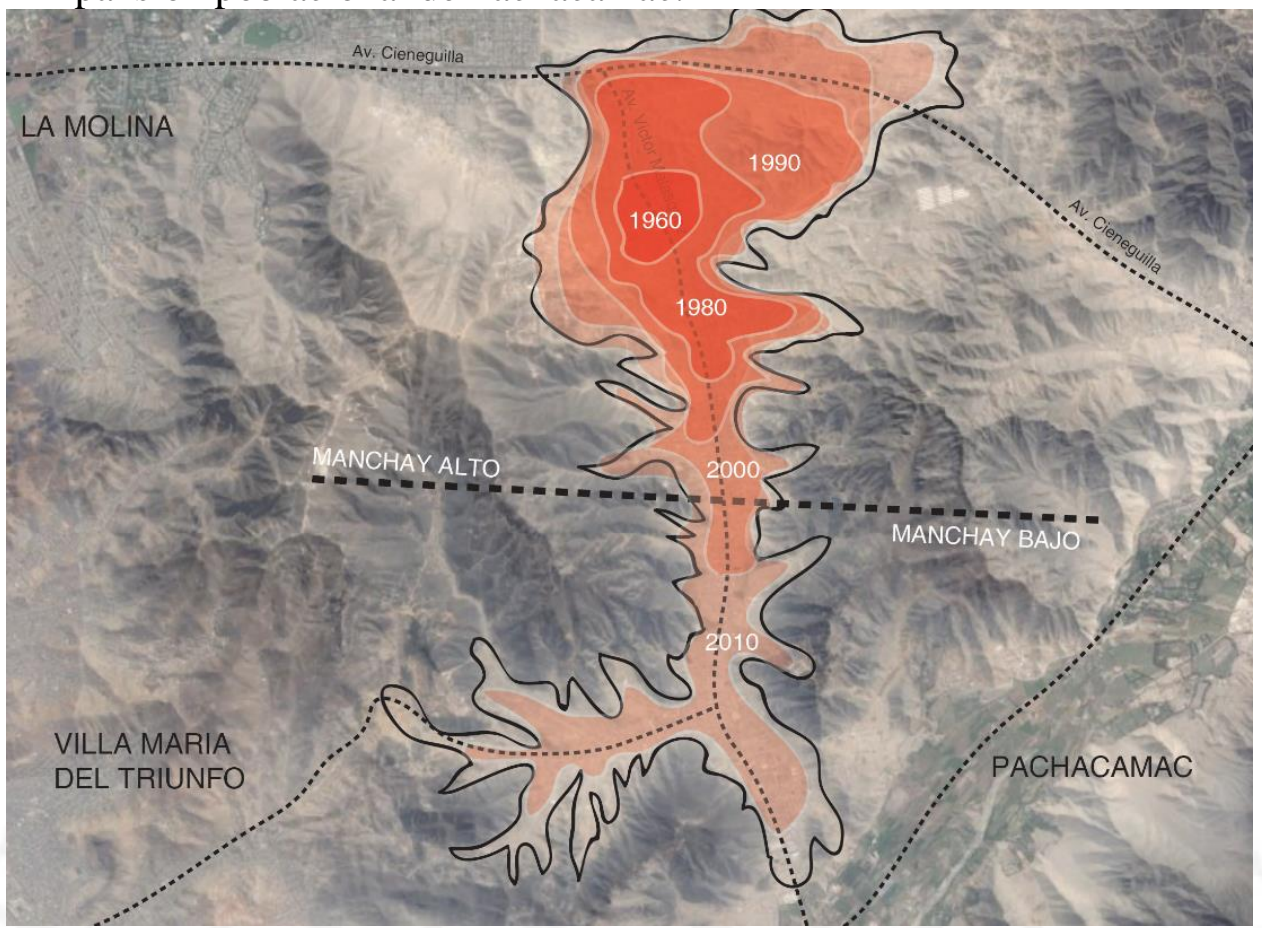

Fuente: Adaptado de Matos Mar (2011)

Los primeros pobladores no vivían tranquilos ya que algunos invasores quemaban las esteras por las noches que no eran ocupadas en los terrenos, para luego apropiarse de ellas o venderlas. Muy pocos obtenían el título de propiedad por parte de la municipalidad de Pachacamac, a cambio, a la mayoría se le otorgó un certificado que los reconoce como posesionarios. (Matos-Mar, 2011)

La primera dificultad de los pobladores era la accesibilidad al lugar ya que cuenta con un $60 \%$ de terreno en pendiente con solamente el $40 \%$ de terreno semiplano. Otras dificultades era la carencia de servicios básicos como agua y luz, también el uso de esteras como vivienda, sin contar con derecho sobre los terrenos, sus pobladores carecían de empleo y los niveles educativos eran muy bajos. En los años 90 Manchay era considerada la zona de pobreza extrema en Lima. (Matos-Mar, Perú: Estado desbordado y sociedad nacional emergente, 2011)

En 1996 la realidad empieza a cambiar cuando el arzobispado de Lima nombra párroco al sacerdote jaujino José Chuquillanqui y decide considerar la zona de Manchay como proyecto de su labor social. Desde entonces no solo se inicia la organización de los pobladores para algunos proyectos comunales, sino que también atrae la atención de los medios de comunicación y de los políticos. Poco a poco se empezaron a instalar 
algunos programas de gobierno. En el año 2002 cuando en ese entonces alcaldía de Lima, Luis Castañeda Lossio, le presta especial atención a la zona más marginada de Lima como Manchay y le empieza a dar servicios básicos. Luego fue el gobierno central con infraestructura y también otros organismos privados quienes se movilizaron para hacer visible la pobreza de esta zona de la capital. (Matos-Mar, Perú: Estado desbordado y sociedad nacional emergente, 2011)

Figura 2.7

Iglesia de Manchay (Manchay, 2008)

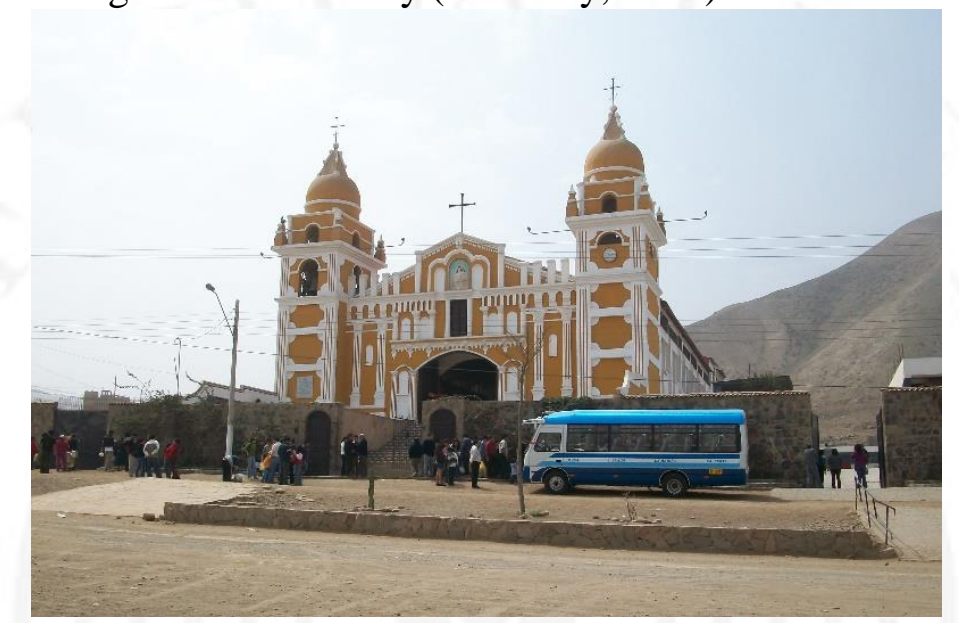

Fuente: Roger, J. (2008)

Es necesario resaltar el apoyo inicial hecho por el padre Chuquillanqui, con mano de obra de los pobladores lograron superarse logrando sus principales servicios mediante programas de salud, educación, derechos humanos, defensa del niño y del adolescente y, sobre todo, por la lucha de tener títulos de propiedad, tener un trabajo estable, saber defenderse de los traficantes de terrenos y pensar grupalmente para escoger bien a sus líderes. Gracias a todos estos apoyos Manchay, que cuenta con aproximadamente tres cuartas partes de la población total de Pachacámac, está integrada por una veintena de barriadas articuladas por una carretera que la conecta con La Molina y Lurín. Tienen agua, luz eléctrica, cable y servicio de serenazgo. Sin embargo para la primera década del siglo XXI solo se ha logrado pasar de la pobreza extrema a la pobreza. (Matos-Mar, 2011, p. 480)

La participación ciudadana estuvo presente desde los inicios de la formación de Manchay como por ejemplo en la construcción de la catedral, que con ayuda de capital extranjero, el Arzobispado de Lima y el trabajo de la población sobre todo de los jóvenes. 
Posterior a ello las iglesias evangelicas empezaron a ubicarse en distintos puntos y del mismo modo, la misma población ayudó a la construcción. Además muchos de ellos construian sus casas de material noble con ayuda de sus vecinos, esto demuestra el potencia que tiene la mano de obra para el servicio y construcción. (Matos-Mar, 2011, p. 481)

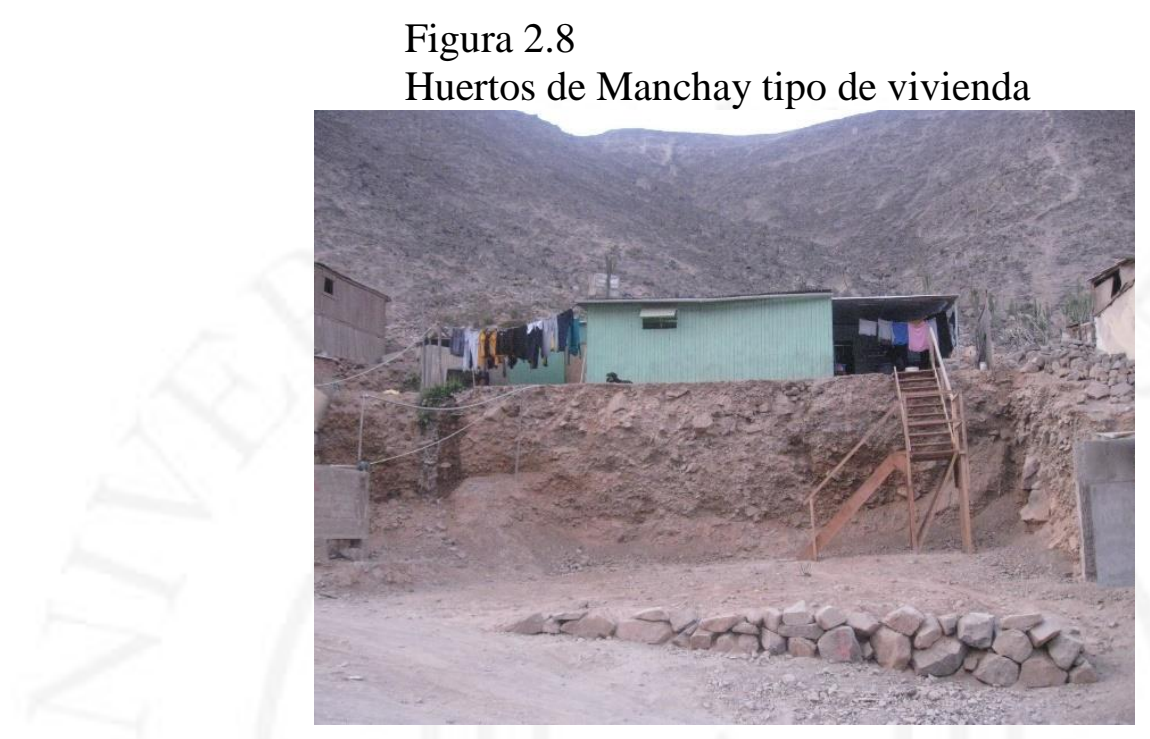

Fuente: López, R. (2010)

\subsection{Información de Pachacamac y Manchay}

El distrito Pachacámac está ubicado, al Sur de Lima Metropolitana, fue creado hace más de 150 años sin fijar los límites de la demarcación territorial. Ello ha contribuido a la cesión de territorios, en diversas ocasiones, para la conformación de otros distritos y a los conflictos limítrofes con algunos distritos colindantes como Lurín y Villa María del Triunfo. El distrito de Pachacámac ocupa el 90\% de la cuenca baja del río Lurín y está integrada por 5 zonas:

- Centros Poblados Rurales -CPRs- de Quebrada Manchay (zona 5)

- Centro Poblado Rural-CPR- Unidos Margen Derecha (zona 3)

- Zona Paúl Poblet Lind (zona 2)

- Zona José Gálvez - Atocongo (zona 4)

- Zona Pachacámac Histórico (zona 1) 
Figura 2.9

Zonas de Pachacamac

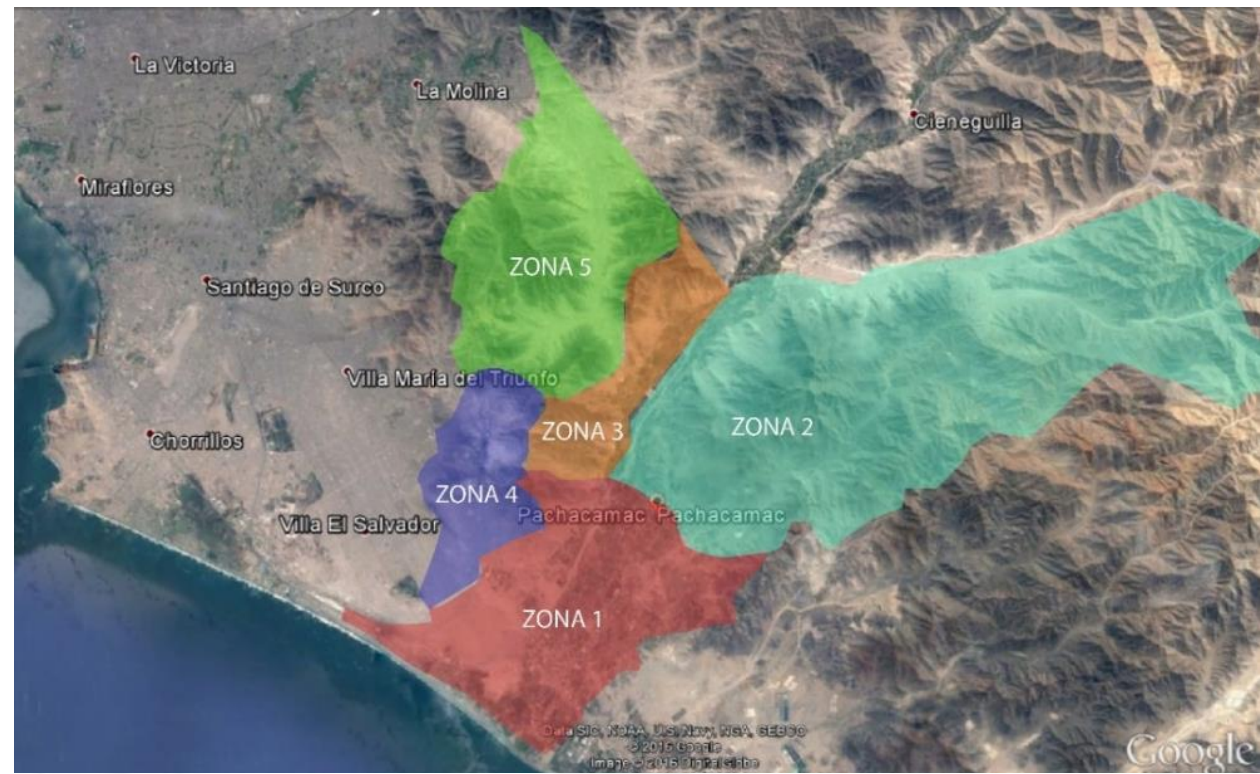

Fuente: Google Earth. (2016)

\subsubsection{Ubicación geográfica}

Descripción geográfica del distrito de Pachacámac.

Latitud: $12^{\circ} 14^{\prime} 30^{\prime \prime}$ Longitud: $76^{\circ} 52^{\prime} 11^{\prime \prime}$

Figura 2.10

Distrito de Pachacamac satelital

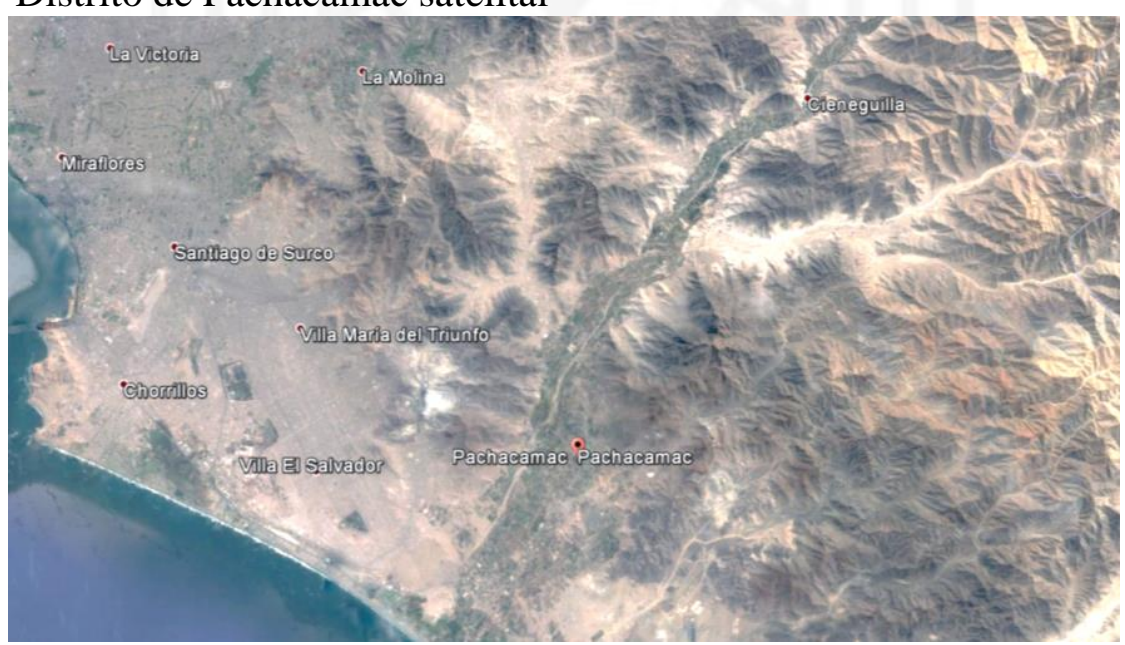

Fuente: Google Earth. (2016)

\subsubsection{Límites}

Norte: Distrito de Cieneguilla y Distrito de La Molina.

Sur: El Océano Pacífico.

Este: Distrito de Lurín y Distrito de Santo Domingo de los Olleros. 
Oeste: Distrito de Villa el salvador y Distrito de Villa María del Triunfo.

\subsubsection{Extensión y Ubicación}

El Distrito de Pachacamac tiene una superficie territorial de 267.87 km2. Su ubicación se establece en un valle costero perteneciente al Río Lurín que se encuentra al Sur de Lima a unos $25 \mathrm{~km}$. El distrito de Pachacamac pertenece a uno de los 44 distritos de la Provincia de Lima, en el Departamento de Lima. (Municipalidad-de-Pachacámac, 2010)

\subsubsection{Terreno}

El Distrito de Pachacamac tiene una ocupación mayormente agrícola que representa un 90\% de su territorio, tiene una característica de plano inclinado, debido a que las altitudes van en aumento con dirección al Este debido a la presencia de la Cordillera de los Andes. Las zonas urbanas del distrito representan un $10 \%$, dentro de ese porcentaje se encuentra Manchay que posee la mayor concentración de población del distrito con un 58\%. (Municipalidad-de-Pachacámac, 2010)

\subsubsection{División Territorial}

Las zonas identificadas y sectorizadas del Distrito de Pachacamac son 5 y son:

Zona 1: Pachacamac Histórico donde se encuentran las comunidades de San Antonio, Cruce de Huertos de Pachacamac, Mamacona, Huerto de Pachacamac, Huertos de Lurín, Villa Libertad, Casica, El Olivar, Pampa Grande, Rinconada de Puruhuay. (Municipalidad-de-Pachacámac, 2010)

Zona 2: Paul Poblet Lind que comprende los Jirones Lima, Jr. Grau, Jr. Ocoña, Jr.Comercio, Jr. Progreso, Jr. Monje, las avenidas El Descanso y Av. San Miguel, entre las comunidades que abarca están Cuatro Bocas, Casa Blanca, Tomina, Minas Perdidas, Torrecillas, Santa Anita, San Fernando, Cardal Mal Paso, Manzano y Pampa Flores. (Municipalidad-de-Pachacámac, 2010)

Zona 3: Centros Poblados Rurales que son ocupadas por las comunidades de Quebrada Verde, Picapiedra, Guayabo, Manchay Alto, Manchay Bajo, Lote B, Rumi Wasi, 
Puente Manchay, Tinajas, San Juan y Curva Zapata. (Municipalidad-de-Pachacámac, 2010)

Zona 4: José Gálvez Barrenechea donde se encuentra la comunidad poblada rural Las Palmas, Pampa Limay, Los Lúcumos, Las Flores, Mobiliarías, Santísimo Salvador, Villa las Palmas, Fundo Las Palmas, 1ro de Diciembre, Villa Alejandro, Santuario, San José, Comité 72, San Camilo, Zarumilla, Monte Carmelo, Villa San Luis, Sáenz Peña, Av. Lima, Asentamiento Humano Unidas, San José, Jr. Callao, Camino Real, Comité 100, El estado, 10 de Octubre, Villa La Merced, Fujimori Fujimori, Las Orquídeas, Los Gómez, Las Lomas de Salamanca y José Gálvez. (Municipalidad-de-Pachacámac, 2010)

Zona 5: Huertos de Manchay que comprende a la Comunidad Campesina Collanac, El Sector de Nueva Esperanza y los distintos sectores que pertenecen a la Comunidad de Huertos de Manchay como Sector de la Florida, Sector los Cactus, Sector Nuevo Progreso, Sector de Pedregal, Sector B, Sector Rinconada Alta, Sector Virgen del Carmen, Sector Bello Horizonte, Sector Los Jardines, Sector C, Sector Central, Sector San Rosa, Sector El Balcón, Sector G, Sector La Pradera, Sector La Meseta, Sector Villa Hermosa, Urbanización Popular de Interés Social (UPIS) Corazón de Jesús, Sector Los Eucaliptos, Sector F, Asentamiento Humano (AA.HH.) La Merced, AA.HH. Los Ángeles, AA.HH. San Pablo Mirador, AA.HH Portada de Manchay III, CPR Sector R, CPR Parcela 1, Asociación de vivienda Franja Comercial Santa Catherine, CPR Rinconada Alta, Asociación de Propietarios Santa Cruz de Collanac, Comunidad Campesina de Collanac, Asociación de Viviendas San Cristóbal, AA.HH Portada de Manchay I, AA.HH Portada de Manchay II, Asociación de Viviendas Virgen de Chapi, AA.HH. Manchay Ampliación , Asociación de viviendas Corazón de María, Cooperación de viviendas Las Dunas, Cooperación de viviendas El Paraiso, AA.HH. Paul Poblet Lind y Cooperación de viviendas Oasis. (Municipalidad-de-Pachacámac, 2010) 


\subsubsection{Población}

Según los censos y los estudios realizados por el INEI, se estimó que la población del Distrito de Pachacamac en el año 2015 es de 63.515 hombres y 66.138 mujeres que en total dan 129.653 habitantes. Pero Pachacamac es considerado como uno de los distritos más poblados de Lima. La Población Económicamente Activa (PEA) representa el 43.68\% de la población censada del Distrito. (INEI, 2015)

Tabla 2.2

Población por edades del Distrito de Pachacamac

\begin{tabular}{|c|c|c|c|c|c|c|c|}
\hline \multirow{2}{*}{$\begin{array}{l}\text { DEPARTAMENTO, } \\
\text { PROVINCIA, } \\
\text { ÁREA URBANA Y } \\
\text { RURAL, } \\
\text { SEXO Y TIPO DE } \\
\text { VIVIENDA }\end{array}$} & \multirow[b]{2}{*}{ TOTAL } & \multicolumn{6}{|c|}{ GRANDES GRUPOS DE EDAD } \\
\hline & & $\begin{array}{c}\text { MENOS } \\
\text { DE } \\
1 \text { AÑO }\end{array}$ & $\begin{array}{l}1 \text { A } 14 \\
\text { AÑOS }\end{array}$ & $\begin{array}{c}15 \mathrm{~A} \\
29 \\
\text { AÑ்S }\end{array}$ & $\begin{array}{r}30 \mathrm{~A} \\
44 \\
\text { AÑOS }\end{array}$ & $\begin{array}{c}45 \mathrm{~A} \\
64 \\
\text { AÑO } \\
\mathrm{S}\end{array}$ & $\begin{array}{c}65 \mathrm{~A} \\
\text { MÁS } \\
\text { AÑNOS }\end{array}$ \\
\hline Distrito Pachacámac & 68441 & 1353 & 20499 & 20537 & 16131 & 7799 & 2122 \\
\hline Hombres & 34222 & 702 & 10316 & 10279 & 7884 & 3962 & 1079 \\
\hline Mujeres & 34219 & 651 & 10183 & 10258 & 8247 & 3837 & 1043 \\
\hline URBANA & 67553 & 1338 & 20272 & 20296 & 15950 & 7655 & 2042 \\
\hline Hombres & 33736 & 694 & 10192 & 10147 & 7789 & 3881 & 1033 \\
\hline Mujeres & 33817 & 644 & 10080 & 10149 & 8161 & 3774 & 1009 \\
\hline RURAL & 888 & 15 & 227 & 241 & 181 & 144 & 80 \\
\hline Hombres & 486 & 8 & 124 & 132 & 95 & 81 & 46 \\
\hline Mujeres & 402 & 7 & 103 & 109 & 86 & 63 & 34 \\
\hline
\end{tabular}

Fuente: Municipalidad de Pachacamac. (2012)

\subsubsection{Aspectos Sociodemográficos}

Según los censos realizados por el INEI del 2010 y el distrito de Pachacamac, resalta que su población pertenece a la clase baja representando el $70 \%$ de su población, un $25 \%$ pertenece a la clase media y un $5 \%$ es de clase alta, que en realidad son personas de otras partes de Lima que tienen una segunda vivienda ya sea casa de campo o de playa. Entre las actividades más desarrolladas en el distrito se encuentra la agricultura, la fruticultura y la ganadería con un $90 \%$ por otro lado el comercio formal e informal representan el 10\% restante. (Municipalidad-de-Pachacámac, 2010)

\subsubsection{Pobreza}

La detección del nivel de pobreza en una zona geográfica se necesita de un método denominado Necesidades Básicas Insatisfechas (NBI), son necesidades básicas de la 
población insatisfechas con respecto a la situación socioeconómica que no logra cubrir sus necesidades más básicas para lograr un nivel mínimo de satisfacción. Con respecto a esta definición se pueden tener varios indicadores para detectar cada necesidad básica. Para América Latina se tiene seleccionado 5 indicadores que identifican las carencias de los países como Perú (Ministerio del Trabajo y Promoción del Empleo, 2005). Los indicadores según la NBI son:

1. Población con viviendas de características físicas inadecuadas.

2. Población con hogares sin servicio de desagüe.

3. Población en hogares con niños que no asisten a educación básica.

4. Población en hogares con mucha dependencia económica.

5. Población con viviendas hacinadas.

La población que tiene sus necesidades básicas cubiertas y satisfechas se considera por la metodología de NBI como poblaciones no pobres, mientras que las poblaciones que cuentan con uno o más de los indicadores mencionados anteriormente se les considera poblaciones pobres. Las poblaciones pobres también categorizaciones, por ejemplo, si tiene una NBI se consideran pobres no extremos, mientras que si una población presenta 2 o más de estas NBI son considerados como pobres extremos. (Ministerio del Trabajo y Promoción del Empleo, 2005)

Uno de los distritos más pobres de Lima Metropolitana es el distrito de Pachacamac, con un $41.7 \%$ de su población en una situación de pobreza ya que presentan una de la NBI y con un $11.7 \%$ de su población un una situación de pobreza extrema con 3 o más NBI, la situación va en aumento por el crecimiento descontrolado de la población en zonas no consolidadas del distrito donde los servicios básicos o la infraestructura adecuada no llegan. (Ministerio del Trabajo y Promoción del Empleo, 2005)

\subsubsection{Educación}

La educación es importante para el desarrollo de la juventud y por ende de los futuros pobladores de una ciudad. Tener un indicador que nos permita saber el nivel de educación alcanzó una determinada población es importante para un análisis socio-demográfico más profundo por sus repercusiones que se tiene a largo plazo por su lucha por superar la pobreza, mejorando así el desarrollo de las ciudades, de la población, generando más 
oportunidades para la movilidad social y además para reducir la fecundidad al tener información sobre planificación familiar y prevención contra embarazos no deseados. El nivel de educación de una población da a conocer los conocimientos acumulados y sus capacidades para desarrollarse a lo largo del día a día en la sociedad a través de los años. (Ministerio del Trabajo y Promoción del Empleo, 2005)

Un empadronamiento realizado en las zonas marginales del distrito de Pachacamac entre la población de 15 a más años de edad, se obtuvo que el $21.7 \%$ no tiene estudio alguno o tiene nivel primaria incompleta, el $60.4 \%$ ha logrado aprobar por lo menos un año de educación secundaria pero con educación primaria completa y el $12.7 \%$ de los empadronados alcanzó algún nivel superior ya sea técnicos o universitarios. (Ministerio del Trabajo y Promoción del Empleo, 2005)

Los resultados adquiridos del nivel de educación en este rango de edades se consideran como limitadas, por los conocimientos, destrezas y habilidades acumuladas para un trabajo, lo que por consiguiente no se garantiza una buena oportunidad para entrar al campo laboral, ya que cada día se vuelve más tecnificado, exigente y competitivo. Pero también al obtener información de los sectores no pobres del distrito con al menos una NBI se identificó que el $16.5 \%$ de este grupo cuenta con estudios superiores en comparación con los pobres que son un $6.6 \%$ o de los pobres extremos que son un $4 \%$. (Ministerio del Trabajo y Promoción del Empleo, 2005) 
Tabla 2.3

Población educada en Pachacamac (2010)

\begin{tabular}{|c|c|c|c|c|c|}
\hline & & Total & con $1 \mathrm{NBI}$ & Con 2 a $5 \mathrm{NBI}$ & \\
\hline Total & 100,0 & 100,0 & 100,0 & 100,0 & 100,0 \\
\hline Sin nivel & 0,1 & 0,2 & 0,1 & 0,4 & 0,1 \\
\hline Inicial & 0,2 & 0,3 & 0,3 & 0,4 & 0,1 \\
\hline Primaria incompleta & 11,0 & 13,4 & 12,5 & 15,8 & 9,4 \\
\hline Primaria completa & 10,4 & 10,9 & 10,3 & 12,9 & 10,0 \\
\hline Secundaria incompleta & 25,8 & 29,6 & 29,0 & 31,5 & 23,3 \\
\hline Secundaria completa & 34,6 & 32,8 & 34,2 & 28,8 & 35,8 \\
\hline Superior no universitaria incompleta & 3,9 & 2,5 & 3,0 & 1,3 & 4,7 \\
\hline Superior no universitaria completa & 4,7 & 2,4 & 2,8 & 1,4 & 6,1 \\
\hline Superior universitaria incompleta & 2,0 & 0,9 & 1,0 & 0,7 & 2,7 \\
\hline Superior universitaria completa & 2,1 & 0,8 & 0,9 & 0,6 & 3,0 \\
\hline No especificado & 5,3 & 6,0 & 5,9 & 6,3 & 4,9 \\
\hline Hombre & 100,0 & & 100,0 & 100,0 & 100,0 \\
\hline Sin nivel & 0,0 & 0,1 & 0,0 & 0,1 & 0,0 \\
\hline Inicial & 0,1 & 0,1 & 0,1 & 0,1 & 0,1 \\
\hline Primaria incompleta & 7,8 & 9,9 & 9,4 & 11,1 & 6,5 \\
\hline Primaria completa & 9,4 & 10,0 & 9,0 & 12,9 & 9,0 \\
\hline Secundaria incompleta & 26,9 & 31,2 & 30,0 & 34,4 & 24,2 \\
\hline Secundaria completa & 40,0 & 38,8 & 40,5 & 34,0 & 40,7 \\
\hline Superior no universitaria incompleta & 3,8 & 2,6 & 3,0 & 1,3 & 4,5 \\
\hline Superior no universitaria completa & 4,5 & 2,3 & 2,4 & 1,9 & 5,8 \\
\hline Superior universitaria incompleta & 2,4 & 1,2 & 1,3 & 0,7 & 3,1 \\
\hline Superior universitaria completa & 2,0 & 0,8 & 0,8 & 0,8 & 2,8 \\
\hline No especificado & 3,2 & 3,3 & 3,5 & 2,7 & 3,1 \\
\hline Mujer & 100,0 & & 100,0 & 100,0 & 100,0 \\
\hline Sin nivel & 0,2 & 0,3 & 0,2 & 0,6 & 0,1 \\
\hline Inicial & 0,3 & 0,6 & 0,5 & 0,7 & 0,1 \\
\hline Primaria incompleta & 13,9 & 16,6 & 15,4 & 20,0 & 12,2 \\
\hline Primaria completa & 11,3 & 11,8 & 11,4 & 12,9 & 11,0 \\
\hline Secundaria incompleta & 24,7 & 28,3 & 28,1 & 28,8 & 22,3 \\
\hline Secundaria completa & 29,6 & 27,4 & 28,5 & 24,1 & 31,1 \\
\hline Superior no universitaria incompleta & 3,9 & 2,5 & 2,9 & 1,3 & 4,9 \\
\hline Superior no universitaria completa & 4,9 & 2,6 & 3,2 & 1,0 & 6,4 \\
\hline Superior universitaria incompleta & 1,6 & 0,8 & 0,8 & 0,6 & 2,2 \\
\hline Superior universitaria completa & 2,2 & 0,8 & 0,9 & 0,3 & 3,1 \\
\hline No especificado & 7,3 & 8,4 & 8,0 & 9,5 & 6,5 \\
\hline
\end{tabular}

Fuente: Ministerio del Trabajo y Promoción del Empleo (2010) 
Tabla 2.4

Indicadores de Educación en Lima Sur (2007)

\begin{tabular}{|c|c|c|c|c|c|c|}
\hline INDICADOR & Lurin & Pachacámac & $\begin{array}{c}\begin{array}{c}\text { San Juan } \\
\text { de } \\
\text { Miraflores }\end{array} \\
\end{array}$ & $\begin{array}{l}\text { Villa EI } \\
\text { Salvador }\end{array}$ & $\begin{array}{l}\text { Villa Maria } \\
\text { del Triunfo }\end{array}$ & Lima Sur \\
\hline $\begin{array}{l}\text { Población en edad escolar ( } 6 \text { a } 16 \\
\text { años) que no asiste a la escuela y es } \\
\text { analfabeta }\end{array}$ & 0,4 & 0,6 & 0,5 & 0,6 & 0,6 & 0,6 \\
\hline $\begin{array}{l}\text { Edad promedio de los que asisten al } \\
\text { sexto grado de educación primaria }\end{array}$ & 12,3 & 12,9 & 12,1 & 12,1 & 12,6 & 12,4 \\
\hline $\begin{array}{l}\text { Edad promedio de los que asisten a } \\
\text { quinto año de educación secundaria }\end{array}$ & 16,8 & 17,0 & 16,5 & 16,8 & 17,1 & 16,8 \\
\hline $\begin{array}{l}\text { Población analfabeta de } 6 \text { a } 11 \text { años } \\
\text { que tienen de } 2^{\circ} \text { a } 6^{\circ} \text { grado de } \\
\text { educación primaria }\end{array}$ & 0,3 & 0,4 & 0,2 & 0,2 & 0,2 & 0,2 \\
\hline TASA DE ANALFABETISMO & & & & & & \\
\hline Total & 2,7 & 3,4 & 2,4 & 2,2 & 2,5 & 2,4 \\
\hline Femenino & 4,3 & 5,4 & 3,8 & 3,6 & 4,0 & 3,9 \\
\hline
\end{tabular}

Fuente: MTPE-Observatorio Socio Económico Laboral Lima Sur. (2009)

\subsubsection{Población Económicamente Activa (PEA)}

Para el análisis de la población trabajadora activa se consideró para el empadronamiento a jóvenes desde los 6 años de edad a más de las zonas marginales de Pachacamac debido a que la participación de los niños y adolescentes en el mercado laboral es frecuente más aún cuando se vive en situación de pobreza o pobreza extrema.

Los resultado del empadronamiento en las zonas urbanas marginales de Pachacamac, el $51.7 \%$ son económicamente activos (PEA) que ya tiene un trabajo o se encuentran buscando uno, el $48.3 \%$ es población inactiva y lo conforman estudiantes, amas de casa, rentistas, pensionistas, etc. El PEA total el 59.3\% son hombres mientras que el $40.7 \%$ restante son mujeres. Por otro lado la población económicamente inactiva (PEI) es al contrario, el $61.9 \%$ son mujeres mientras que el $38.1 \%$ son hombres. (Ministerio del Trabajo y Promoción del Empleo, 2005) 
Tabla 2.5

PEA en el distrito de Pachacamac (2005)

\begin{tabular}{|c|c|c|c|c|}
\hline \multirow[b]{2}{*}{ Grupos de edad / Sexo } & \multicolumn{3}{|c|}{ Condición de actividad } & \multirow[b]{2}{*}{ Tasa de actividad } \\
\hline & Total & $\begin{array}{c}\text { Población } \\
\text { economicamente } \\
\text { activa (PEA) }\end{array}$ & $\begin{array}{c}\text { Población } \\
\text { economicamente } \\
\text { inactiva (PEI) }\end{array}$ & \\
\hline Total & 23091 & 11935 & 11156 & 51,7 \\
\hline De 6 a 14 años & 6079 & 318 & 5761 & 5,2 \\
\hline De 15 a 17 años & 1776 & 552 & 1224 & 31,1 \\
\hline De 18 a 24 años & 3619 & 2424 & 1195 & 67,0 \\
\hline De 25 a 29 años & 2548 & 1925 & 623 & 75,5 \\
\hline De 30 a 39 años & 4545 & 3578 & 967 & 78,7 \\
\hline De 40 a 49 años & 2486 & 2004 & 482 & 80,6 \\
\hline De 50 a 59 años & 1211 & 860 & 351 & 71,0 \\
\hline De 60 y más años & 827 & 274 & 553 & 33,1 \\
\hline Hombre & 11321 & 7072 & 4249 & 62,5 \\
\hline De 6 a 14 años & 3069 & 176 & 2893 & 5,7 \\
\hline De 15 a 17 años & 884 & 317 & 567 & 35,9 \\
\hline De 18 a 24 años & 1819 & 1443 & 376 & 79,3 \\
\hline De 25 a 29 años & 1178 & 1123 & 55 & 95,3 \\
\hline De 30 a 39 años & 2139 & 2088 & 51 & 97,6 \\
\hline De 40 a 49 años & 1232 & 1191 & 41 & 96,7 \\
\hline De 50 a 59 años & 592 & 537 & 55 & 90,7 \\
\hline De 60 y más años & 408 & 197 & 211 & 48,3 \\
\hline Mujer & 11770 & 4863 & 6907 & 41,3 \\
\hline De 6 a 14 años & 3010 & 142 & 2868 & 4,7 \\
\hline De 15 a 17 años & 892 & 235 & 657 & 26,3 \\
\hline De 18 a 24 años & 1800 & 981 & 819 & 54,5 \\
\hline De 25 a 29 años & 1370 & 802 & 568 & 58,5 \\
\hline De 30 a 39 años & 2406 & 1490 & 916 & 61,9 \\
\hline De 40 a 49 años & 1254 & 813 & 441 & 64,8 \\
\hline De 50 a 59 años & 619 & 323 & 296 & 52,2 \\
\hline De 60 y más años & 419 & 77 & 342 & 18,4 \\
\hline
\end{tabular}

Fuente: Ministerio del Trabajo y Promoción del Empleo (2005)

\subsubsection{Ocupaciones}

En las zonas marginales urbanas del distrito de Pachacamac el 37\% de la población no son trabajadores calificados o son peones que trabajan en el campo, de ellos el $21.3 \%$ son limpiadores, lavanderos o trabajadores domésticos y el $7.3 \%$ trabajan como vendedores ambulantes. En $20.9 \%$ de la población empadronada son trabajadores calificados donde el $12 \%$ son vendedores comerciantes al por menor, el $2.7 \%$ son cocineros calificados y el $1.6 \%$ tiene una bodega o puesto en algún mercado. Un $17.6 \%$ tienen un trabajo en construcción como obreros o confeccionadores de productos, el $11.8 \%$ son obreros u operarios de alguna máquina, el 3.8\% tiene un título profesional, el 3.1\% trabajan en alguna oficina, el $2.9 \%$ son técnicos a nivel medio y el $2.3 \%$ tienen un trabajo en el campo como agricultores o ganaderos. (Ministerio del Trabajo y Promoción del Empleo, 2005) 


\subsubsection{Vivienda}

Para conocer la calidad de vida con la que viven las personas se debe de conocer primero que tipo de vivienda habitan y las condiciones en las que se encuentran en la ciudad. Esta información es muy importante para la mejora y desarrollo de las ciudades junto a una planificación urbana previa para mejorar el estado de confort con la que viven sus habitantes.

Las zonas marginadas del distrito de Pachacamac la vivienda independiente es la que se encuentra en mayor cantidad, tiene su ingreso y salida directa a la calle. El 90.9\% de residentes tiene esta condición. Según las necesidades satisfechas e insatisfechas básicas, se obtuvo que al menos carecen una necesidad básica insatisfecha (NBI) que son las personas pobres no extremas en un $81.3 \%$ de las viviendas independientes, esta cifra va disminuyendo para los que tienen 2 a 5 necesidades básicas insatisfechas, que son los pobres extremos que llegan al $69.5 \%$ de sus viviendas independientes. Por otro lado los no pobres en un $99.6 \%$ cuentan con una casa independiente. (Ministerio del Trabajo y Promoción del Empleo, 2005)

La demanda de vivienda en estas zonas marginadas de Pachacamac, como Manchay por ejemplo, no siempre se realizan por procedimientos formales, es por ello que la población de acuerdo a sus ingresos y necesidades optan por la invasión y la construcción gradual de sus viviendas sin autorización de la municipalidad o permiso de edificación. Es por eso que el $8.8 \%$ de las viviendas de Pachacamac son viviendas improvisadas, y de estas el $21.6 \%$ son de segmentos pobres y el resto son pobres extremos. Esta situación alerta a los gobiernos locales para emprender políticas de vivienda para la demanda de los segmentos más pobres. (Ministerio del Trabajo y Promoción del Empleo, 2005) 
Figura 2.11

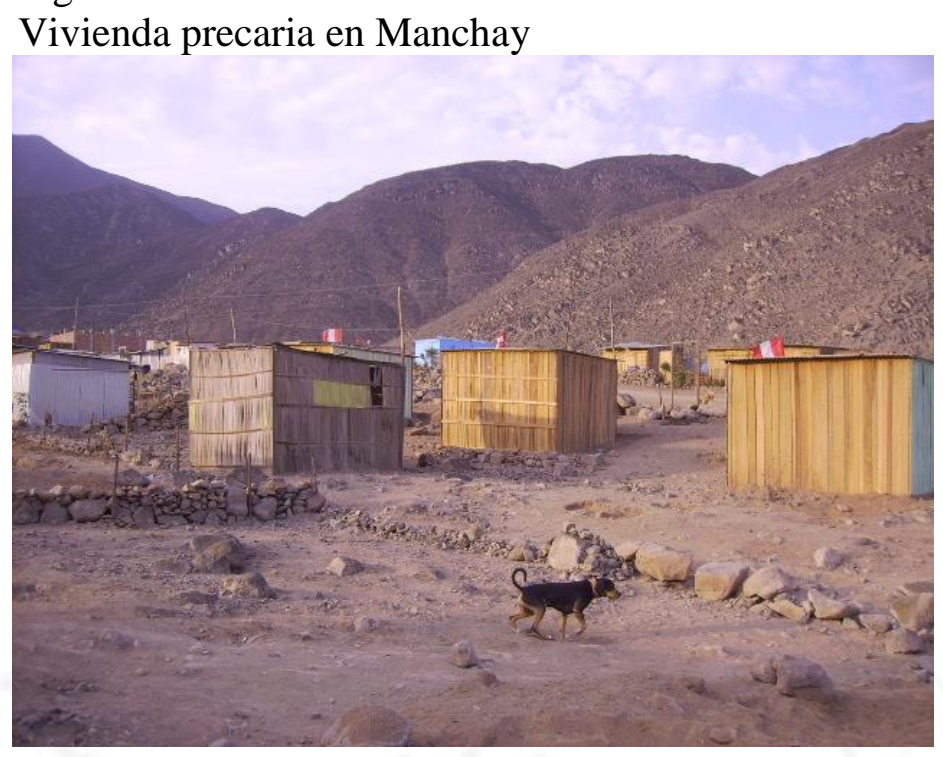

Fuente: Cortes E. (2012)

La viviendas que se encuentran en pisos de tierra es otro indicador de pobreza, esto afecto a un gran porcentaje del distrito a un 37.8\%, donde 4 de cada 10 viviendas presentan esta característica. (Ministerio del Trabajo y Promoción del Empleo, 2009)

Para conocer la manera en cómo se distribuyen en una vivienda se debe de conocer la cantidad de personas que habitan en ella, de esta manera también dependiendo del tipo de vivienda y sus dimensiones se puede deducir el nivel de privacidad e intimidad en la convivencia. Así mismo esta información puede ser de ayuda para nuevas normas que permitan mejorar las condiciones de habitabilidad en los sectores más necesitados.

En el empadronamiento de las zonas marginales urbanas de Pachacamac se obtuvo que el $23.6 \%$ de las viviendas cuentan con una única habitación, en los hogares pobres esta cifra se duplica llegando al $47.1 \%$ de las viviendas y con las viviendas de extrema pobreza las viviendas con una habitación llegan al $72.9 \%$. Por otro lado en las viviendas de los no pobres solo representa el 7.6\%. Las viviendas con dos habitaciones en las zonas urbanas marginales del distrito representa el $33.9 \%$, de tres habitaciones el $23.7 \%$ y de cuatro a más habitaciones un $18.8 \%$. En el caso de las poblaciones pobres se obtiene que tienen tres habitaciones el $14.2 \%$ y los de extrema pobreza el 5.2\%. Con esta información se llega a la conclusión que mientras más pobre es el hogar menos habitaciones tiene la vivienda. (Ministerio del Trabajo y Promoción del Empleo, 2005) 
Tabla 2.6

Número de habitantes por vivienda en Pachacamac (2005)

\begin{tabular}{|l|c|c|c|c|c|}
\hline \multirow{2}{*}{$\begin{array}{c}\text { Número de } \\
\text { habitaciones }\end{array}$} & \multirow{2}{*}{$\begin{array}{c}\text { Total } \\
(\%)\end{array}$} & \multicolumn{3}{|c|}{ Con al menos un NBI } & \multirow{2}{*}{ Con NBS } \\
\cline { 3 - 5 } & & Total & Con 1 NBI & Con 2 a 5 NBI & \\
\hline \multicolumn{1}{c}{ Total } & 100,0 & 100,0 & 100,0 & 100,0 & 100,0 \\
\hline habitación & 23,6 & 47,1 & 37,9 & 72,9 & 7,6 \\
2 habitaciones & 33,9 & 33,2 & 37,7 & 20,8 & 34,4 \\
3 habitaciones & 23,7 & 14,2 & 17,5 & 5,2 & 30,1 \\
& & & & & \\
\hline
\end{tabular}

Fuente: Ministerio del Trabajo y Promoción del Empleo (2005)

\subsubsection{Acceso a Servicios Básicos}

Para el distrito de Pachacamac el servicio de agua y desagüe está abasteciendo casi en su totalidad en las zonas más bajas del distrito por el valle de Lurín, pero en las zonas más altas como en Manchay, los servicios no está abasteciendo en su totalidad a su población debido a la accesibilidad al terreno en ladera y deben ser abastecidos por camiones cisternas o reservorios de agua. Estos servicios son fundamentales para una buena calidad de vida que permite tener una buena higiene y al contar con un sistema que llegue a la vivienda se ahorran el trabajo de traer agua de lugares lejanos poniendo sus vidas en riesgo por el constante peso que se carga y los caminos de difícil acceso que deben de recorrer. (Ministerio del Trabajo y Promoción del Empleo, 2005)

El tener acceso al agua potable es una condición mínima de sanidad y es requisito para las necesidades básicas del día a día en la vivienda, la falta de este servicio afecta directamente la salud, la higiene, el bienestar de sus habitantes y la dificultad que generaría para hacer las labores domésticas. Pachacamac es el distrito con mayor problema del servicio de agua y desagüe de Lima Sur. El 32.8\% tiene falta o problemas en la red de desagüe, tiene una red mediante pozos un $79.5 \%$ y no cuenta con una red de agua potable el $84.9 \%$ de la población esto significa que de cada 10 viviendas 8 no tienen servicio de agua potable (Municipalidad-de-Pachacámac, 2010) 
Tabla 2.7

Carencias en los distritos de Lima Sur, en porcentaje (2007)

\begin{tabular}{|c|c|c|c|c|c|c|}
\hline INDICADOR & Lurín & Pachacámac & $\begin{array}{l}\text { San Juan } \\
\text { de } \\
\text { Miraflores }\end{array}$ & $\begin{array}{l}\text { Villa EI } \\
\text { Salvador }\end{array}$ & $\begin{array}{l}\text { Villa María } \\
\text { del Triunfo }\end{array}$ & Lima Sur \\
\hline $\begin{array}{l}\text { Total de hogares en viviendas } \\
\text { particulares con ocupantes } \\
\text { presentes (absoluto) }\end{array}$ & 15619 & 18133 & 82591 & 86493 & 90937 & 293773 \\
\hline $\begin{array}{l}\text { Sin agua, ni desagüe ni alumbrado } \\
\text { eléctrico }\end{array}$ & 1,8 & 5,3 & 0,7 & 0,9 & 1,4 & 1,3 \\
\hline Sin agua, ni desagüe de red & 19,4 & 32,8 & 3,1 & 5,6 & 7,5 & 7,9 \\
\hline Sin agua, de red o pozo & 32,7 & 79,5 & 10,2 & 18,7 & 23,0 & 22,1 \\
\hline Sin agua de red & 44,1 & 84,9 & 8,3 & 16,8 & 20,3 & 21,2 \\
\hline Sin alumbrado eléctrico & 13,6 & 29,4 & 5,6 & 7,0 & 10,7 & 9,5 \\
\hline Con piso de tierra & 24,0 & 37,8 & 12,0 & 14,9 & 20,9 & 17,8 \\
\hline Con una habitación & 22,5 & 33,8 & 15,6 & 15,4 & 22,3 & 19,1 \\
\hline Sin artefactos electrodomésticos & 8,4 & 10,9 & 6,5 & 6,8 & 7,1 & 7,1 \\
\hline $\begin{array}{l}\text { Sin servicio de información ni } \\
\text { comunicación }\end{array}$ & 24,7 & 27,0 & 20,5 & 23,1 & 24,0 & 23,0 \\
\hline $\begin{array}{l}\text { Que cocinan con kerosene, carbón, } \\
\text { leña, bosta/estiercol, y otros sin } \\
\text { chimenea en la cocina }\end{array}$ & 20,9 & 32,1 & 16,8 & 21,7 & 22,2 & 21,1 \\
\hline
\end{tabular}

Fuente: MTPE-Observatorio Socio Económico Laboral Lima Sur (2009)

Tabla 2.8

Acceso a servicios básicos de la vivienda en Lima Sur, en porcentaje (2008)

\begin{tabular}{|c|c|c|c|c|c|c|c|c|}
\hline \multirow[b]{2}{*}{$\begin{array}{l}\text { DISTRITOS POR } \\
\text { NIVELES DE } \\
\text { POBREZA }\end{array}$} & \multicolumn{3}{|c|}{$\begin{array}{c}\text { TIPO DE ALUMBRADO EN LA } \\
\text { VIVIENDA }\end{array}$} & \multicolumn{2}{|c|}{$\begin{array}{l}\text { ABASTECIMIENTO } \\
\text { DE AGUA }\end{array}$} & \multicolumn{3}{|c|}{ SERVICIOS HIGIENICOS } \\
\hline & Electricidad & $\begin{array}{c}\text { Kerosene } \\
\text { petróleo, } \\
\text { vela, otro }\end{array}$ & $\begin{array}{c}\text { No } \\
\text { tiene }\end{array}$ & $\begin{array}{l}\text { Red } \\
\text { pública }\end{array}$ & $\begin{array}{l}\text { Pilón, } \\
\text { camión, } \\
\text { pozo, río, } \\
\text { acequia, } \\
\text { otro }\end{array}$ & $\begin{array}{c}\text { Red } \\
\text { pública }\end{array}$ & $\begin{array}{c}\text { Pozo } \\
\text { séptico, } \\
\text { pozo } \\
\text { ciego, río, } \\
\text { acequia, } \\
\text { otro }\end{array}$ & $\begin{array}{l}\text { No } \\
\text { tiene }\end{array}$ \\
\hline \multicolumn{9}{|l|}{ Lurín } \\
\hline Total absoluto & 6555 & 480 & 20 & 3594 & 3461 & 3140 & 3741 & 174 \\
\hline Pobre extremo & 1,8 & 62,3 & 55,0 & 0,6 & 11,7 & 0,2 & 9,9 & 28,2 \\
\hline Pobre no extremo & 70,6 & 37,7 & 45,0 & 54,9 & 82,2 & 51,6 & 82,3 & 71,3 \\
\hline No pobre & 27,6 & 0,0 & 0,0 & 44,5 & 6,1 & 48,2 & 7,9 & 0,6 \\
\hline \multicolumn{9}{|l|}{ Pachacámac } \\
\hline Total absoluto & 8526 & 628 & 84 & 1200 & 8038 & 770 & 8135 & 333 \\
\hline Pobre extremo & 6,9 & 69,9 & 58,3 & 0,8 & 9,0 & 0,4 & 7,4 & 36,9 \\
\hline Pobre no extremo & 81,0 & 30,1 & 41,7 & 51,0 & 85,0 & 33,0 & 85,9 & 62,5 \\
\hline No pobre & 12,2 & 0,0 & 0,0 & 48,3 & 6,0 & 66,6 & 6,7 & 0,6 \\
\hline
\end{tabular}

Fuente: MTPE-Observatorio Socio Económico Laboral Lima Sur (2009)

\subsubsection{Riesgo social}

El riesgo social se le atribuye a las poblaciones que tienen situaciones o factores de desventaja social o de carencia que las priva de oportunidades o servicios y las coloca en una posición débil y subordinada. (Ministerio del Trabajo y Promoción del Empleo, 2009) 
La pobreza mantiene una relación estrecha con los riesgos y la vulnerabilidad, ya que estos sectores sociales no cuentan con ingresos suficientes para solventar o tener una capacidad alta de consumo, esto les da una menor ventaja y los hace más vulnerables. Las poblaciones pobres tienen más exposición a los riesgos y son consideradas también como las más indefensas a los problemas, injusticias y carencias sociales. (Ministerio del Trabajo y Promoción del Empleo, 2009)

La vulnerabilidad social presenta algunas características en común(Ministerio del Trabajo y Promoción del Empleo, 2009):

- No es exclusiva de la pobreza, esto se debe a la presencia de ciertos factores que afectan las condiciones de vida generando situación que alteren el bienestar.

- El contexto socioeconómico se ve en las oportunidades y acceso a bienes, actividades y servicios que mejoren el bienestar en el hogar.

- Los aportes que ofrece el Estado a la comunidad y al mercado de la población también son reflejo de ello.

- La vulnerabilidad social no es estática, ya que algunos persisten en el tiempo y otros se generan con los cambios en la familia, la población, el mercado, oportunidades de empleo y la participación del Estado con ellos.

- El análisis de la vulnerabilidad permite obtener condiciones objetivas y subjetivas de desprotección e incertidumbre para entender los cambios en las personas, hogares y comunidades, además ofrece un punto de vista distinto a otros enfoques.

Los principales grupos de riesgo social presentan características particulares como por ejemplo la presencia de una gran cantidad de niños, una concentración demográfica alta, alto nivel de desempleo, presencia de niños trabajadores, niñas y adolescentes que son madres o la falta de información sobre enfermedades de transmisión sexual. A estas se le suman algunos datos básicos como son la edad, el sexo y la condición física (Ministerio del Trabajo y Promoción del Empleo, 2009).

Los principales grupos vulnerables son:

- Niños, niñas y adolescentes que trabajan.

- Adolescentes y niñas madres. 
- Jóvenes que no estudian ni trabajan.

- Adultos de la tercera edad.

- Amas de casa.

- Personas que presentan alguna discapacidad motora o sensorial.

Tabla 2.9

Población en riesgo social en Pachacamac, en porcentajes (2005)

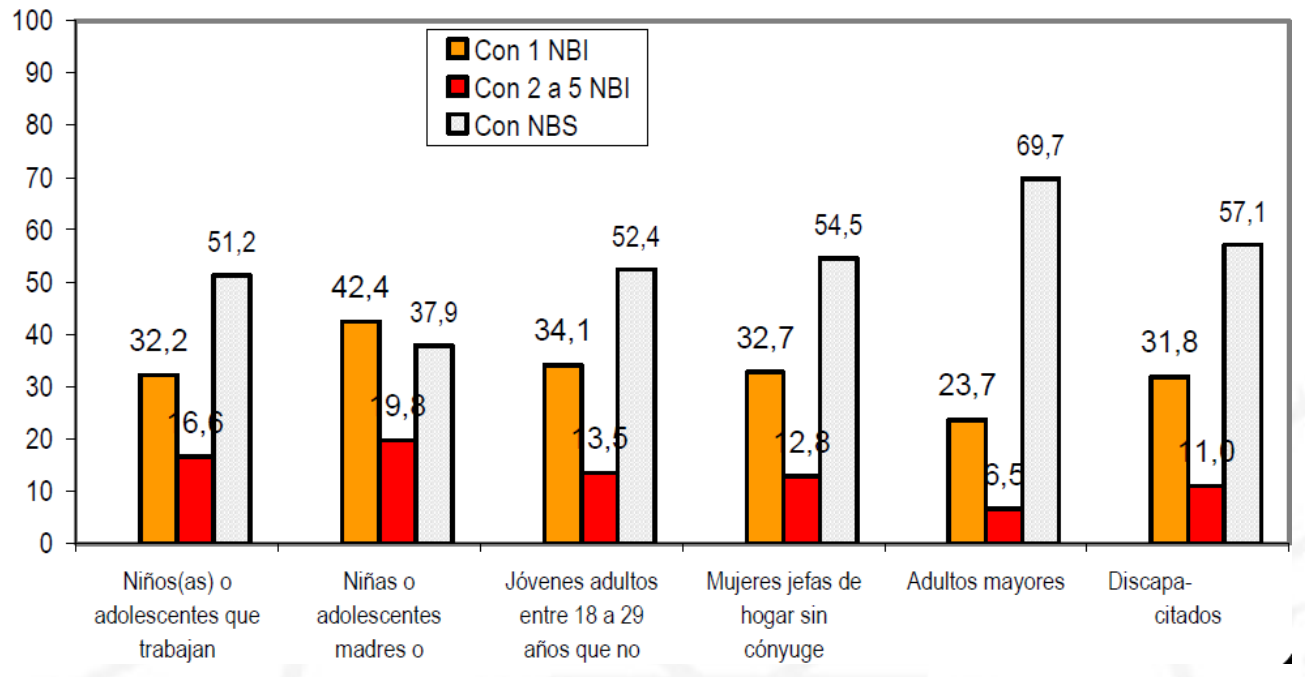

Fuente: MTPE-Observatorio Socio Económico Laboral Lima Sur. (2009)

Tabla 2.10

Tipos de poblaciones en Riesgo Social, Pachacamac (2005)

Tipos de población en riesgo social / Sexo
Total de población empadronada
En riesgo social
Niños(as) o adolescentes que trabajan
Niñas o adolescentes madres o embarazadas
Jóvenes adultos entre 18 a 29 años que no estudian ni trabajan
Mujeres jefas de hogar sin cónyuge
Adultos mayores
Discapacitados
Sin riesgo social
Hombre
En riesgo social
Niños(as) o adolescentes que trabajan
Jóvenes adultos entre 18 a 29 años que no estudian ni trabajan
Adultos mayores
Discapacitados
Sin riesgo social
Mujer
En riesgo social
Niñas o adolescentes que trabajan
Niñas o adolescentes madres o embarazadas
Jóvenes adultas entre 18 a 29 años que no estudian ni trabajan
Mujeres jefas de hogar sin cónyuge
Adultas mayores
Discapacitadas
Sin riesgo social

\begin{tabular}{|c|c|c|c|c|c|}
\hline \multirow[b]{2}{*}{ Total } & \multicolumn{3}{|c|}{ Con al menos una NBI } & \multirow{2}{*}{$\begin{array}{l}\text { Con } \\
\text { NBS }\end{array}$} & \\
\hline & Total & Con $1 \mathrm{NBI}$ & $\begin{array}{c}\text { Con } 2 \text { a } 5 \\
\mathrm{NBI}\end{array}$ & & \\
\hline 27516 & 11468 & 8252 & 3216 & 16046 & ? \\
\hline 4779 & 2134 & 1519 & 615 & 2643 & 2 \\
\hline 779 & 380 & 251 & 129 & 399 & \\
\hline 177 & 110 & 75 & 35 & 67 & 0 \\
\hline 1690 & 804 & 576 & 228 & 885 & \\
\hline 967 & 440 & 316 & 124 & 527 & 0 \\
\hline 841 & 254 & 199 & 55 & 586 & \\
\hline 808 & 346 & 257 & 89 & 461 & \\
\hline 22737 & 9334 & 6733 & 2601 & 13403 & \\
\hline 13549 & 5619 & 4045 & 1574 & 7929 & \\
\hline 1574 & 661 & 468 & 193 & 912 & I \\
\hline 433 & 223 & 143 & 80 & 210 & 0 \\
\hline 423 & 174 & 125 & 49 & 248 & \\
\hline 414 & 113 & 95 & 18 & 301 & 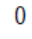 \\
\hline 419 & 190 & 139 & 51 & 229 & 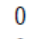 \\
\hline 11975 & 4958 & 3577 & 1381 & 7017 & 0 \\
\hline 13967 & 5849 & 4207 & 1642 & 8117 & 1 \\
\hline 3205 & 1473 & 1051 & 422 & 1731 & \\
\hline 346 & 157 & 108 & 49 & 189 & 0 \\
\hline 177 & 110 & 75 & 35 & 67 & 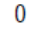 \\
\hline 1267 & 630 & 451 & 179 & 637 & 0 \\
\hline 967 & 440 & 316 & 124 & 527 & 0 \\
\hline 427 & 141 & 104 & 37 & 285 & 1 \\
\hline 389 & 156 & 118 & 38 & 232 & 1 \\
\hline 10762 & 4376 & 3156 & 1220 & 6386 & \\
\hline
\end{tabular}

Fuente: MTPE-Observatorio Socio Económico Laboral Lima Sur. (2009) 
Según los estudios Pachacamac tiene una población vulnerable socialmente de $17.4 \%$, focalizada en Manchay siendo la zona menos consolidadas del distrito y a su vez la más poblada del distrito.

Del total de la población en riesgo en Pachacamac el 55.3\% que son aproximadamente 2,643 no son pobres. Por otro lado el $44.7 \%$ que son aproximadamente 2,134 personas son pobladores pobres, de estos 31.8\% tiene una necesidad básica insatisfecha (NBI) y el $12.9 \%$ tiene 2 a 5 NBI que son considerados como pobres extremos. (Ministerio del Trabajo y Promoción del Empleo, 2009)

El mayor porcentaje de las personas que se encuentran en riesgo social se encuentran una situación de no pobreza. Para ellos los factores que les afecta e impide que se desarrollen con normalidad en sus vidas es la dificultad en sus situaciones de bienestar como los constantes gastos en la familia, falta de derechos, deudas, bajos ingresos económicos por familia, el barrio en donde viven, accesibilidad a la zona, distancia de los distintos servicios, etc.

\subsubsection{Sistema Vial}

Las principales vías que atraviesan el distrito actúan como ejes canalizadores de flujos internos y flujos con el entorno metropolitano y regional, a la vez que promueve cambios en los usos del suelo. Las más importantes son las siguientes:

- Antigua Panamericana Sur

- Nueva Panamericana Sur

- Av. Pedro Malásquez

- Av. Manuel Valle

La vía más importante que pasa por Manchay es la Av. Pedro Malásquez y conecta de sur con la Av. Manuel Valle y al este con la Av. La Molina.

La infraestructura vial es deficitaria, la conexión vial es muy limitada, sólo el casco urbano central tiene parte de las vías asfaltadas, el resto solo cuenta con vías de acceso sin asfaltar. (Plan Integral de Gestión Ambiental de Residuos Sólidos en Pachacamac, 2005) 
Figura 2.12

Vías importantes del distrito de Pachacamac

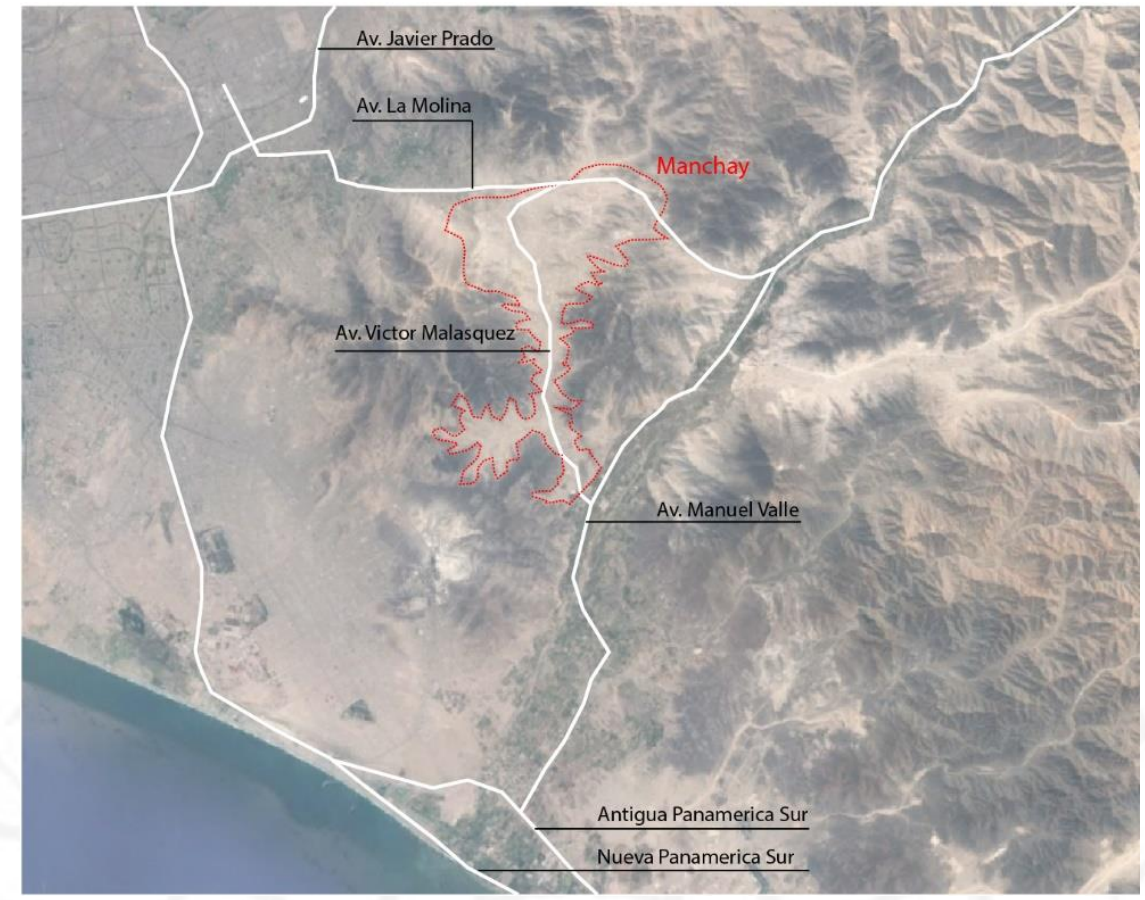

Elaboración propia (2018)

\subsubsection{Organización Social}

Para el Plan Integral de Desarrollo 1999-2010 se tuvieron varias organizaciones civiles aparte de las organizaciones vecinales y agracias, Entre las Organizaciones Agrarias se encuentran:

- Junta de usuarios del Distrito de Riego Lurín-Chilca.

- Asociación de Pequeños Agricultores de Manchay (APACAM).

- Asociación de Horticultores del Predio Casica.

- Asociación de Propietarios y Criadores de Caballos Peruanos de Paso. 10 asociados con sede en Mamacona.

- Asociación de Criadores de Gallos de Pelea.

- Fondo de Fomento de la Ganadería Lechera.

Entre las organizaciones vecinales y otras están (Plan Integral de Gestión Ambiental de Residuos Sólidos en Pachacamac, 2005):

- 65 Comités del Vaso de Leche (CVL) agrupados en una Central de CVL.

- 70 Comedores Populares 
- 100 Organizaciones vecinales

- Cofradías y hermandades (religiosas)

\subsubsection{Sistema de Salud}

El distrito de Pachacamac tiene una organización de tres redes de salud para cubrir con la demanda del distrito, estas se encuentran en los 3 puntos más poblados del distrito que son: Pachacamac Centro, Lurín y Portada de Manchay. En total se encuentran 5 centros de salud y 11 postas médicas. Los Centros de Salud se encuentra en Pachacamac Centro que pertenece a la micro red de salud de Pachacamac, luego en Huertos de Manchay y Portada de Manchay que pertenecen a la micro red de Manchay y El Centro de Salud Julio C. Tello y Centro de Salud José Gálvez pertenecen a la micro red de Lurín. En el caso de las postas médicas están en distintos puntos como: Guayabo, Manchay Alto, Quebrada Verde, Picapiedra, Cardal, Tambo Inga, Pampa Grande, Manzanao y villa Libertad que pertenecen a la micro red de Pachacamac y las postas de Collanac y Los Parques que pertenecen a la micro red de Portada de Manchay. (Municipalidad-dePachacámac, 2010)

Se observa el déficit de infraestructura sanitaria de mayor cobertura; Pachacámac no cuenta con un hospital. La cobertura hospitalaria corresponde al Hospital María Auxiliadora de Villa María del Triunfo (Plan Integral de Gestión Ambiental de Residuos Sólidos en Pachacamac, 2005).

\subsection{Manchay en cifras}

Manchay tiene aproximadamente 70000 habitantes en su mayoría compuesta por familias jóvenes, y representan las tres cuartas partes de la población del distrito de Pachacamac (INEI, 2014).

A continuación se mostrarán unos mapas con información relevante a la zona de Manchay que es la zona de mayor concentración de personas en el distrito y de mayor precariedad de servicios, equipamiento y vivienda. 


\subsubsection{Rango de Edades}

Figura 2.13

Mapa de rango de edades en Lima Metropolitana

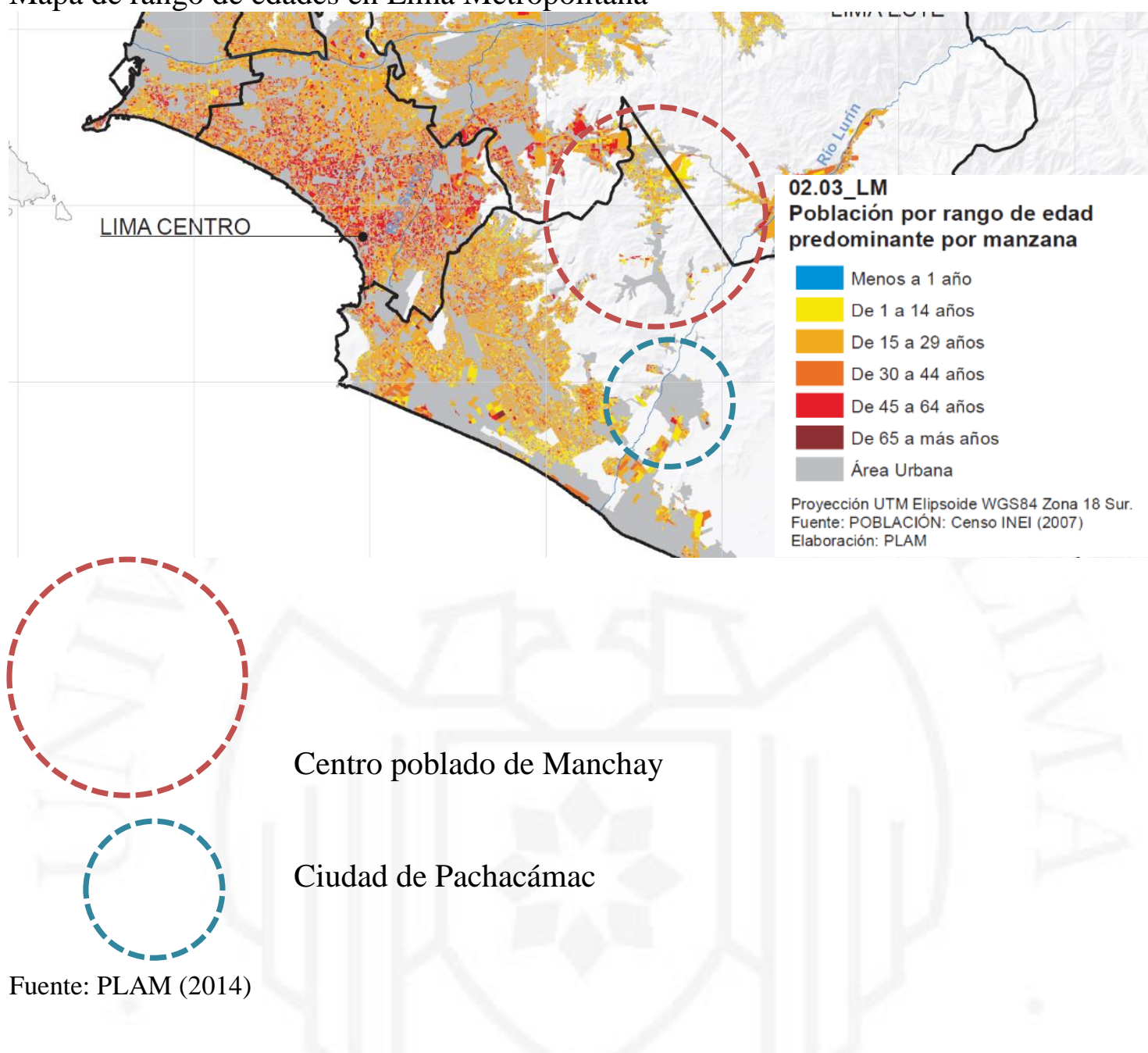

El centro poblado de Manchay cuenta con una población muy joven donde el 70\% va entre los 0 y 36 años. Son familias jóvenes que se establecieron para dar oportunidades a sus familias, así mismo, la zona es joven porque apenas tiene 33 años de consolidación con el Distrito de Pachacamac.

Tabla 2.11

Distribución de edades en la Población de Manchay (2016) Centro poblado de Manchay Población: 70000 habitantes (INEI,2016)

Niños 0-5 años

Niños 6 a 11 años 8890 personas $(12.7 \%)$

Adolescentes 12 a 17 años 8680 personas $(12.4 \%)$

Adultos 18 a 36 años

8190 personas $(11.7 \%)$

Adultos 37 a 59 años 24150 personas $(34.5 \%)$

Adulto mayor 60 a +años

16310 personas $(23.3 \%)$

Son menores de edad

Fuente: Adaptado de Fuente: PLAM (2014) 25760 personas $(36.8 \%)$ 


\subsubsection{Densidad Poblacional}

Figura 2.14

Zonas por densidad poblacional en Lima Metropolitana

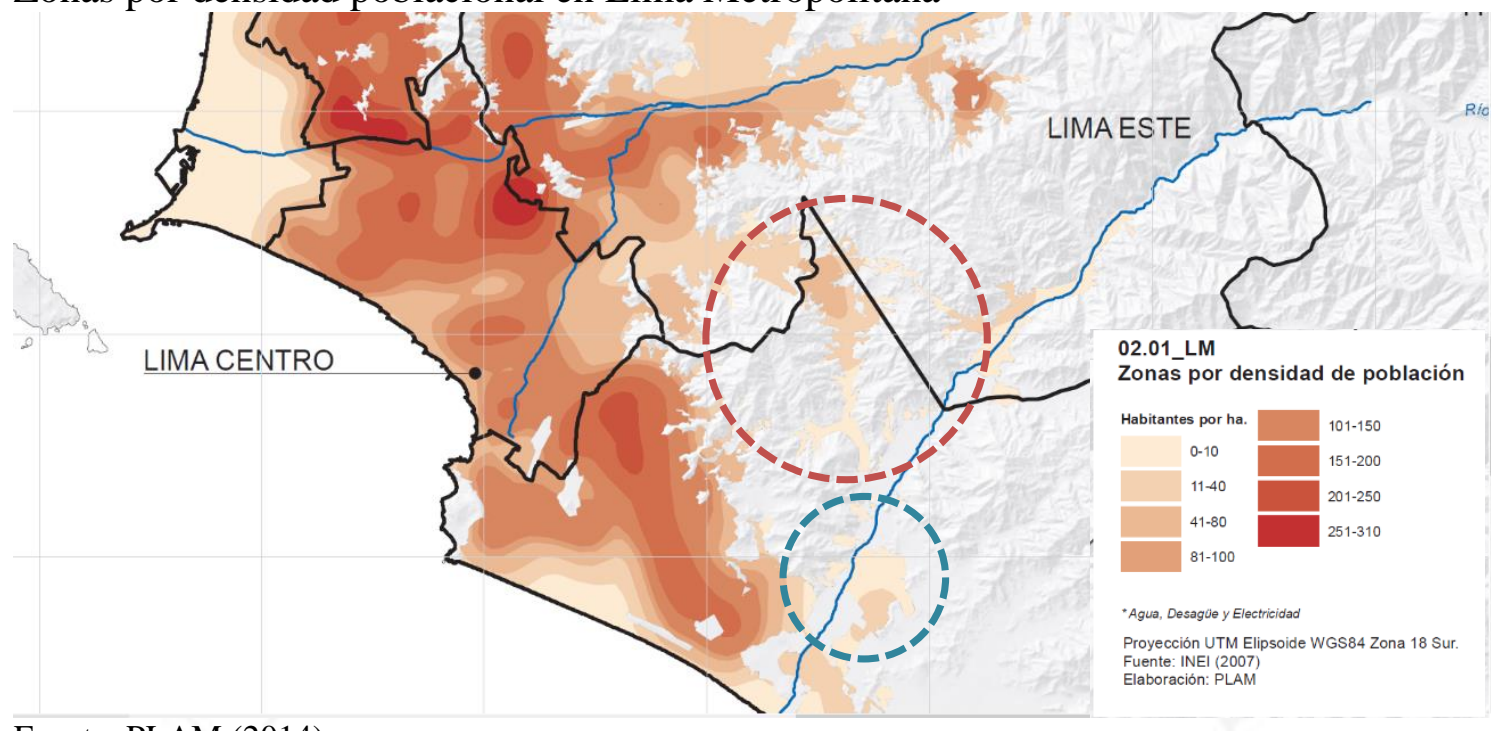

Fuente: PLAM (2014)

Manchay es la zona más poblada del distrito de Pachacamac con 70000 habitantes. Y su concentración va de acuerdo a su expansión histórica a los largo de los años. (INEI, 2014)

\subsubsection{Crecimiento Poblacional}

Figura 2.15

Tasa de creciemiento poblacional en Lima Metropolitana

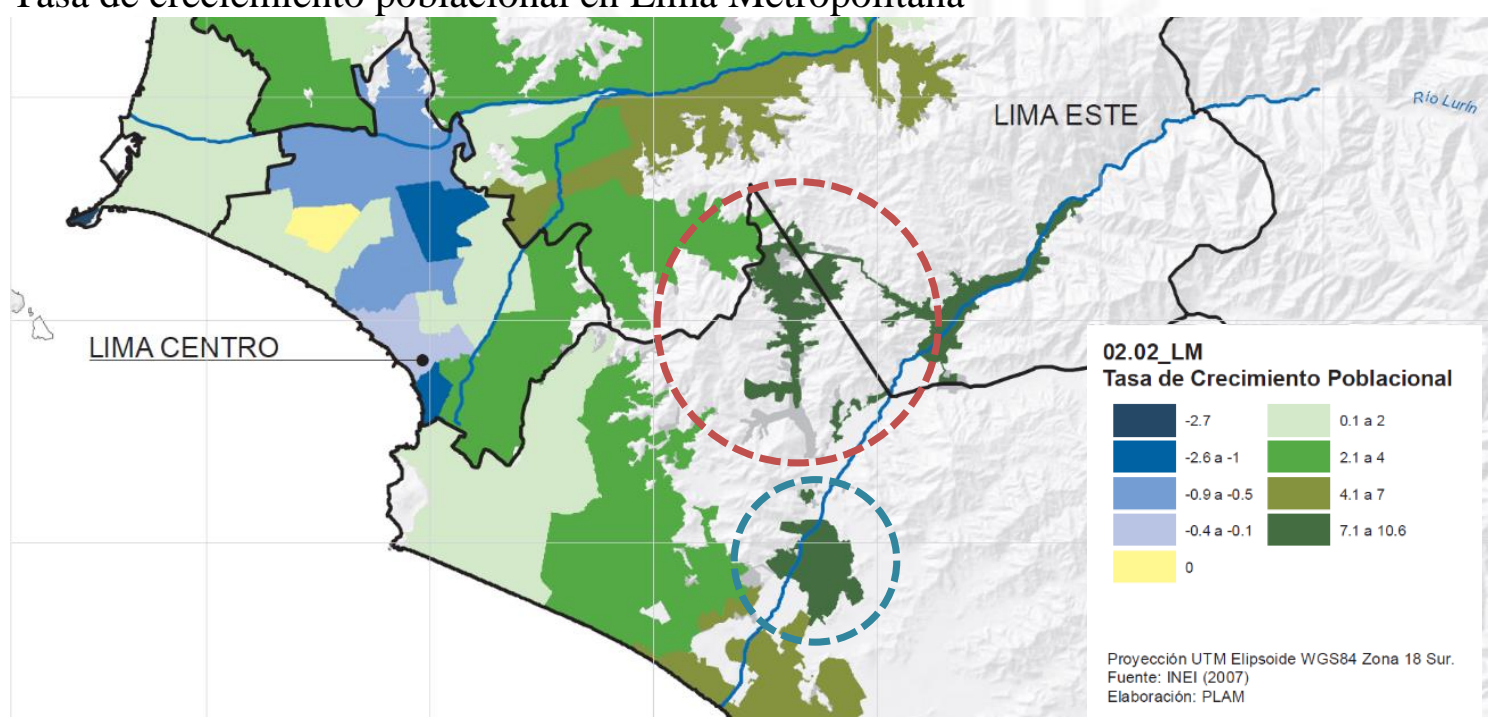

Fuente: PLAM (2014)

Manchay tiene una tasa de crecimiento anual de 7.1 a 10.6 anual. Lo que lo hace uno de los lugares de más alto crecimiento poblacional de Lima. (INEI, 2014) 


\subsubsection{Población Económicamente Activa (PEA)}

Figura 2.16

Población Económicamente Activa en Lima Metropolitana

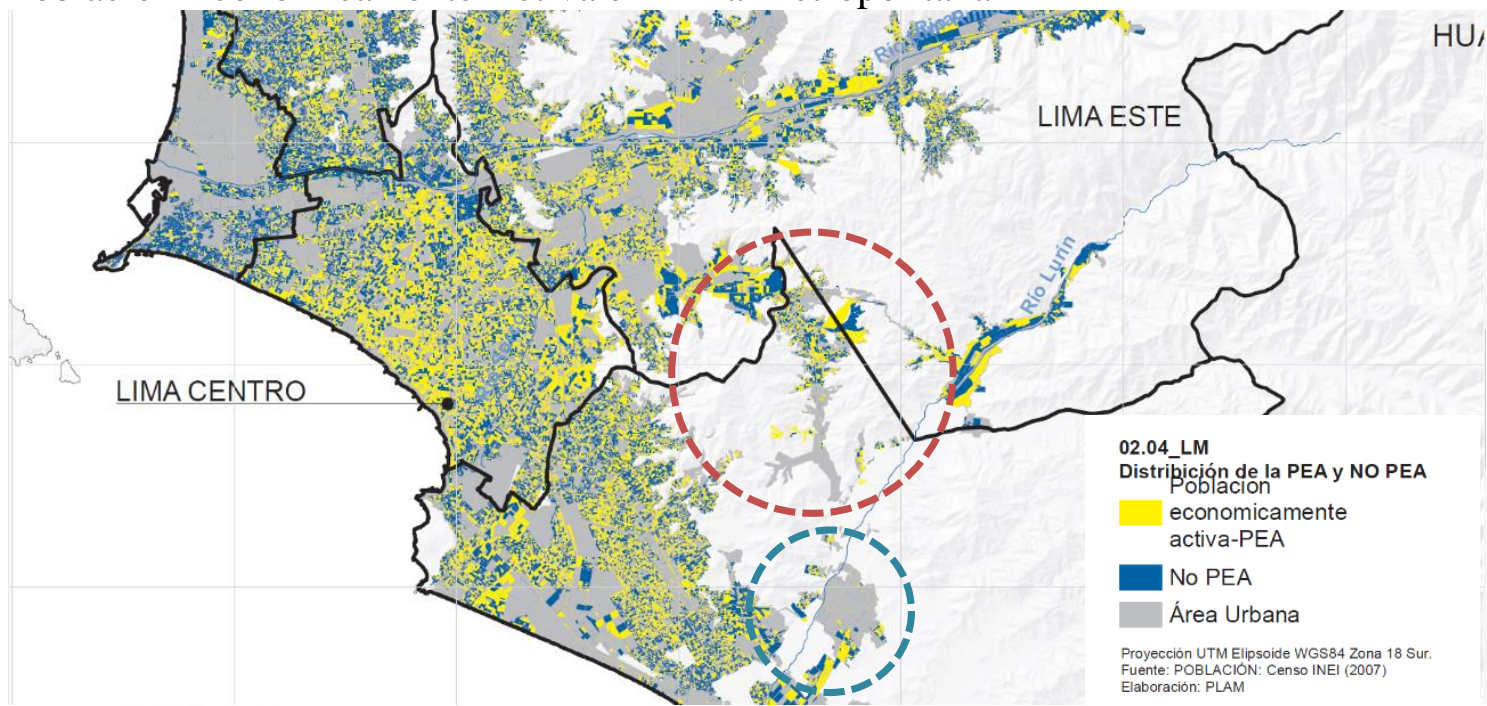

Fuente: PLAM (2014)

La población de Manchay tiene un 57.8\% de Población Económica Activa. 53.6\% es subempleada, el $35.6 \%$ es desempleada y el $10.8 \%$ tiene un empleo adecuado. (PRODUCE, 2014)

\subsubsection{Pobreza Monetaria}

Figura 2.17

Pobreza Monetaria en Lima Metropolitana

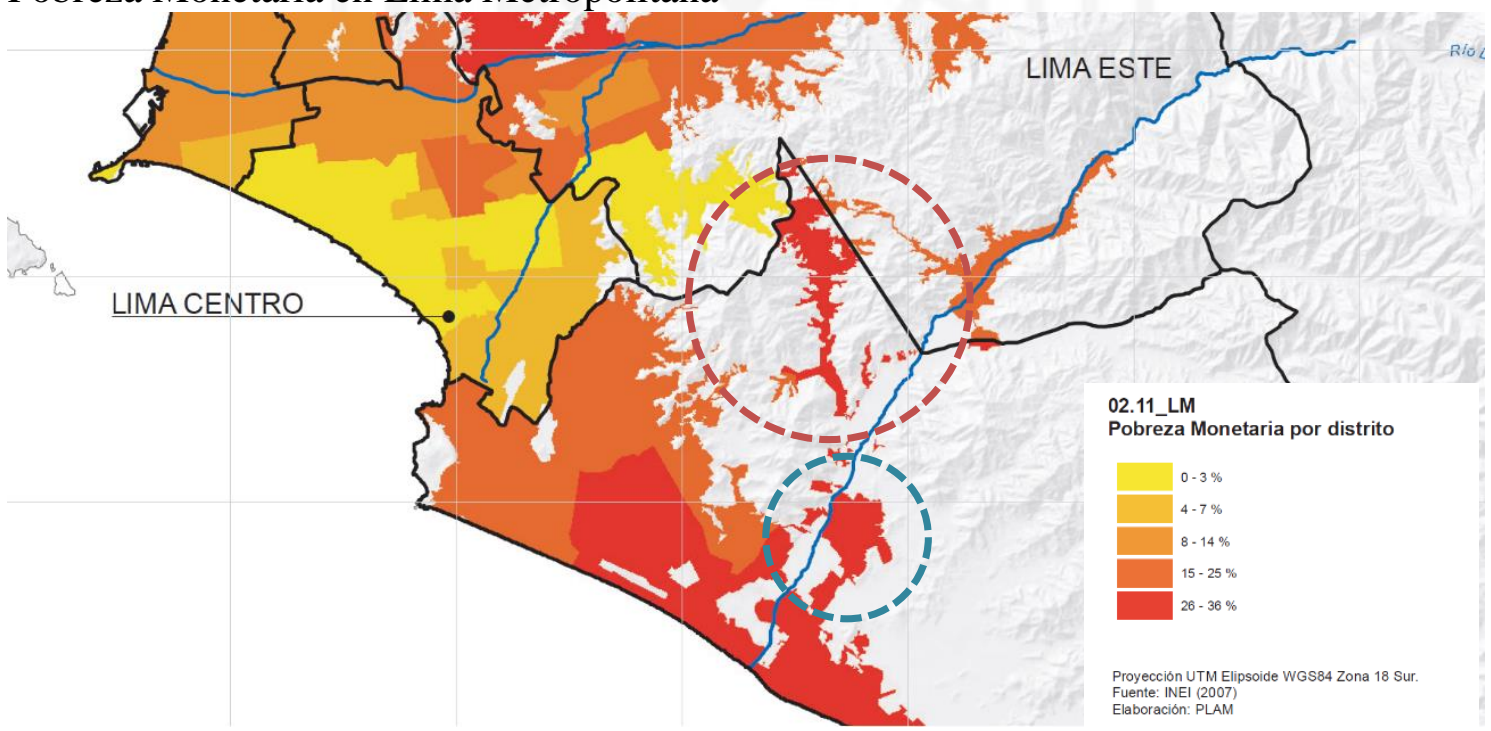

Fuente: PLAM (2014)

El 36\% de la población de Manchay es considerada pobre. Y su concentración se encuentra en las zonas menos consolidadas las quebradas o faldas de los cerros. (BCRP, 2014) 


\subsubsection{Ingresos Económicos}

Figura 2.18

Ingresos económicos en Lima Metropolitana.

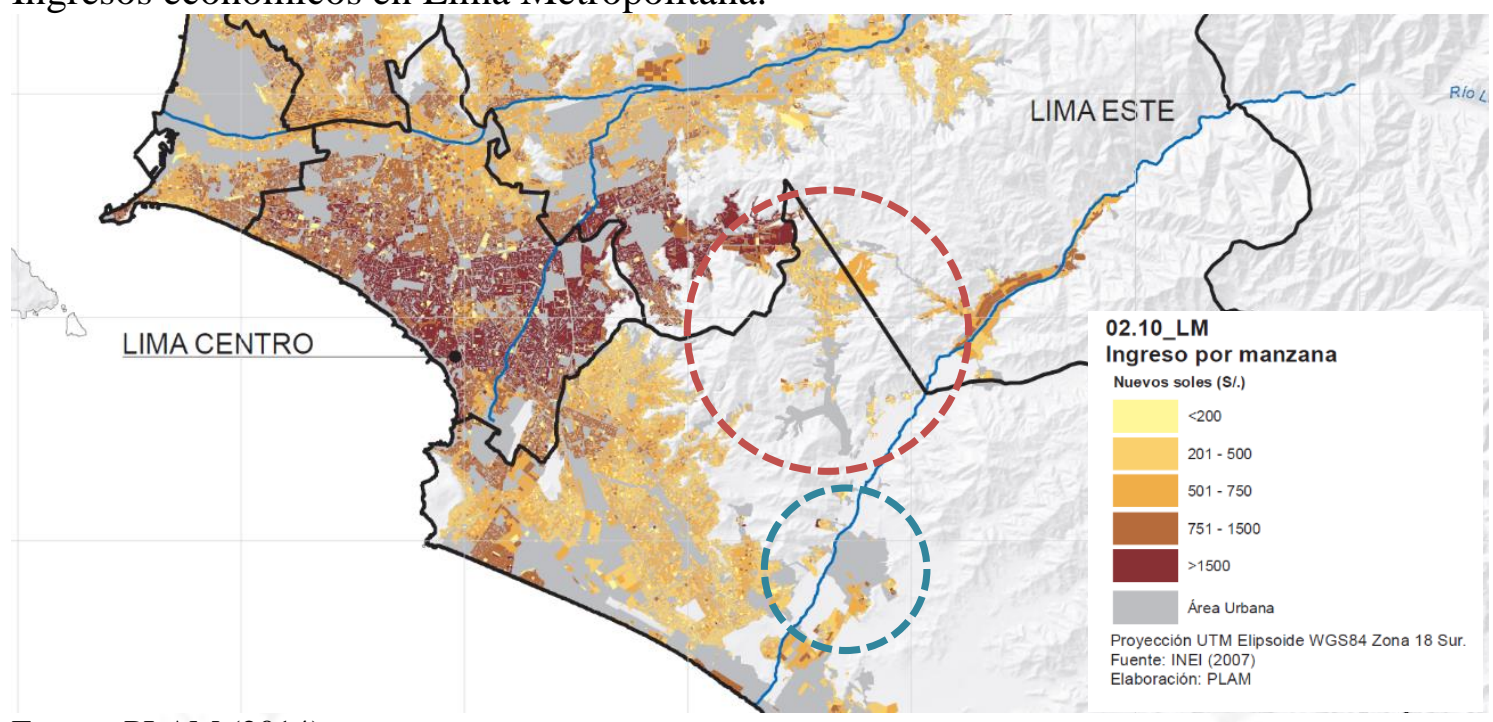

Fuente: PLAM (2014)

El ingreso promedio de Manchay por familia es de entre 250 a 1100 soles mensuales. (BCRP, 2014)

\subsubsection{Población que únicamente ha alcanzado educación primaria}

Figura 2.19

Población que únicamente ha alcanzado educación primaria

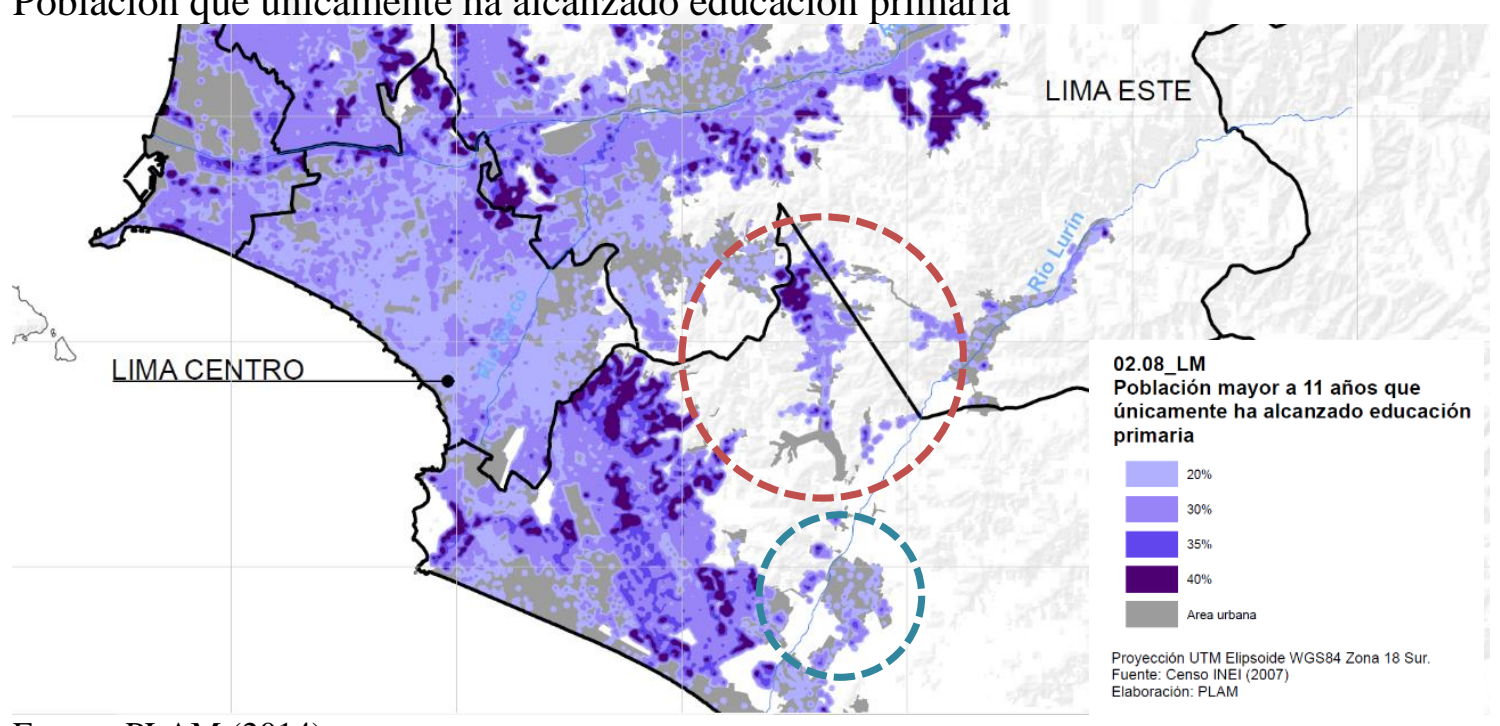

Fuente: PLAM (2014)

El 51.7\% de la población tiene la secundaria completa y uno de los problemas es que el 57\% de los niños y jóvenes dejan los estudios entre los 12 y 17 años. (INEI, 2014) 


\subsection{8 Índice de Desarrollo Humano (IDH)}

Figura 2.20

Índice de desarrollo Humano (IDH) en Lima Metropolitana

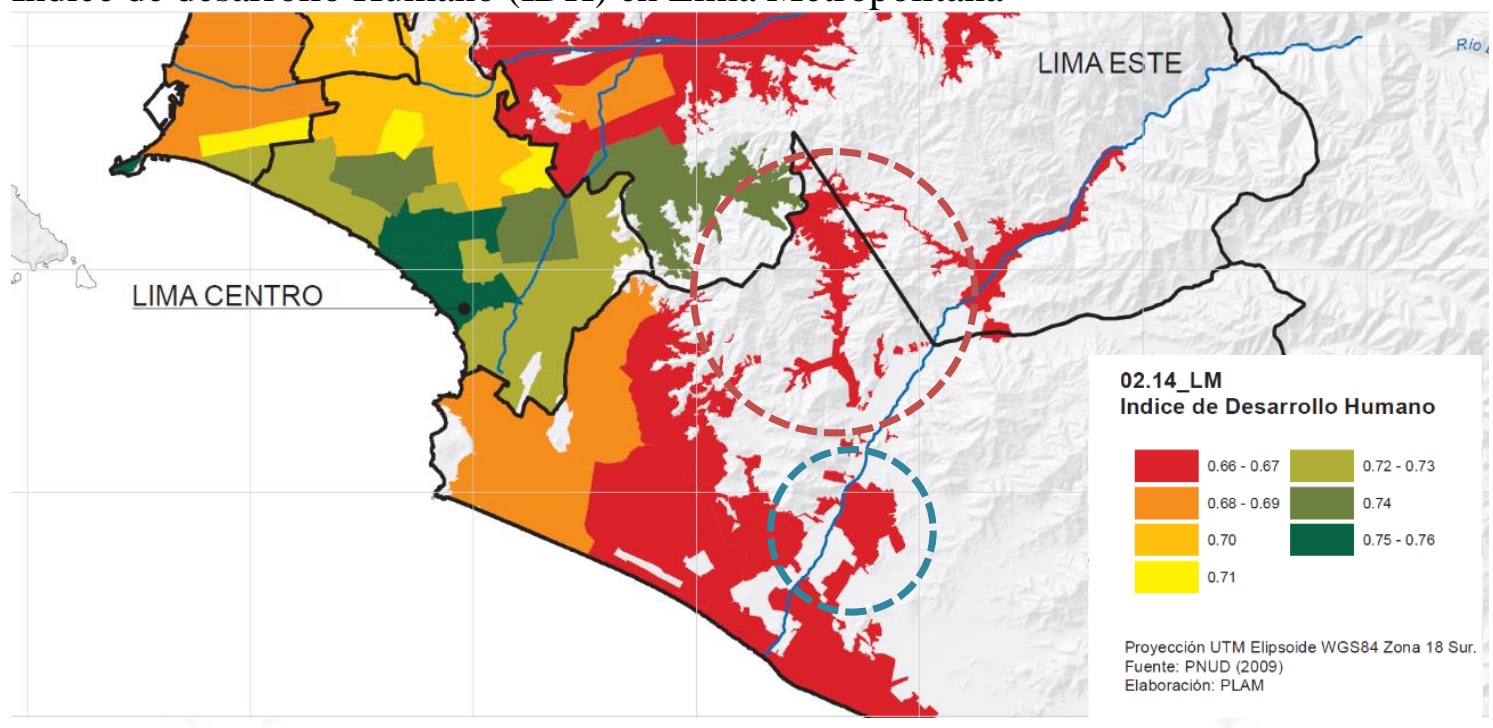

Fuente: PLAM (2014)

El Índice de Desarrollo Humano (IDH) de Manchay es el más bajo de Lima con 0.66 considerando distintos factores como: Salud, seguridad, educación y vivienda. (IPE, 2014)

\subsubsection{Población con Discapacidad Motora}

Figura 2.21

Población con Discapacidad Motoro en Lima Metropolitana

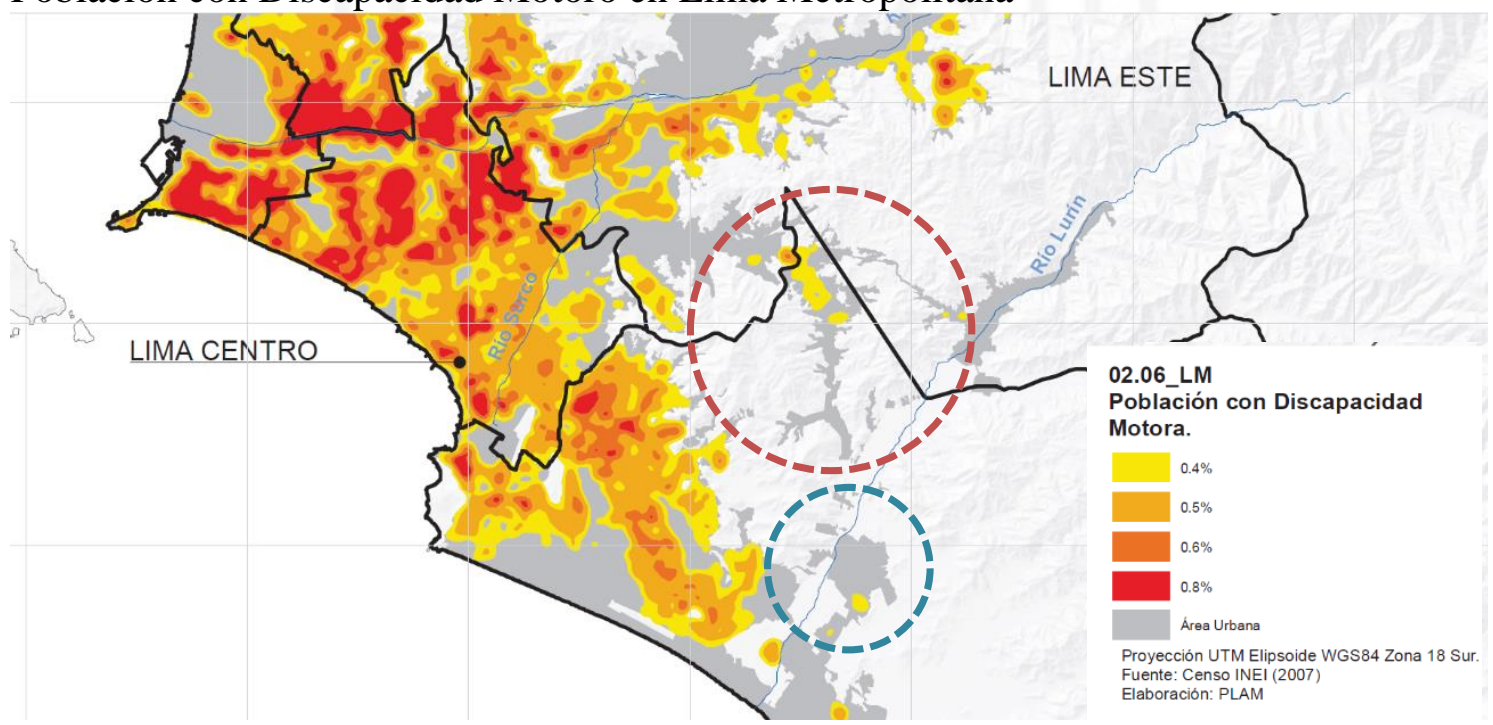

Fuente: PLAM (2014)

Menos del $0.1 \%$ de la población de Manchay tiene alguna discapacidad motora. (INEI, 2014) 


\subsubsection{Población con Discapacidad Sensorial}

Figura 2.22

Población con Discapacidad Sensorial en Lima Metropolitana

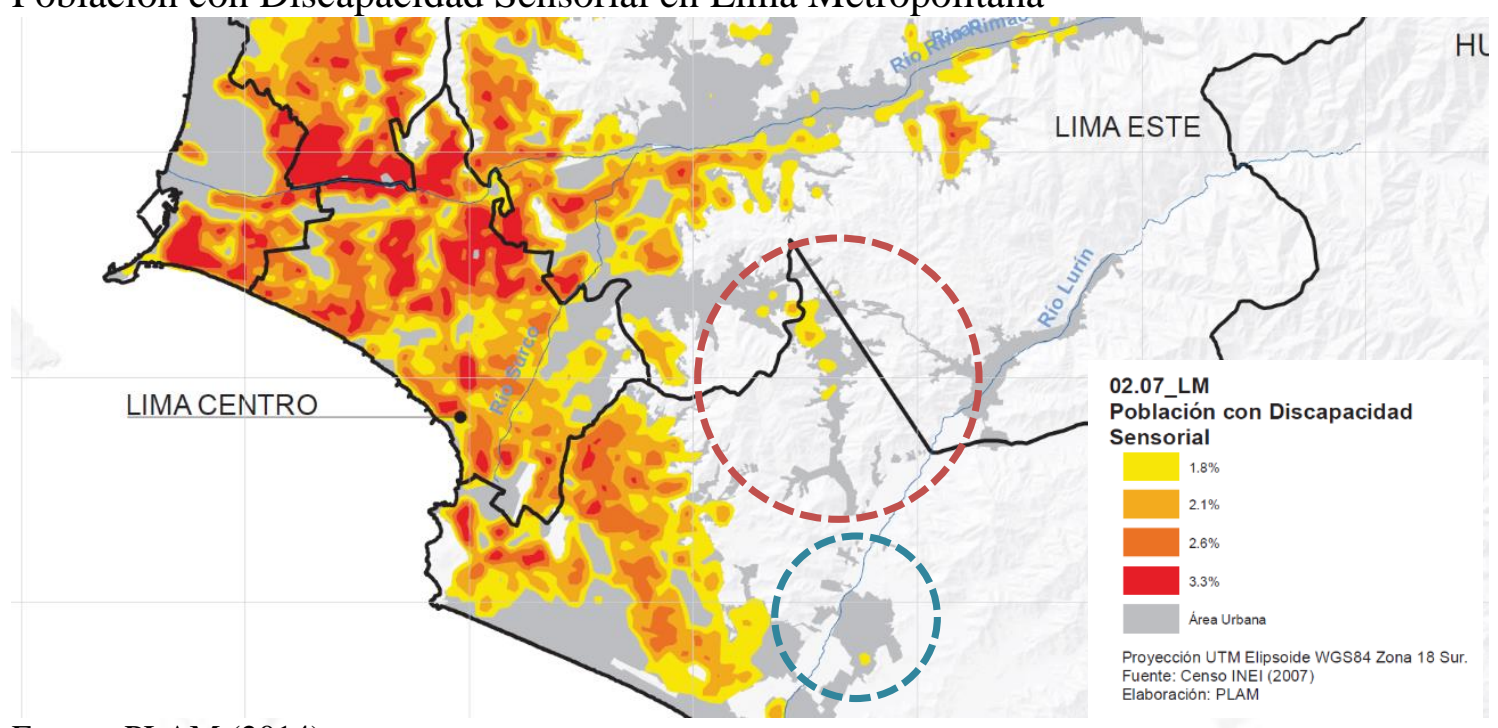

Fuente: PLAM (2014)

Solo una pequeña cantidad de la población de Manchay tiene alguna discapacidad sensorial como: ceguera, sordera o pérdida del equilibrio. (INEI, 2014)

\subsubsection{Zonas de Concentración de Precariedad}

Figura 2.23

Zonas de Concentración de Precariedad en Lima Metropolitana

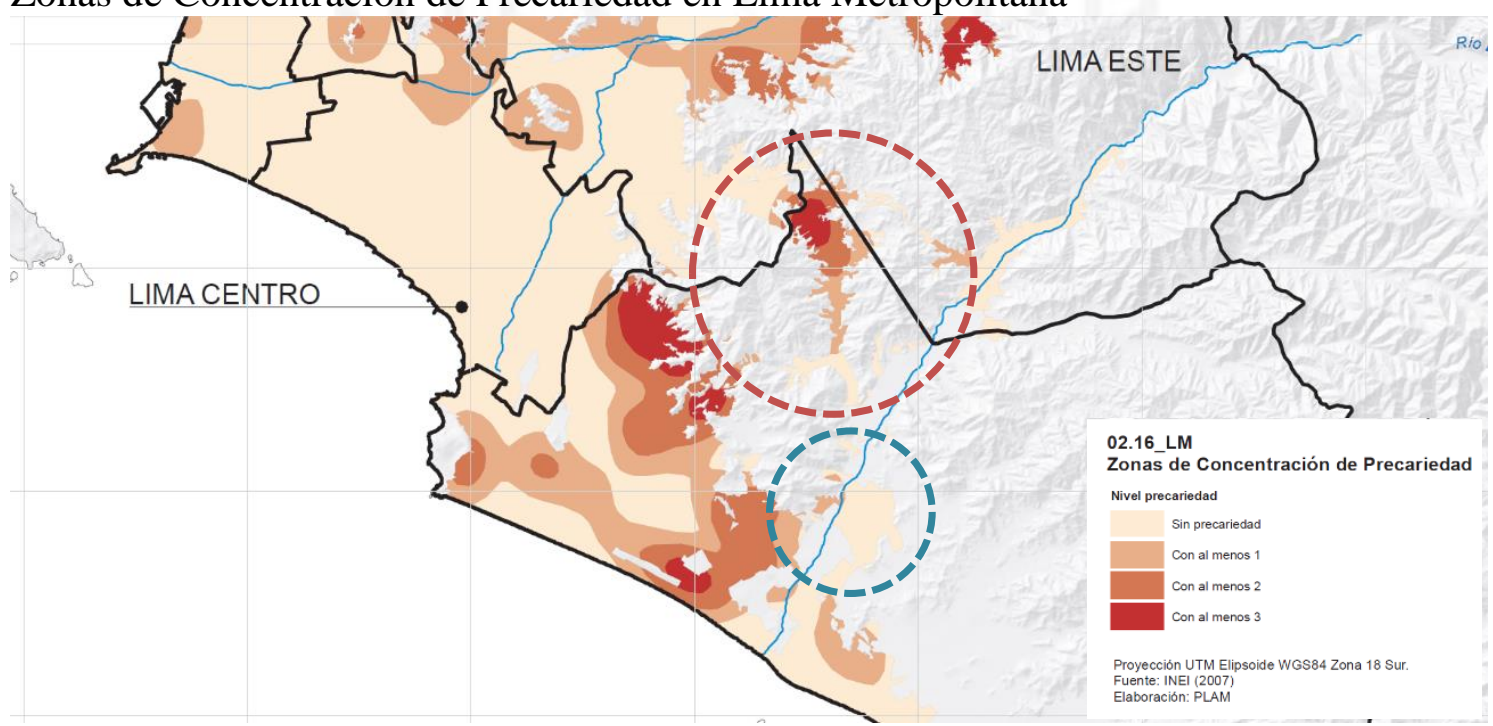

Fuente: PLAM (2014)

La zona con mayor concentración de precariedad de Manchay, es en Manchay Alto en las zonas más altas de las quebradas. (PREDES, 2014) 


\subsubsection{Tipología de Vivienda}

Figura 2.24

Tipo de Vivienda en Lima Sur

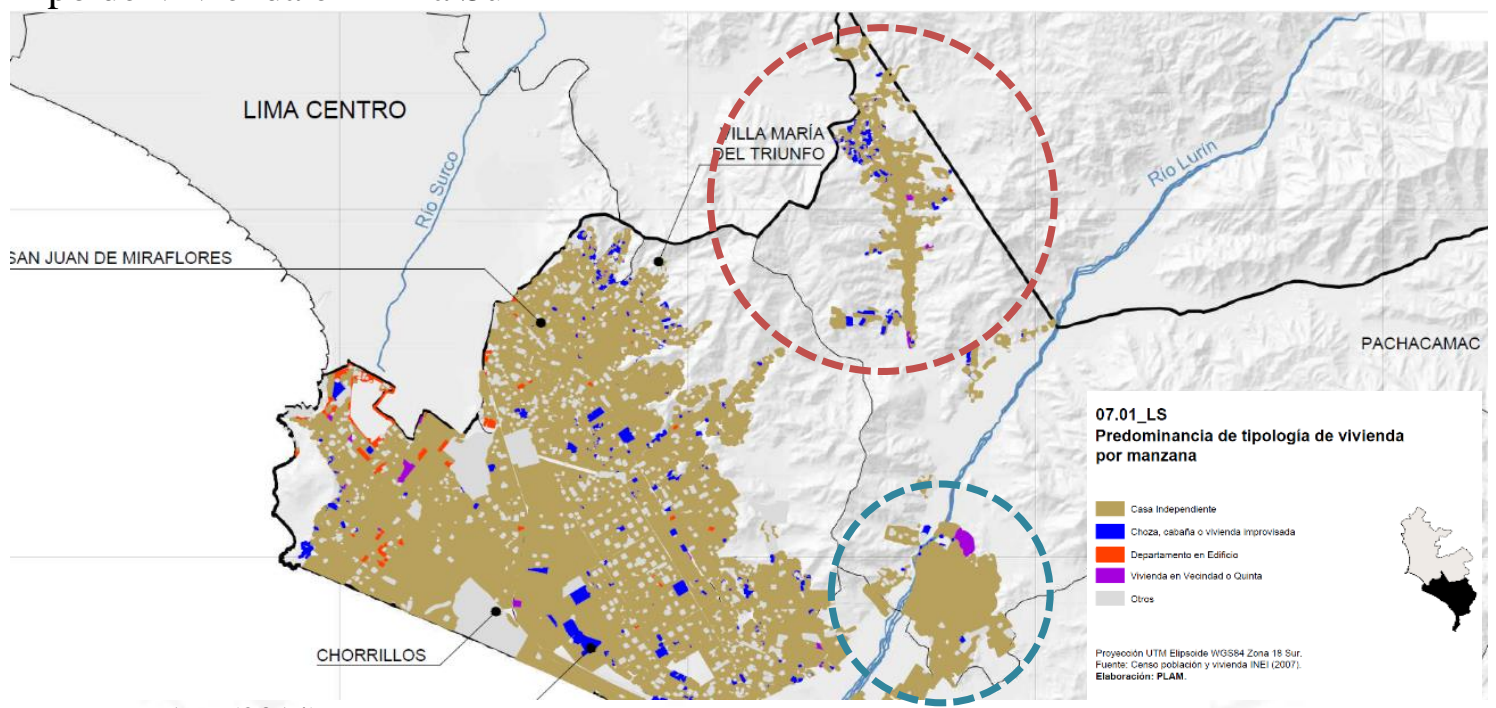

Fuente: PLAM (2014)

Gran parte de las viviendas son de material noble pero aún existe una gran cantidad de viviendas informales en las zonas altas de las quebradas con materiales precarios. (INDECI, 2014)

\subsubsection{Vivienda con Estado de Tenencia}

Figura 2.25

Vivienda con Estado de Tenencia en Lima Sur

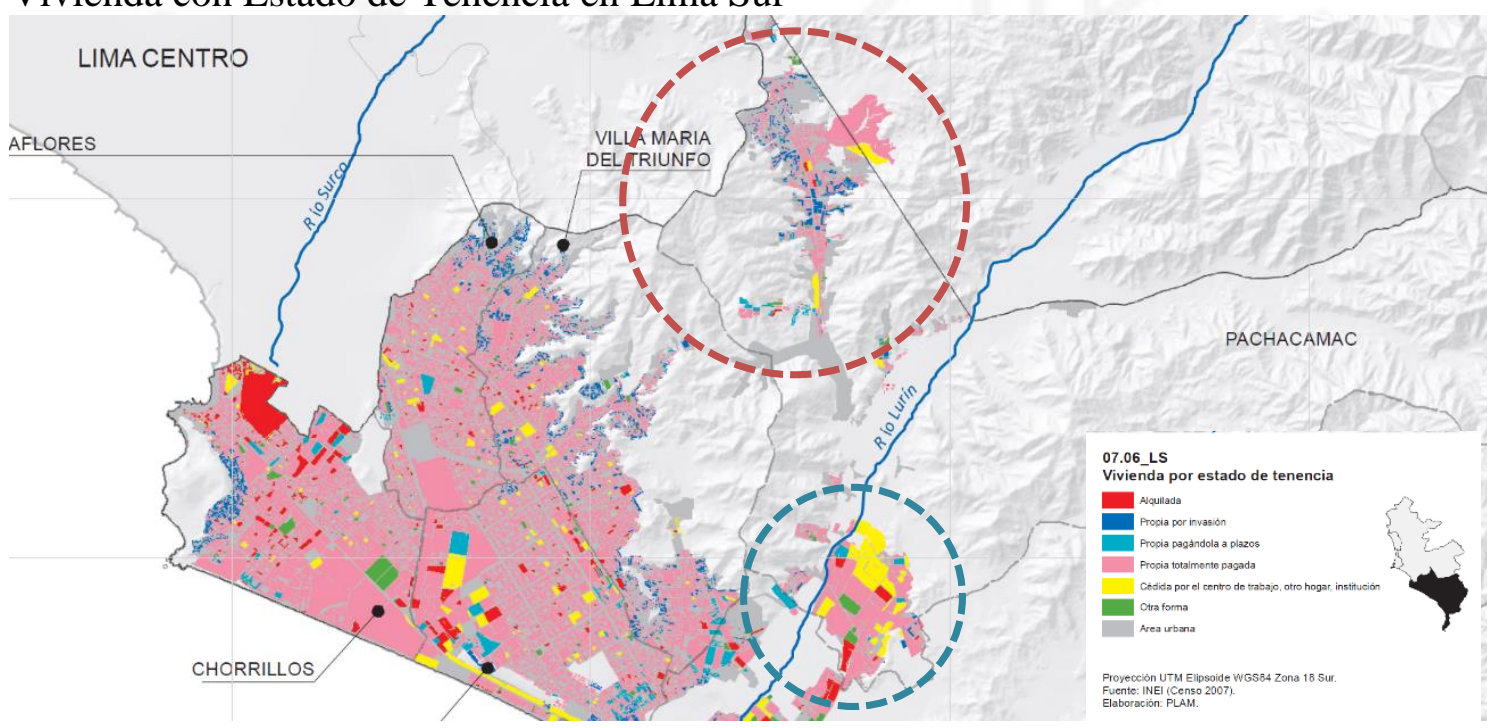

Fuente: PLAM (2014)

La mayoría de las viviendas son de propiedad privada ya que fueron compradas y pagadas, pero en algunas zonas fueron adquiridas por invasión. (INEI, 2014) 


\subsubsection{4 Áreas Verdes Públicas por Habitante}

Figura 2.26

Verdes Públicas por Habitante en Lima Metropolitana

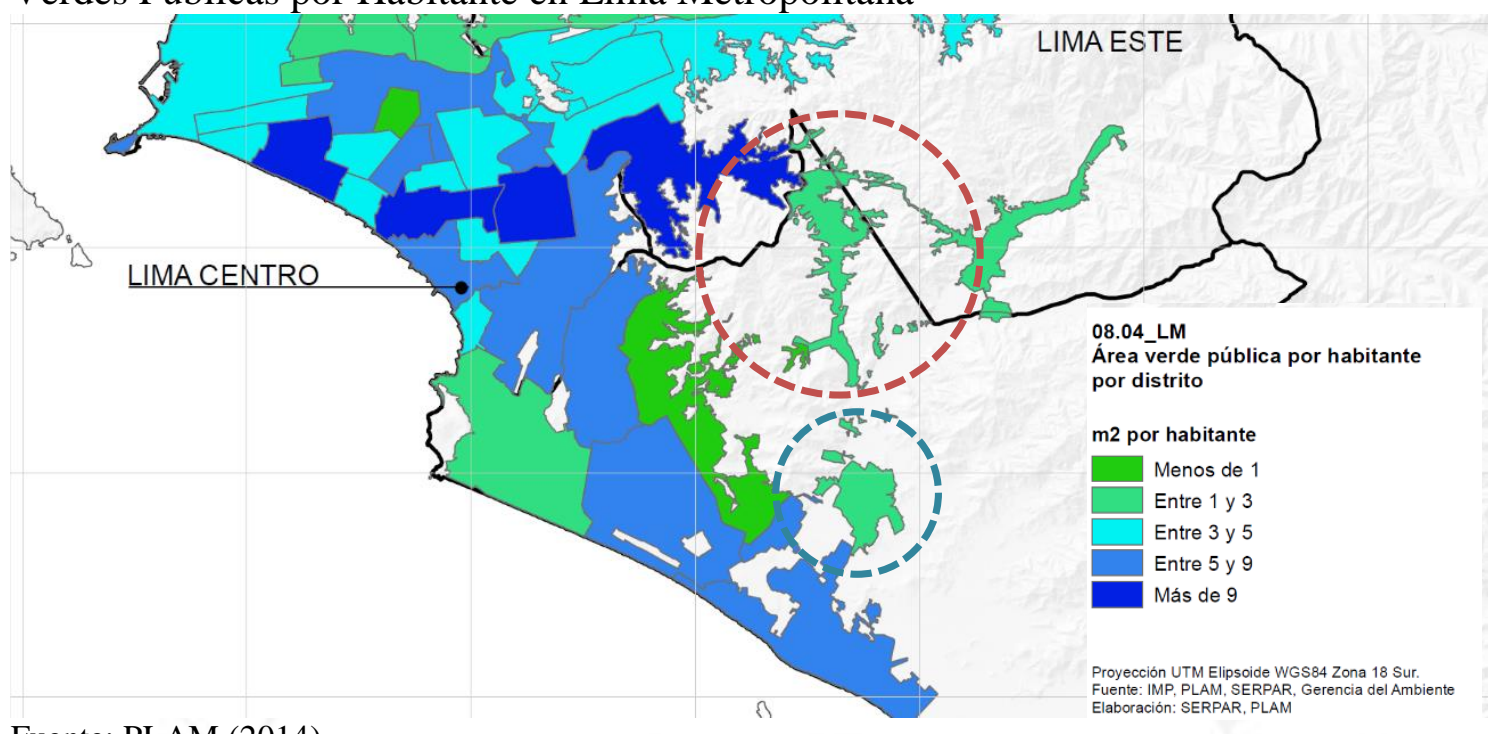

Fuente: PLAM (2014)

La población tiene menos de $1 \mathrm{~m} 2$ de área verde por habitante a los $8 \mathrm{~m} 2$ como mínimo que debería de tener por habitante. (SERPAR, 2014)

\subsubsection{Parques Públicos}

Figura 2.27

Parques Públicos en Lima Metropolitana

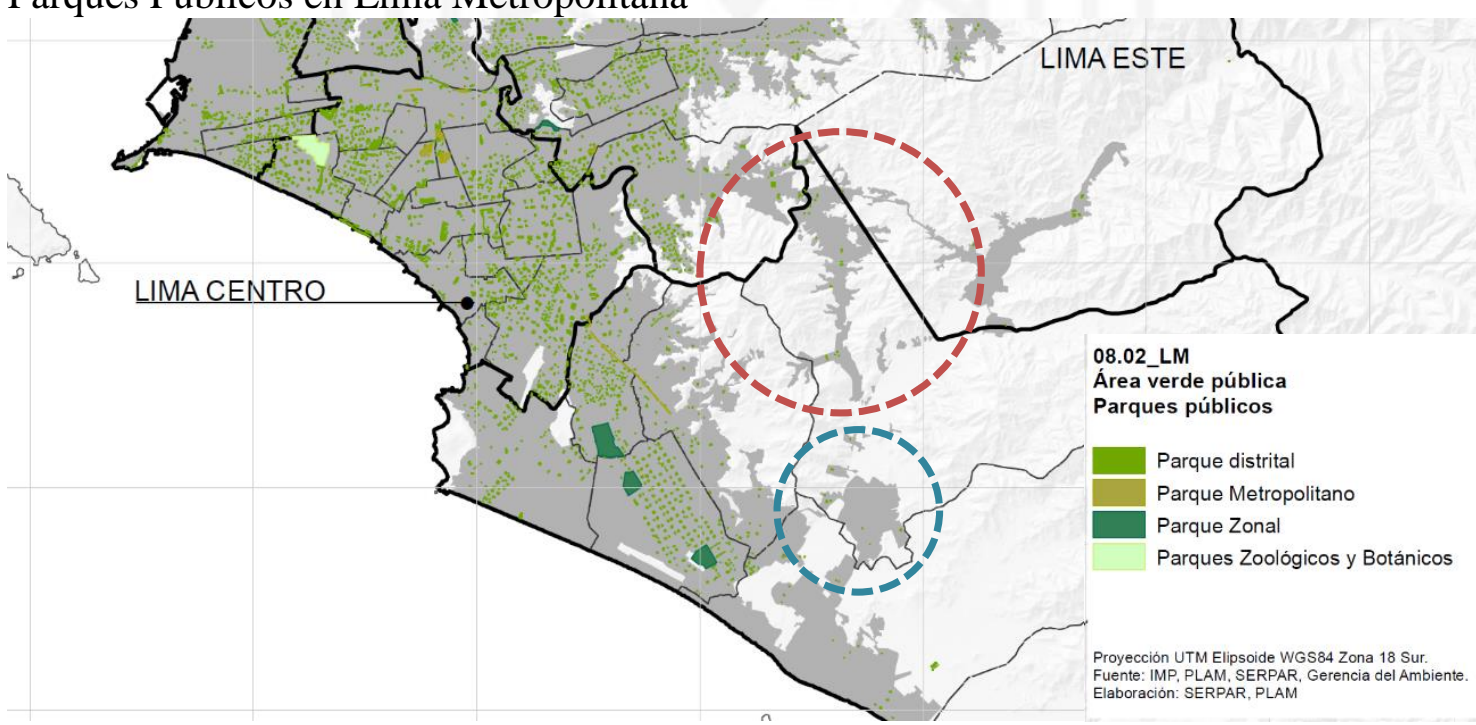

Fuente: PLAM (2014)

Manchay no cuenta con parques públicos suficientes para el recreo de sus pobladores. Y cuenta con poco espacio público. (SERPAR, 2014) 


\subsubsection{Presiones Urbanas}

Figura 2.28

Presiones Urbanas en Lima Metropolitana

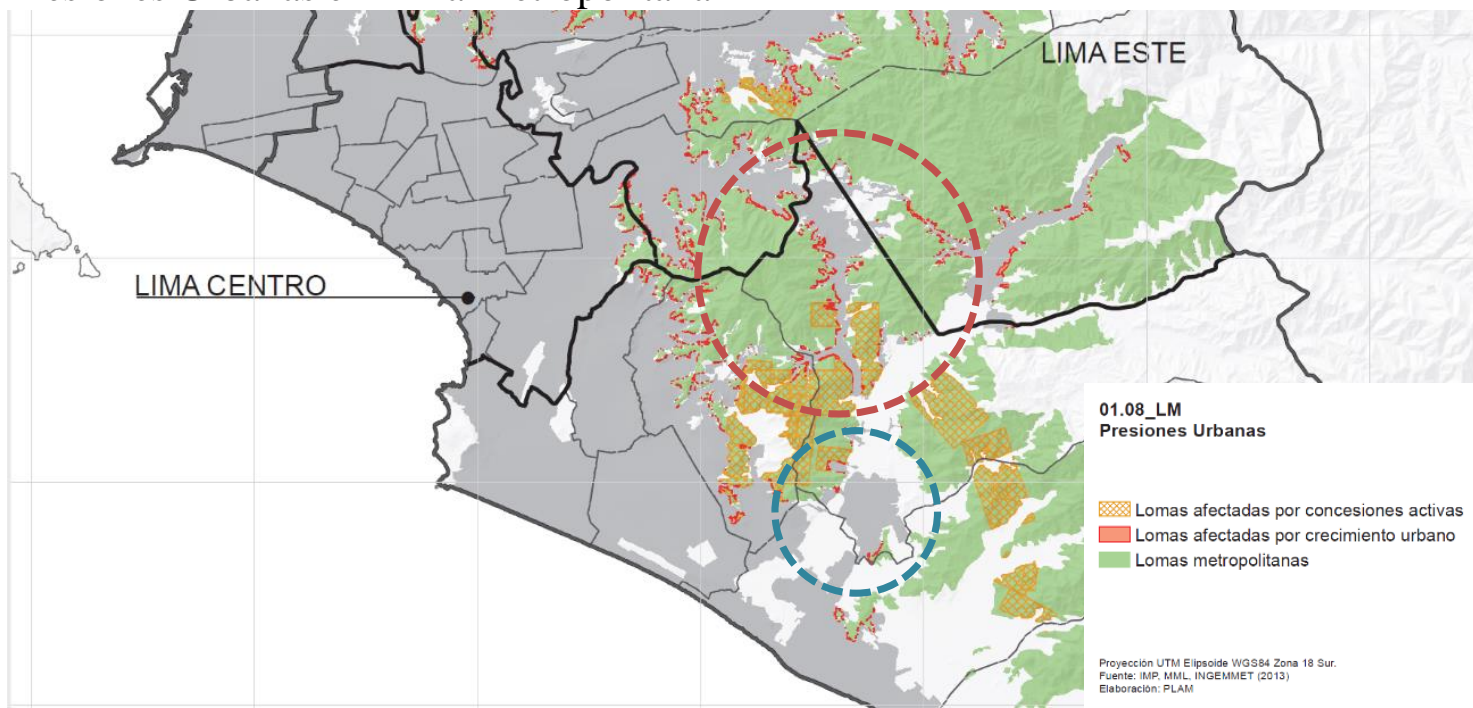

Fuente: PLAM (2014)

El crecimiento descontrolado en las quebradas de Manchay afectan las zonas de las lomas naturales (Municipalidad de Pachacamac, 2014).

\subsubsection{Equipamiento de Comercio y Abastos}

Figura 2.29

Equipamiento de Comercio y Abastos en Lima Sur

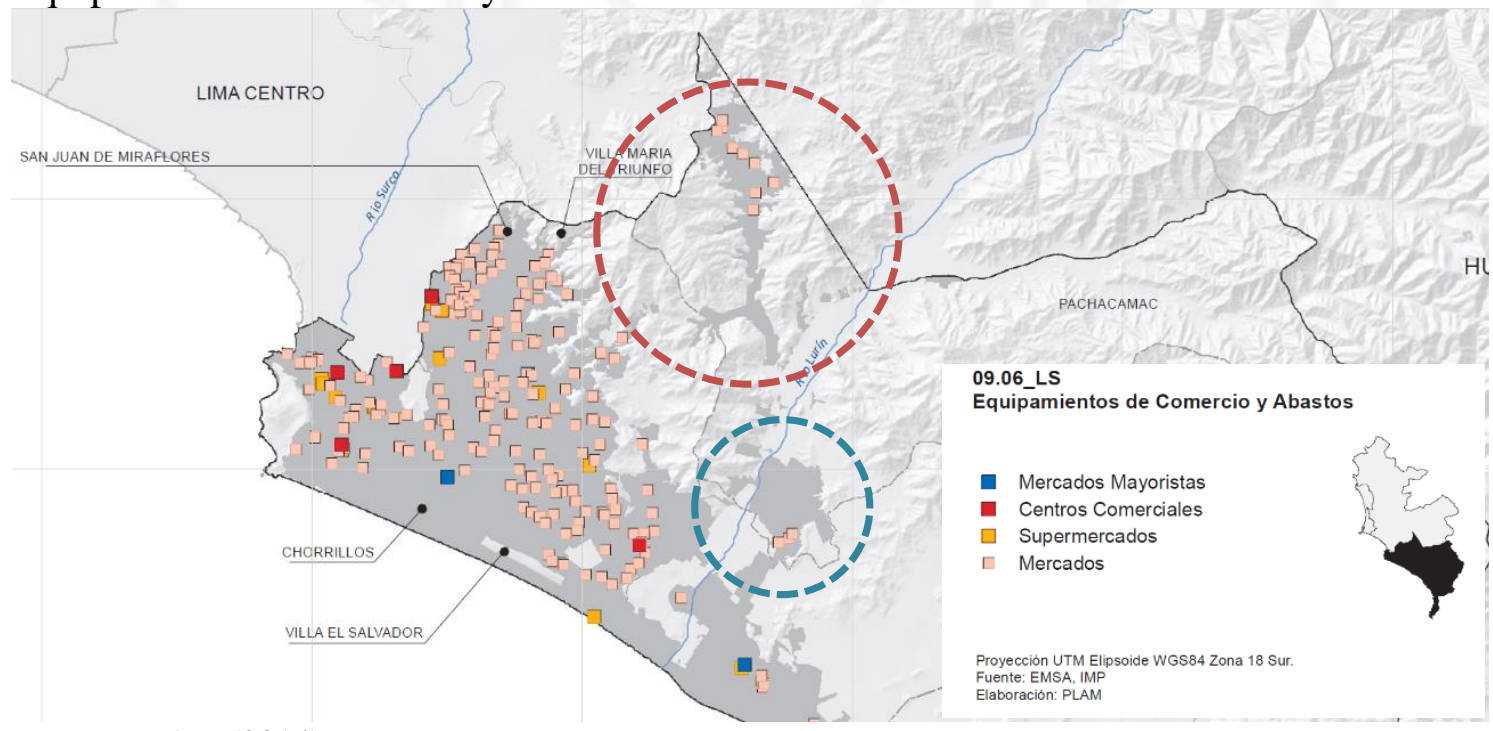

Fuente: PLAM (2014)

Manchay tiene solo mercados barriales como equipamiento comercial. (Municipalida de Pachacamac, 2014) 


\subsubsection{Equipamiento Cultural}

Figura 2.30

Equipamiento Cultural en Lima Sur

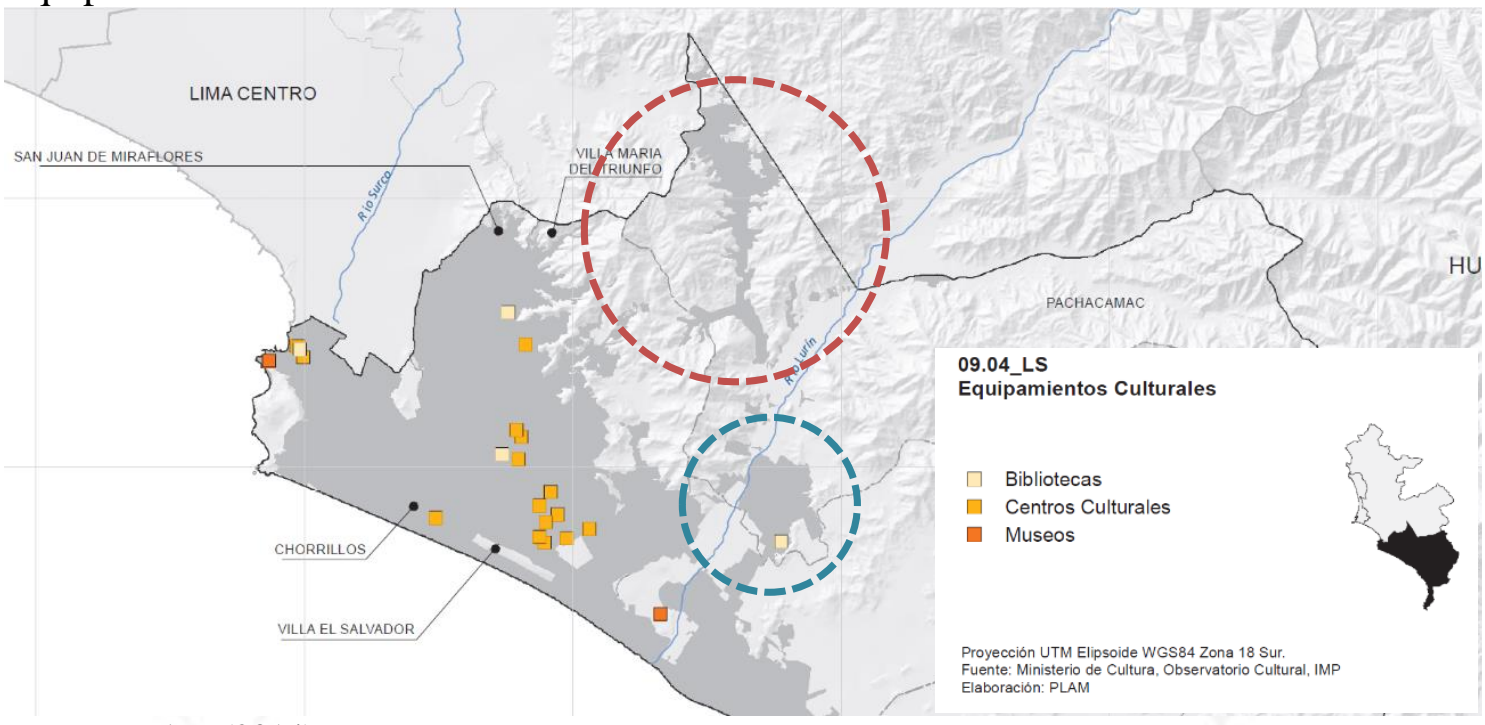

Fuente: PLAM (2014)

Manchay no cuenta con equipamiento cultural como bibliotecas, Centros culturales ni museos. (Municipalidad de Pachacamac, 2014)

\subsubsection{Equipamiento Deportivo}

Figura 2.31

Equipamiento Deportivo en Lima Sur

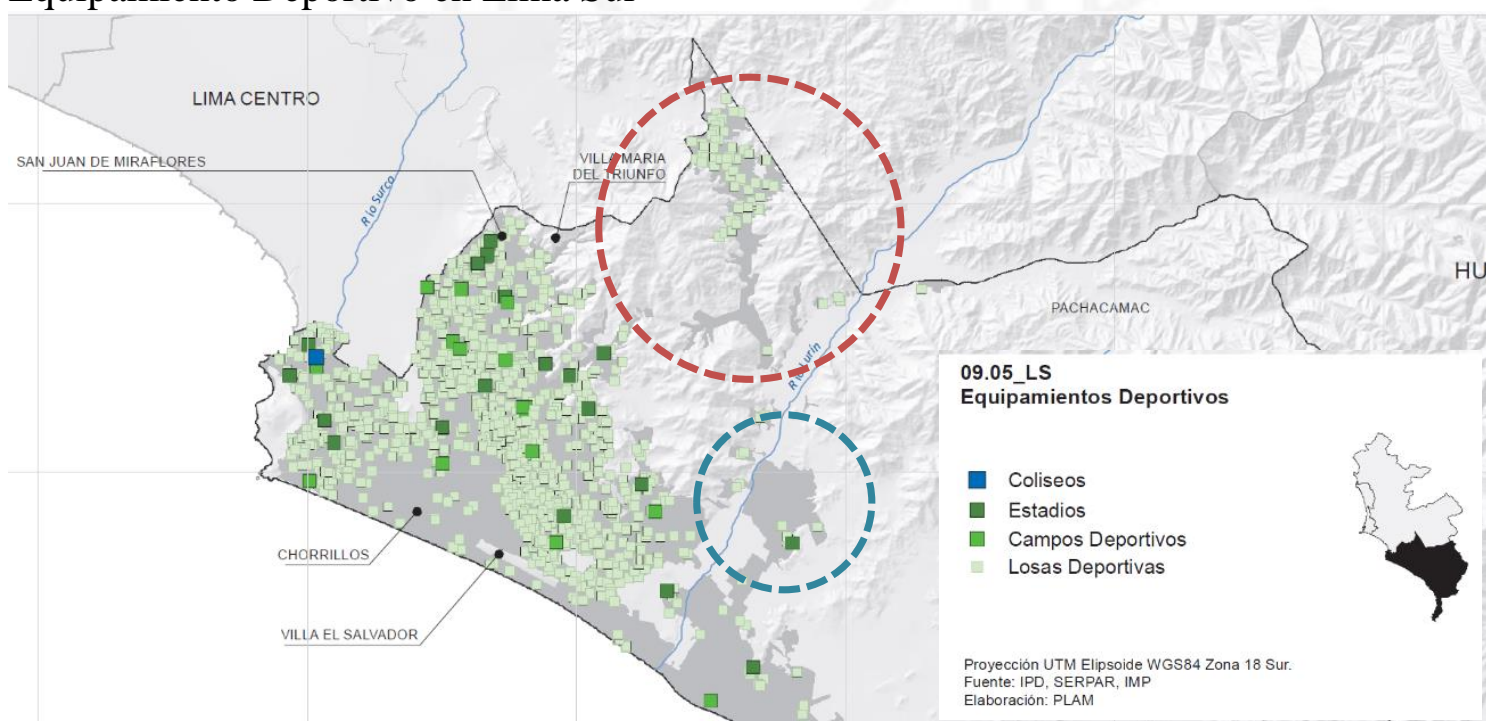

Fuente: PLAM (2014)

El equipamiento deportivo son en su mayoría losas de cemento y algunas pocas de gras sintético (Municipalidad de Pachacamac, 2014). 


\subsubsection{Equipamiento Educativo}

Figura 2.32

Equipamiento Educativo en Lima Sur

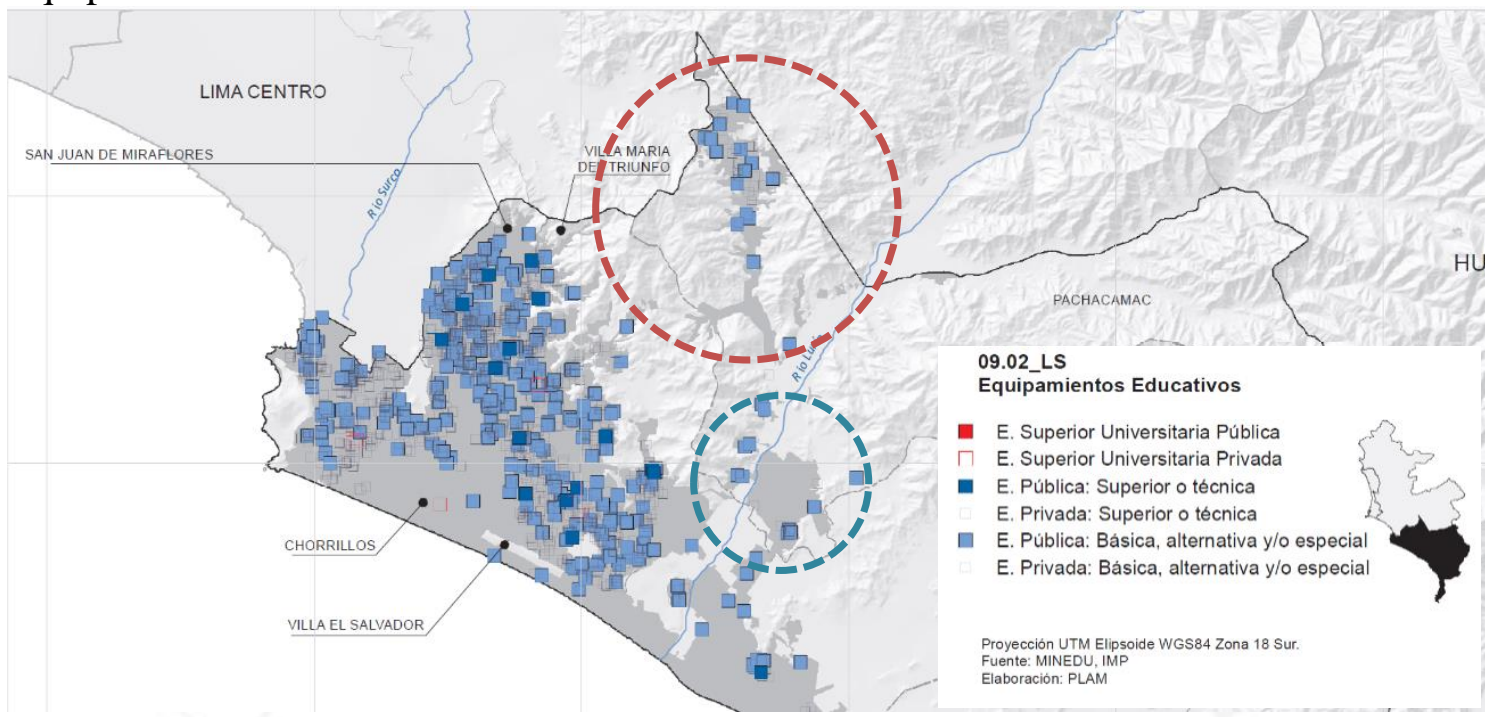

Fuente: PLAM (2014)

Manchay cuenta con 41 centros de educación Inicial, 33 colegios de nivel primaria, 29 colegios de nivel secundaria y 4 centros de estudios superiores (MINEDU, 2018).

\subsubsection{Equipamiento de Salud}

Figura 2.33

Equipamiento de Salud en Lima Sur

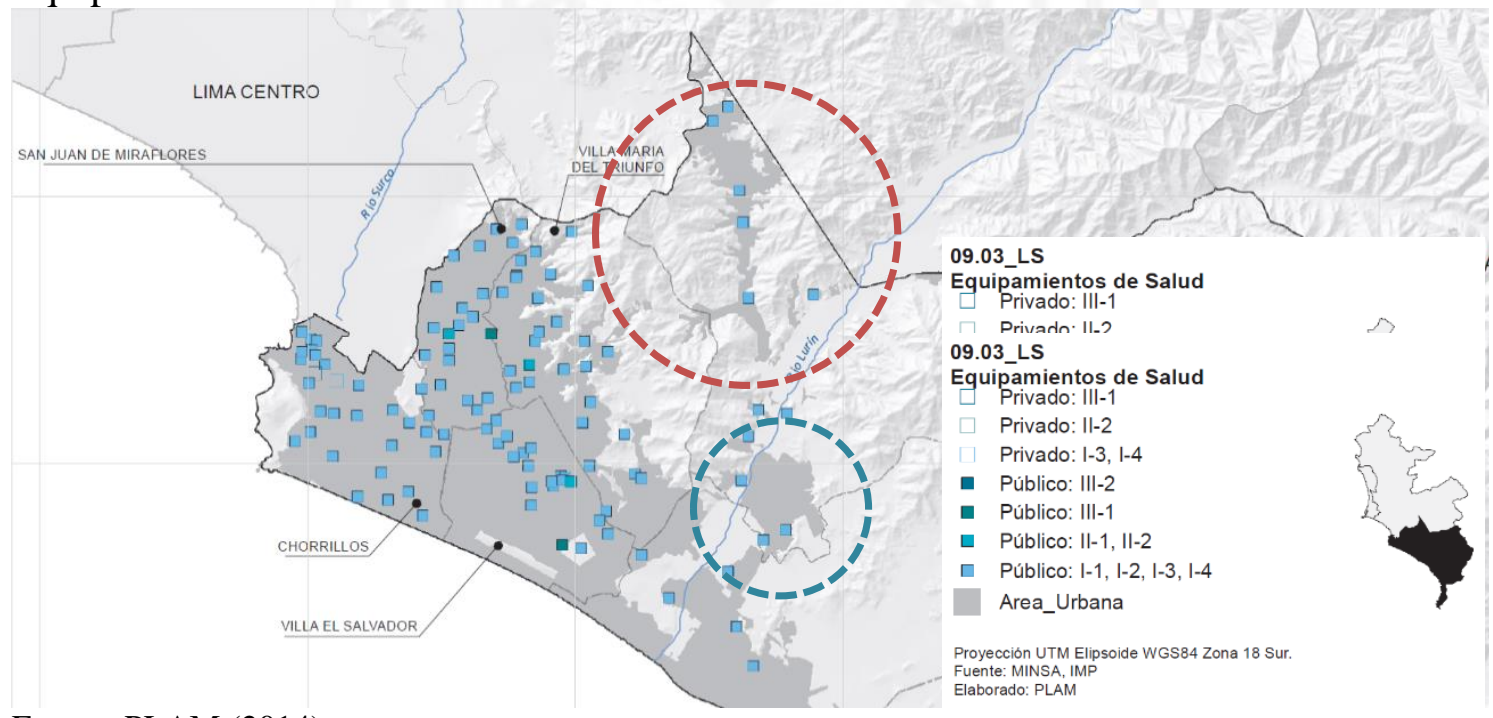

Fuente: PLAM (2014)

Cuenta con 2 postas médicas, 2 centros de salud, 1 centro materno y 1 policlínico. (Municipalidad de Pachacamac, 2014) 


\subsubsection{Equipamiento Seguridad Ciudadana}

Figura 2.34

Equipamiento Seguridad Ciudadana en Lima Sur

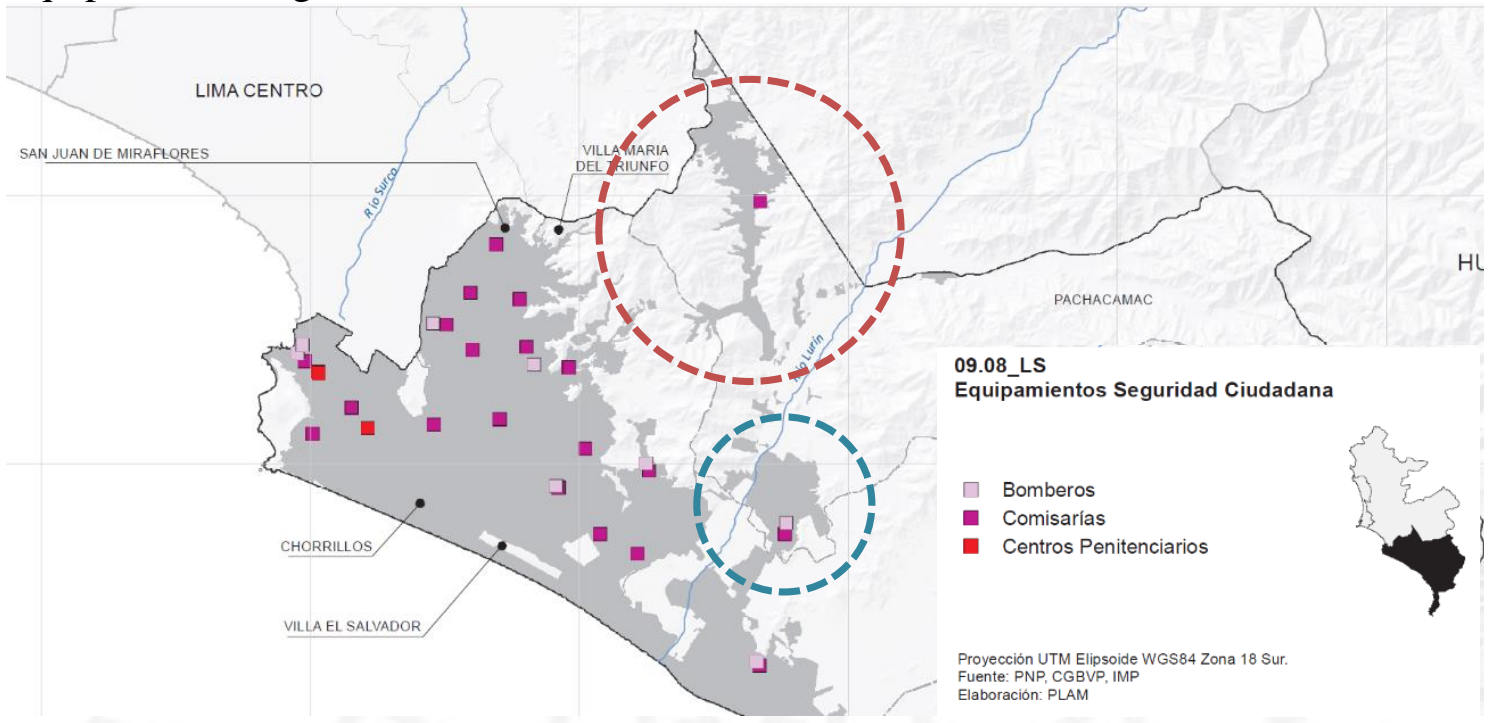

Fuente: PLAM (2014)

El único equipamiento de Manchay es una comisaria, no cuenta con cámaras de seguridad y pocas casetas de serenazgo, contabilizando 1 un agente de serenazgo por cada 1352 habitantes. Tampoco cuenta con una estación de bomberos. (Municipalidad de Pachacamac, 2014)

2.6 Objetivos para el mejoramiento urbano según el Plan de desarrollo urbano de Lima Metropolitana (PLAM 2035)

La Municipalidad de Lima y los desarrolladores del PLAM 2035 han propuesto programas urbanos de mejora urbana o PUI (Proyecto Urbano Integrado) en distintos puntos de la ciudad. Entre esos puntos se encuentra la zona de Manchay, el PLAM solo lo menciona como un punto que necesita este tipo de intervención para solucionar problemas como alta exposición a peligros geológicos, inadecuadas e insuficientes vías de acceso, bajos niveles de habitabilidad y déficit de espacios públicos, saneamiento físico legal incompatible con la realidad de la zona y la indefinición de límites y tráfico de terrenos. (Municipalidad-de-Lima, 2015) 
El PLAM 2035 tiene varios objetivos con este plan de mejora urbana, las cuales son: (Municipalidad-de-Lima, 2015)

- Rehabilitar urbana de zonas en vías de consolidación de manera sostenible y económica.

- Optimizar correctamente las condiciones y servicios que se ofrecen en los distintos equipamientos de las poblaciones.

- Realizar diseño participativo con el fin de promover al intercambio de ideas de la ciudadanía en los distintos proyectos urbanos y sociales que beneficiarán sus zonas.

- Orientar los proyectos urbanos hacia un ideal de ciudad compacta.

- Desarrollar sub centralidades con buen equipamiento y servicios básicos que se integren a la ciudad mediante un eficiente sistema de transporte público.

- Reducir el riesgo en zonas de pendiente como en las laderas de cerros.

- Proyectar espacios públicos de buena calidad y unidades de vivienda dignas que estén acorde a un sistema de ocupación sostenible.

- Proyectar el futuro del crecimiento habitacional en el borde urbano, así como la gestión del uso de sus suelos para habilitar las fronteras acorde al plan urbano.

\subsection{Estrategias de Desarrollo Municipal de Pachacamac}

Un Plan de Desarrollo es parte de una importante iniciativa para buscar formas y mecanismos que permitan un óptimo desarrollo local del distrito. En Lima Sur, Pachacamac es considerado como el distrito más pobre esto se debe a sus actividades económicas que generan empleos que principalmente están en los rublos de los servicios y el comercio, estas 2 actividades acumulan el 69\% de PEA del distrito, estas de distribuyen ya sea en tiendas, bodegas y puestos de venta en mercados locales, muchos de ellos se iniciaron informalmente. El Plan de Desarrollo del Distrito no contempla algún programa para formalizarlos o mejorarlos, pero si fue bueno identificarlos para mejorar los procesos de formalización y de entrega de licencia de funcionamiento para la venta y manipulación de alimentos. (Ministerio del Trabajo y Promoción del Empleo, 2009) 
El ingreso promedio que gana un poblador dentro de su distrito es de 601 soles y aquellos que trabajan fuera del distrito pero en Lima tienen un ingreso promedio de 751 soles. De esta manera se entiende que es difícil de activar la economía local por no tener poder adquisitivo alto como para comprar o invertir. También se puede ver en esta situación solo se podría aumentar los ingresos creando más puestos de trabajo, fomentando la formalidad y capacitaciones para los comerciantes. (Ministerio del Trabajo y Promoción del Empleo, 2009)

Una de las problemáticas latentes en el distrito es la del abastecimiento y optimo servicio de los servicios básicos como agua, luz y desagüe. Según el Plan de Desarrollo de Pachacamac (2010) los planes aún no piensan cubrir en la totalidad del distrito a pesar de ser distrito con mayor porcentaje de necesidades básicas insatisfecha. Desde el año 2009 se tiene un fondo participativo para la construcción de nuevos sistemas de agua y desagüe, así como una planta de tratamiento de residuos sólidos. El principal problema que se presenta para desarrollar estos proyectos es la escasez de recursos asignados para tales fines, limitando de esta manera las oportunidades de contar con estos servicios. (Ministerio del Trabajo y Promoción del Empleo, 2009)

Algunos planes con respecto a la cultura y al turismo es generar nuevos espacios públicos recreativos donde puedan desarrollarse actividades deportivas, culturales y económicas al aire libre, generar unos circuitos turísticos que recorra todo el distrito y no solo centrarse en la zona sur como el centro histórico de Pachacamac. (Municipalidadde-Pachacámac, 2010)

\subsection{Centros comunales}

El equipamiento comunitario incluye más que los espacios usados como bibliotecas, gimnasios, centros de salud, guarderías, centros juveniles, centros deportivos, etc. También deberían incluirse puntos de cultura, servicios, centros de reunión, espacios donde se desarrollen actividades fuera de sus muros. Son lugares donde los sujetos interactúan y se generan distintos flujos de actividades colectivos que reactivan el entorno. Los centros comunitarios es arquitectura que implica relaciones compartidas, roces de actividades e intercambio de experiencias. (Fernández y Mozas, 2007, p.3)

En el siglo pasado los espacios comunales de una localidad eran construidos y dirigidos por instituciones estatales o religiosas. En estas últimas décadas se han 
construido nuevos centros comunitarios administrados por ONG's, colectivos, universidades y comunidades organizadas. Estos nuevos lugares son producto de procesos y condiciones locales, donde se proponen entender a población y relacionarse con el entorno. Además son lugares de experimentación de nuevas relaciones y prácticas de participación. Se caracteriza por aportar lecciones que articulan los procesos sociales, políticos y arquitectónicos. (Comité Técnico del Pabellón de México, 2016)

Para el diseño de un espacio comunitario es necesaria la participación de un equipo de personas que comparten el territorio para que traten temas afines, generales, compartan problemas y necesidades colectivas para considerarlas en el proceso de desarrollo de ideas de diseño. Contar con estos lugares comunes es fundamental para el desarrollo social de la comunidad, y muchas han sido los resultados al espacio de reunión y de servicio que se utilizan. Estas tipologías de encuentro deben tener un rol activo, social y contemporáneo con las personas que lo acuden en mejora de su calidad de vida. (Dejtiar, 2017)

\subsection{Historia de los servicios comunales y centros comunales en el Perú}

\subsubsection{Sistema comunal prehispánico: Ayni}

En el periodo del Tawantinsuyo, el sistema Ayni era una forma de trabajo por reciprocidad comunal entre los miembros del ayllu ${ }^{3}$ para el desarrollo de distintas actividades para el beneficios de ellos mismos, ya sea en los trabajos de cultivo, ganadería o de construcción. Para las labores agrícolas ellos realizaban las actividades acorde al ciclo agrario donde había fechas para la preparación del terreno, abono, siembra, cosecha y recolección de alimentos, además cada miembro, acorde a su edad, tenía una función distinta. Durante el tiempo necesario la comunidad participaba en la construcción de viviendas, muros y puentes, además de participar en actividades religiosas como los ritos funerarios de familiares.

Era considerado un intercambio de trabajo dentro de un ayllu, el cual era retribuido luego con las mismas actividades u otras equivalentes al tiempo y esfuerzo ofrecido. Durante ese tiempo era considerado obligatorio por ética del pueblo y tenía también un fin religioso. Si un miembro presentaba una negación al trabajo en

\footnotetext{
${ }^{3}$ Ayllu nombre con que se asigna a los grupos familiares o a una comunidad nativa de la región andina.
} 
comunidad, a este se le rechazaba todo pedido de ayuda bajo esa misma modalidad. Estos trabajos comunales se realizaban mediante un contrato oral, en algunos casos los que recibían la ayuda hacían un "pago" a que realizaban el servicio con alimentos como carne, tubérculo y plantas medicinales, que eran ofrecidas durante el periodo de trabajo (Altarmirano y Bueno, 2011).

El Ayni era una actividad milenaria de contexto social, cívico y religioso. Actualmente son algunas las comunidades andinas de Ecuador, Perú y Bolivía que aún emplean ese sistema de manera parcial o tienen distintas variantes ya acordados por la misma comunidad (Altarmirano y Bueno, 2011, pp. 53-54).

\section{Figura 2.35}

El Ayni en el antiguo Perú

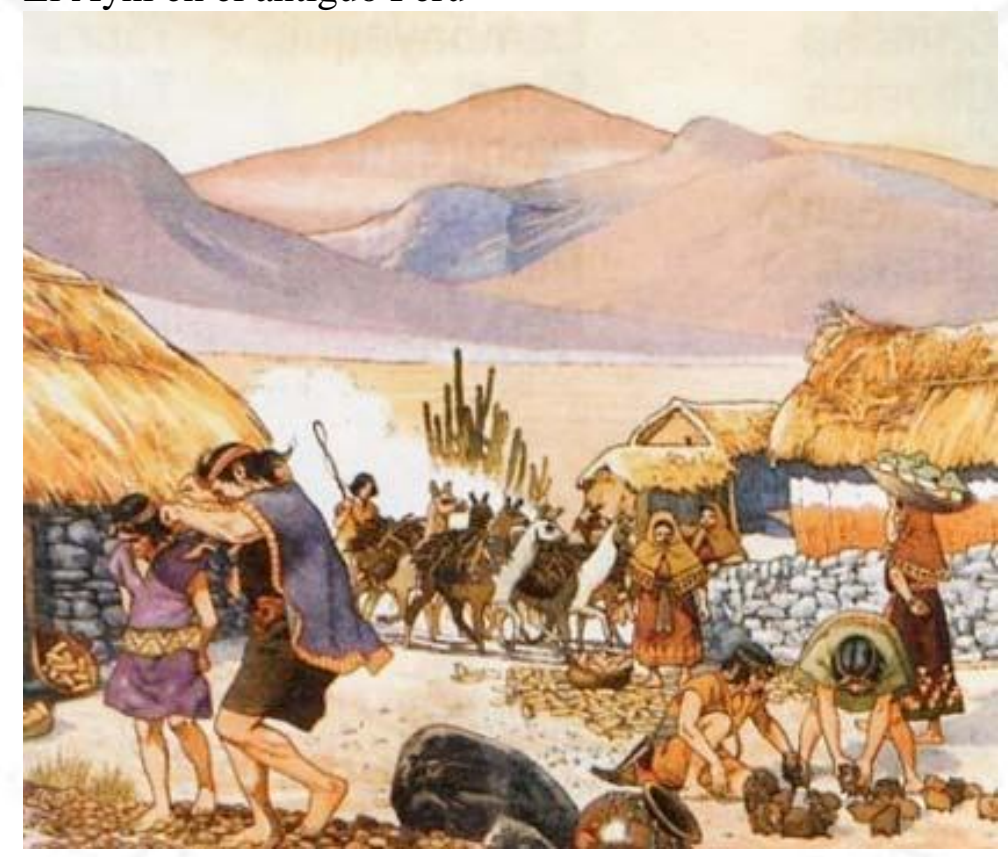

Aramayo M. (2011)

\subsubsection{Centros sociales en el Virreinato del Perú y América}

Durante la conquista de América, los españoles fueron los que trajeron el servicio a la comunidad a América mediante la Iglesia y sus múltiples órdenes que fueron esparciéndose a lo largo de las capitales americanas y pueblos.

El 25 de abril de 1521 el Papa León X concedió la autorización a las órdenes mendicantes el encabezar la tarea misional en los nuevos territorios del Nuevo Continente por ende del Perú (Santos, 1992). 
La Compañía de Jesús, también llamados jesuitas, es una orden de la iglesia Católica, fundada en 1540 por San Ignacio de Loyola, en París. Que estuvieron conformados por sacerdotes, estudiantes, hermanos, en su mayoría eran formados por varones. Ellos llegaron a América en 1566 y un año después, en 1567, llegan a Perú. Las principales características de esta orden fueron llegar al nuevo mundo para convertir y educar, luego ellos regresaban a Europa y compartían sus conocimientos interpretando la vida en América y enseñando sobre el nuevo mundo. Su evangelización a los nuevos pueblos en formación se basa en el humanismo cristiano y realizaban trabajos en conjunto con la comunidad para lograr una mejor integración empleando el evangelio como un medio para unir indígenas y españoles a una sociedad más justa (Santos, 1992).

Los Franciscanos conformaron otra orden que llego a América con el fin de evangelizar el nuevo mundo durante el siglo XVI, llegando al Perú en 1553. Se caracterizaron por compartir la vida con los indígenas y así evitar el maltrato y la violencia con los indios y los pobres. Buscaban la igualdad entre la comunidad generando la participación colectiva y el derecho a ser escuchados y respetan el derecho a la vida de los nativos y generar un sentimiento de dignidad humana con ello. (Abad-Perez).

Los Dominicos establecieron una orden de predicadores formada en 1216 por el Papa Honorio III. En 1510 arriban a América y llegan a Perú en 1529. Se caracterizan por ayudar a las comunidades indígenas a generar en ellas una lucha propia por la dignidad humana. Además empleaban las manifestaciones culturales como la música, el teatro, la poesía y el dibujo para educar, generar valores y evangelizar a la comunidad.

De esta manera muchas otras congregaciones y órdenes religiosas llegaron al Perú para apoyar a las comunidades más necesitadas, dándoles apoyo en salud, educación y participación para generar el sentimiento de unidad no solo a las comunidades indígenas sino también a los más pobres y esclavos traídos desde todas partes del mundo.

Estas órdenes religiosas cumplieron la función de unificar mediante la religión y el trabajo colectivo a las comunidades indígenas. Sus centros de encuentro contaban con capillas, comedores, talleres. Eran espacios para el compartir, ayudar e instruir por lo que se pueden considerar como los primeros centros comunales de carácter religioso-social en el Perú. 
Figura 2.36

Los Jesuitas (1767)

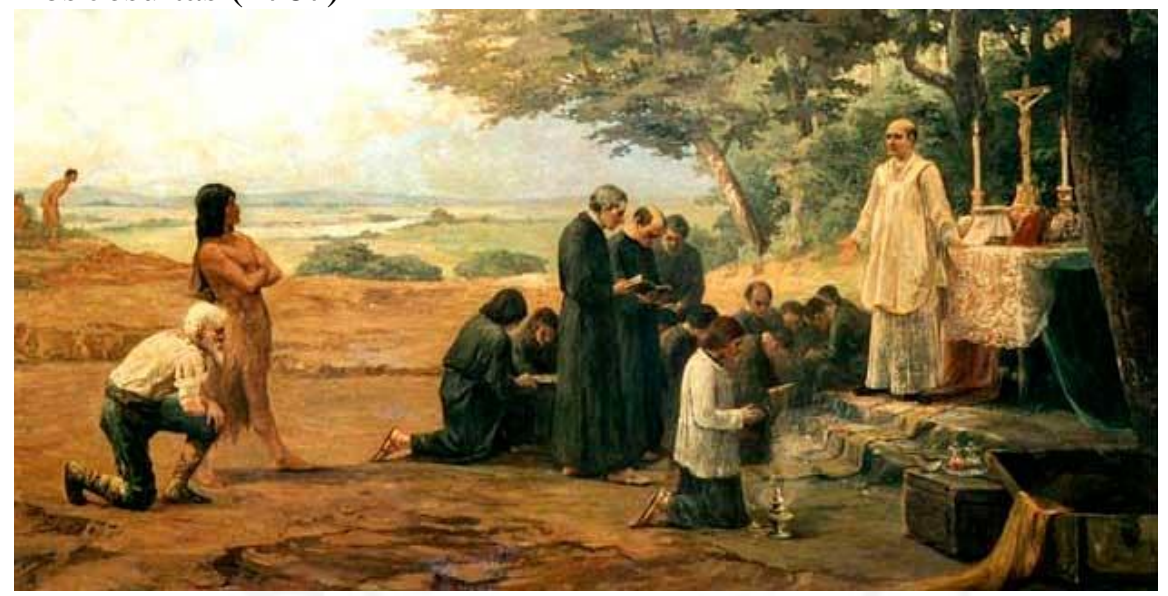

Fuente: Anónimo (1767)

\subsubsection{Centros y programas sociales en La República del Perú}

Uno de los programas asistenciales sobre alimentación más conocidos hasta 1980 son los Comedores Populares, posterior a ellos en los años 80 y 90 se crearon nuevos programas que hasta el día de hoy existen como es el caso de los programas Vaso de leche - (1985), el Fondo de Cooperación para el Desarrollo Social también llamados FONCODES (1991), El Programa Nacional de Asistencia Alimentaria PRONAA - (1992), el Centro de Promoción de Pequeña y Micro Empresa Prompyme y actualmente se llama Mi Empresa - (1997), El Sistema Integral de Salud - (1998), El Consejo Nacional para la Integración de Personas Discapacitadas Conadis - (1998), El Programa de Capacitación Laboral Juvenil Projoven - (1999) y entre otro programas orientado apoyar a las poblaciones emergentes (Alfaro y Diego, 2011).

El programa FONCODE fue uno de los que destacó más debido a su capacidad para repartir los recursos públicos a los distintos grupos sociales a través de sus representantes. El programa PRONAA también es uno de los más importantes por tener en prioridad la reducción de los problemas más importantes en los países en vías de desarrollo como por ejemplo la lucha contra la desnutrición crónica. Algunos de los resultados obtenidos para inicios del año 2000 fueron la disminución de la desnutrición y la disminución de la pobreza que fueron las metas principales trazadas por las políticas sociales (Alfaro y Diego, 2011). En Manchay el programa FONCODE a ofrecido distintos servicios como la construcción de nuevos puestos de salud en la zona de Nueva Esmeralda donde encuentran con consultorios médicos, áreas de usos múltiples, sercios higiénicos y zona 
de anteción ambulatoría. Se estima que 4 mil pobladores, en su mayoría compuesta por niños y mujeres de Pachacamac serán los beneficiarios (Foncodes, 2012).

El concepto de inclusión social surge desde el año 2000 cuando se empleaban frases como "economía con rostro humano" o "economía social de mercado". Estos lemas fueron muy comunes y utilizados durantes compañas presidenciales, primero por Alejandro Toledo y posteriomente por Alan Garcia durante sus correspondientes campañas. Desde entonces se propusieron nuevos programas sociales, pero no llegaban a articularse entre si. En el año 2005, como respuesta frente a dicha desarticulación se creó el Programa Juntos, el cual consiste en hacer transferencias monetarias a las familias de escasos recursos de los cuales deberian de tener como mienbros a niños y niñas menores a los 15 años o tener mujeres gentantes. Otro beneficio que reciben gracias a este programa son servicios de educación y servicios médicos que deben asistir con fecuencia. (Alfaro y Diego, 2011)

Un artículo realizado por los investigadores Romón Diaz y Carolina Trivelli que aborda el tema de la pobreza en las zonas rurales y el Programa Juntos, llegaron a un resultado donde las transferencias del programa representan el 25\% de los ingresos monetarios de los hogares aptos para el programa y alrededor de un $30 \%$ son los casos de hogares en extrema pobreza. (Alfaro y Diego, 2011)

El Programa PRONAA inició en el año 2006 una reestructuración de las funciones de distintos programas y aportes hacia otros gobiernos locales. De esta manera surge el Programa Integral de Nutrición (PIN) con dos objetivos importantes mejorar la educación y mejorar la alimentación. Ademas se obtuvo que en el año 2009, deacuerdo a estandares internacionales, 1 de cada 3 menores de 5 años de edad tiene desnitrición crónica en el Perú (Alfaro y Diego, 2011). En el 2014 el Programa Pronaa entregó material para la implementación de comedores populares y ofrecer una mejor asistencia alimenticia (Municipalidad de Pachacamac, 2014).

La Estrategía Nacional Crecer es el resultado de la necesidad de tener una mejor articulación con la Comisión Interministerial de Asuntos Sociales (CIAS) que tiene como proposito reducir los índices de desnutrición y pobreza. Se plantearon solucionar 3 problemas latentes que son la alimentación inadecuada del niño, infecciones respiratorias agudas y las diarreas agudas, también se consideraron el problema de los niños que nacen con poco peso al nacer. Estos objetivos se deberán de combatir en los 880 distritos 
identificados con mayor incidencias de dichas problemáticas a nivel nacional y deberán estar bajo la conducción de sus propios gobiernos regionales. (Alfaro y Diego, 2011)

Para el año 2009 se incorporó un sistema parecido a los FONCODE, con el objetivo de asegurar las transferencias monetarias a las poblaciones identificadas con este fin, pero las crisis financieras y procesos electorales están más al tanto de resolver las tensiones sociales a corto plazo que atacar el objetivo principal que es la lucha contra la pobreza y la desnutrición a largo plazo. (Alfaro y Diego, 2011)

En octubre del año 2011 se crea el Ministerio de Desarrollo e Inclusión Social (MIDIS) cuyo objetivo principal es mejorar la calidad de vida de las poblaciones vulnerables y en estado de pobreza, asimismo promover oportunidades, como acceso a servicios, capacitaciones y dar a conocer los derechos de las poblaciones. El MIDIS coordina con distintas entidades públicas o privadas para brindar los distintos programas sociales, entre algunas de ellas se cuentan el Programa Nacional Cuna Más, el Programa Qaliwarma y el Programa Juntos. (Ministerio-de-Desarrollo-e-Inclusión-Social(MIDIS), 2016). Los MIDIS están en constante aporte al distrito de Pachacamac para mejorar los servicios alimentarios del programa Qaliwarma, así como capacitaciones para las familias de bajos recursos (Municipalidad de Pachacamac, 2015).

Figura 2.37

Programas Sociales en Manchay

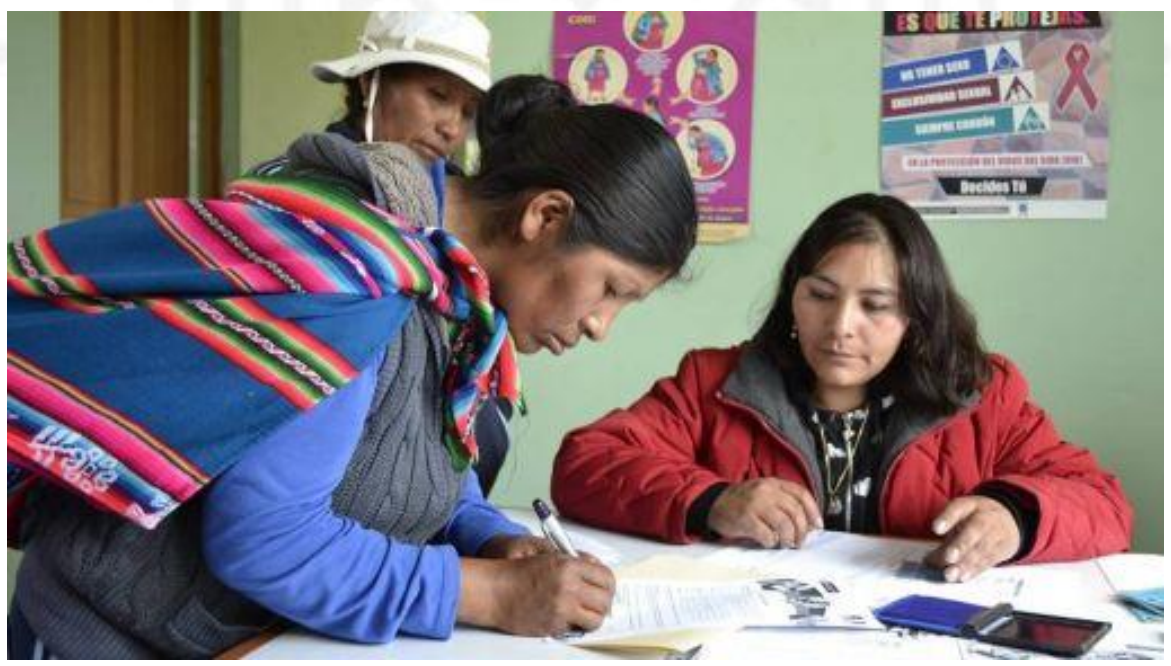

Fuente: Riós M. (2015) 


\subsection{Espacios públicos}

El espacio público se presenta como una dinámica representativa de una ciudad. Se vive en una yuxtaposición entre las tradiciones y las políticas modernas, donde la identidad colectiva no necesariamente tiene a la ciudad como escenario constitutivo. Los espacios públicos pueden tener una representación pero también un problema, como sucede en Lima, que cuenta con una composición socioeconómica, cultural y urbanística tan diferenciada que varía de intensidad según el lugar de residencia del sujeto y su posibilidad de acceso a dichos espacios. Los espacios públicos son espacios de intercambio cultural y social, con el tiempo va generando "contenedores" entre sus plazas y calles, donde la intervención artística es visible y son transmitidos de manera visual a sus usuarios (Hamann, 2013).

Estos lugares cumplen un papel importante en la ciudad. Se consideran un concepto urbano ya que se encuentra relacionado directamente con la ciudad, lugar de origen de la cultura y la civilización intercambiadas por sus habitantes, se puede decir que es un espacio colectivo que hace la ciudad. A su vez al ser la ciudad un centro de acontecimientos históricos importantes, los espacios públicos llegan a tener también un comparativo histórico donde se expresan, comparten, relacionan y se diferencia de una agrupación de viviendas y edificios por concentrarse en un gran espacio abierto colectivo (Gamboa, 2003).

El espacio público ciudadano no es un espacio residual entre calles y edificios. La ciudad es entendida como un sistema, de redes o de conjunto de elementos, como las calles y plazas como si son espacios de comunicación, áreas comerciales, equipamientos culturales es decir espacios de uso colectivos debido a la apropiación progresiva de la gente que permiten el paseo y el encuentro, que ordenan cada zona de la ciudad y le dan sentido, que son el ámbito físico de la expresión colectiva y de la diversidad social y cultural. Es decir que el espacio público es a un tiempo el espacio principal del urbanismo, de la cultura urbana y de la ciudadanía. Es un espacio físico, simbólico y político (Borja, 2000).

Es considerado como un indicador de calidad pero también como una herramienta para hacer ciudad y mejorar las periferias, mantenerlas activas, renovar centros y generar nuevas centralidades, de esta manera unir los tejidos urbanos y aumentar el valor al suelo gracias a nueva infraestructura pública (Borja, 2000). 


\subsection{Parques públicos de Lima}

En Lima existe una entidad pública denominada Servicio de Parques de Lima (SERPAR) que administra los parques metropolitanos y zonales, además de controlar la disposición áreas verdes y espacios públicos para el desarrollo de actividades al aire libre como deporte, talleres culturales sin ningún costo o en caso de parques zonales a un costo módico. Los espacios ofrecidos en los parques deben cumplir con servicios básicos, amplios espacios cómodos y limpios, donde toda la familia pueda hacer uso de las instalaciones y talleres. En algunos parques metropolitanos se ofrecen prácticas de juegos lúdicos para niños o espacios para que las madres puedan aprender distintos oficios, además de tener ambientes y salas para usos múltiples por si se necesita para alguna actividad pública o privada (SERPAR, 2017).

Por otro lado en los parques zonales existe la intención de construir centros culturales llamados CREALIMA, de los cuales algunos ya fueron construidos, donde ofrecen servicios como talleres culturales, deportivos, educativos para la familia y grupos escolares. (SERPAR, 2017)

El objetivo de SERPAR es hacer de la ciudad más verde, para lograr tal objetivo se creó el programa Adopta un Árbol, donde se propone dar en adopción árboles a instituciones educativas y organizaciones sociales. Desde un inicio los grupos son capacitados con talleres para que se realice una óptima plantación, cuidado y mantenimiento de las especies y son seguidos por el programa. En el 2014 se plantaron en adopción a 500.000 mil árboles en distintos distritos de Lima Metropolitana.(SERPAR, 2017)

Los parques en Lima han pasado por una serie de transformaciones, por ejemplo los parques ciudadanos eran encerrados por muros ciegos, por lo que se accedió a retirarlos para hacerlos más públicos o reemplazarlos por cercos vivos o rejas para hacer más permeable la visual al interior, sin dejar de lado la seguridad y el orden del parque.

El crecimiento desmedido de Lima que paso durante los años 80 produjo una gran demanda de servicios urbanos y sociales, creando de esta manera una ciudad con muchos déficit de servicios y equipamiento. Lima no estaba preparada para este crecimiento de miles de personas en tan poco tiempo. Actualmente aún se vive esa insatisfacción de espacios públicos y áreas verdes por habitante, teniendo $3.2 \mathrm{~m} 2$ de área verde pública por 
persona de los $9 \mathrm{~m} 2$ que se debería de tener según la Organización Nacional de la Salud (OMS).(SERPAR, 2017)

Hoy en día la ciudad de Lima cuenta con 27 grandes parques entre zonales y metropolitanos, de los cuales solo 8 están ubicados en grandes distritos poblados en vías de una mejor consolidación. SERPAR propone una iniciativa llamada "Revolución de los Parques" que busca mejorar y brindar servicios en los distintos espacios públicos de la ciudad. (SERPAR, 2017)

La propuesta "Revolución de los Parques" está sustentada por 2 puntos importantes. En el primero habla del derecho a la accesibilidad ciudadana de tener un parque cerca. Este derecho está contemplado en la Carta Mundial por el Derecho a la Ciudad en el año 2005, donde se enfoca en la mejora de la calidad de vida en una ciudad urbanizada, considerando también una escala residencial, barrial y natural inmediato. Este derecho a la ciudad incluye el derecho a un mejor entorno ambiental, al desarrollo urbano y también al derecho a participar en la planificación urbana para preservar la herencia cultural e histórica del lugar. El segundo punto donde se sustenta la propuesta es la responsabilidad del Estado para administrar y brindar espacios públicos con áreas verdes a las ciudades a través de las municipalidades. Dentro de las responsabilidades del Estado es la de mejorar e implementar mejores políticas públicas que garanticen una mejor proximidad y calidad de parques a los ciudadanos. (SERPAR, 2017)

SERPAR y gracias a la propuesta "Revolución de los Parques" se propuso la idea de brindar parques abiertos que busca la diversificación de los servicios ofrecidos, generando espacios de participación y conciencia ciudadana, apuntando a mejorar y poner en valor los barrios de una manera económica, ambiental y sostenible a lo largo del tiempo. (SERPAR, 2017)

Según las encuestas desarrolladas por Lima Como Vamos, el 41\% de la población de Lima Sur, incluye al distrito de Pachacamac, no se encuentran satisfechos con los parques y áreas verdes de uso público en sus zonas. El 50\% manifestó no estar ni satisfecho ni insatisfecho, así mismo el $27 \%$ no se encuentra satisfecho con los espacios público y el $44.7 \%$ ni satisfecho ni insatisfecho. Las áreas verdes en el distrito de Pachacamac son menos de $1 \mathrm{~m} 2$ por habitante y el nivel de insatisfacción de los espacios públicos en sus barrios o cerca de ellos en ese distrito es del 57.9\% (Lima Como Vamos, 2017). 
El distrito de Pachacamac es una zona en constante expansión urbana por lo que el requerimiento de espacios públicos es exigido por las familias para el esparcimiento. Actualmente en Manchay las áreas públicas se encuentran deterioradas, tanto en cuanto a áreas verdes como infraestructura. La iluminación es restringida y presenta limitaciones, tienen desgaste de estructura y varios no cuentan con luminarias. La infraestructura urbana, como bancas, tachos y juegos infantiles está descuidada. Los árboles plantados están deteriorados o son especies que requieren un riego constante. (Municipalidad de Pachacamac, 2015)

Por otro lado existe una iniciativa ambiental por parte del Arzobispado de Lima con un proyecto desarrollado por Monseñor Adriano Tomasi, Obispo Auxiliar de Lima, con el fin de hacer un cambio por el medio ambiente en Manchay llamado "Manchay Verde”. El proyecto apunta a aumentar conciencia por el cuidado y el respeto por medio ambiente de las zonas más pobres, creando áreas verdes públicas empleando aguas tratadas en zonas donde este elemento es escaso. Durante el año 2009 construyeron una red de contactos para desarrollar la primera planta de tratamiento de agua y se empezó a implementar actividades educativas con colegios de la zona. (Arzobispado de Lima, 2009).

El proyecto también busca difundir una educación ambiental, con visitas educativas, haciendo eventos, charlas y participación. El proyecto es financiado por el Arzobispado de Lima, la Parroquia Espíritu Santo, el Instituto Trentino Juan Pablo II de Manchay y la ONG católica FIDESCO, del programa participan voluntarios de distintas disciplinas y 6 colegíos de la zona. Algunas de las contribuciones aportadas son por parte de la Municipalidad de Pachcacamac, la Universidad Agraria La Molina, La Universidad Nacional de Ingeniería (UNI) y algunas empresas nacionales. (Los Custodios de la Creación, 2018)

Desde el año 2009 se arborizó un total de 6 hectáreas, se sembraron más de 2000 árboles y durante cada año se logró tratar 3600m3 de agua, se programan 100 visitas pedagógicas y se recicla 8 toneladas de residuos sólidos con los colegios asociados. (Los Custodios de la Creación, 2018) 


\subsection{Historia de los Parques Zonales}

Durante los últimos años de la década del 60, en Lima, se proponen los primeros parques zonales. En sus inicios eran simple losas deportivas con algunas áreas verdes que luego se convertirían en grandes centros de encuentro y símbolos de las nuevas ciudades compuesta en su mayoría por migrantes.(SERPAR, 2017)

En el año 1967 se finaliza la construcción del primer parque zonal, El parque Sinchi Roca, en el distrito de Comas. En los años 70 este parque zonal tenía zonas de chacras y sus primeros vecinos eran migrantes de la región andina que aún conservaban sus costumbres, habitaban viviendas muy precarias y no contaban con todos los servicios básicos. En esos años el Parque Zonal Sinchi Roca contaba con áreas verdes, losas deportivas y juegos para niños, y a pesar de no contar con más servicios tenía una gran popularidad en la ciudad, considerándose como el primer espacio populoso de migración andina en Lima (SERPAR, 2017).

En el año 1969 se funda el segundo parque zonal, denominado Túpac Amaru, en el distrito de San Luis. Desde su apertura en ese año se ofrecieron actividades deportivas y culturales, con obras de teatro, talleres y distintas competencias deportivas. Todo se mantuvo de esa manera hasta que en el año 1981 durante el gobierno del presidente Fernando Belaunde, pasó a otra administración convirtiéndolo hoy en el Instituto Peruano del Deporte (IPD) (SERPAR, 2017).

Durante la década de los 70 como respuesta del crecimiento poblacional de Lima, el Estado planificó la construcción de 28 parques zonales y metropolitanos que servirían de soporte a futuro para áreas de esparcimiento de las futuras generaciones.

Así, empezaron a surgir más parques zonales como el Parque Zonal Huiracocha, en el distrito de San Juan de Lurigancho en el año 1971, y le siguieron durante esos años el Parque Zonal Cahuide en Ate-Vitarte y el Parque Zonal Lloque Yupanqui, en el distrito de Los Olivos. A mediados de los 70 se inauguró el Parque Zonal Huáscar, en distrito de Villa el Salvador y se convirtió en el símbolo de ese distrito migrante ubicado en el desierto.

Estos nuevos parques zonales propuestos para satisfacer la necesidad de espacios públicos obtuvieron un gran éxito, pero debido a la debilidad institucional del Estado no se logró contar con los fondos necesarios para continuar con estos proyectos, llegando a 
solo construirse 8 de los 28 parques propuestos y desarrollados para fines de los años 80 (SERPAR, 2017).

Durante los años 80, en el Perú, se vivió una crisis económica y territorial que afectaron la administración y concurrencia de los parques zonales. Con los fondos que contaba el Estado destinados a parques públicos solo se pudo para cubrir los mantenimientos, mas no para hacer mejoras u ofrecer otros servicios. Incluso algunos de estos grandes parques zonales perdieron terreno, asignados a otros usos públicos, como por ejemplo una parte del Parque Sinchi Roca se asignó para ser usado como relleno sanitario (SERPAR, 2017).

En los años 90 no se hicieron cambios o nuevas reformas para mejorar los parques zonales, pero se debe reconocer que durante la gestión del ex alcalde de Lima Alberto Andrade (1996-2003) se evitó pasar la administración de los parques zonales a los respectivos distritos donde se encuentran. También durante el periodo del burgomaestre el Parque de la Exposición, considerado un parque metropolitano, estuvo en remodelación para luego ser reabierto después de muchos años de abandono (SERPAR, 2017).

Recién durante los inicios del año 2000 se plantearon las grandes transformaciones para los parques zonales, durante la gestión municipal de aquel entonces alcalde de Lima Luis Castañeda Lossio se planteó la remodelación y ampliación de los parques tanto zonales como metropolitanos. Por ejemplo se renovó el Parque Universitario y se llevó a cabo los proyectos de construcción de los parques Los Anillos, La Muralla y La Alameda de Las Malvinas. Asimismo se construyó el Circuito Mágico del Agua en el Parque de la Reserva. Los parques zonales fueron remodelados, involucrando fuertes inversiones para la implementación de áreas recreativas y culturales, como ofrecer piscinas que resultaron ser un gran atractivo para la población que visitaba los parques (SERPAR, 2017).

Cabe resaltar que desde la década de los 70, la Municipalidad de Lima no se anuncia la construcción de nuevos parques zonales y es preocupante que las nuevas autoridades no cumplan con ofrecer nuevas áreas verdes para la ciudad que se encuentra a un ritmo de crecimiento constante (SERPAR, 2017). 


\subsection{Línea de tiempo}

Sistema de trabajo AYNI para trabajo colectivo de la

comunidad.

Sistema MINKA para mantener el vínculo de solidaridad.

1521: El Papa León X da autorización a las órdenes religiosas para ir al Nuevo Mundo a evangelizar.

1529: Llegan al Perú los dominicos para promover el arte entre las comunidades.

1553: Llegan al Perú los franciscanos para luchar contra la violencia de los indígenas y pobres.

1566: Llegan al Perú los jesuitas para unir a las comunidades.

28 de julio 1821: Independencia del Perú

70's Proyección de los futuros Parques Zonales en Lima

4 de enero 1985: Programa del Vaso de Leche.

1997: Seguro Escolar Gratuito

1998: Seguro Materno Infantil

20 de Julio 1999: Programa PROJOVEN, para mejorar la empleabilidad de los jóvenes más pobres.
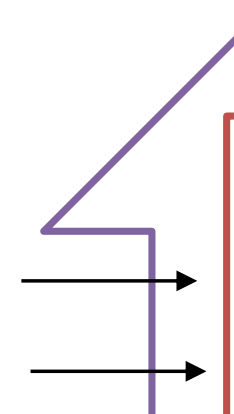

ton

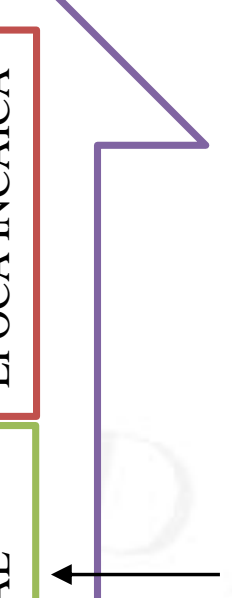

18 de enero 1535: Se funda la ciudad de Lima

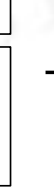

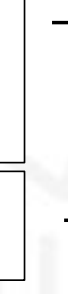 \\ .}

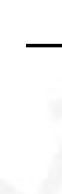
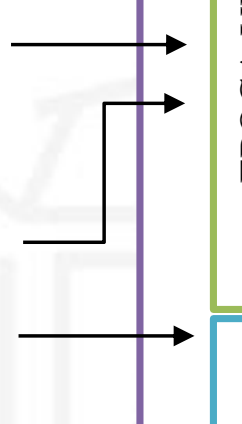

(1)

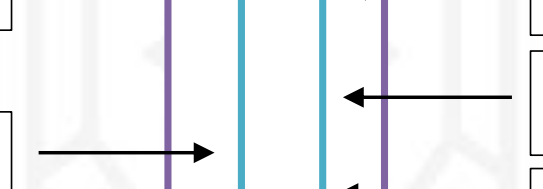

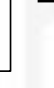

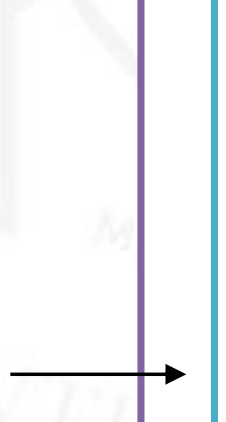

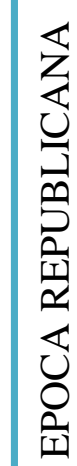

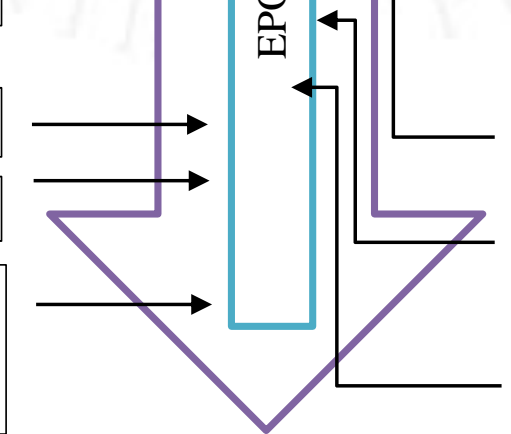

1573: Se funda el pueblo

Santísimo Salvador de

Pachacamac

1573: Se funda el pueblo

Santísimo Salvador de

Pachacamac

1856: Se crea la Municipalidad de Pachacamac.

1960: llegan los primeros pobladores a Manchay

1980: Se establecen en Manchay personas huyendo del terrorismo interno.

1980: Se establecen en Manchay personas huyendo del terrorismo interno.

8 de marzo 1983: Se crea el Centro Poblado Huertos de Manchay, con 8000 habitantes

1983: Pachacámac es declarado como distrito turístico.

1990: Pachacámac es declarado como distrito ecológico.

1996: La iglesia hace labor social a la munidad de Manchay. 
2001: Construyendo Perú, para la capacitación de la población desempleada de bajos recursos

29 de enero 2002: Seguro Integral de Salud (SIS)

2003: Programa de complementación alimentaria (PCA).

2006: Programa de electrificación rural.

23 de octubre 2006: Programa Nacional de Infraestructura Educativa (PRONIED)

23 de febrero 2007: Programa Agua para Todos.

7 de abril 2007: Programa de Restitución de la Identidad y Apoyo Social (PRIAS), para otorgar documentos de identidad a los más necesitados.

Abril 2007: Fondo de inversión en telecomunicaciones (FITEL)

5 de mayo 2007: Mi Empresa, impulsar y mejora de las MYPES

8 de mayo 2007: Programa Mejoramiento Integral de Barrios y Pueblos.

1 de Junio 2007: Programa CRECER, para reducir la desnutrición crónica.

30 de Junio 2007: Programa de Mejoramiento de la Calidad en la Educación Secundaria (MECEP)

2011: Ministerio de Desarrollo e Inclusión Social (MIDIS)

2011: Pensión 65

2011: Programa Beca 18

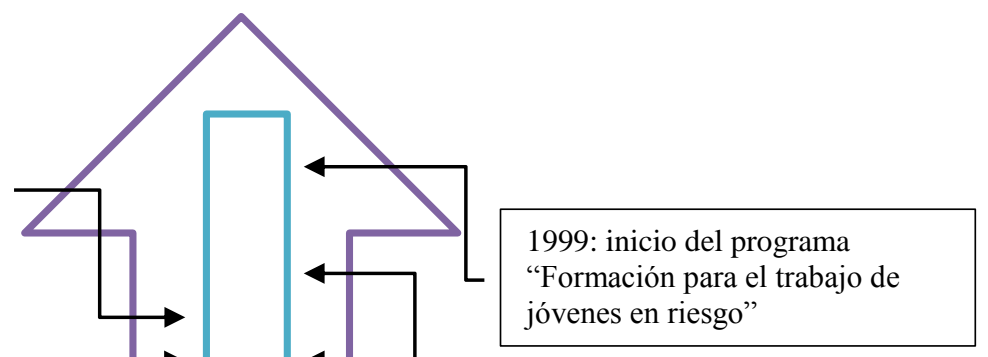

000: Considera símbolo de la pobreza en Lima.

2002: Gana popularidad por el Candidato a la Alcaldía de Lima Luis Castañeda.

2003: Empiezas las obras para la articulación de Manchay con el resto de Lima

2011: Se inaugura la Plaza Cívica de usos múltiples en Manchay Alto

2004: Se inaugura la carrera que conecta Manchay a Lima.

2014: Manchay tiene casi 70000 habitantes

Fuente: Elaboración propia (2016). Línea de tiempo [Esquema]. 


\subsection{Conclusiones Parciales}

- Lima es una ciudad en constante cambio que sus inicios fue planificada y constaba con un ordenamiento pero con el pasar de los años a causa de cambios políticos, económicos y sociales la ciudad capital fue expandiéndose de una manera acelerada horizontalmente a la periferia de las zonas más consolidadas, desabasteciendo de esta manera a la ciudad y no generando un ordenamiento adecuado que cuenta con el equipamiento necesario para satisfacer a toda la población. Se planteará un plan de mejoramiento en la zona de Manchay Alto como en la generación de un gran espacio público para el encuentro y recreación, también se contará con programas culturales, educativos para la participación comunal.

- Las periferias de la ciudad de Lima son las zonas menos consolidadas a nivel de infraestructura y equipamiento, como centros de atención médica, seguridad ciudadana, educación y sobre todo de espacios públicos, sumándole a todo ello la falta de servicios básicos como agua, luz o desagüe. Por lo que hacer una intervención en esas zonas es de total urgencia en especial porque son lugares que habitan familias jóvenes, la presencia de niños y adolescentes es alta, siendo ellos los más perjudicados.

- Pachacamac es unos de los distritos más vulnerables con un porcentaje considerable de pobreza, dicha concentración se encuentra al lado Este del distrito, en la zona de Manchay, que es la zona más poblada y posee poco más de 30 años de formación, en su mayoría está formado por migrantes del interior del país huyendo del terrorismo. Un proyecto de espacio público que incluya áreas verdes, áreas de recreación, zonas de expresión cultural y espacios comunitarios para que los jóvenes puedan integrarse y ser el futuro que mejoren las condiciones en las que viven actualmente.

- La Municipalidad Metropolitana de Lima tiene el PLAM para Lima 2035 (2014), en él se mencionan los proyectos PUI (Proyecto Urbano Integrado) considerando a Manchay como una zona con necesidades de espacios públicos, vivienda y sociedad, por lo que proponer un proyecto de mejoramiento de la zona está validado. Por parte de la Municipalidad Distrital de Pachacamac no se tiene un plan de mejoramiento urbano a nivel de espacios públicos, como regeneración de parques o generar nuevos. Tienen proyectos de mejora vial y de abastecimiento 
de servicios, sería esta una oportunidad de mostrar ideas y potencialidades para apoyar a zonas vulnerables de bajos recursos en terrenos de difícil acceso.

- Los espacios públicos son importantes para una vida en comunidad, genera identidad y espacios de ocio, aparte de ser un espacio para representaciones culturales, comerciales y sociales. Manchay al ser una ciudad que carece de estos espacios no genera una empatía por su entorno, no cuentan con espacios para formar una identidad colectiva donde plasmar experiencias de vida. Al tener un espacio en comunidad generará más actividades, encuentro y por ende nuevas historias en sus vidas.

- Lima es una ciudad alimentada de valles fértiles, sus parques son regados por agua proveniente de los ríos cercanos, los más importantes, también denominados parques zonales y municipales cuentan con áreas verdes, de recreación, zonas deportivas y esparcimiento para toda la familia. Para las zonas periféricas los parques zonales son un punto de encuentro masivo para las poblaciones del distrito, estos van acompañados de Centros comunales que ofrecen talleres culturales, educativos y capacitaciones para grandes y chicos. La descentralización del espacio público en la periferia propone espacios de encuentro en zonas de difícil acceso acercando estas posibilidades a más poblaciones ayudaría a que se sientan parte de la ciudad y puedan ejercer su derecho a la ciudadanía. Pero desde los años 70 no se logra desarrollar grandes proyectos verdes, por lo que proponer un proyecto de espacio público con recreación y áreas verdes apoyaría al déficit de estos espacios en las zonas periféricas de la ciudad.

- Una buena gestión de proyecto debe de garantizar obras públicas urbanas que sean sostenibles en el tiempo y sean atractivas de inversión para zonas en consolidación. Para que el proyecto funcione y genere ciudad se debe promover la participación de los vecinos para aportar ideas en base a sus necesidades e identidad. 


\section{CAPÍTULO III: MARCO TEÓRICO}

\subsection{Base teórica}

\subsubsection{Arquitectura Contextualista}

Durante las últimas décadas del siglo pasado se plantearon distintas corrientes arquitectónicas que se podría tomar para el diseño de un edificio en relación con su entorno inmediato, considerando algunos parámetros que delimitaban o se encontraba en el terreno, a esto se le denomino el contextualismo. Según el arquitecto Roberto Fernández ${ }^{4}$ resalta que el método de plantear y diseñar debe deducirse del contexto preexistente y define al contextualismo como toda propuesta arquitectónica que se deduce del lugar (Fernández, R. 2000).

Además, reconoce en esta corriente la existencia de una posible lógica proyectual, no la única en el marco de la modernidad según la cual el proyecto es un punto de llegada o conclusión respecto de un conjunto de operaciones formales deductivas, desde lo macro (ciudad o estructura territorial preexistente, en general) a lo micro (el objeto resultante del acto proyectual) (Fernández, R. 2000).

Esta corriente sugiere que debe existir una relación efectiva entre edificio y contexto, integrándose a la topografía, siguiendo líneas, ejes, escalas. Donde llenar el espacio, es optimizar y valorar el terreno. Según el arquitecto Fernández la arquitectura debe ser la prótesis de la ciudad que le permite articular usos, conexiones y entorno. Esta arquitectura no debe ser sobredimensionada a lo preexistente para seguir con una continuidad de lo edificado, dando valor a la zona y "corrigiendo" ese vacío en la ciudad. Él lo considera un método basado en la deducción, del conocimiento de los aspectos físicos, sensoriales y visuales que se encuentra. También resalta que el conocer el contexto no solo es lo físico y material cercano, sino que también se debe se considerar los valores culturales e históricos del lugar, no solo considerar una configuración espacial de continuidad de líneas, también proponer una conexión más formal que genere una identidad acorde a la cultura local logrando de esta manera una producción cultural relacionando la arquitectura con la ciudad.

\footnotetext{
${ }^{4}$ En la revista Summa+ “Contextualemente correcto?”
} 
La relación entre arquitectura y paisaje pueden ser naturales, por referencia a lo más lejano y de carácter significativo como aquellas pautas devenidas de lo cultural y cuya fuerza se impone a los condicionantes, más próximos, del paisaje inmediato. Por otro lado la arquitectura contextualista con respecto al paisaje va cuando ambos se relacionan y se resuelven mediante conexiones o acercamiento inmediato. No se refiere a una adaptación o mimetización a un medio cultural como es la arquitectura vernácula sino relacionada al contexto físico inmediato. (Sosa, 1993)

Uno de los principales problemas de la arquitectura contemporánea es que deja de lado algunos factores importantes como son: las relaciones entre los usuarios, el vínculo a un contexto cultural, la relación entre las obras construidas de su entorno. Hace falta de una continuidad histórica y cultural, convirtiéndola simplemente en una pieza de diseño. Existe un fenómeno llamado "Globalización Específica" estudia diferentes proyectos arquitectónicos son construidos por varios arquitectos, en el mismo territorio y en el mismo tiempo, lo que promueve una relación mutua entre sí y con el contexto social y físico, con la finalidad de crear un conjunto urbano contextual que refuerce la identidad de la zona o ciudad. Este fenómeno busca colocarse y adecuarse a cada lugar distinto en el nivel local (Carevic y Domínguez, 2012).

En la Globalización Específica se pueden identificar dos líneas conceptuales que se deben relacionar una con otra como son lo individual y lo colectivo, el proyecto arquitectónico y la ciudad, lo social y lo físico, lo nuevo y lo antiguo, la arquitectura y el urbanismo. Por tal motivo las edificaciones se relacionan en un contexto social y físico, considerando su historia, donde se establecen relaciones no solo entre los usuarios, sino también entre edificios cercanos para conectar y ordenar mejor la ciudad. Es un caso que se refleja en la antigua ciudad de Santa Cruz de la Serós (España), donde se respetaron las tradiciones arquitectónicas de su pasado, manteniendo el estilo, la escala y la ubicación de la estructura (Carevic y Domínguez, 2012).

De esta manera se puede obtener una red arquitectónica hecha a manera de un sistema estructural, diseñada con distintas interpretaciones de contextos específicos, construyendo una urbanidad contextualizada. Ese es su objetivo, un conjunto urbano estructurado por proyectos arquitectónicos contemporáneos, que corresponden y se adecuan al contexto cultural del territorio específico, buscando una buena relación sociofísica entre ellos. Algunas maneras para abordar este tema es reconocer el lugar y el tiempo en la cual se construyó la ciudad, para poder seguir una continuidad de ideas y 
formas a través de la interpretación histórica y así la arquitectura pueda dialogar con la parte antigua. En el caso de una ciudad antigua debe reflejar una variante a la tipología arquitectónica, considerando clima, geografía, estilo de vida, etc. (Carevic y Domínguez, 2012)

\section{Figura 3. 1}

Santa Cruz de la Serós: nueva y antigua arquitectura en una harmonía

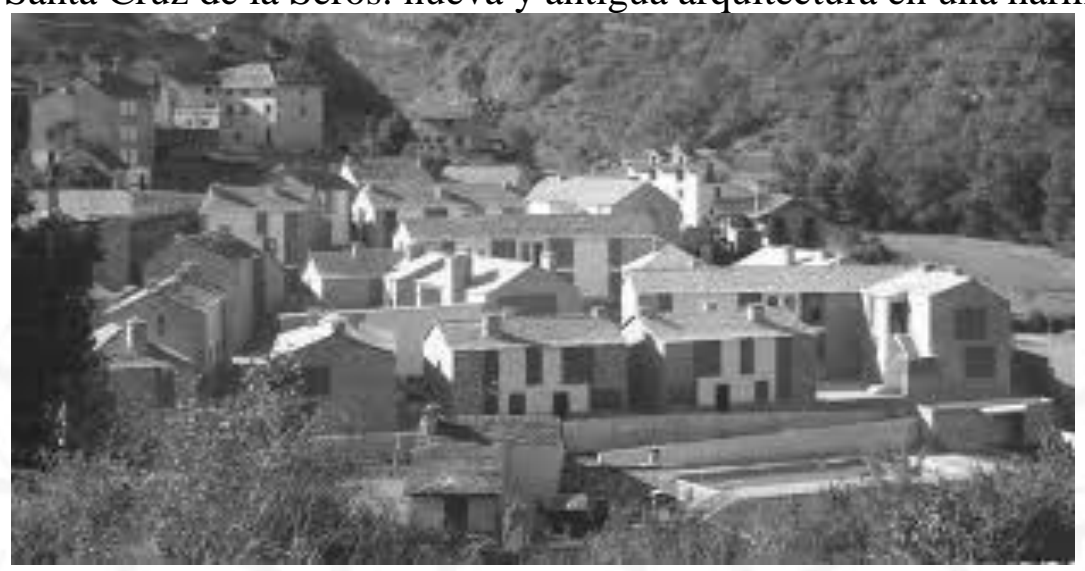

Fuente: Carevic N. y Domínguez L. (2012)

Otro caso a observar es el bloque de viviendas de Sálgase, en una zona urbana de Frankfurt (Alemania) que fue construida durante los años 80. Es un grupo de 17 casas diseñadas por 25 arquitectos ubicados en el centro histórico de la ciudad, manteniendo la identidad histórica de las construcciones vecinas y de las que fueron destruidas durante la Segunda Guerra Mundial. Las viviendas nuevas tienen una tipología que forma una representación, unidad y armonía de las antiguas estructuras urbanas de la calle del siglo XVII. Todas las casas emulan de una manera libre y amplia las reglas establecidas de la cultura y la geografía de Frankfurt. Considerando la disposición de las viviendas en serie, los techos inclinados, el uso de elementos como: ventanas, puertas, chimeneas, balcones, ornamentos y el uso de materiales locales (Carevic y Domínguez, 2012). Esta representación de lo colectivo fue un gran reto que hizo recuperar la armonía y el contexto de una forma grupal al antiguo barrio de Saalgasee. 
Figura 3.2

Representación de la calle Saalgasse en un grabado de 1628

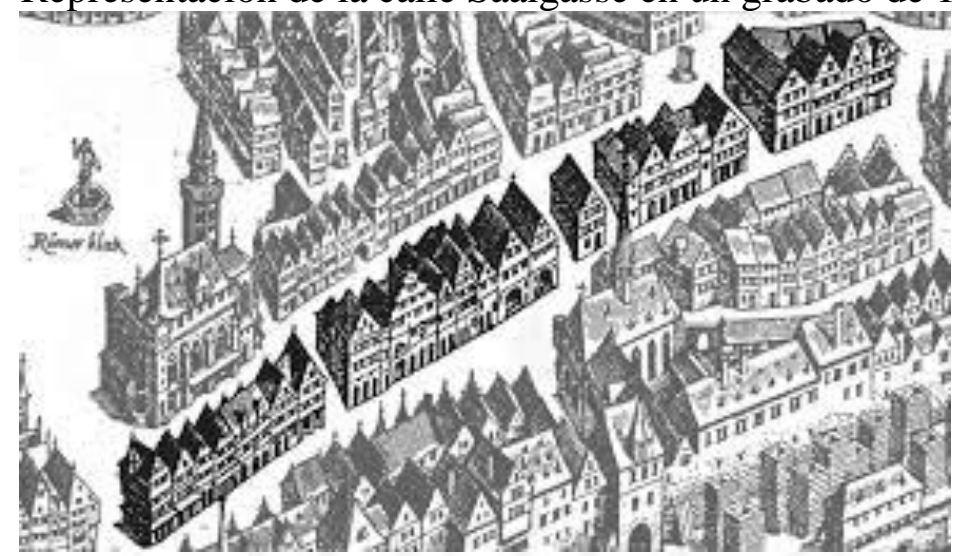

Fuente: Carevic N. y Domínguez L. (2012)

Figura 3.3

Nuevas casas en Saalgasse
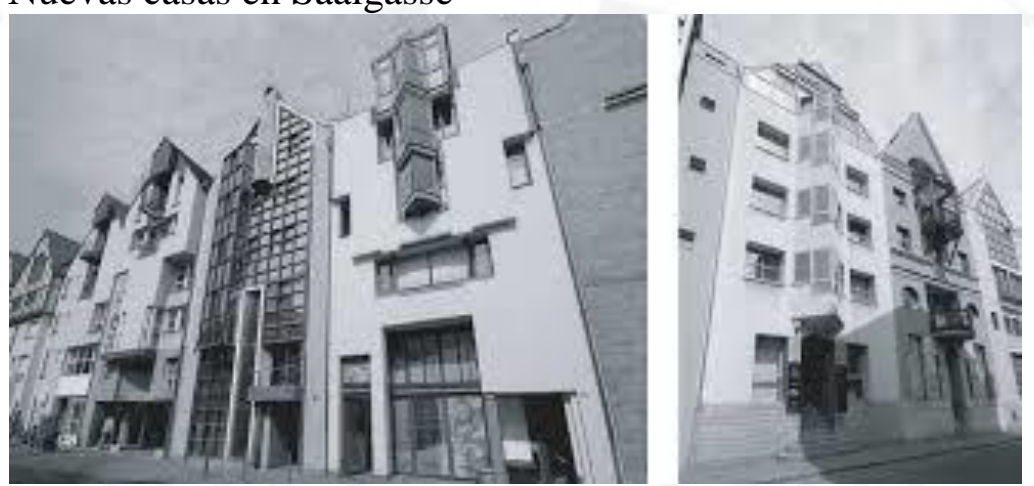

Fuente: Carevic N. y Domínguez L. (2012)

\subsubsection{Paisajes Transparentes}

La ciudad es una entidad dinámica, compleja, sometida a actividades culturales, económicas y sociales, reconocida por la experiencia sensorial dentro del espacio. El estudio de experiencias sensoriales individuales permite una reflexión de la percepción de los cambios a través de la observación.

Una persona puede elegir entre estar ausente o no relacionarse con el entorno más cercano. El espacio urbano puede llegar a ser transparente cuando carece de referencias para entenderlo o reconocerlo, por tal motivo ante un espacio urbano transparente el sujeto puede mostrar indiferencia, generando una memoria colectiva negativa, dejando sin valor a dicho lugar (Lefebvre, 1974). 
Para Henri Lefebvre ${ }^{5}$ el espacio es un producto alimentado de dos tipos de ilusiones: la ilusión de transparencia y la ilusión de opacidad. En la ilusión de transparencia está referida al pensamiento y a las reacciones mentales donde la realidad esta oculta por la actividad mental. La ilusión opaca existe por si misma sin la necesidad de pensamientos o deseos y tienen sobrecarga de significado. Lefebvre observa que el proceso de descubrimiento de una nueva realidad espacial está siempre ligado a la ilusión de transparencia. Y que desgraciadamente, aquella realidad espacial guiada y dominada por el imaginario del arte, la cultura, el dinero, el mercado, el intercambio y el poder lleva al espacio a la ilusión de opacidad (Lefebvre, 1974).

La percepción que se tiene del paisaje urbano es múltiple, no es solo es reconocido por los sentidos como el oído, la visión, tacto u olfato, sino que existe una gama multisensorial como es la generar recuerdos, sentimientos y pensamientos con respecto al lugar. La manera en cómo cada sujeto se relaciona con su entorno refleja mucho de cómo se siente emocionalmente, estos sentimientos son causados en el entorno, el paisaje es uno de ellos, donde el confort o la experiencia de estar en él puede hacer que los sujetos se sientan bien, por ejemplo estar una mañana bajo la sombra de un árbol es un caluroso día de verano, escuchar el sonido del viento entre la vegetación o encontrar un refugio natural fuera del entorno duro de la ciudad (Lacasta, 2013).

También se puede decir que la noción sobre el paisaje se relaciona con la mirada, la forma de ver, percibir, plasmar y enfocar, ya sea desde nuestros propios ojos o a través de algún dispositivo digital, o desde una distancia cercana a una a lo lejos. Esto construye en el espectador unos conceptos vinculados a los diversos territorios y lugares. Cada lugar es una escena a recordar que se aprende y se hace paisaje (Gurevich, 2017).

Según el geógrafo Joan Nogue:

El paisaje no sólo nos muestra cómo es el mundo, sino que es también una construcción, una composición de este mundo, una forma de verlo (...) Entendiendo el paisaje como una mirada, como una "manera de ver", es fácil asumir que dichas miradas acostumbran a no ser gratuitas, sino que son construidas y responden a una ideología que busca transmitir una determinada forma de apropiación del espacio. Las miradas sobre el paisaje -y el mismo paisaje- reflejan una determinada forma de organizar y experimentar el orden

\footnotetext{
${ }^{5}$ En su trabajo The Production of Space (1974)
} 
visual de los objetos geográficos en el territorio (Nogue, citado en Gurevich, 2017, p.8)

La mirada enfoca, clasifica y selecciona, no funciona como un espejo transparente ni representa objetividad y menos una herramienta neutra que produce saber. La mirada produce símbolos, imaginación, creencias y valores así mismo delimita elementos y procesos específicos. (Citado en Gurevich, 2017, p.8)

\subsubsection{Paisaje como Memoria}

El paisaje como memoria se puede entender de 2 maneras manera. Primero, está formado por interacciones y diálogos que le dan continuidad y estabilidad. Esto hace que el tiempo genere memoria a sus usuarios dándoles un significado del espacio al cual acuden. Segundo, el paisaje es memoria del territorio porque forma parte de un sistema de signos y elementos con características que pueden ser interpretadas dándole importancia a la percepción del lugar (Ojeda y Cano, 2009).

Ambas perspectivas apoyan la idea de que el paisaje puede ser un indicador del desarrollo para la comunidad con respecto al trabajo colectivo sin degradar el territorio.

La arquitecta Karina Borja de la Universidad Católica del Ecuador, afirma al paisaje como un concepto complejo pero sobre todo que es un entorno que vive y pertenece a quienes lo habitan, descansan, trabajan o pasan sobre él. Desde esa premisa hace un análisis a un barrio de la ciudad de Quito en Ecuador llamado San Isidro, el cual se caracteriza por ser habitado por poblaciones originarias nativas, migrantes del campo y mestizos. En el estudio realizado ella destaca que aún se viven las tradiciones culturales transmitidas de generación en generación, poniendo en manifiesto las culturas andinas del barrio dentro de una ciudad urbanizada, teniendo como escenario el espacio público y el paisaje, mostrando la interculturalidad del barrio que une al barrio por la fiesta a pesar de tener distintos orígenes. Las tradiciones plasmadas en el espacio público mediante ritos, bailes, cantos en el espacio público hace que se reconstruya parte de su historia y ese sentimiento le agrega valor al espacio y fortalece su identidad. Una forma de generar memoria a un espacio público es la de generar momentos, experiencias o actividades tradicionales que fortalezca la relación de ese espacio con el barrio (Ojeda y Cano, 2009). 
Por otro lado la arquitectura puede poner en valor la edificación y generar un centro para el recuerdo de la sociedad para ello se diferenciara el lugar del espacio. Primero entender el lugar como un espacio de crecimiento constante de relaciones culturales y sociales por parte de un individuo a lo largo de su vida. El lugar permite al individuo alimentarse colectivamente de una sociedad con orígenes culturales más o menos similares que habitan un mismo territorio, por lo que pueden tener lugares de encuentro en común en donde puedan compartir y manifestarse. Y Segundo, el espacio es un tema que se relaciona con la intervención y que fue modificado por el hombre, mientras que el lugar tiene una esencia más natural. ¿Cómo puede la arquitectura generar un lugar? Si lo construido constituye un espacio y lo natural un lugar. Si se ve al pasado del pasado de la arquitectura moderna se buscó una nueva técnica sincera que relacionara los principios del modernismo y la ética para que pueda ser desarrollada dentro de un mundo en constante cambio (Montestruque, 2015).

La racionalidad fue el camino para seguir el panorama constructivo enfocándose en la idea de estructura y funcionalidad, que se concentra en la técnica para desprenderle el carácter del lugar. En ese caso la imagen es la encargada de mostrar las características del lugar como fueron los proyectos desarrollados en la segunda mitad del siglo XX y donde basa la imagen como portadora de identidad y cultura. (Montestruque, 2015). En Latinoamérica la memoria es una de las condiciones más importantes antes que la técnica para volver al espíritu del lugar para recuperar un valor cultural y social (Montestruque, 2016).

Otro punto importante a tratar es el espacio como medio para recordar. $\mathrm{Su}$ característica es la de recoger la tradición moderna en cuanto a la creación de un nuevo lugar que guarda poca relación con su contexto geográfico o histórico. Estos espacios para recordar buscar vincular una construcción de la ciudad con algo histórico o importante para mantenerlo en la memoria colectiva de la comunidad. Los espacios para recordar son estructuras arquitectónicas construidas para recordar hecho o situaciones sociales o culturales pero que pueden o no guardar relación con el contexto. Muchos de estos lugares busca reforzar y resguardar tradiciones o actividades colectivas de una sociedad (Montestruque, 2016).

Es importante generar espacios con dinámica pública para mantener una memoria viva que se enfoque en el tema urbano y desarrollo cívico. Esto nuevos lugares deben 
entender los acontecimientos actuales que vive la sociedad para producir nuevas líneas de reflexión para la comunidad y la ciudad (Montestruque, 2016).

Mario Botta en una conferencia con motivo de su premiación al Premio Javier Carvajal 2014 considera que la arquitectura y memoria son dos términos que caracterizan las condiciones del espacio y tiempo, donde el arquitecto construye u organiza el espacio de la vida de las personas y de la naturaleza. La memoria es la configuración de la historia operativa, teniendo al pasado como acceso al tiempo que permite ver las posibilidades para desarrollar el presente (Botta, 2014).

Louis Kahn sugería a los arquitectos considerar al pasado como un amigo, ya que el presente es el resultado a través de la historia vivida de otras personas mediante el significado de los orígenes. El tiempo es complejo y rápido, se necesita buscar espacios de reflexión donde se debe descubrir los significados más profundos del hacer, construir y del edificar. La arquitectura es una forma expresiva que dicen cosas más allá de la función, también puede asumir aspectos metafóricos y simbólicos que persisten sobre su uso inmediato y logran ser parte de la historia de la zona a donde pertenece. Por ejemplo un territorio ya construido y luego abandonado forma una "historia" de donde se puede aprender el significado del origen del hacer (Kahn, citado en Botta, 2014, p. 97)

Es mediante los aspectos simbólicos y metafóricos que la arquitectura asume la interpretación de la sensibilidad de su tiempo. La memoria encuentra en el arte un modo silencioso de ser una condición antropológica para sugerir estrategias proyectuales. El proyecto arquitectónico exige un proceso de síntesis y está obligado a interpretar la realidad de su tiempo para reflejar la vida contemporánea. De acuerdo a ello, el territorio de la memoria encuentra en la ciudad un paradigma a través de las relaciones en el tejido urbano y la estratificación histórica (Kahn, citado en Botta, 2014, p. 97). La ciudad es el territorio preferido por la memoria por ser un habitad construido gradualmente con belleza, funcionalidad y flexibilidad. El tejido urbano resuena como expresión formal de la historia, por todas las transformaciones en estilos, tramas, formas adquiridas de la cultura de esas épocas y que actualmente se sigue edificando y diseñando sobre ellas consolidando el pasado como reconocimiento a la identidad. La memoria es un valor importante porque recuerda lo que existió, existe y seguida existiendo (Botta, 2014).

Se debe reconocer que la velocidad de las transformaciones, como las que se viven hoy en día, son proporcionales al olvido. Dicho de otra forma, a mayor velocidad, más 
olvido. Por tal motivo es importante lograr que las obras arquitectónicas contemporáneas vuelvan a encontrar las condiciones que interprete con fuerza la sensibilidad del tiempo en la que se está proyectando (Botta, 2014).

\subsubsection{El paisaje como educación}

El espacio público, al igual que el paisaje, ayuda al desarrollo cognitivo y social de los niños y niñas para permitirles tener actitudes y hábitos positivos con respecto al cuidado del medioambiente. Uno de los problemas relacionados sobre el medioambiente es la continua explotación sin regeneración de los recursos naturales, que implica el desgaste del suelo y la pérdida de biodiversidad. La falta de consciencia, los residuos sólidos y la contaminación son agentes que deterioran gradualmente nuestro entorno actualmente. En las ciudades es más común ver esto factores que degradan el medioambiente por parte de la acción del hombre, muchas de estas acciones nocivas son producto de dos aspectos el primero es la economía y segundo los cambios sociales. Estos dos aspectos están redefiniendo el concepto de medioambiente haciendo considerar tanto los aspectos naturales como aspectos sociales (Novo, 1996).

Es importante que las nuevas generaciones desarrollen consciencia en favor del medioambiente y la naturaleza, para esto es importante la participación de la educación y la familia estén presentes en los niños y niñas. Se debe de formar esta sensibilidad al entorno tanto en la escuela, en casa y desde fuera en el espacio público. Se debe reflexionar sobre el cuidado de los espacios que tienen constante contacto a los que tienen que cuidarlo y tener respeto si son espacios comunes con el resto de la población.

La educación es parte de la responsabilidad social ya que forma a las nuevas generaciones que gestionarán y habitarán las ciudades. Serán responsables de las futuras decisiones que se tomen con respecto al medio ambiente y la manera en cómo afrontar los problemas ocasionados en la ciudad (Aramburu, 1993).

Una educación con base ambiental generará un criterio consciente a los problemas que se viven en el mundo, comprendiendo a la economía y los cambios sociales, buscando soluciones ante problemas que presenten conservando el entorno. Esta educación sobre el cuidado del entorno debe ser difundida también para jóvenes y adultos y sobre todo darle más énfasis a los sectores de la sociedad en vías de consolidación para formar las bases de una sociedad más informada. 
La etapa de educación inicial se debe abordar temas como la apreciación del paisaje, obteniendo mejores resultados si se toman ejemplos directos de la vida cotidiana ya que se base en experiencias o tienen una relación directa con su entorno como el barrio, la ciudad, su casa, los parques o entornos naturales cercanos. De esta manera se busca enseñar distintas formas de paisaje y su relación uno con el otro, enseñarles que son partes de un sistema con distintos elementos que componen el entorno construido y natural, y que la acción del hombre junto a fenómenos naturales pueden modificar todo ese sistema de manera positiva o negativa. Una educación sustentada en la comprensión del paisaje tiene como objetivo educar con contenido específico, experimental y sensorial, y por otra parte crea un pensamiento reflexivo para mejorar y conservar las condiciones del lugar (Gómez, 1993).

Con el objetivo de promover una conciencia ambiental y paisajista se debe ofrecer espacios de donde aprender considerando las experiencias de la vida cotidiana. Así las escuelas pueden realizar clases vivenciales en los parques de la comunidad o realizar actividades al aire libre con la naturaleza dentro de sus instalaciones, hacer recorridos seguros a la escuela identificando el paisaje, las problemáticas y las posibles soluciones. Promover la mejora en sus capacidades para observar y analizar, ofrecer valores positivos para cuidar el paisaje fuera de la escuela y dar a entender sobre las consecuencias q tiene la intervención humana con su medio. (Gómez, 1993)

\subsubsection{Arquitectura educativa del estructuralismo holandés}

El estructuralismo holandés es uno de movimientos modernos más importantes de la tercera generación de arquitectos modernos que pertenecientes del Congreso Internacional de Arquitectura Moderna (CIAM) conocidos como el "Team X". (Acosta, 2009) Este movimiento resalta por tener una óptica antropológica estructural, a diferencia de una visión analítica y funcional de las cuales se basaban las primeras generaciones que enfocaban la arquitectura y la ciudad. Entre los arquitectos que resaltan se encuentran Van Eyck y Herman Hertzberger, quienes usan el concepto del tejido arquitectónico, el primero se refiere a la diferencia entre la escala arquitectónica y la escala urbana de esta manera:

Es mejor decir que una hoja es un árbol, que decir que una casa es una ciudad, porque inmediatamente esto nos congela la jerarquía de dimensiones; todas las 
cosas deben tener una escala humana, o puede ser también inhumana (Van Eyck, 1992)

El arquitecto holandés Aldo van Eyck entre los años de 1959 y 1967, pudo difundir sus ideas sobre el abandono de la idea funcionalista de la arquitectura moderna y retornar a los conceptos antropológico-estructuralistas para el diseño de nuevos espacios de la arquitectura, estas ideas serían de base y motivación para el arquitecto holandés Herman Hertzberger. Un primer proyecto que desarrolló fue el "Playgrounds" que en español se refiere a los parques de recreo de los niños ya que considera que la educación preescolar y en la vida de los niños y niñas, el juego es una actividad importante para su proceso de aprendizaje tanto académico como social, ya que realizando las actividades por sí mismos es una manera de aprender y descubrir el mundo. Por ese motivo se consideró necesario incluir los playgrounds o parques de juego en el diseño arquitectónico dentro de las escuelas o espacios públicos. Aunque ese proyecto no fue planteado para un colegio, si fue pensado como parte de sus proyectos de "arquitectura para la infancia" como un aporte importante para las áreas de recreo y también para las mismas aulas que luego propondría Hertzberger (Marín Acosta, 2009).

En Ámsterdam, entre las décadas del 1950 y del 1970, Van Eyck diseñó más de 700 parques de juegos y fuera de la ciudad se implementaron parques de juegos con características similares. Estos nuevos espacios diseñados eran trabajos tipo ejercicio sobre la composición no jerárquica dentro del entorno, resaltando la igualdad de condiciones al elegir la composición de elementos como las bancas, los árboles, formas de bordes y piedras de diferentes tamaños, colores y formas. Los pasamanos metálicos que diseño para estos espacios de juego, por ejemplo, tenían el mismo estatus, estaban resaltadas en los areneros y el concreto del pavimento.

Una de las iniciativas que se tomó al respecto la ubicación de estos espacios de juegos era de hacer una regeneración a unos espacios vacíos dentro de la ciudad de Ámsterdam además de reutilizar espacios abandonados o parques en desuso para que miles niños puedan disfrutar a diario junto a sus familias (Marín Acosta, 2009).

El objetivo de estos nuevos espacios de juego para niños es considerar al infante como un individuo autónomo, con la libertad de desplazarse por el espacio descubriendo nuevas experiencias y puedan enfocarse en sí mismo y generar relaciones con otros niños para mejorar sus habilidades sociales. En estos nuevos espacios públicos no existe una 
jerarquía espacial, ya que cada lugar es considerado importante para explorar, por tal motivo todo espacio donde el niño este, es una experiencia enriquecedora para él. Así como en casa se encuentra con toda la libertad y movilidad combinado con la imaginación de sus juegos y ocurrencias, ellos mismos imaginan y crean sus propios juegos a través del espacio y la percepción del mismo para motivar su imaginación (Marín Acosta, 2009).

Entre los años 1960 y 1966, Herman Hertzberger hizo el proyecto de la Escuela Montessori en la ciudad de Delf, en Holanda. En ese proyecto el arquitecto holandés usa intenciones inspiradas de los parques de juegos de Aldo Van Eyck para el diseño arquitectónico, entre las ideas se destacan las siguientes: (Hertzberger, 2001)

- Coloca al usuario como el principal factor para las decisiones de diseño.

- Los espacios y detalles arquitectónicos se adaptan de acuedo a su escala.

- Para el diseño de los ambientes se prioriza la versatilidad para motivar a la creatividad y diversidad de las clases.

- Los ambientes del edificio puede funcionar de manera independiente, generando a su vez que estos se abran al exterior mediante patios exteriores para ampliar el espacio.

- El proyecto corresponde a un contexto urbano y su forma espacial no cuenta con jerarquías formales o espaciales para reflejar la importancia de todos los espacios educativos como tal.

- La versatilidad de los ambientes permite adaptarse a distintas necesidades, ya sea para grupos pequeños o grandes, adaptan también el espacio a uno cerrado o parcialmente abierto con acceso al exterior.

Hertzberger también se basa en las teorías de María Montessori para proponer las aulas de las cuales tienen base pedagógica que lo mezcla son sus ideas sobre arquitectura educativa logrando así un proyecto completo superando las expectativas de los holandeses (Hertzberger, 2001).

En el diseño propuesto los salones funcionan como unidades autónomas, como si fueran pequeñas viviendas a lo largo del colegio emulando una calle que unifica todo. Los profesores son los responsables de los niños y juntos deciden cómo será la atmósfera del día. Ellos configuran su propio espacio tanto al interior como al exterior. No existen salones determinados para cada grado escolar, el espacio se apropia acorde al placer que se percibe de él. Los alumnos pueden estar trabajando en una esquina, otros mirando al 
exterior al mismo tiempo, no existe interferencias y generan una diversidad de actividades controladas por el profesor del curso. Les dan la libertad de escoger cuál es su forma más óptima de concentrarse y aprender.

Una característica resaltante del proyecto es la autosuficiencia de cada bloque, teniendo sus propios baños, salones, espacios de trabajo, biblioteca, cocina, laboratorios y todo aquello que esté disponible para desarrollar sus actividades necesarias y los estudiantes puedan aprender con el ambiente circundante. De esta manera la arquitectura y el mobiliario motivan a los niños a tener distintos grados de experiencias que motiven a su crecimiento personal, social y educativo del día a día.

Los proyectos educativos desarrollados usan materiales y sistemas convencionales para construir de la arquitectura, por ejemplo el uso del concreto y la madera permiten la neutralidad suficiente para que los niños puedan descubrir el entorno y usar su imaginación. (Marín Acosta, 2009)

\subsection{Clasificación de Centros Comunales}

\subsubsection{Clasificación según su rol}

\subsubsection{Centros comunales orientados a la educación}

Un Centro comunal tiene como uno de sus objetivos dar el servicio y el acceso a la educación y el brindar conocimiento a la comunidad, como son los Centros de Cultura, Recreación y Educación Ambiental (CREA) en algunos Parques Zonales de Lima. Los Centros Comunales brindan muchos servicios y actividades que incluye el acceso a distintas tecnologías de la información y comunicación para que el individuo pueda desarrollarse personal y colectivamente.

Actualmente la educación va relacionada al uso de nuevas tecnologías de la información como es la educación continua o el acceso a internet, que día a día va creciendo la demanda por ser un medio de aprendizaje a distancia. Esto se debe a que la sociedad se encuentra en constante cambio y que busca mantenerse al día mediante distintas fuentes de información en diferentes plataformas que brindan flexibilidad y adaptabilidad a las distintas necesidades educativas. Es necesario entender estas 
necesidades tecnológicas para lugares de bajos recursos para que puedan plantearse nuevas estrategias de diseño de espacios de aprendizaje comunales.

Es importante brindar educación de calidad usando medios tecnológicos y otros medios alternativos para la búsqueda de información y agilizar el aprendizaje de las personas (Arrabal, Pérez, y Salinas, 2000).

Los tipos de espacios para centros comunales que son de apoyo para el aprendizaje en puntos céntricos de la ciudad son:

1. Aulas tradicionales. Son las aulas de tipo normal donde se llevan a cabo la mayoría de los procesos de aprendizaje del común de los estudiantes. En estos espacios se puede llevar a cabo las lecciones usando una computadora con acceso a internet que puede ser utilizada por alumnos y profesores, generando nuevas oportunidades de aprendizaje. Los espacios tradicionales tiene un alto potencial, por poder adaptarse al uso que le quieran dar los maestros, de esta manera el espacio, el uso de materiales y distintos recursos para hacer interactiva la clase son recursos complementarios para distintas actividades (Arrabal, Pérez, y Salinas, 2000, pp. 3-4).

2. Aulas taller. Son considerados como laboratorios orientados a un uso especifico. Son espacios acondicionados para realizar tareas con un nivel de complejidad alto, donde se requieren otras tecnologías. Algunas de las actividades requieren de material didáctico multimedia, así como otros programas, etc. Por tal motivo se necesita contar con equipos preparados que cumplan con el desarrollo apropiado y fluido de la clase (Arrabal, Pérez, y Salinas, 2000, pp. 3-4).

3. Aulas de usuarios. Estos espacios prometen un servicio más flexible y abierto. Cuentan con un número determinados de equipos interconectados a una red y cuentan con lo necesario para que cualquier usuario, cual sea su necesidad, puedan hacer uso de ella. Son espacios de libre acceso que pueden tener o no un asesor como un profesor que pueda apoyar, son ideales para desarrollar tareas o para hacer consultas en internet. Tambien pueden ser espacios para clases con consulta multimedia y actividades interactivas. (Arrabal, Pérez, y Salinas, 2000, pp. 3-4)

Colombia ha desarrollado algunos avances con respecto a este tipo de centros, como aquellos que brindan servicios educativos son los centros que pertenecen a la Red de Bibliotecas de Medellín, también conocidos como Parques Biblioteca que operan en los lugares más vulnerables de la ciudad para lograr distintos centros para el desarrollo 
integral, cultural e incluyente de los barrios que las rodean. Estos parques al igual que sus programas son gestionados, administrados y operados por organizaciones públicas y privadas desde el año 2004. Estos proyectos sociales y comunitarios son considerados como espacios que transforman la zona urbana teniendo 3 pilares importantes: la educación, la sociedad y la cultura. (Peña, 2011)

A nivel educativo, los ciudadanos acceden al conocimiento mediante el uso de recursos presenciales y virtuales con apoyo de programas creados para una constante enseñanza. Algunos de los servicios son los programas lúdicos para los niños y de asesoría para el emprendimiento de los jóvenes y adultos. También para de sus servicios educativos se clasifican en:

1. Gestión de información: Ofrecen acceso a bases de datos, a información local y de distintas instituciones así como a una amplia gama de colecciones en distintos temas.

2. Servicios de información: servicio de asesorías especializadas y de préstamo de documentación.

3. Servicios de formación de usuarios: Visitas guiadas, clases de inducción y de enseñanza en herramientas tecnológicas para búsqueda y creación de información.

4. Servicios de promoción de lectura y escritura: Programas de lectura para todas las edades, desde bebes, nichos, adultos, adultos mayores y personas con discapacidades físicas y cognitivas.

5. Servicio de extensión bibliotecaria: ofrecen el convenio con otros grupos educativos, culturales y asesorías.

6. Unidades de información como agencias de prácticas sociales: servicio social para estudiantes y voluntarios.

\subsubsection{Centros comunales orientados al desarrollo empresarial}

Se sabe que los sistemas locales de empresas juegan un papel relevante en los procesos de crecimiento y cambio estructural urbano, debido a que impulsan el crecimiento y el desarrollo económico. Además, las iniciativas locales se han convertido en una de las formas preferidas de la política de desarrollo, generando capacitaciones, asesorías y charlas para generar nuevos empleos, desarrollar ideas de emprendimiento y mejorar el mercado de oportunidades entre la comunidad (Vázquez, 2000 p. 3). 
En algunos países de América Latina, se están implementando servicios que apoyan a los emprendedores a desarrollar sus ideas para generar empresas, algunas son financiadas por entidades privadas, como universidades, instituciones civiles sin fines de lucro u organismos privados que fomentan el desarrollo y la investigación. Así mismo el Estado también interviene generando programas para el desarrollo empresarial o incubadora de empresa, estas iniciativas públicas ofrecen una serie de servicios al público en general con ideas y motivaciones de generar empresa. Algunas de estos programas se encuentran operando en zonas en consolidación para que los mismos pobladores tengan la oportunidad de crecer y prosperar en sus propias ciudades sin tener que alejar de donde viven y de sus familias. Es de gran ayuda para personas de bajos recursos para que también puedan ser parte del desarrollo económico y aportar a la comunidad. Uno de los casos más resaltantes es el caso de los Centros de Desarrollo Empresarial Zonal (CEDEZO) en Medellín, Colombia. (CEDEZO Centro, 2010)

Los CEDEZO son un programa diseñado por la Alcaldía de Medellín como un articulador de iniciativas orientadas al apoyo del emprendimiento, la generación de ingresos, el desarrollo la consolidación de familias y microempresas de la ciudad; contribuyendo al desarrollo económico del territorio zonal y generando inversiones en distintos puntos y articulando estos lugares a zonas más consolidadas. Los objetivos de estos centros son satisfacer las necesidades específicas de emprendedores y empresarios de los distintos puntos de la ciudad con actividades de formación, asesoría, dando crédito y dándoles acceso al mercado local. También buscan generar nuevas unidades económicas para satisfacer la demanda del mercado. Estos centros de desarrollo generan un espacio de encuentro empresarial del sector público y la empresa privada, representado mediante organismos e instituciones educativas como universidades orientado al desarrollo empresarial. Ofrece varios servicios pero se basan en dos líneas, la primera es el apoyo al emprendimiento e ideas, y la segunda, al fortalecimiento a las pequeñas empresas existentes, mediante programas, proyectos y actividades como: capacitaciones, asesorías personalizadas, red de microcrédito, apoyo a la comercialización, reuniones empresariales, visitas empresariales, guías empresariales, chalas, conferencias y talleres empresariales. (CEDEZO Centro, 2010)

Estos programas están abiertos a todas las personas que tengan negocios o ideas de negocio claras, y solo deben acercarse al CEDEZO de su comunidad. Tienen el propósito de favorecer a las personas de cualquier estrato social y tienen el apoyo de la 
Alcaldía de Medellín, a través de la Secretaria de Desarrollo Social, cuenta con el programa Banco de los Pobres, el cual busca otorgar alternativas de financiamiento con créditos pequeños y que pueden pagarse de varias maneras de una forma flexible facilitando así la oportunidad de tener nuevos ingresos para mejorar la calidad de vida de las comunidades del municipio de Medellín (CEDEZO Centro, 2010).

Un punto importante es la participación de la mujer para el desarrollo de una sociedad más justa y equitativa, considerando que el Perú cuenta con 3 programas apoyados por el Estado que promueven el emprendimiento femenino. El Perú tiene la tasa de emprendedoras más alta de la región pese al poco respaldo por parte del Estado (ASEP, 2017). Si se compara con otros países que forman parte de la Alianza del Pacífico, Colombia lidera con 23 programas, Chile con 14 y México con 11 según los indican los "Programas de apoyo al emprendimiento femenino en la Alianza del Pacífico" presentado por la Asociación de Emprendedores del Perú (ASEP) y el Observatorio Estratégico de la Alianza del Pacífico, Mujeres del Pacífico y la Asociación de Emprendedores de Latinoamérica- ASELA. (PQS, 2017)

Como ya se mencionó anteriormente, el Perú lidera dentro de los países de la Alianza del Pacífico en tener mayor participación de emprendimiento femenino. Según la Tasa de Actividad Emprendora (TEA), el Perú cuenta con un 22.9\% de mujeres emprendedoras, seguido de Chile con 19.6\%, luego Colombia con 18.2\% y México con 11.9\%. (ASEP, 2019)

Los 3 programas que apoyan el emprendimiento femenino por parte del Estado son:

1. Municipalidad de Miraflores con el programa Emprende Mujer, donde brindan talleres dirigidos a las mujeres con el propósito de apoyarlas en temas de liderazgo, oratoria y empoderamiento. También ofrecen asesorías para el desarrollo de ideas de negocio (PQS, 2017).

2. Ministerio de la Producción cuenta con los Centros de Desarrollo Empresarial, que brindan atención gratuita, teniendo alianza con instituciones públicas y privadas a nivel nacional. Se dan asesorías y asistencia técnica (PQS, 2017).

3. Ministerio de Trabajo y Promoción del Empleo cuenta con el programa Perú Responsable que es fomentada por La Responsabilidad Social Empresarial (RSE) que implementa proyectos del sector privado con el Estado. Este programa va 
enfocado a jóvenes, madres solteras, personas con habilidades diferentes y mujeres víctimas de violencia (PQS, 2017).

\subsubsection{Centros comunales orientados a la cultura}

Las prácticas artísticas colaborativas desarrollan en la comunidad un proceso colectivo que genera conocimiento, ya que es una manera de compartir experiencias y promover distintas tradiciones culturales. De esta manera las prácticas artísticas como el teatro, el canto, la danza y la pintura quedan concentradas en espacios culturales donde pueden ir a aprender ya sean manifestaciones culturales propias de su comunidad o algunas otras que quieran ser enseñadas. Estos espacios son de carácter público, dirigido por profesionales, artistas y voluntarios para promover la participación de la comunidad, para crear sociedades más conscientes de su cultura o promover las actividades culturales y/o artísticas para educar a los jóvenes y alejarlos de actividades negativas y de vicios negativos. De este modo, se piensa de estos talleres artísticos colaborativos como plataformas de producción y de difusión de conocimientos donde se involucran distintos organismos y personas. Combinan la producción cultural, la comunicación, la difusión y la educación desde una perspectiva abierta e inclusiva y con un marcado carácter social, vinculado y generando la participación de la comunidad. (Collados-Alcaide, 2013 p. 92).

Los espacios comunales culturales urbanos, orientados a la participación, se encuentran en lugares céntricos de las ciudades o comunidades, cerca de una avenida o ruta principal para que todos tengan un fácil acceso a estos espacios culturalesrecreativos. Por ejemplo en algunas zonas de Argentina se tienen espacios culturales sociales donde brindan obras de teatro los fines de semana, eventos musicales, muestras de arte, talleres artísticos para jóvenes y adultos, clases de acrobacias, bailes, gimnasia, así mismo también tiene espacios para alquilar por si alguna institución o grupo grande quieran hacer uso de las instalaciones y cuentan con todos los servicios necesarios para que puedan desarrollar sus actividades como wi-fi, escenario, equipos de sonido y de iluminación. El espacio cultural también ofrece clases de teatro, danza y pintura dirigida por profesionales voluntarios, o personal financiado por las municipalidades u ONG. Además de las actividades culturales mencionadas se hacen charlas motivacionales, desarrollo de expresión en público y mejora del autoestima con actividades recreativas mediante el juego y la participación, de esta manera se genera una sociedad más 
involucrada al arte y la cultura, para que todos tengan acceso al conocimiento y crean una fortaleza sobre su cultura (Pascal-Burga, 2015).

En Lima existe un programa controlado por la Municipalidad Metropolitana de Lima (MML) llamado Cultura Viva Comunitaria que a través de expresiones artísticas y culturales permite la integración y la participación de la comunidad. Tiene el objetivo de mejorar con el desarrollo local y apuntar a una paz social en articulación con organizaciones sociales culturales existentes en la ciudad, apuntan también a la recuperación de espacios públicos y del acceso a las distintas actividades culturales. Algunos de los promotores a estos programas son gestores culturales, artistas, dirigentes sociales, profesionales, estudiantes y miembros de la comunidad que aportan de manera organizada y se comprometen a fortalecer a los grupos culturales existentes. Los trabajos de los grupos que pertenecen al programa aportan a la reducción de la violencia y la delincuencia en muchos barrios, donde niños y jóvenes encuentran el espacio para compartir con otros, la colectividad y la solidaridad son base para el desarrollo óptimo de las actividades. (Cultura Viva Comunitaria, 2018)

Actualmente el programa se encuentra desarrollando las siguientes actividades:

- Fiesta Cultural donde reúne a la población a ser parte de distintas actividades culturales dirigidas por las distintas agrupaciones, ofrecen talleres didácticos con materiales económicos para niños, jóvenes y adultos. La concentración es en un espacio público y dura un día.

- Caravana de la Cultura es una actividad que reúne a los grupos culturales y realizan visitas programa a distintas instituciones públicas o privabas para fomentar la cultura y los distintos talleres que ofrecen.

- Concurso de Proyectos de Arte y Comunidad que brinda apoyo económico a organizaciones comunitarias con proyectos culturales que valoricen la identidad local así como las que promuevan la cooperación y el dialogo para lograr un desarrollo social.

- Apoyo a iniciativas culturales locales.

El Ministerio de Cultura tiene una iniciativa llamada "Puntos de Cultura" que desde el 2011 busca promover las actividades culturales a nivel comunitario, con énfasis en la infancia, jóvenes y poblaciones vulnerables. De esta manera buscan la inclusión, la interculturalidad y el empoderamiento, creando una red nacional con las organizaciones 
sociales que mantienen un trabajo constante que contribuyan al arte y la cultura de manera individual o comunitaria. (Ministerio de Cultura, 2013)

Un Punto de Cultura es toda organización, cooperativa, colectivo, asociación o agrupación cultural sin fines de lucro que se encuentre registrada y reconocida por el Ministerio de Cultura, que promueva y/o desarrolle iniciativas considerando al arte y la cultura como las principales herramientas para mejorar a una sociedad con diversidad, democracia, memoria y creativa. (Ministerio de Cultura, 2013)

Los beneficios que tienen las organizaciones que pertenecen a esta iniciativa son:

- Reconocimiento y protagonismo: son parte de una gestión participativa bajo criterios de co-responsabilidad. Tienen cobertura y difusión de las actividades que ofrecen a través de medios de comunicación.

- Co-gestión de proyectos: El Ministerio de Cultura se compromete a desarrollar condiciones y mecanismos para la ejecución de los proyectos, dirigiendo recursos humanos y organizando la logística.

- Fortalecimiento de capacidades y gestión del conocimiento: Apoyan al desarrollo de capacitaciones, talleres y estrategias para mejorar la calidad de los servicios ofrecidos y obtener mejores resultados. Promueven la comunicación con distintos Puntos de Cultura y otros agentes culturales para intercambiar puntos de vista, estrategias y ampliar el impacto con la ciudadanía.

- Articulación y comunicación: Hacen un fortalecimiento a la Red de Puntos de Cultura mediante la difusión de su participación en la sociedad, también generan espacios para el intercambio y encuentro de sus miembros.

\subsubsection{Clasificación según financiamiento}

\subsubsection{Programas del Estado}

El Estado Peruano tiene el deber de brindar servicios de calidad y de apoyo a toda la población, por lo que crea distintos ministerios que coordinan y promueven la participación y concentración social para lograr un país más próspero, justo, democrático, descentralizado, moderno y ambientalmente sano, donde los ciudadanos tengan una buena calidad de vida. Estos ministerios se desarrollan en distintos ámbitos y cumplen políticas multisectoriales mediante un marco de ética, responsabilidad y eficiencia. El 
estado financia los ministerios, y estos se encargan de desarrollar y mantener en rumbo los programas de ayuda social como la construcción de centros comunales, donde diversos programas a nivel educativo, salud y vivienda se llegan a desarrollar (Presidencia del Consejos de Ministros PCM, 2015).

\subsubsection{Organizaciones privadas sin fines de lucro:}

Las organizaciones sin fines de lucros usan sus ingresos y utilidades para mejorar como empresa y brindar mejores servicios a sus usuarios y clientes. Algunas empresas se dedican a brindar servicio social sin tener el fin de lucrar sino para llevar oportunidades a quienes no la tienen. Una de estas empresas sin fines de lucro es NESsT Perú, que desarrolla empresas sociales sostenibles para resolver problemas sociales en países emergentes como el Perú. Desde 1997 NESsT ha desarrollado empresas socialmente sostenibles desde su planificación hasta su puesta en marcha, donde utilizan un enfoque multidisciplinario que incluye inversiones financieras, apoyos de capacidades y capital social. Para que sus programas de apoyo tengan inversionistas y aliados nacionales e internacionales, cuentan con una inversión de capital en forma de subvenciones y créditos bancarios para apoyar los diferentes programas. Tiene el objetivo de apoyar a largo plazo a estas empresas sociales de alto impacto para las comunidades. En el impacto que genera se puede destacar la inclusión laboral, donde las empresas dirigidas a los grupos excluidos adquieren un empleo, formación y colocación laboral. Las poblaciones objetivo incluyen a los jóvenes en situaciones de riesgo, minorías étnicas, personas con discapacidad y otras poblaciones excluidas del ámbito laboral. Otro impacto importante son los ingresos sostenibles que gracias a estas empresas que pueden operar en coordinación o asociación de productores para aumentar los ingresos de sus miembros, las poblaciones objetivos incluyen a los artesanos, pequeños agricultores y microempresarios. Las tecnologías asequibles es otro impacto de las empresas que comercializan con energías renovables, para mejorar sus ingresos y la calidad de vida de las comunidades de ingresos bajos, las poblaciones objetivo son las comunidades que no tienen acceso a servicios básicos que satisfagan sus necesidades (NESsT Perú, 2016). 


\subsubsection{Organización No Gubernamental (ONG)}

Es una organización de iniciativa social, independiente de la administración pública, que se dedica a actividades humanitarias, sin fines de lucro. (Real Academia Española RAE, 2016).

Al igual que las organizaciones sin fines de lucro, el financiamiento suele ser un problema. Algunas se apoyan con sus socios o del trabajo voluntario. Pero las fuentes tradicionales de las ONG para financiar sus proyectos sociales son: Cuotas de socios, que sirven muy bien en pequeñas organizaciones. Ingresos por servicios ya sea por alojamiento, talleres, educación, alquiler, etc. Donaciones que dependen mucho de la capacidad de recaudación de la organización y de sus miembros. Patrocinios que se logran juntándose con una empresa y generalmente son la mejor opción ya que muchas empresas buscan mejorar su imagen por lo que apoyan a una ONG o brindan servicios por su responsabilidad social colaborando a la misma ONG. Algunas ONG también provienen del extranjero y se financian con capital extranjero. (Soyentrepreneur, 2009)

Figura 3.4

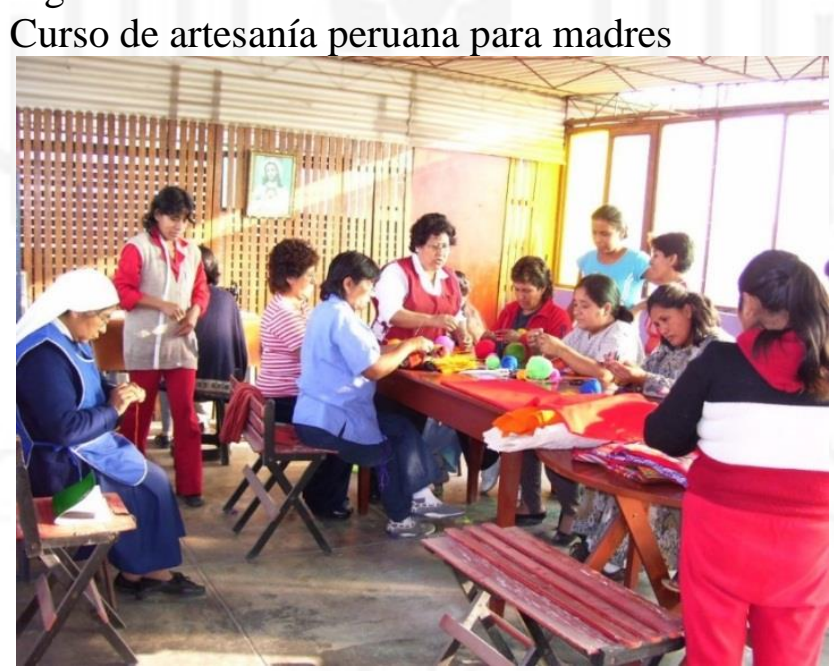

Fuente: Mi Perú (2007)

\subsection{Clasificación de centros comunales orientados a la educación}

\subsubsection{Espacios educativos no tradicionales}

Una de las tipologías propuestas para los centros comunales es la incorporación de los espacios no tradicionales para el aprendizaje y la participación de sus usuarios en 
actividades educativas o en talleres creativos. La idea principal es generar condiciones alternativas a las convencionales, dejar los espacios repetidos y enfocarse en como facilitar las relaciones grupales para así favorecer el desarrollo de las potencialidades de los niños u otros usuarios. La organización del espacio debe ser estimulante y flexible para favorecer el aprendizaje, un sistema repetitivo como el tradicional conlleva a que muchos jóvenes se aburran o pierdan el interés. Modificar la manera de estar en el espacio estimula la creatividad, así se podrá trabajar eficazmente en grupo donde se reúnan en círculos y puedan compartir una experiencia participativa grupal. El espacio debe atraer la atención del usuario y debe cumplir con las actividades grupales, a diferencia de los espacios tradicionales estos deben de tener visuales a otros espacio de acción para motivar a los usuarios a estar en actividad constante, tanto en la participación como en el desarrollo de los talleres, así mismo deben ser espacios flexibles con conexión a distintos ambientes. Así mismo estos espacios deben ser flexibles, generar múltiples visuales, generar relaciones espaciales que estimulen la creatividad de los asistentes (ver Figura 3.5) (Durantini-Villarino, 2014)

Figura 3. 5

Espacios no tradicionales para el aprendizaje

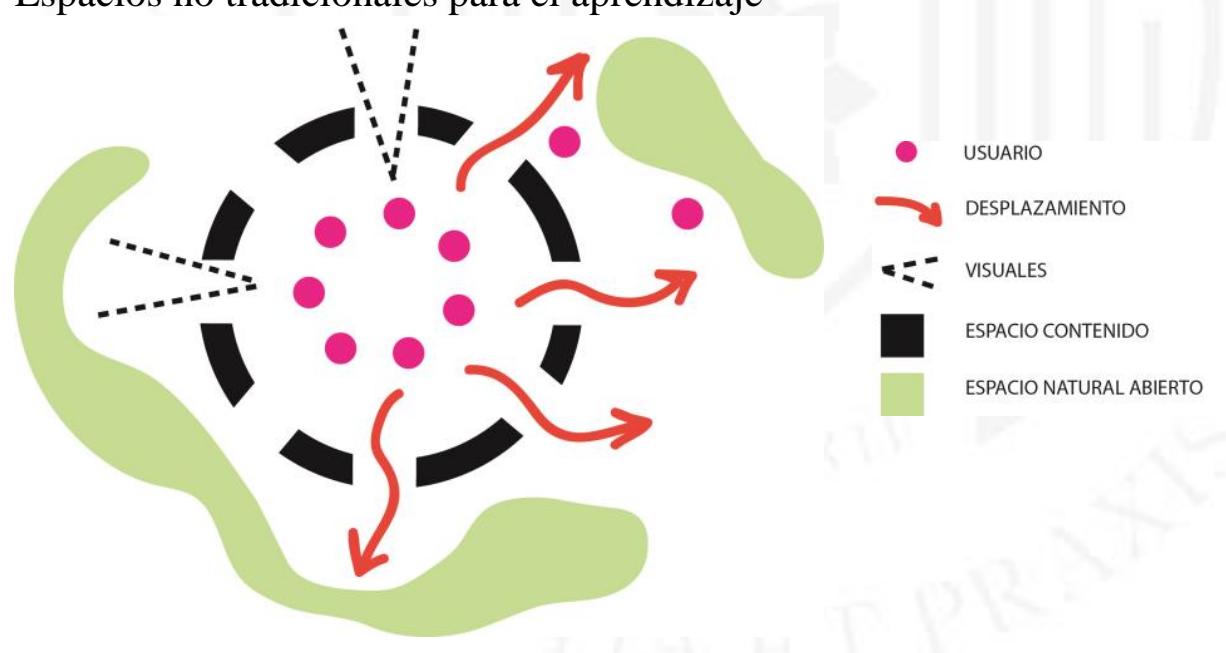

Fuente: Elaboración propia. (2016)

\subsubsection{Espacios educativos que abren al exterior}

Otra tipología planteada para optimizar los resultados de un centro comunitario orientado a talleres participativos son la implementación de espacios al exterior, donde los usuarios tienen un contacto más directo con su medio inmediato, ya sea urbano o natural, donde pueden realizar actividades al aire libre y aprender mediante la experiencia adquirida en 
el exterior, estos espacios deben dar la oportunidad de tener una organización diferente para cada día, con actividades flexibles que se puedan realizar al aire libre o dentro de local. Por ejemplo son ideales para talleres de capacitación o de enseñanza técnica ya sea para la agricultura, o talleres artísticos como el yoga o la danza. Estos espacios deberán de dar la sensación de estar en contacto directo al exterior, no debe ser un espacio de cuatro paredes con pocas visuales o reducida conexiones, por el contrario se debe de concentrar más en el espacio natural ya que el pilar del aprendizaje está en la vivencia del usuario con su medio inmediato. Los espacios comunales, al tener conexión con patios o al exterior generan espacios que favorecen el desarrollo de actividades al aire libre como clases vivenciales en agricultura o juegos, así mismo al abrirse mejora la iluminación y ventilación. (Navarro, Ochoa y Esparza, 2014 p. 56) (Ver Figura 3.6).

Figura 3.6

Espacios exteriores para el aprendizaje

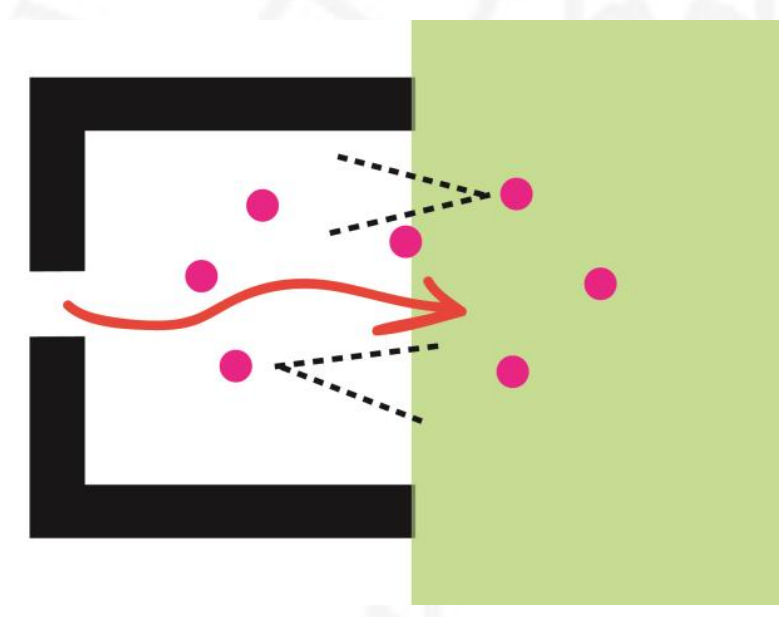

- USUARIO

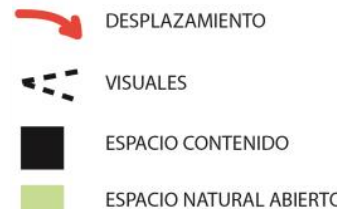

Fuente: Elaboración propia. (2016)

\subsubsection{Espacios educativos móviles}

Son espacios híbridos dentro de una comunidad o espacio natural, que promueven el desarrollo participativo, está formado por módulos móviles prefabricados y que pueden ser trasladados en distintos puntos de una misma zona de intervención. Estos módulos individuales son apoyados por educadores, artistas, científicos, voluntarios y técnicos. Estos espacios tienen la finalidad de reinventar la forma de producción y difusión de la cultura mediante la colaboración artística y social. Estos espacios pueden tener distintos enfoques. Se consideran como espacios sin muros ya que son espacios permeables con relación directa con el exterior. En estos espacios existe una comunicación directa entre 
los usuarios, quieres aprenden sobre la cultura y ciencias mediante la observación y la experiencia. Estos espacios también se pueden convertir en módulos de recopilación de información usando las nuevas tecnologías de la información como talleres de computación, laboratorios, salas de video o talleres que puede abrirse al aire libre. Finalmente los espacios también pueden ser móviles y desmontables, diseñados para adaptarse a las condiciones naturales del lugar, son ideales para lugares alejados de las ciudades para desarrollar proyectos colaborativos, también pueden ser módulos rotativos que van regresando a las distintas zonas cada cierto tiempo, ya sea para recopilar información del desarrollo y mejora de la calidad de vida o para ofrecer nuevos talleres. (Collados-Alcaide, 2013) (Ver figura 3.7)

Figura 3.7

Espacios móviles para el aprendizaje

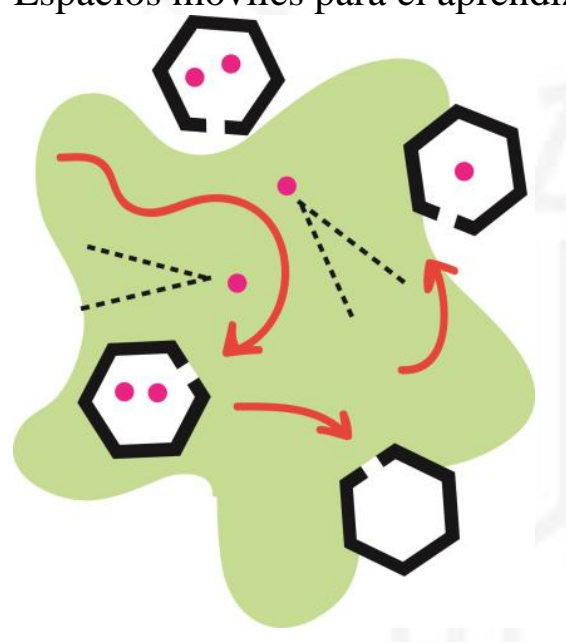

USUARIO

DESPLAZAMIENTO

$\because=$ VISUALES

ESPACIO CONTENIDO

ESPACIO NATURAL ABIERTO

Fuente: Elaboración propia. (2016)

\subsection{Base conceptual}

\subsubsection{Espacio público}

El espacio público tiene un concepto jurídico que abarca una regulación por parte de la administración pública, un propietario u grupo privado que garantizan la accesibilidad para todos y brinda tanto servicios como actividades en el espacio. El espacio público también tiene una relevancia sociocultural donde las personas se identifican y se relacionan, se presentan distintas manifestaciones de carácter comunitario buscando integrar a todos sus asistentes. La misma dinámica de una ciudad y su población pueden generar espacios públicos que jurídicamente no lo son o que no se plantearon con ese fin, 
pueden ser espacios abiertos o cerrados, como depósitos abandonados, espacios vacíos dentro de la trama urbana o paraderos de transporte público (Jiménez, 2000).

Es espacio público de uso social colectivo y multifuncional, teniendo como característica principal la accesibilidad y posible centralidad en algunos lugares. Un espacio público se evalúa de acuerdo a la intensidad y la calidad de las relaciones sociales que facilita como en las actividades que se realizan en el o la capacidad que tiene para estimular la identidad, la expresión y la integración cultural. Por tal motivo es importante que el espacio tenga un diseño continuo con relación al urbano, la capacidad de gestionarse y ordenarse por sí mismo, tener una escala humana, mantener una forma, imagen agradables, uso adecuado de materiales y que su adaptabilidad sea constante a lo largo del tiempo (Jiménez, 2000).

El espacio público también crea ciudad, es un lugar común donde la población hace uso del espacio para desarrollar actividades de distinto ámbito y su valor depende mucho de cómo este lugar mezcla a los grupos e influye su comportamiento. También es considerado como el reflejo de la ciudad y el que une a los barrios ya que son todos los lugares de encuentro con dinámicas como parques, plazas, losas donde pueden ejercer su derecho de vivir en la ciudad (Borja, 1998).

La ciudad es el lugar de encuentro por excelencia, donde la cantidad y la calidad de espacios públicos peatonales ofrecidos determinan su calidad urbanística. Jan Gehl define a un espacio público adecuado como el lugar donde ocurren muchas actividades no indispensables, que son las actividades destinadas al disfrute del usuario. Jan Gehl también indica que la ciudad debe tener características que propicien el contacto con otros y humanizar el espacio, ya sea caminar, ver a la gente, compartir con ellos, etc. La ciudad es un medio para una manera de vivir (Gehl, Peñaloza, Pozuela, Sainz y Valcarce, 2015, p. 7.).

Los espacios públicos deben ser atractivos y capaces de albergar una vida social rica y segura. Los espacios públicos tienen tres categorías de acuerdo a su nivel de actividades: actividades necesarias, actividades opcionales y actividades sociales.

Las actividades necesarias son aquellas obligatorias como ir al colegio o al trabajo, esperar el transporte público, son todas las actividades que se desarrollan fuera del espacio privado, de forma indefectible. 
Los espacios opcionales albergan actividades donde existe un deseo de hacerlo o si lo permiten el tiempo y el lugar como por ejemplo, pasear para tomar aire fresco, tomar el sol, sentarse a leer, etc. Son todas esas actividades que solo se realizan cuando las condiciones externas como el tiempo y el lugar invitar hacerlo. Cabe resaltar que cuando el espacio público es de baja calidad, los usuarios solo se limitan a las actividades obligatorias.

Las actividades sociales son todas las que dependen de la presencia de otras personas en el espacio público y que involucran la interacción entre sujetos, como puede ser participar en los juegos infantiles, saludar, hacer una conversación, realizar actividades grupales, ver, oír a otras personas, etc. Estas actividades son en su mayoría derivan de las primeras dos categorías. Estas se producen de manera espontánea, las actividades sociales son el refuerzo indirecto de las actividades necesarias y opcionales vistas más frecuentemente en óptimos espacios de encuentro.

Los espacios públicos son una oportunidad para ver y oír a otras personas ya sea en la ciudad o en los barrios, siempre se ofrece y se encuentra una valiosa fuente de información sobre el entorno social. En ella se puede deducir como las personas se comportan, se visten, que consumen, que pueden estar pensando, que opinan, que sueñan, etc. Con esa información de las personal del entorno se puede generar distintos niveles de confianza que permitirán regresar o no a ese espacio.

Las actividades de ver y oír a los demás también pueden ayudar a tener ideas e inspirar para hacer algunas actividades. El ser humano se inspira cuando ve a otros en acción. Por ejemplo si los niños ven a otros niños jugando, sienten ganas de unirse a ellos o sentirán curiosidad por lo que hacen y motivará hacer alguna otra cosa (Gehl et al., 2015, p.29).

La experiencia de estar con otras personas supone una oportunidad para recibir estímulos, ya que donde haya gente haciendo actividades otras personas se sentirán atraídas. Las actividades que se desarrollan también pueden motivar a generar nuevas actividades.

Existe una estrecha relación entre la calidad de los espacios y las actividades exteriores, mediante el diseño un buen espacio público y las actividades al aire libre que se realizan en él. Si las actividades van en aumento se ve por la situación del espacio público (Gehl et al., 2015, pp.39-45). 
El espacio al igual que el tiempo hace que las personas se agrupen y desarrollen acontecimientos y el nivel de actividades y usuarios describe la calidad del entorno público. No es suficiente crear espacios que permitan a la gente ir y venir, también se deben desarrollar condiciones para deambular, distraerse así como participar de distintas actividades sociales y recreativas. Los grandes acontecimientos se desarrollan a partir de muchos otros pequeños. (Gehl et al., 2015, pp.144-145)

El espacio público es un ambiente ideas para realidad actividades al aire libre y algunas de las más indispensables son la de caminar y sentarse.

El caminar es considerado como un tipo de transporte, una forma de estar en el espacio y es considerado como un acto necesario. Es una actividad que exige espacio, el cual debería ser amplio y rico en experiencias. La amplitud de la cantidad de personas por flujo, puede haber personas con discapacidad, silla de ruedas, padres con cochecitos, padres con niños tomados de la manos que exigiría tener caminos amplios para que puedan haber una fluidez en el recorrido. Una condición importante para los caminos es el pavimento y la superficie. Los adoquines, la arena, la grava gruesa y los terrenos con superficies irregulares resultan inadecuados e incomodos, más aún si algunos usuarios tienen alguna dificultad para caminar. La distancia aceptable para caminar es una cuestión sumamente subjetiva, la calidad del recorrido es tan importante como su longitud real aunque las personas casi siempre van escoger los caminos directos y atajos. Al diseñar espacios públicos con caminos se debe evitar recorridos rectos y largos, generar curvaturas lo hace más interesante y además ayuda a reducir la molestia del viento. Generar una red peatonal debe alternar calles y pequeñas plazas para provocar una percepción más corta del recorrido total, ya que concentrará a las personas a llegar a una plaza a otra, así mismo la los espacios de sombra hace más ameno el recorrido (Gehl et al., 2015, pp.147-159).

Sentarse es otra de las actividades más comunes en el espacio público y debe haber una razón para hacerlo, se deben desarrollar actividades exteriores atractivas y meritorias para permanecer. Algunas de esas actividades puede ser comer, leer, dormir, jugar, tomar el sol, mirar a la gente, charlar, contemplar el espacio, etc. Los lugares para sentarse se vuelven más usados cuando se encuentran más protegidos de las condiciones medio ambientales. 
No es recomendable poner asientos al azar, estos deben ubicarse con alguna estrategia en mente, deben tener una cualidad propia, un lugar, ya sea dentro de otro espacio, un nicho, rincón, un espacio que produzca intimidad y seguridad, un lugar con una atmosfera tranquila y de confianza. Deben estar orientados con respecto al sol y direccionar hacia algún estímulo visual interesante y de acuerdo al usuario ya sea niño o adulto debe ser accesible ya sea en tamaño y uso (Gehl et al., 2015).

Los espacios públicos deben hacer sentir a las personas seguras en medio de otras personas desconocidas para ellos. En el caso de un barrio o urbanización el sentimiento de seguridad es mayor porque conocen a sus vecinos o son conocidos por la frecuencia que los ven.

Jane Jacobs define al espacio público como aquel espacio con libre tránsito peatonal donde el usuario debe sentirse en paz y seguro. Esa seguridad no debe ser garantizada principalmente por un policía, si no debe ser proporcionada por los mismos usuarios que la recorren, observan, genera controles y respuestas voluntarias para fortalecer la seguridad (Jacobs, 2013, pp.55-82).

Un espacio público con más frecuencia de usuarios tiene más posibilidad de ser una zona más segura, esto se debe a los ojos que miran a la calle que no dejan espacios ciegos en el lugar ni en los recorridos. Estos espacios deben ser atractivos, dinámicos para llamar la atención de las miradas y la concurrencia de las personas, ya sea con espacios de juego, encuentro, ocio, actividades que se pueden desarrollar al aire libre (Jacobs, 2013, pp.55-82).

El comercio u otras actividades públicas cerca a los caminos y espacios públicos pueden garantizar un flujo de personas tanto de vecinos como desconocidos pueden usar esos servicios y al mismo tiempo ser observadores en la zona aumentando la sensación de seguridad. Así mismo un espacio acudido por personas puede llamar a mucha más gente porque las personas siempre se encuentran en actividad y siempre atraerá la curiosidad de los demás. Un espacio activo siempre motiva a los demás a involucrase o a observar y mientras más diverso sean las actividades mejor aún (Jacobs, 2013, pp.55$82)$. 


\subsubsection{Paisaje}

El paisaje puede ser considerado como la manifestación formal de la relación sensible de los individuos y de las sociedades en el espacio y en el tiempo con un territorio más o menos intensamente modelado por los factores sociales, económicos y culturales. El paisaje es así el resultado de la0 combinación de aspectos naturales, culturales, históricos, funcionales y visuales (...) Esta relación puede ser de orden afectivo, identitario, estético, simbólico, espiritual o económico e implica la atribución a los paisajes por los individuos o las sociedades de valores de reconocimiento social a diferentes escalas local, regional, nacional o internacional. (Carta del Paisaje Mediterráneo, 1993)

El paisaje es todo aquello que está en el territorio percibido por la población y es el resultado de factores naturales, ambientales e intervención humana, de esta manera el territorio percibido cual sea su característica es considerada paisaje. Puede ser algo tan bello como una playa, un bosque como también tu propio parque, barrio y todo aquello que forma el entorno de alrededor ya tengan valor o estas se estén perdiendo en el tiempo.

El paisaje no tiene una descripción completa, es un término subjetivo ya que lo que se piensa y se siente cuando se contempla o recuerda un espacio que forma parte de él (Convenio Europeo del Paisaje, 1993).

El concepto de paisaje debe tener algunas distinciones importantes como por ejemplo la de referirse a paisaje como una porción de superficie terrestre que puede verse desde un punto determinado y posee un carácter preferente visual (Aguilar Díaz, 2012). Por otro lado existe también un concepto del paisaje cultural donde el término del paisaje tiene un significado que va más allá de una vista placentera de una escena, sino que denota también las interacciones de la gente con el lugar, el actuar de un grupo social en su entorno, a un lugar donde pertenecen y donde sus integrantes obtienen parte de su identidad y sentido común (como se citó en Peimbert, 2014, p.4).

Así como existe un grupo social que se siente identificado con un determinado lugar, existe también un punto de vista donde los conceptos de lugar y paisaje pueden ser visto como un espacio económico y demográfico que refleja cultura, poder y acumulación de capital, refiriéndose a una práctica más materialistas. El paisaje representa la construcción espacial de clase social, género y relaciones de raza impuestas por 
instituciones con poder. Esto forma el panorama que se percibe tanto del paisaje como del poder ya sea por las catedrales, fábricas, edificios, barrios marginales, centros comerciales, etc. Un paisaje intercede el simbolismo y lo material, entre lo social y lo económico (como se citó en Peimbert, 2014, p.4).

\subsubsection{Vacíos urbanos}

Es todo aquel espacio que no presenta alguna identidad, ni tiene relación alguna con lo que lo rodea, tampoco un significado histórico ni percibido de manera inmediata por los habitantes de la ciudad. También pueden ser denominados como un no lugar, ya que puede ser un espacio ajeno a la ciudad que no se une o entrelaza a lo preexistente, por lo que pierde valor, uso y no es concurrido dejándolo vacío. Son como islas interiores carentes de uso y dinámica urbana.(Augé, 2008)

Algunos lugares considerados vacíos urbanos son aparentemente olvidados donde predomina una fuerte idea del pasado sobre el presente, son lugares obsoletos con algunos puntos residuales de valor como iconos o referencias para la ciudad, son considerados como espacios extraños fuera de importancia productiva. (De Solá Morales, 2002)

También el vacío urbano es definido como espacios sin definir, como un residuo o espacio mal resuelto de un proyecto el cual reclama un uso en la ciudad, estos espacios pueden ser reciclados para generar un agregado positivo dentro de la estructura urbana, como un espacio público, una nueva área verde, un punto de venta o de información (Rodriguez Tarduchy, 2011).

Los vacíos urbanos son un tipo de espacio entendido como una parte que queda de un todo o espacio que queda inutilizable. Son vacíos no porque carezcan de materia, sino porque carecen de una función o uso dentro de la trama de la ciudad, o pueda ser que cumplieron con su propósito y fueron desechados. También pueden ser catalogados como espacios vacantes, ya que son espacios vacíos sin utilizar y que podrían tener en algún momento una función dentro de la ciudad.

La aparición de estos espacios en la trama de la ciudad llama la atención algunos urbanistas, paisajistas y artistas. Como la del arquitecto Ignasi de Ignasi De Solà-Morales que los define como lugares aparentemente olvidados, donde el pasado predomina a la 
del presente, que mantiene valores de aquellas épocas y que son lugares extraños, externos y están fuera del sistema urbano productivo (De Solà-Morales, 2002, p.127).

Para el arquitecto paisajista Gilles Clément se refiere a estos lgares como "El tercer paisaje". Son espacios sin función, indecisos que resulta difícil darles un nombre y que le pertenece a la luz y a las sombras. También los considera como espacios indeterminados o que perdieron su esencia con el paso del tiempo pasando a ser un espacio olvidado y que solo la sociedad podría darle un segundo uso e incorporarlo a la ciudad (Clément, 2007, p.9).

Por otro lado Kevin Lynch define a estos espacios vacíos como wastelands o páramos o "lugares en los márgenes", donde integra también a espacios como los terrenos baldíos, basureros, callejones, etc. Son espacios expulsados y marginados de la estructura urbana y que tienen un carácter como lugar alternativo a lo que se ofrece regularmente (Lynch, 2010).

\subsubsection{Ciudad periférica}

Las ciudades periféricas son las que se encuentran al borde de la ciudad consolidada, con realidades complejas, distintas y en constante transformación. A pesar de que las ciudades del mundo son distintas unas de otras, las ciudades periféricas comparten características semejantes, como por ejemplo: tienen problemas de infraestructura, accesibilidad, ordenamiento territorial, sociedades vulnerables, segregación social, falta de equipamiento urbano y sus necesidades no son satisfechas por la gobernanza metropolitana. Estas ciudades son generadas con el establecimiento de sociedades marginadas o que huyeron de sus antiguos asentamientos para acercase más a los centros donde los servicios y oportunidades abundan(Regionales, 2015).

Las ciudades también pueden generar cambios sociales, ambientales y económicos, por lo que el desplazamiento de las personas por llegar a esas ciudades las sitúan a su alrededor para continuar con el crecimiento desde sus límites, hacia fuera de ellas. Este crecimiento puede ser constante y agresivo dejando sin abasto a los servicios básicos, vivienda y saneamiento. En el caso de América Latina muchas de las ciudades periféricas son producto de la informalidad y la falta de planificación que generan una insostenibilidad en el tiempo. Al carecer de planificación, los gobiernos no contemplan la atención a sus necesidades básicas, dejándolos en zonas precarias donde se concentran 
un gran número de personas que viven en pobreza y vulnerabilidad. Su infraestructura es improvisada con difícil acceso a la zona y posible zona de riesgo ambiental (Aguilar y López, 2016).

La periferia es un fenómeno típico de las ciudades contemporáneas, esto ocurre cuando las ciudades empiezan a expandirse más allá de sus "límites" consolidados. Algunas de las características resaltantes de estas zonas periféricas son las viviendas de bajo costo, zona industrial, insuficientes servicios y equipamientos, actividades poco diversas y población en constante relación con el centro consolidado (Arteaga, 2005, pp.100-101).

A nivel urbano se hace referencia a la morfología de la ciudad como el producto de un constante crecimiento, mostrando distintas periferias alrededor del centro con distinta trama y estructura urbana. Es la zona externa construida producto del crecimiento desbordado. Históricamente la periferia es identificada con el crecimiento acelerado en torno a la ciudad compacta durante el siglo XX. En el caso de las ciudades industrializadas se entiende como la zona con viviendas de menos ingresos económicos y de bajo nivel de calidad de vida en comparación a su centro consolidado. Esta expansión es ocupada en su mayoría por inmigrantes de zonas alejadas que buscar mayores oportunidades acercándose al centro. Estas zonas tienen un valor bajo en el mercado, no tienen muchas vías de accesibilidad, en algunos casos se le atribuye como una parte negativa de la ciudad, tiene déficit infraestructural lo cual lo hace deficiente y dependiente de su centro.

Sin embargo, ahora se está apuntando a reconocerlo como un lugar donde se debe construir y reconstruir la ciudad actual y formar nuevas centralidades, usas los vacíos urbanos, conectar los tejidos urbanos, unificar las zonas dispersas, generar espacios públicos e invertir en equipamiento urbano de salud, comercio, educación, trabajo y ocio (Arteaga, 2005, pp.105-109).

\subsection{Conclusiones parciales}

- El espacio como memoria genera un vínculo especial con sus usuarios gracias a las actividades de integración ciudadana que puedan desarrollarse a nivel cultural, social o deportivo, mientras más experiencias colectivas se puedan plasmar en el lugar, este 
se vuelve un lugar más importante para ellos y para lograr el espacio debe estar a disposición de ellos.

- La memoria es la herramienta que permite acceder al tiempo ya transcurrido y que ayuda a ver posibilidades para apuntar y desarrollar el presente. Manchay no fue planificada. Ahora es momento de "reconstruir" la ciudad generando conectividad, espacios públicos, nuevas centralidades, ofrecer una sensibilidad relacionada a su entorno para hacerla parte de ellos y sea parte de su nueva memoria a futuro.

- Los vacíos urbanos pueden generar grandes problemas, así como grandes oportunidades para las personas que rodean estas zonas, para generar trabajo colectivo en mejora de sus barrios, de esta manera también podrían conocerse mejor, fortalecer vínculos, generar identidad para un mismo propósito. Todo esto concluiría en la generación de un espacio a futuro para la ciudad y los ciudadanos.

- El parque no puede ser un espacio desperdiciado, no debe quedar como un elemento transparente en el panorama, debe ser un punto de atracción, de encuentro y dinámicas. Espacios que generen memorias y recuerdos para sus actores.

- La observación es una actividad constante que permite ver y percibir, lo cual invita pensar y plasmar una idea capaz de ser transmitida. También permite entender la ciudad y la sociedad que vive en ella. El proyecto apuntará a observar tanto su entorno como a su población para poder llegar a un diseño integrador en base a sus necesidades y requerimientos que les permita desarrollarse como barrio y como comunidad. Manchay es una ciudad con actividad peatonal constante por parte de niños y mujeres, de esta manera es idéntica el nivel de confianza y relación que tienen con sus vecinos, la cual es alta.

- Un diseño tanto arquitectónico como paisajístico debe ser contextualista para tener una armonía visual con respecto al lugar, respetar la topografía, los recursos, mejorar la accesibilidad ponerla en valor. Esto significa también respetar lo existente, adaptarse a la trama urbana y la cultura de la zona para fortalecer la identidad y no ser un lugar ajeno para los pobladores.

- Para el desarrollo del proyecto se debe considerar tanto su contexto territorial como su continuidad histórica y cultural para lograr reforzar la identidad de la zona. Manchay es una ciudad muy joven con una infraestructura mayormente producto de la autoconstrucción. A nivel urbano se muestra poco desarrollado, por lo que se seguirá con esa continuidad. La mayor parte de la población es migrante del interior 
del país, muchos de ellos aún mantienen algunas costumbres como cultivar sus propios alimentos y hacer tejido típico. Para mantener viva sus tradiciones se implementarán espacios comunales que fortalezcan estas prácticas y puedan ser compartidas con el resto de la población.

- Una educación paisajística adecuada hoy en día puede hacer que la mentalidad de la futura sociedad sea mejor y por consiguiente mejorarán los espacios públicos. El conocimiento y el cuidado podrán generar una conciencia colectiva que unirá a los estudiantes y a la comunidad. La transformación del paisaje mejorará el entorno y generará en los estudiantes una actitud de respeto hacia el mismo y un interés hacia su cuidado, reconociendo así las acciones que son benefactoras para su conservación o aquellas que son perjudiciales.

- Uno de los referentes más cercanos son los Parques Biblioteca de Medellín Colombia. Son proyectos sociales que se ubican en zonas vulnerables con el objetivo de promover la integración y la cultura a la comunidad. Estos proyectos sociales han tenido un impacto significativo en la población, generando seguridad en la zona, aumentando la participación ciudadana, etc. Para el proyecto de tesis se tendrá como referente su manera organización, gestión e interacción con la población para poder lograr sus objetivos, así mismo también se centrará en sus 3 puntos más importantes: la educación, la sociedad y la cultura.

- Perú lidera dentro de los países de la Alianza del Pacífico en tener la mayor participación de emprendimiento femenino. Cabe resaltar que la zona de San Pablo Mirador existe un grupo de madres emprendedoras que con ayuda de la ONG Ruwa Sunchis lograron crear una marca social llamada Ayllu que ofrece productos tejidos por madres de Manchay. Actualmente no cuentan con una infraestructura adecuado para el desarrollo de sus actividades empresariales. El proyecto de tesis apunta a desarrollar los espacios necesarios para su integración, desarrollo y producción para mejorar la calidad de sus productos e integrarlas más como comunidad.

- La importancia de generar un nuevo espacio público con áreas verdes en una zona en vías de consolidación es para ser un referente de cómo se debería tratar un paisaje en ladera y en una zona donde el agua es un recurso importante, será importante el uso de especies que requieran poco consumo del elemento. Es importante que se pueda enseñar a las nuevas generaciones que existen alternativas y distintos tipos de paisajes para conocer sus requerimientos. También debe ser un espacio donde las 
escuelas puedan acudir para brindar formación acerca del medio ambiente en base a la experiencia directa con un medio natural.

- Para el diseño del espacio es importante considerar al usuario como el factor determinante, considerar sus necesidades y proporcionar una arquitectura acorde a un programa capaz de satisfacer sus demandas. Como el diseño de espacios lúdicos y flexibles para que ellos mismos puedan organizarse y crear sus propias atmosferas de trabajo, estudio u ocio como producto de la necesidad, demanda, uso o dinámicas.

- Los espacios propuestos deben de ser flexibles tanto al interior como al exterior, generar espacios semi-abiertos para tener una relación con el exterior, generar una libertad espacial para que también fluya la movilidad y la creatividad de quienes lo usen, en caso de los niños sería de gran ayuda para que ellos mismos descubran su manera más cómoda para jugar, aprender o estudiar.

- Los espacios públicos también deben apuntar a la diversificación de usos para garantizar una ocupación constante del mismo. Si se plantea espacios de encuentro preferible tener espacios con la misma jerarquía para que sean usadas y vistas de la misma manera y no ser excluidas por las personas que lo acuden. En el caso del diseño de zonas de juegos para niños se debe de apuntar a generar espacios que no limiten a su imaginación, como colocar elementos o formas que puedas descubrir por su cuenta y crear sus propios juegos.

\section{CAPÍTULO IV: MARCO NORMATIVO}




\subsection{Estándares arquitectónicos}

Para el desarrollo del proyecto arquitectónico se considerarán las normativas vigentes del Reglamento Nacional de Edificaciones (RNE) tomando en cuenta algunos capítulos.

\subsubsection{Norma A.090 Servicios Comunales}

Puntos importantes de la Norma A.090:

- Su arquitectura debe ser un centro que facilite el desarrollo de la comunidad.

- El proyecto con uso de centro comunal debe ser compatible con la zonificación del terreno a trabajar o debe estar propuesto en algún plan urbano.

- Se debe considerar los espacios para las futuras ampliaciones.

- El diseño también debe cumplir con la Norma A.120 sobre accesibilidad para discapacitados

- Por un tema de evacuación si el volumen supera los $500 \mathrm{~m} 2$ de planta se debe de tener una escalera de emergencia adicional.

- En caso el centro comunal tenga 4 o más pisos se debe de contar con ascensor.

- En el diseño debe contar con iluminación natural o artificial óptima para hacer usos de los servicios del centro.

- La ventilación debe ser natural, considerando el área de los vanos superior al $10 \%$ del área del ambiente que ventila.

- Debe cumplir con los requisitos de seguridad establecidas en la Norma A.130 Requisitos de Seguridad.

- Se debe asignar $10 \mathrm{~m} 2$ por persona para oficinas administrativas.

- Se debe asignar $1 \mathrm{~m} 2$ por persona para áreas de reuniones a pie.

- Lugares de exhibición o sala de lectura para bibliotecas debe ser $4.5 \mathrm{~m} 2$ por persona.

- El ancho de los vanos para evacuación debe ser superior a $1 \mathrm{~m}$.

- Los centros comunales deberán de contar con servicios higiénicos para empleados y para público en general.

- La implementación de baño para discapacitados es obligatorio. 
- El cálculo de estacionamientos es de 1 por cada 10 personas para público en general y del personal es 1 por cada 6 empleados. El cálculo de estacionamientos también dependerá de las condiciones socio económico de la zona y del plan urbano. Los estacionamientos deberán estar cerca al centro para facilitar el acceso para personas discapacitadas, transporte de materiales o servicios de emergencias.

- Las instalaciones eléctricas, sanitarias o comunicaciones deben estar en ductos de fácil acceso por nivel para un óptimo mantenimiento y control.

\subsubsection{Neufert}

Con el manual del Neufert se podrá diseñar óptimamente al programa a proponer, proporcionando medidas estándares para aprovechar y distribuir el espacio considerando al usuario como medida y objetivo principal. (Neufert, 2014)

Se revisarán los temas siguientes:

- Arquitectura accesible para sillas de ruedas

- Dimensiones básica y proporciones con respecto al espacio necesario y modulación de la edificación.

- Bioconstrución para mejora del espacio interior.

- Percepción visual del espacio.

- Estudio de los elementos constructivos como: cimentaciones, muros, cubiertas, ventanas, vanos, escaleras y rampas.

- Tema educativo para centros de educación infantil, parques infantiles, áreas para espacios de enseñanza y aprendizaje.

- Tema cultural como museos, salas de exposición, proyección.

- Tema administrativo para diseño de oficinas, bibliotecas, talleres.

- Tema de sanidad para diseño de centro de atención tipo enfermería.

- Tema deportivo y ocio para diseño de campos de juegos, instalaciones deportivas.

- Tema de construcción en exteriores para el diseño de paisajismo, evacuación de agua.

- Temas de sostenibilidad para iluminación natural, sistemas térmicos y acústicos para la construcción. 


\subsection{Ministerios y organizaciones locales}

Algunos de los ministerios mencionados a continuación tienen protagonismo en el distrito que apoyan a la comunidad de Pachacamac y Manchay y también se mencionan algunas organizaciones que apoyan en Manchay para su desarrollo, integración y mejora de la población. El conocimiento de la existencia de éstas organizaciones permite saber que tanto más se está trabajando en el distrito, los resultados obtienen con la población, los programas participativos que ofrecen a niños, jóvenes y adultos, además de ser potenciales aliados para apoyar dentro del proyecto Parque Recreativo y Centro Comunal Mirador de Manchay.

\subsubsection{Ministerio de Desarrollo e Inclusión Social}

El Ministerio de Desarrollo e Inclusión Social (MIDIS) es un organismo del Poder Ejecutivo cuyo objetivo principal es mejorar la calidad de vida de la población en situaciones de vulnerabilidad y pobreza, promueven los derechos de las comunidades, el acceso a oportunidades y al desarrollo de sus propias capacidades. El MIDIS coordina y articula con las diversas entidades del sector público, privado y sociedad civil, fomentando los programas sociales consigan las metas propuestas a través de las evaluaciones, potenciación, capacitación y trabajo coordinado entre sus gestores.

El Ministerio de Desarrollo e Inclusión Social fue creado por la Ley N 29792 el 20 de Octubre de 2011. La juramentación de su primera Ministra se llevó a cabo en la ciudad del Cusco el 21 de octubre del mismo año (Ministerio de Desarrollo e Inclusión Social, 2016). Algunos de los programas que ofrece son:

- Programa Nacional Cuna Más.

- Programa Nacional de Alimentación Escolar - Qali Warma.

- Programa Nacional de Apoyo Directo a los más pobres - JUNTOS.

- Fondo de Cooperación para el Desarrollo Social - FONCODES.

- Programa Nacional de Asistencia Solidaria Pensión 65.

\subsubsection{Ministerio de la Producción}

El Ministerio de la Producción fue creado por Ley 27779 del 10 de julio del 2002. Tiene como finalidad de diseñar, ejecutar, establecer y supervisar, en armonía con la política 
general y los planos de gobierno, sectoriales y políticas nacionales aplicables a los sectores de pesquería y de MYPE e industria, asumiendo rectoría respecto de ellas.

Dicta normas y lineamientos técnicos para la adecuada ejecución y supervisión de las políticas, la gestión de los recursos del sector, así como para el otorgamiento, reconocimiento de derechos, la sanción, fiscalización y ejecución coactiva.

Uno de sus funciones es brindar orientación y apoyo para desarrollar una empresa, como por ejemplo con el programa StarUp Perú que tiene como objetivo promover el surgimiento y la consolidación de nuevas empresas mediante la asesoría en gestión empresarial (StarUp Perú, 2015).

\subsubsection{Municipalidad de Pachacamac}

La Municipalidad Distrital de Pachacamac es un órgano de gobierno local en Lima Sur. Se creó en 1856 y actualmente es considerado como un distrito ecológico y turístico de la capital. Sus principales autoridades fueron elegidas popularmente. Promueven el desarrollo local. Goza de autonomía política, económica y administrativa en los asuntos de competencia. Fomenta el bienestar de los vecinos y el desarrollo integral y armónico de la circunscripción de la jurisdicción. Tiene como misión planificar, ejecutar e impulsar a través de los organismos competentes brindar las condiciones vitales en aspectos de vivienda, salubridad, abastecimiento, educación, recreación, transporte y comunicaciones a sus habitantes. Asimismo, promueve el desarrollo económico local con importancia en la micro y pequeña empresa, el desarrollo del turismo y el desarrollo integral para viabilizar el crecimiento económico, la justicia social y sostenibilidad ambiental, en concordancia con el Plan de Desarrollo Local Concertado. Uno de los servicios que brinda a sus zonas menos consolidadas es el Programa de Vaso de Leche que da alimentación a niños y jóvenes de bajos recurso para que tengan una buena alimentación. También realizan actividades comunales para promover el deporte y la inclusión social es sus actividades como competencias deportivas y ferias. (Municipalidad de Pachacámac, 2010) 


\subsubsection{Defensoría Municipal del Niño y el Adolescente (DEMUNA)}

La DEMUNA es un servicio del Sistema Nacional de Atención Integral al Niño y al Adolescente que brinda atención gratuita mediante la conciliación en materia de régimen de visitas, tenencia y aporte para alimentos. Son los encargados de proteger, defender y vigilar el cumplimiento de los derechos que la ley reconoce a los niños, niñas y adolescentes.

Buscan que los niños, niñas y adolescentes no sean vulnerados en sus derechos, asistir profesionalmente a padres de familia para el debido cumplimiento de los derechos que le asisten los menores de edad. Participa de forma continua y perenne en labores de difusión y defensa de los derechos de los menores. También tiene el objetivo de sensibilizar a las familias y autoridades sobre la importancia de los derechos de los niños, niñas y adolescentes, así mismo contribuye a que el poblador acceda a la justicia y permita una atención legal. (Municipalidad de Lima, 2015)

\subsubsection{Ruwasunchis (ONG)}

Ruwasunchis es una palabra en quechua que significa "Hagámoslo Todos Juntos". Son un equipo multidisciplinario de jóvenes que trabajan con niños, jóvenes y adultos en la comunidad de San Pablo el Mirador (Manchay), bajo un Modelo Creativo de Desarrollo Comunitario. Tiene como misión crear espacios de encuentro que acompañen el descubrimiento de capacidades y oportunidades de desarrollo de personas en comunidades vulnerables (Ruwasunchis, 2016).

Algunos de sus programas son:

- Tejiendo Oportunidades. Es una plataforma de oportunidades que promueve el crecimiento personal y técnico de tejedoras de comunidades peruanas.

- Programa de Jóvenes. Es un espacio de encuentro donde los jóvenes desarrollan habilidades y se les conecta con oportunidades de estudio y trabajo.

- Programa de Niños. Se brinda propuestas pedagógicas de juego y aprendizaje libre. Una mirada de respeto a la individualidad y procesos de autonomía.

Cumplen algunas estrategias importantes para que estos programas sean los más eficientes como: mejora de la nutrición, el desarrollo integral, estrategias ambientales y el desarrollo de arquitectura comunitaria. También involucran a los jóvenes a entender su 
entorno y pensar en estrategias que les permitan mejorar su entorno y desarrollar proyectos de intervención urbana que ayude a su comunidad. (Ruwasunchis, 2016)

\subsubsection{Los custodios de la creación (Asociación Católica)}

Es una asociación católica fundada en el 2008 con el objetivo de promover proyectos al cuidado del medio ambiente, nace de una iniciativa del Arzobispado de Lima y cuenta con algunos proyectos como Manchay Verde, que una iniciativa ambiental que apunta a aumentar conciencia por el cuidado y el respeto por medio ambiente de las zonas más pobres, creando áreas verdes empleando aguas tratadas en zonas donde este elemento es escaso. Han desarrollado una planta de tratamiento de agua y se empezó a implementar actividades educativas con colegios de la zona, también busca difundir una educación ambiental, con visitas educativas. Desde el año 2009 se sembraron más de 2000 árboles (Los Custodios de la Creación, 2018).

Otro proyecto similar es Huaycan, que desde el año 2016 sembró 300 árboles y usan aguas servidas de una planta ubicada en el colegio San Francisco de Asís en Huaycan -ATE. Al igual que el proyecto de Manchay Verde, busca promover una conciencia de respeto, cuidado y recuperación del medio ambiente mediante talleres, charlar y actividades participativas, donde los niños, jóvenes y adultos de la comunidad puedan aportar de manera sostenible a su barrio y ciudad (Los Custodios de la Creación, 2018).

Otra iniciativa es el proyecto Las Ollas de la Caridad, que trata de recuperar los productos aún comestibles no vendidos de los establecimientos comerciales pero que no son muy atractivos para que en vez de ser desechados, sean donados y puedan ser recogidos para preparar cenas saludables a las poblaciones más necesitadas. Buscan fomentar un uso responsable de productos "residuales" como productos enlatados, frutas, verduras, o aquellos que no se vendieron y que puedan malograrse de no consumirse rápido. En este proyecto trabajan voluntarios que recogen los productos el mismo día que serán preparados los alimentos, y las cocineras que se encargan de preparar las cenas. Actualmente se dan cenas en el Colegio San Pedro del Agustino y para los residentes de la casa hogar Santo Toribio (Los Custodios de la Creación, 2018). 


\subsubsection{World Visión Perú (Organización Cristiana)}

World Vision Perú es una organización cristiana de acción social, enfocada en la protección y desarrollo del potencial de niños y niñas como agentes de cambio. Sus acciones contribuyen a que vivan y crezcan saludables, con capacidades, oportunidades y un entorno que les permita alcanzar una vida plena y transformada.

Impulsan acciones para que las familias y la comunidad construyan una sociedad más segura para la niñez.

Se enfocan en el potencial del niño, promoviendo espacios y oportunidades para un crecimiento, desarrollo y educación integral temprana.

Promueven el ejercicio de la ciudadanía de los niños a través de su participación en cambios sostenibles que contribuyen a la reducción de la pobreza en su comunidad. Se financian mediante donaciones, trabajo voluntario, ingreso de la iglesia, empresas con sentido social y voceros de distintas partes del mundo (World Vision Perú, 2015).

\subsubsection{PERUINCUBA}

PERUINCUBA es una Asociación Peruana de Incubadora de Empresas sin fines de lucro, constituida el 14 de febrero del 2006 por 11 instituciones, universitarias e instituciones superiores, a nivel nacional, ubicadas en Arequipa, Huancayo, Lima, Piura y Trujillo. Actualmente son 18 instituciones asociadas.

Su misión es agrupar de manera gremial a las instituciones con incubadora de empresas peruanas, fomentarlas, representarlas y defender sus intereses, ante entidades públicas y privadas, nacionales e internacionales, promoviendo el desarrollo nacional a través del impulso brindado al surgimiento y consolidación de empresas que desarrollen o hagan uso de las tecnologías y promoviendo la relación entre la generación de conocimiento y la actividad empresarial (PERUINCUBA, 2009).

Sus objetivos son los siguientes:

- Promover y consolidar el movimiento de incubadoras de empresas en el Perú.

- Promover la creación de nuevas incubadoras de empresas y el fortalecimiento de las existentes. 
- Promover una regulación adecuada sobre la incubación de empresas en la normativa vigente.

- Difundir los conceptos y las aplicaciones de las incubadoras de empresas.

- Promover la sensibilización de la sociedad con respecto al tema de la generación de nuevas empresas para el desarrollo de la comunidad.

\subsubsection{StarUp Perú (Programa del Ministerio de la Producción)}

StarUp Perú es una iniciativa del Estado Peruano liderada por el Ministerio de la Producción, que tiene por objetivo promover el surgimiento y consolidación de nuevas empresas peruanas que ofrezcan productos y servicios innovadores, con alto contenido tecnológico, de proyección a mercados internacionales y que impliquen la generación de empleos de calidad.

Esta iniciativa nace de la necesidad del país por modificar su tejido empresarial hacia uno de mayor valor agregado, donde los nuevos emprendimientos no sean solo de subsistencia, sino que nazcan con los elementos suficientes para diferenciarse, sobrevivir, crecer y expandirse en el tiempo. Esta iniciativa se sustenta en la gran habilidad del peruano para desarrollar soluciones creativas a problemas complejos.

StarUp Perú surge a finales del 2012 y ha ampliado los servicios que ofrece on el pasar de los años. Consiste de un conjunto de concursos y líneas de financiamiento para emprendedores, empresas en edad temprana, e incubadoras. También construye una plataforma de encuentro y colaboración para todos los actores de la comunidad StarUp del país, para así también ser un punto de enlace con redes de colaboración internacional.

StarUp Perú es financiada de diversas fuentes del ámbito público, siendo su principal aportante el Fondo Marco para la Innovación, Ciencia y Tecnología FOMITEC, creado a través de la Ley de presupuestos del año 2013. También utiliza recursos ordinarios del Ministerio de la Producción y fondos del Proyecto de Innovación para la Competitividad FINCYT (StarUp Perú, 2015). 


\subsection{Parámetros municipales}

La municipalidad de Pachacamac tiene ordenanzas actuales sobre el uso de las zonificaciones compatibles en el distrito. Se propone usar un terreno que sea compatible con el uso de Centro Comunitario y zona recreativa. Usando un terreno con tipo de zonificación ZHE que son lotes mínimos de 10,000 m2. 


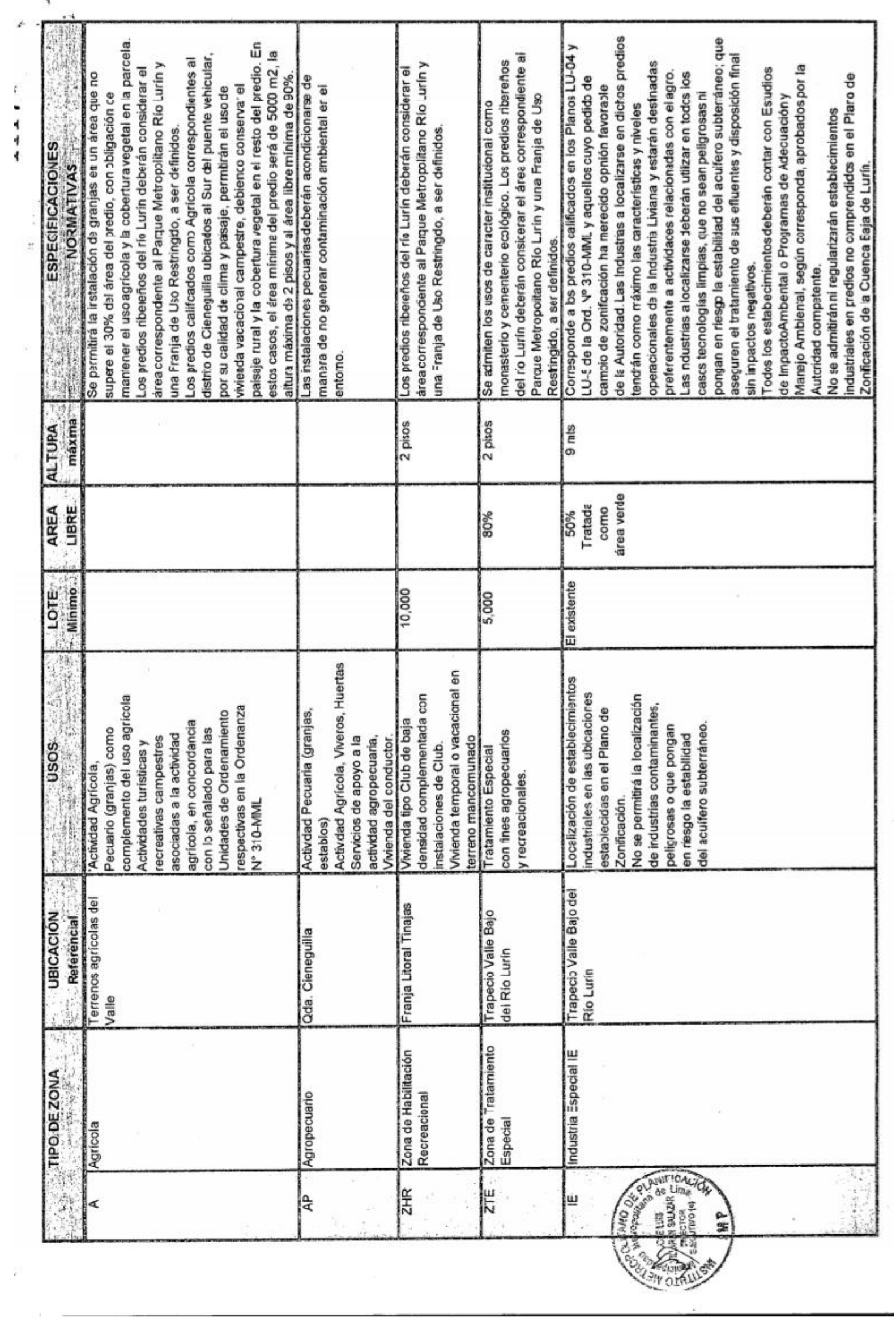




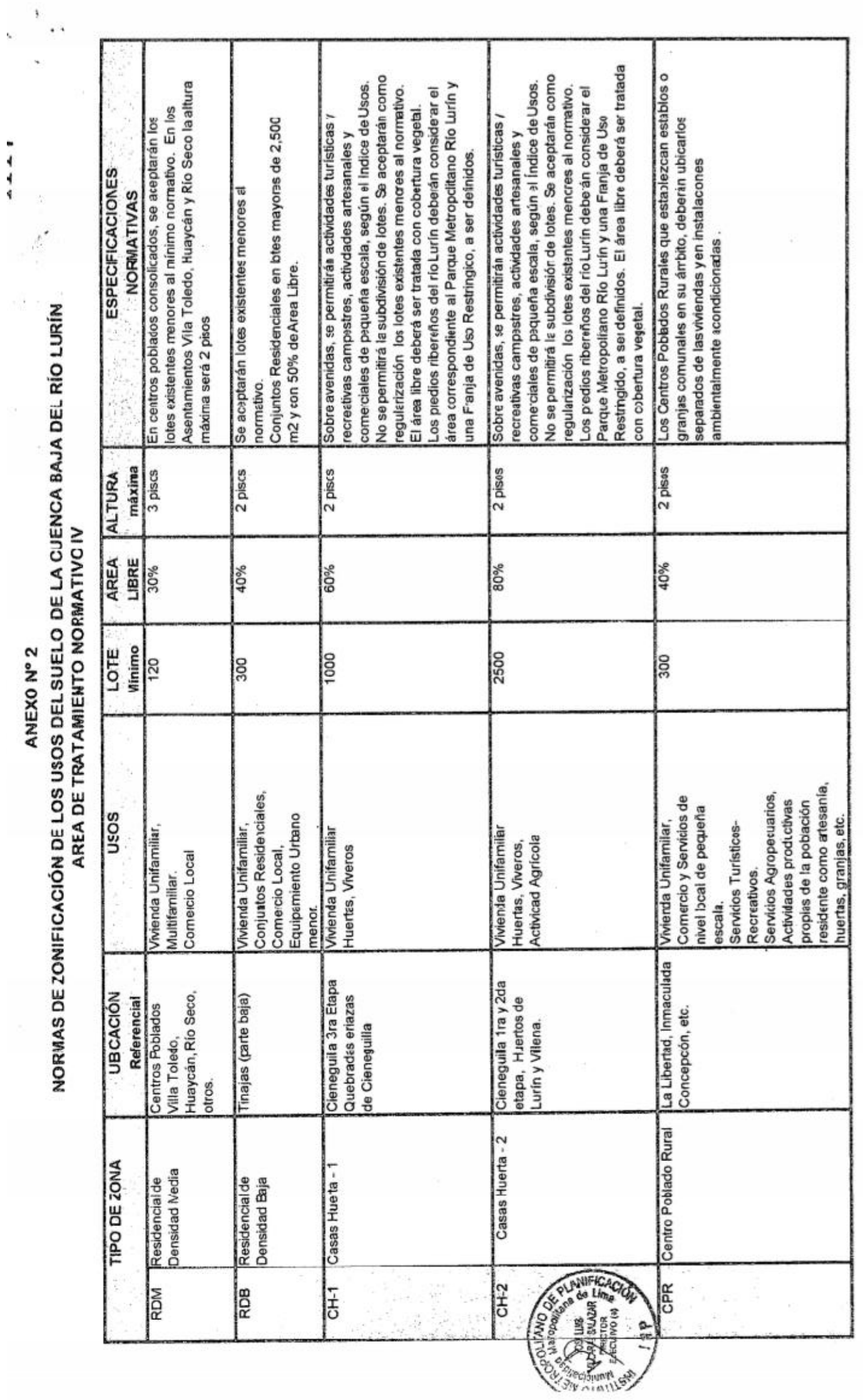




\subsection{Conclusiones parciales}

- La Municipalidad de Pachacamac cuenta con una normativa de usos para su territorio, el uso de terreno para para actividades recreativas es ideal para proponer el diseño del parque recreativo con centro comunal, ya que son asignadas a terrenos con más de 10000 metros cuadrados y tiene compatibilidad para proponer un centro comunal.

- Las instituciones afines marcan un precedente de la ayuda comunitaria que necesita la zona para ayudar a la población vulnerable, en especial a los jóvenes. Organizaciones como Ruwasunchis es un presente cercano al cual se pretende llegar con respecto a programa social, en apoyo a la educación de niños y jóvenes con problemas de aprendizaje de la zona. Para ayudarlos a tener confianza, brindarles herramientas de estimulación y trabajar con la comunidad.

- Es necesario contar como aliado al programa Manchay Verde permitirá un apoyo en conjunto para arborizar las laderas del proyecto y fomentar la participación de la población en el cuidado del medio ambiente.

- Las normas proveen de un marco para viabilizar el diseño y orientarlo de manera constructiva y funcional. Para optimizar el espacio, generar un buen espacio para la comunidad, humanizar el espacio y satisfacer al usuario.

- Las normas que se apliquen al diseño del parque como para al centro comunal deberán satisfacer las necesidades de las personas con discapacidad como en los flujos, accesos, evacuación y servicios. Ya que el proyecto debe ser inclusivo y accesible para todo ciudadano. 


\section{CAPÍTULO V: MARCO OPERATIVO}

\subsection{Análisis de variables}

\subsubsection{Ubicación y Relación con el Entorno}

Se emplearon planos de localización a distintas escalas para entender su entorno inmediato y su ubicación geográfica.

Se analizaron las vías principales, las líneas de transporte público y privado, así como las estaciones y los servicios de la zona para saber la dinámica del lugar. También se analizará el perfil urbano mediante una sección.

\subsubsection{Programa y Relaciones Programáticas}

Para el análisis del programa se empleará planos arquitectónicos de las obras y mediantes esquemas gráficos, se desarrollará un mapa de relaciones espaciales y un cuadro de áreas que servirán para el diseño del proyecto.

\subsubsection{Tipología Espacial}

El estudio de la forma del volumen y su colocación en el terreno, así como la distribución de sus funciones determinará que tipología con respecto a los Centros Comunales pertenece. Se hará gráfico la explicación, del volumen con relación al terreno.

\subsubsection{Público - Privado}

Se analizará las plantas diseñadas y posteriormente se graficarán las zonas públicas, semipúblicas y privadas, serán plasmadas en los planos de planta y corte, así mismo se sacará el porcentaje que cada uno de estas funciones del proyecto. También se desarrollará un análisis de flujos y circulaciones en las distintas horas del día. 


\subsubsection{Tecnología}

Se explicará los sistemas constructivos empleados en los proyectos referentes mediante esquemas gráficos, señalar donde se ubican las estructuras y de qué manera afecta el medio ambiente en él.

\subsubsection{Impacto Social}

Se analizará el impacto que tiene el proyecto a las distintas escalas que estos representen, así mismo se verá de qué manera cambia su calidad de vida gracias a estos servicios y de qué manera permite a los usuarios mantener una participación.

\subsection{Estudio de casos análogos:}

\subsubsection{Centro de Recursos para el Aprendizaje y la Investigación (CRAI), México.}

Arquitectos: Arq. Rafael Plascensia García y Arq. Marco García Ruiz. (3Arquitectura)

Ubicación: Guadalajara, México.

Tipo de Proyecto: Centro de recursos para el aprendizaje.

Usos: Educativo, social y emprendimiento.

Área: $5749 \mathrm{~m} 2$

Año: 2013

\subsubsection{Parque Biblioteca León de Grieff, Colombia.}

Arquitecto: Giancarlo Mazzanti

Ubicación: Medellín, Colombia.

Tipo de Proyecto: Centro comunitario.

Usos: Educativo, Cultural y Emprendimiento.

Área: $6605 \mathrm{~m} 2$

Año: 2007 


\subsubsection{Centro de Cultura, Recreación y Educación Ambiental (CREA), Perú.}

Arquitectos: Arq. Ronald Moreyra y Arq. Vanessa Torres.

Ubicación: Lima, Perú

Tipo de Proyecto: Centro comunitario.

Usos: Cultural, recreativo y educativo.

Área: $1395 \mathrm{~m} 2$

Año: 2014

\subsubsection{Uva el Paraíso, Colombia.}

Arquitectos: Equipo de diseño de la Empresa de Desarrollo de Medellín (EDU) Ubicación: Medellín, Colombia.

Tipo de Proyecto: Centro comunitario.

Usos: Educativo, recreativo y cultural.

Área: $4331 \mathrm{~m} 2$

Año: 2015

5.2.5 Proyecto: La Misteriosa Historia del Jardín que Produce Agua, España.

Arquitectos: Arq. Mónica García Fernandéz y Arq. Javier Rubio Montero (Cómo crear historias)

Ubicación: Murcia, España.

Tipo de Proyecto: Centro comunitario.

Usos: Salud y recreación.

Área: 3000 m2

Año: 2015 


\subsection{Cuadro resumen}

\subsubsection{Proyecto}

Los proyectos analizados tienen un carácter educativo y social, donde brindan servicios a la comunidad y generan espacios públicos para el ocio. A nivel arquitectónico sus diseños y formas tratan de resaltar en el paisaje, siendo un punto de atracción para quienes pasan por la zona.

1. Centro de Recursos para el Aprendizaje y la Investigación (CRAI).

Proyecto educativo, social y emprendimiento.

2. Parque Biblioteca León de Grieff.

Proyecto educativo, social, cultural y de emprendimiento.

3. Centro de Cultura, Recreación y Educación Ambiental (CREA).

Proyecto cultural, social, recreativo y educativo.

4. Uva el Paraíso.

Proyecto educativo, social, recreativo y cultural.

5. La Misteriosa Historia del Jardín que Produce Agua.

Proyecto social, de salud y recreación.

\subsubsection{Ubicación y Relación con el entorno}

Los proyectos analizados se encuentran en zonas periféricas de sus respectivas ciudades, ubicados en barrios vulnerables y construidos mayormente en un terreno con pendiente. Están cerca de vías donde pasa el transporte público y a las escuelas. Esto proyectos son parte de un terreno mayor algunos dentro de un contexto natural y otras más urbano.

1. Centro de Recursos para el Aprendizaje y la Investigación (CRAI).

Ubicado en la zona residencial Colinas de San Javier, pertenece a la ampliación del colegio Liceo del Valle, terreno sin pendiente y cercano a una zona natural Bosque Los Colonos.

2. Parque Biblioteca León de Grieff.

Ubicado en zona residencial a la periférica de San Miguel, forma parte del Parque La Ladera, terreno en pendiente y cercano a zona natural Bosque Limoncito 
3. Centro de Cultura, Recreación y Educación Ambiental (CREA).

Ubicado en la zona residencial de San Juan de Lurigancho perteneciente al Parque Zonal Huiracocha, terreno sin pendiente.

4. Uva el Paraíso.

Ubicado en zona natural a la periferia de la ciudad de Medellín, cercano a la zona residencial de San Antonio de Prado, el terreno se encuentra en pendiente y cercano a una zona natural agrícola.

5. La Misteriosa Historia del Jardín que Produce Agua.

Ubicado en la zona residencial El Coso, terreno en pendiente y cercano a la zona agrícola de la ciudad de Cehegín.

\subsubsection{Perfil Urbano}

A nivel arquitectónico no superan los 3 niveles y respetan el perfil urbano de la zona, pero buscan resaltar en el contexto por su forma y ubicación. Los proyectos en ladera resaltan en el paisaje desde distintos puntos de la ciudad, dándoles una importancia como hito.

1. Centro de Recursos para el Aprendizaje y la Investigación (CRAI).

Perfil bajo respetando altura de la zona, no supera las 2 pisos.

2. Parque Biblioteca León de Grieff.

Volúmenes semienterrados, su ubicación en ladera con respecto al resto de la ciudad lo hace un hito.

3. Centro de Cultura, Recreación y Educación Ambiental (CREA).

Perfil bajo respetando la ciudad, no supera los 2 pisos.

4. Uva el Paraíso.

Volumen Semienterrado en ladera de perfil bajo.

5. La Misteriosa Historia del Jardín que Produce Agua.

Arquitectura semienterrada en ladera, mantiene el perfil bajo de la zona.

\subsubsection{Programa y relaciones programáticas}

A nivel programático tienen un uso educativo y social, brindando espacios para talleres, salas de estudio, salas de usos múltiples, espacios culturales, oficinas y talleres para 
asesorías de emprendimiento, servicios, espacios administrativos y espacios de recreación. Todos sus espacios son para toda la comunidad desde niños hasta adultos mayores. La relación que tienen con sus programas es mediante un espacio central que distribuye a zonas con un programa específico ya sea educativo, cultural, administrativo, emprendimiento y recreativo, comparten espacios comunes que los articulan unos con otros, como patios o salas de usos múltiples.

1. Centro de Recursos para el Aprendizaje y la Investigación (CRAI).

Cuenta con programa educativo, cultura, de oficinas, de servicio y espacio público.

2. Parque Biblioteca León de Grieff.

Cuenta con programa cultural, educativo, emprendimiento, servicios y espacio público.

3. Centro de Cultura, Recreación y Educación Ambiental (CREA).

Cuenta con programa cultural, educativo y espacio público.

4. Uva el Paraíso.

Cuenta con programa educativo, cultural, servicios y espacio público.

5. La Misteriosa Historia del Jardín que Produce Agua.

Cuenta con programa de salud, educación y espacio público.

\subsection{5 Áreas}

En los casos analizados, los proyectos se encuentran en terrenos mayores a una hectárea, pero el programa construido tiene un promedio de 4500 metros cuadrados. Dándole una mayor porción al espacio público y recreativo en un 50\%, luego a nivel de áreas les siguen los talleres educativos, culturales y de emprendimiento con otro $40 \%$, y finalmente las áreas administrativas y servicios que representan el $10 \%$.

1. Centro de Recursos para el Aprendizaje y la Investigación (CRAI).

Terreno: 3,500 m2 (asignado) 38,510 $\mathrm{m} 2$ (terreno total)

Construido: $5,749 \mathrm{~m} 2$

2. Parque Biblioteca León de Grieff.

Terreno: 6,800 m2 (asignado) 32,954m2 (terreno total)

Construido: $6,605 \mathrm{~m} 2$

3. Centro de Cultura, Recreación y Educación Ambiental (CREA).

Terreno: 1,800 m2 (asignado) 243,540 m2 (terreno total) 
Construido: $1,395 \mathrm{~m} 2$

4. Uva el Paraíso.

Terreno: $3,800 \mathrm{~m} 2$

Construido: $4,331 \mathrm{~m} 2$

5. La Misteriosa Historia del Jardín que Produce Agua.

Terreno: 4,436 m2

Construido: $715 \mathrm{~m} 2$

\subsubsection{Tipologías espaciales}

A nivel de tipología el programa forma parte de un gran espacio público que lo distribuye a todo el programa, mediante patios y caminos, en los casos estudiados la superficie de los techos son aprovechados como espacio de encuentro con programa recreativo u ocio.

\subsubsection{Espacio Público-Privado}

Para el análisis se consideraron el nivel de privacidad que adquiere el programa arquitectónico y como resultado se tiene que un 50\% del programa que corresponde a espacio de recreación y encuentro es público, un $40 \%$ son espacios semi-privados que corresponde a los talleres que se ofrecen y un $10 \%$ que son espacios privados correspondientes a zonas administrativas y depósitos.

1. Centro de Recursos para el Aprendizaje y la Investigación (CRAI).

Espacio público: $44.55 \%$ del proyecto construido

Espacio semipúblico: $37.93 \%$ del proyecto construido

Espacio privado: $17.52 \%$ del proyecto construido

2. Parque Biblioteca León de Grieff.

Espacio público: $60 \%$ del proyecto construido

Espacio semipúblico: $35 \%$ del proyecto construido

Espacio privado: $5 \%$ del proyecto construido

3. Centro de Cultura, Recreación y Educación Ambiental (CREA).

Espacio público: $62 \%$ del proyecto construido

Espacio semipúblico: $35 \%$ del proyecto construido

Espacio privado: $3 \%$ del proyecto construido 
4. Uva el Paraíso.

Espacio público: $72 \%$ del proyecto construido

Espacio semipúblico: $25 \%$ del proyecto construido

Espacio privado: $3 \%$ del proyecto construido

5. La Misteriosa Historia del Jardín que Produce Agua.

Espacio público: $86 \%$ del proyecto construido

Espacio semipúblico: $10 \%$ del proyecto construido

Espacio privado: $4 \%$ del proyecto construido

\subsection{8 Área ocupada}

Los casos estudiados se encuentran edificados en terrenos superiores a una hectárea, teniendo un promedio de $50 \%$ de área construida necesaria para el programa y otro 50\% asignada para áreas públicas, áreas verdes y de recreación.

1. Centro de Recursos para el Aprendizaje y la Investigación (CRAI). Área ocupada del terreno: $37 \%$ Área libre del terreno: 63\%

2. Parque Biblioteca León de Grieff. Área ocupada del terreno: $17.5 \%$ Área libre del terreno: $82.5 \%$

3. Centro de Cultura, Recreación y Educación Ambiental (CREA).

Área ocupada del terreno: $48.4 \%$

Área libre del terreno: $51.6 \%$

4. Uva el Paraíso.

Área ocupada del terreno: $79 \%$

Área libre del terreno: $21 \%$

5. La Misteriosa Historia del Jardín que Produce Agua.

Área ocupada del terreno: $13.8 \%$

Área libre del terreno: $86.2 \%$

\subsubsection{Tecnologías}

Los sistemas constructivos utilizados en los proyectos estudiados son construcciones tradicionales correspondientes a sus zonas, pero en su mayoría usan el concreto armado 
y la albañilería en casi toda la edificación, algunas estructuras son soportadas por vigas o columnas metálicas, que es países como México y España es muy accesible. Como varios de los proyectos se encuentran en zona de pendiente también se consideró la implementación de muros de contención.

1. Centro de Recursos para el Aprendizaje y la Investigación (CRAI).

Uso placas de concreto armado y losas colaborantes, también se empleó estructuras metálicas para circulaciones verticales y pérgolas en los pasillos exteriores.

2. Parque Biblioteca León de Grieff.

Uso de sistema de placas, columnas y muro de concreto armado. Para la entrada de luz se hace uso de celosías fijas. Uso de sistema de muro de contención y losas colaborantes.

3. Centro de Cultura, Recreación y Educación Ambiental (CREA).

Uso de losas y columnas de concreto armado, cerramiento de albañilería y uso de muro verde soportado por malla metálica.

4. Uva el Paraíso.

Se usó muros de concreto armado, losas aligeradas, paneles metálicos como celosía, sistema de cubierta verde sobre losa tipo Hydrotech para tener jardines en los techos y evitar la humedad.

5. La Misteriosa Historia del Jardín que Produce Agua.

Se empleó muros de contención, columnas de concreto armado que soportan una estructura metálica, la separación de espacios interiores hacen uso del drywall y para el espacio público se empleó listones de madera, y resina epoxica para tratar los caminos.

\subsubsection{Impacto social}

El impacto social de cada proyecto tiene un área que abarca a nivel ciudad, ya que los programas que se ofrecen y la accesibilidad, tanto como la ubicación, permite ser un punto atractivo dentro de la zona está en vías de consolidación, además de ofrecer espacio público de calidad. Se estima que cientos de personas correspondientes a sus ciudades son las beneficiarias ya que son concurridas diariamente tanto por los talleres o servicios ofrecidos como al espacio público que otorga a la ciudad. 


\subsection{Conclusiones parciales}

- Con el estudio de los casos tenemos un ratio para el pre dimensionamiento de los espacios del programa que se quiere ofrecer en el parque recreativo con centro comunal. En los casos se vieron distintos programas educativos, culturales y de emprendimiento para niños, jóvenes y adultos. Estos programas van orientados aquellas sociedades vulnerables que se encuentran en zonas que están en vías de ser consolidadas en la ciudad.

- El área promedio para el programa arquitectónico obtenido es de entre 4500 y 5 $500 \mathrm{~m} 2$ para una población de aproximadamente 50000 personas en un radio de influencia a nivel distrital.

- En algunos de los casos estudiados, el diseño participativo con los niños y jóvenes ayudaron a idear mejor sus espacios de aprendizaje y de encuentro con la comunidad, como también en la distribución del programa en el terreno donde se construiría la propuesta. El diseño del espacio público también fue aportado por la comunidad ya que ellos se conocen como vecinos y conocen la zona.

- El programa arquitectónico cuenta con espacios educativos, culturales y de emprendimiento en su mayoría, cuentan con amplios espacios comunes, patios, zonas deportivas y administrativas. Se concluye que un $50 \%$ de estos espacios sea de libre acceso, un $40 \%$ será semi privado y finalmente un $10 \%$ será de área privada. Para la propuesta del programa se considerará la realidad en la que viven los habitantes de la zona, y se pondrá en prioridad mejorar las condiciones en las que se encuentran mejorando sus espacios de aprendizaje, generándoles nuevas oportunidad y mejores espacios de encuentro para las familias y vecinos.

- Los terrenos de los casos estudiados son variados, algunos en pendientes pronunciadas otras en superficies planas pero el programa se desarrolla mayormente en un nivel plano adecuado al terreno, en el caso del proyecto "La misteriosa historia del parque que produce agua" que tiene un tratamiento de paisaje en pendiente que los otros casos no lo desarrollan por completo. El uso del agua es muy importante para mantener las áreas verdes de los espacios públicos, por ello se debe de considerar en un sistema de almacenamiento y purificación de agua para regar nuevamente la vegetación. 
- Es importante resaltar que el uso de espacios flexibles ayudarán a optimizar el espacio para múltiples actividades y cambiar el uso dependiendo de la cantidad de usuarios, necesidades, días y horas. Esto también se puede llevar a cabo con un buen mobiliario flexible. De esta manera los espacios de aprendizaje serán más adaptables y lúdicos.

- Los espacios públicos deben de contar con espacios de transición integrando el parque a los espacios interiores. Las zonas más públicas también deben ser amplias y cómodas para generar un programa al exterior, como talleres, actividades culturales como danzas, juegos y deportes. Como se plantea generar un parque los espacios de sombra y de estar son importantes para llevar a cabo estas actividades al aire libre.

- La percepción del espacio interior y exterior debe estar integrado, por un tema de diseño y de adaptar el proyecto al terreno, que el parque entre a los espacios interiores, que la naturaleza sea algo que se encuentre y se aprecie al interior y que lo interior salga al exterior y se transforme en público, generando mobiliario, juegos, espacios, rampas, escaleras, plataformas, coberturas, etc.

- Los sistemas constructivos empleados en los referentes son el concreto armado y el sistema de albañilería convencionales. También hacen uso de estructuras metálicas para aligerar la estructura.

- Los espacios diseñados deben ser flexibles al uso y al paso del tiempo, considerando zonas para futuras ampliaciones.

- El trabajo en pendiente se afrontará con muros de contención para mantener el talud seguro y usando una buena cimentación dependiendo a la calidad del suelo. El proyecto debe ser un centro de integración social, y la accesibilidad no debe ser impedimento para nadie, el uso de rampas se contemplará y se integrará como un diseño de paisaje.

- El impacto social que se espera es la de reducir la deserción escolar en los jóvenes, otorgándoles mejores ambientes para que puedan desarrollarse como estudiantes pero también como niños y jóvenes, donde puedan compartir con su comunidad y al mismo tiempo el proyecto va generar nuevas oportunidades para la empleabilidad generando talleres de emprendimiento y de cómo prepararlos para el mundo laboral. Estos nuevos espacios será para toda la comunidad de la 
zona, serán espacios de apoyo y de complementación para los colegios de la zona que no cuentan con los espacios suficientes o completamente equipados.

\section{CAPÍTULO VI: MARCO CONTEXTUAL}

\subsection{Análisis del lugar}

Manchay es una de las áreas más pobladas de Lima Este según el INEI (2016) contando con aproximadamente 70000 habitantes. (INEI, 2016). Es la ciudad con mayor deserción escolar en Lima donde 35\% son niños de entre 12 y 17 años deja los estudios. Otras poblaciones vulnerables son los jóvenes que no consiguen empleo y no tiene recursos para estudiar y las mujeres que en su mayoría son madres. Manchay al ser una ciudad dormitorio las dinámicas de la ciudad son muy tranquilas, pero podría tener un gran potencial si se generan espacios para integrar y fortalecer la participación de estas poblaciones vulnerables, mejorando su calidad educativa, generando nuevas oportunidades de emprendimiento y de empleabilidad. El estudio demográfico también ayudará a generar programas para distintos grupos de edades, tanto en actividades individuales como de integración, donde los niños podrán pasar tiempo con sus madres, o los jóvenes puedan enseñar a sus menores.

Manchay se encuentra en una zona de quebradas, con pocas áreas planas donde el 90\% de su población habita en laderas de cerros. El proyecto busca integrarse a la topografía para mejorar la accesibilidad de la zona, generar nuevas áreas verdes con programas usando los vacíos urbanos en riesgo de ser invadidos o de convertirse en basurales. Así mismo al ser un proyecto en ladera que pueda ser replicado en otras zonas con las mismas condiciones.

Teniendo en cuenta estos puntos en un mapa se identificarán 3 terrenos potenciales para el proyecto del Centro Comunal, en 3 zonas identificadas como las más necesitadas del sector. Para elegir finalmente el terreno de intervención se tomarán varios criterios más específicos que hará resaltar más las necesidades y precariedades de la zona. Con ayuda de una calificación según la escala de Likert, del 1 al 7, donde 1 es muy malo y 7 es muy buena. 
Para la selección final, el terreno que obtenga el puntaje menor será el terreno adecuado para desarrollar el proyecto arquitectónico de Centro Comunal debido a la cantidad de carencias identificadas que generan esta desigualdad y desarticulación con el resto de la comunidad.

Identificar las zonas con mayor déficit de educación primaria o secundaria en la población, así como las zonas con mayor desempleo entre la población económicamente activa.

\subsubsection{Criterios para la selección del terreno adecuado}

\subsubsection{Características de las Construcciones de la zona}

Se analizará el perfil urbano de la zona, identificando el tipo de vivienda o de construcción existente y su estado de precariedad, se mencionara los materiales empleados y las alturas.

Se hará una descripción del entorno inmediato considerando el estado en la que están.

\subsubsection{Consideraciones Ambientales}

Se identificara el tipo de clima presente en la zona del terreno, reconociendo el recorrido del sol, la dirección de los vientos, la frecuencia de lluvias, las temperaturas medias, la humedad relativa y los cambios de temperatura por estaciones y sus distintos cambios durante el día.

\subsubsection{Riesgos}

La clasificación del tipo de suelos permitirá saber si el lugar es edificable y saber su grado de vulnerabilidad ante un movimiento sísmico. También se identificará si su ubicación geográfica es propensa a algún otro tipo de desastre natural como inundaciones, deslizamientos de tierra o huaycos. Si es posible, también conocer los antecedentes del lugar para ver si terreno tiene algún riesgo geológico o medio ambiental. 


\subsubsection{Limitaciones Normativas}

Señalar si el terreno se encuentra legalmente con el uso que le corresponde, o si no está proyectado algún equipamiento nuevo en el terreno, también conocer si está en orden con su documentación y no tenga algún problema legal para poder desarrollar el proyecto.

\subsubsection{Acceso al Terreno}

Identificar los frentes que tiene el terreno con la ciudad, así como su accesibilidad a este de manera peatonal o vehicular, y conocer si tiene vecinos próximos.

\subsubsection{Vías de Acceso}

Considerar y medir las distancias que tiene el terreno con las vías más importantes o secundarias del distrito, también como las rutas peatonales y vehiculares que se tomaran para llegar al terreno e identificar los paraderos y rutas de transporte público más cercanos.

\subsubsection{Infraestructura y servicios disponibles}

Conocer si el terreno o la zona cuentan con los servicios básicos de agua, alcantarillado y electricidad para el desarrollo del proyecto, también identificar si tiene pistas pavimentadas, veredas, alumbrado público y si la zona tiene un sistema de recolección de residuos sólidos o algún programa de reciclaje.

\subsubsection{Uso de Suelos}

Identificar la zonificación asignada por la municipalidad al terreno de análisis y conocer sus posibles compatibilidades o restricciones. También se acudirá a las parámetros arquitectónicos del terreno en caso lo tengan. 


\subsubsection{Morfología}

Conocer la forma del terreno de análisis, sus proporciones e identificar sus zonas de pendientes, así como sus medidas.

\subsubsection{Percepción}

Identificar las visuales que tiene el terreno por cada uno de sus frentes, conocer las sensaciones que provoca el medio inmediato de donde esta y conocer cuáles son sus agentes contaminantes ya sean visuales, sonoros u olores.

\subsubsection{1 Áreas verdes}

Identificar los espacios públicos, con áreas verdes disponibles en la zona y/o conocer el déficit que tienen para generar una oportunidad de tenerlo.

\subsubsection{Educación y Trabajo}

Se debe de identificar terrenos cercanos a las escuelas para que sirvan de extensión y puedan ser de fácil acceso y en menor tiempo posible. Considerar las zonas donde se concentra el déficit de servicios y una mayor concentración de niños y jóvenes en etapa escolar. 


\subsubsection{Análisis del lugar para obtener el terreno de la propuesta arquitectónica}

Figura 6. 1

Información de Manchay

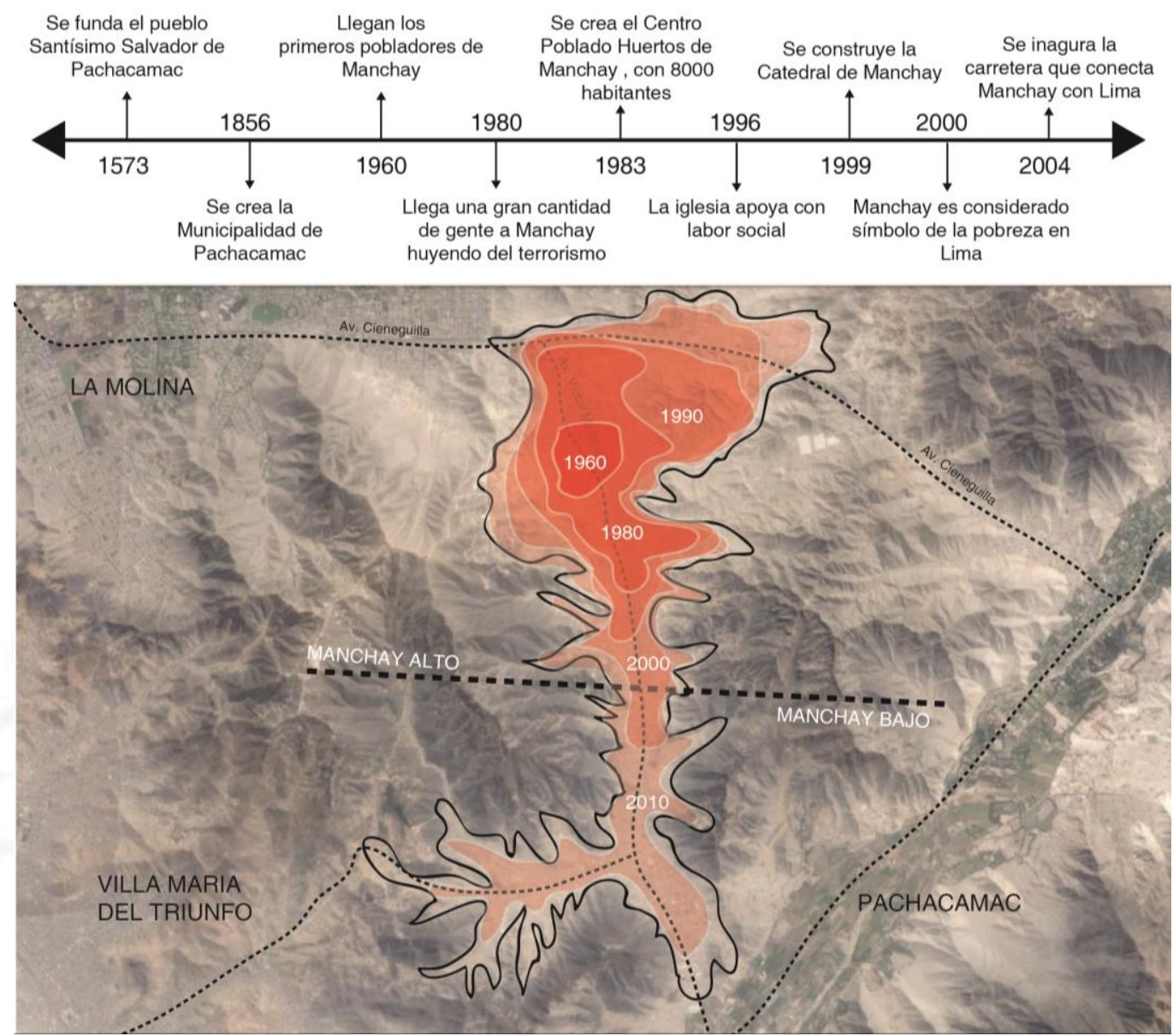

Fuentes: (Matos-Mar, Perú: Estado desbordado y sociedad nacional emergente, 2011) , (Matos-Mar, Potugal, \& otros, El Valle de Lurín y el pueblo de Pachacamac. Cambios sociales y culturales, 1964) Íconos: recuperados de https://thenounproject.com Gráfica: Elaboración propia (2016) 
Figura 6. 2

Corte del terreno de Manchay

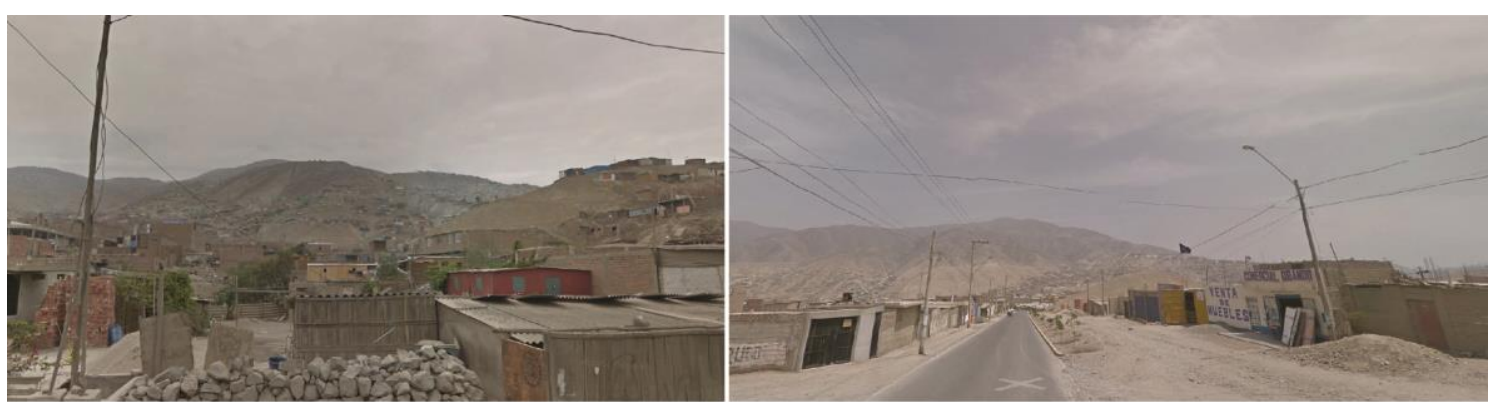

Vista al Centro Poblado Huertos de Manchay

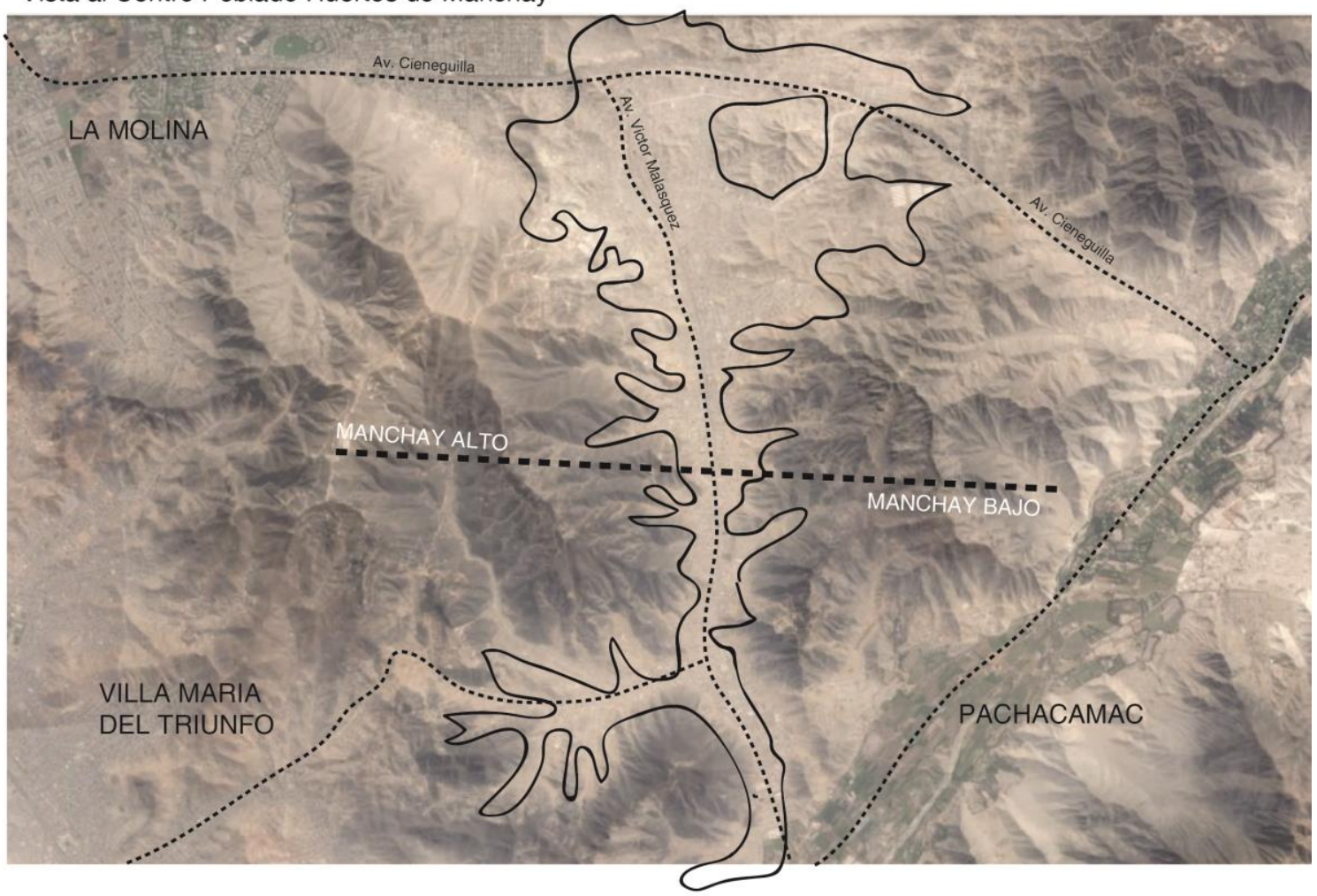

Corte de la quebrada

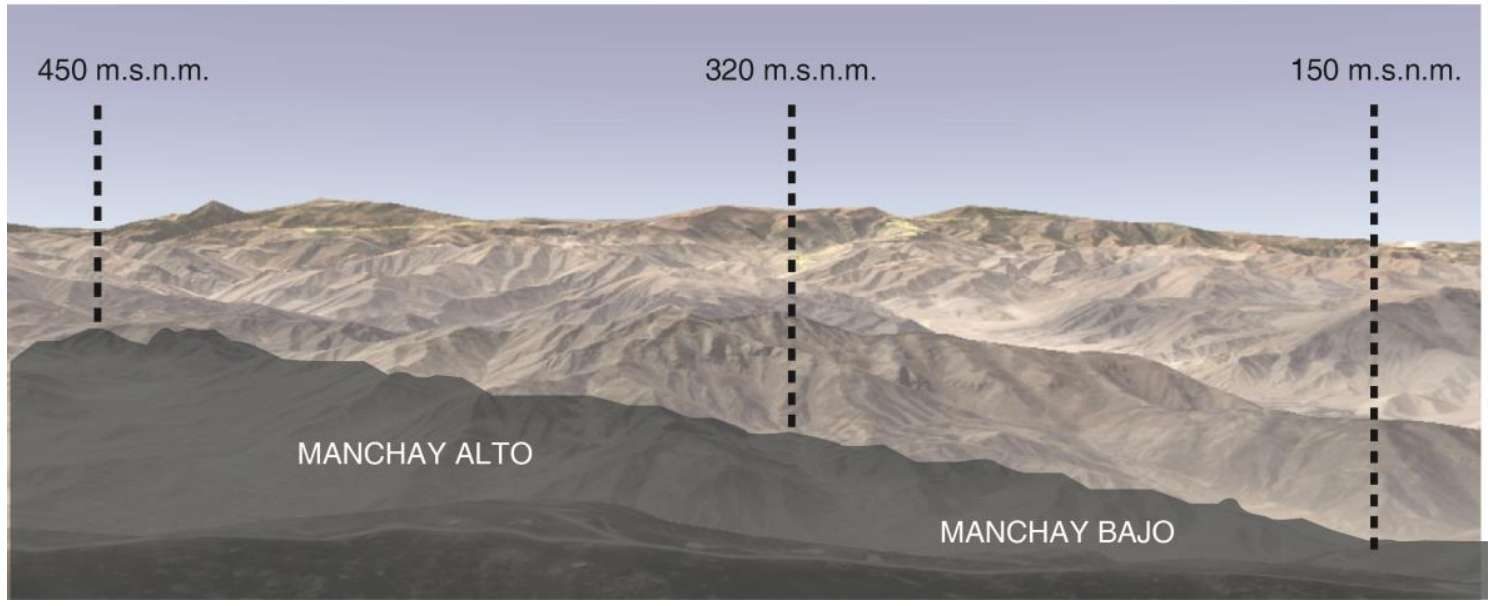

Fuentes: Google Maps 2016

Mapas: Google Earth Pro 2016.

Íconos: recuperados de https://thenounproject.com

Gráfica: Elaboración propia (2016) 
Figura 6.3

Mapa concentración de población en Manchay

1. MANCHAY_Población
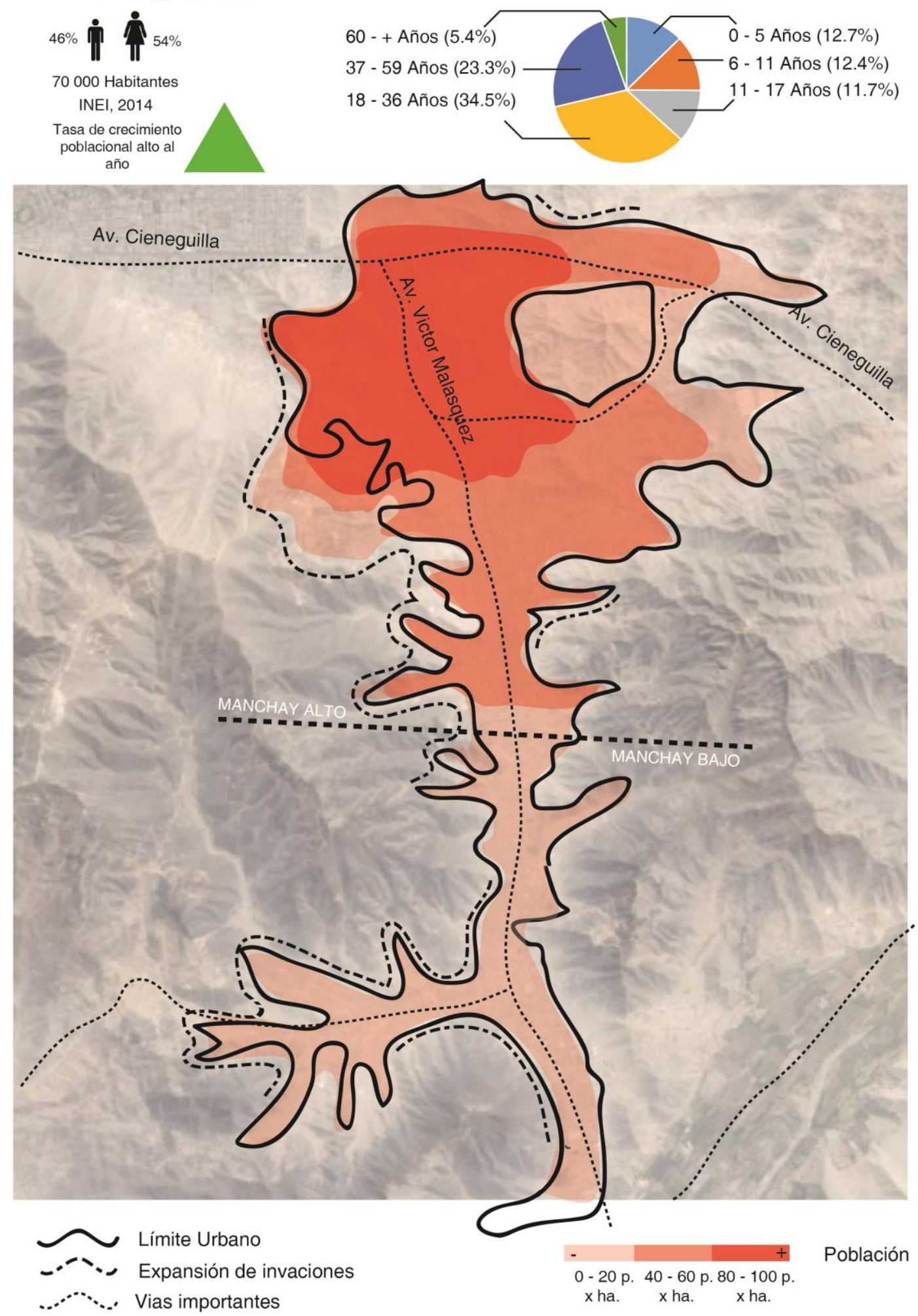

Fuentes: INEI 2016, (Municipalidad-de-Pachacámac, 2010)

Mapas: Google Earth Pro 2016.

Íconos: recuperados de https://thenounproject.com

Gráfica: Elaboración propia (2016) 
Figura 6.4

Mapa concentración de población económicamente activa en Manchay

2. MANCHAY_Trabajo
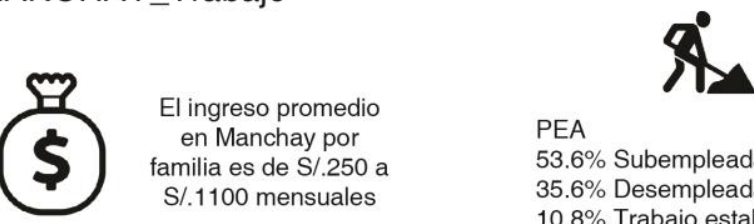

PEA

$53.6 \%$ Subempleada

$35.6 \%$ Desempleada

$10.8 \%$ Trabajo estable y adecuado
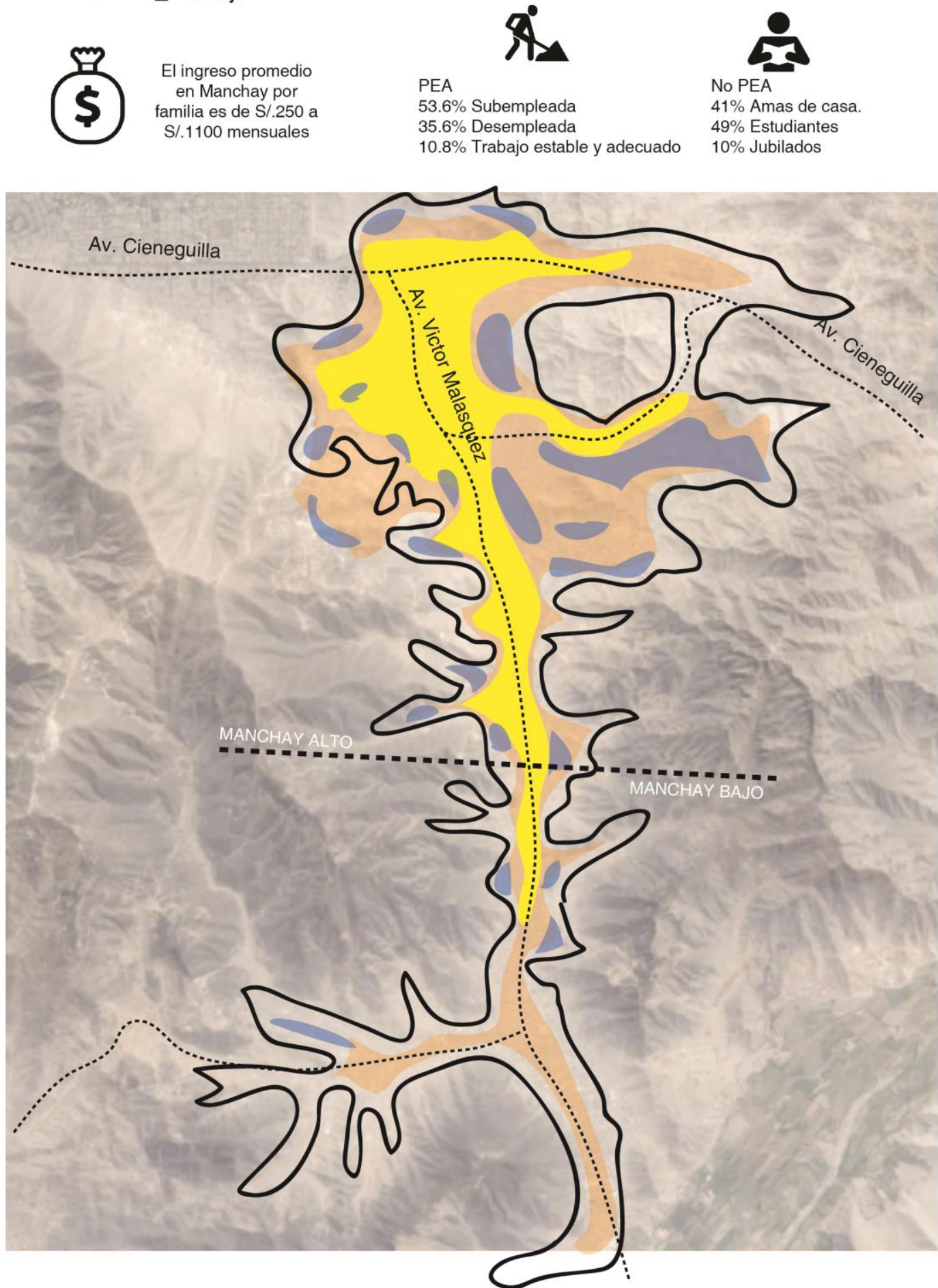

Población económicamente activa con trabajo fijo o con ingreso del sueldo minimo o menos- PEA Población económicamente activa mayormente en busca de trabajos constantes- PEA

Población económicamente no activa - No PEA

Fuentes: INEI 2016, (Municipalidad-de-Pachacámac, 2010), (Ministerio-de-Desarrollo-e-InclusiónSocial-(MIDIS), 2016)

Mapas: Google Earth Pro 2016.

Íconos: recuperados de https://thenounproject.com

Gráfica: Elaboración propia (2016) 
Figura 6. 5

Mapa de concentración de precariedad de vivienda en Manchay

3. MANCHAY_Vivienda
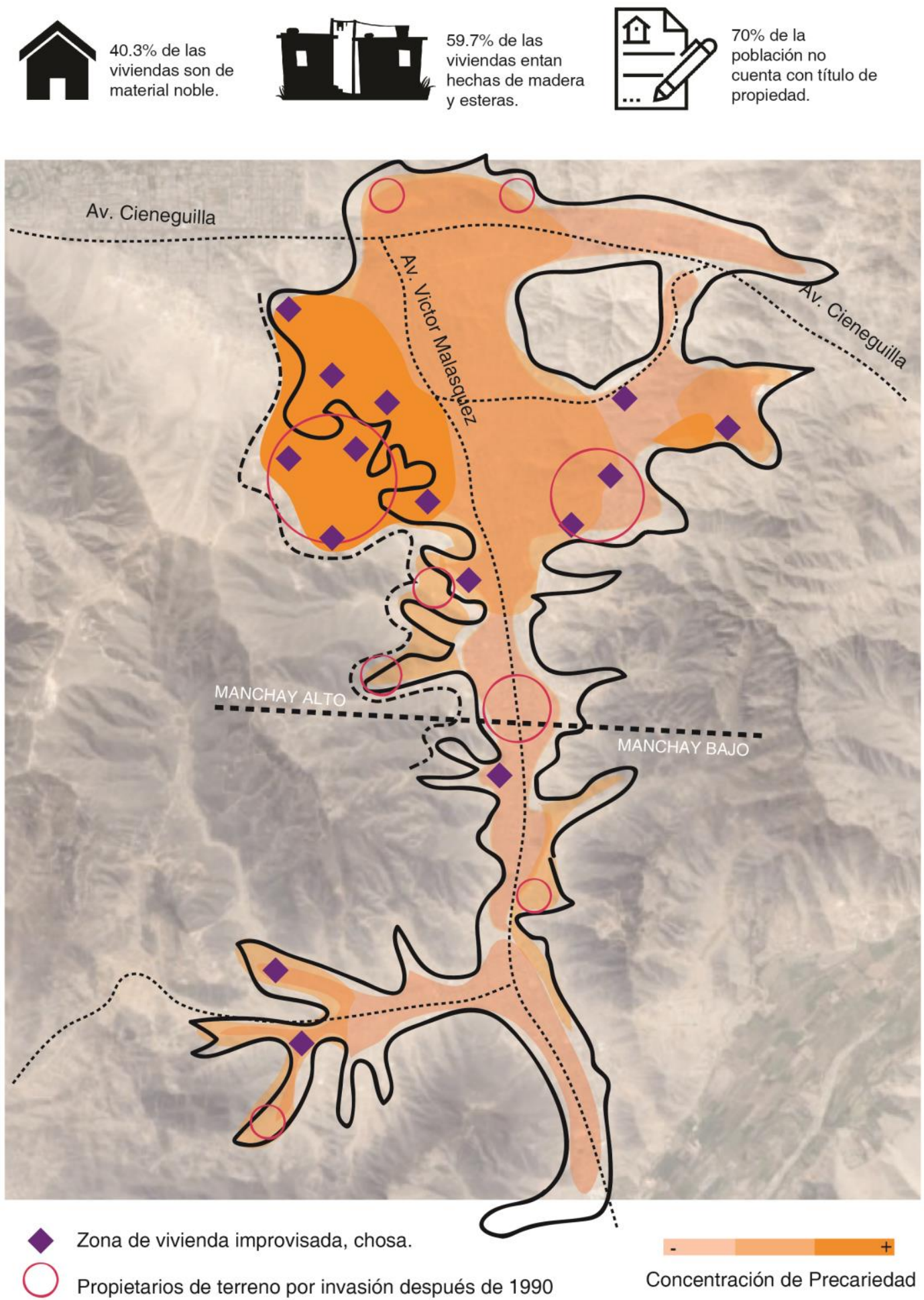

Fuentes: INEI 2016, (Municipalidad-de-Pachacámac, 2010), (Ministerio-de-Desarrollo-e-InclusiónSocial-(MIDIS), 2016)

Mapas: Google Earth Pro 2016.

Íconos: recuperados de https://thenounproject.com

Gráfica: Elaboración propia (2016) 
Figura 6. 6

Mapa de concentración de servicios básicos en Manchay

4. MANCHAY_Servicios básicos
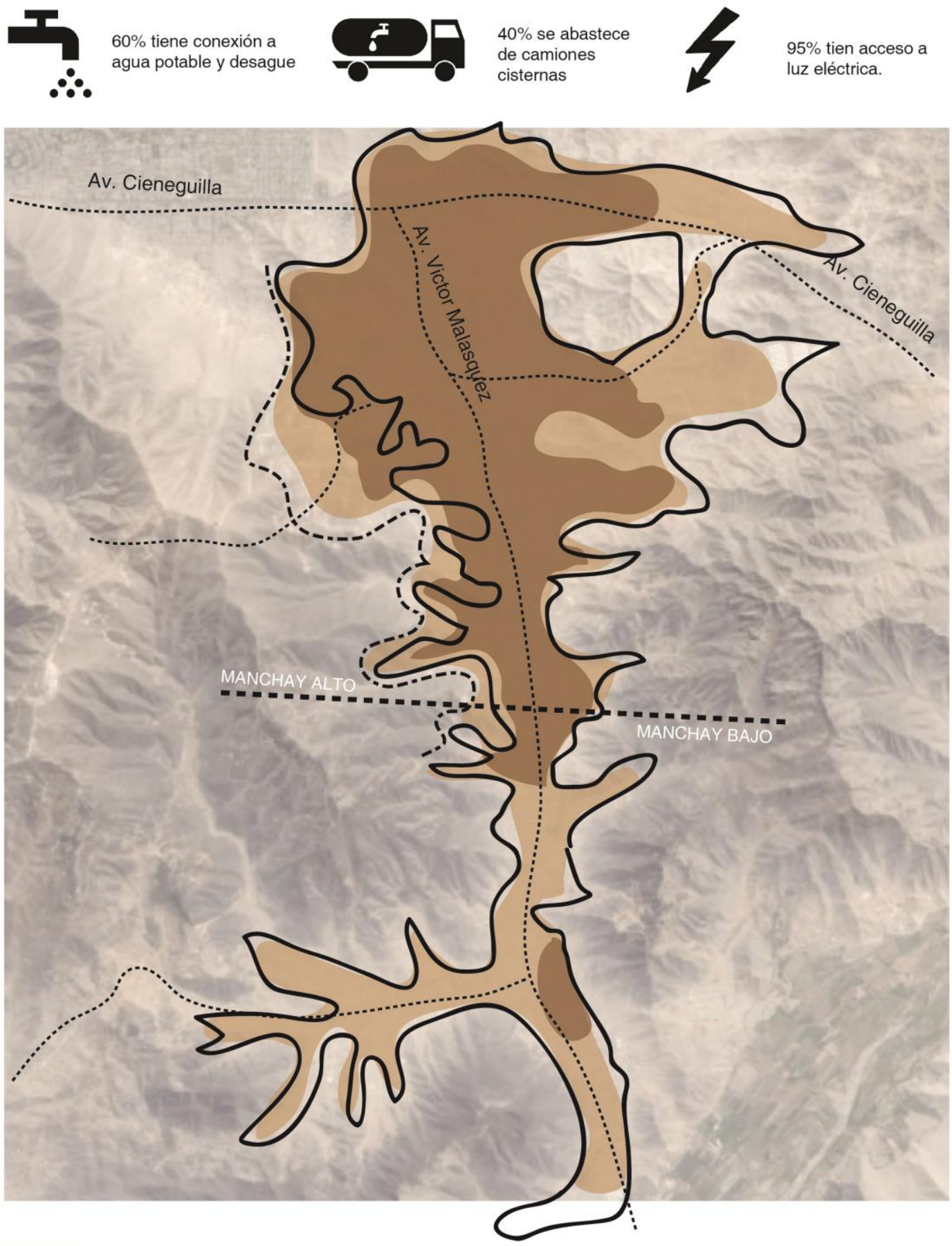

Zonas con servicio de agua y desague.

Zonas con servicio de electricidad.

Fuentes: INEI 2016, (Municipalidad-de-Pachacámac, 2010), (Ministerio-de-Desarrollo-e-InclusiónSocial-(MIDIS), 2016)

Mapas: Google Earth Pro 2016.

Íconos: recuperados de https://thenounproject.com

Gráfica: Elaboración propia (2016) 
Figura 6.7

Mapa de concentración deserción escolar en población mayor de 11 años en Manchay

\section{MANCHAY_Educación}
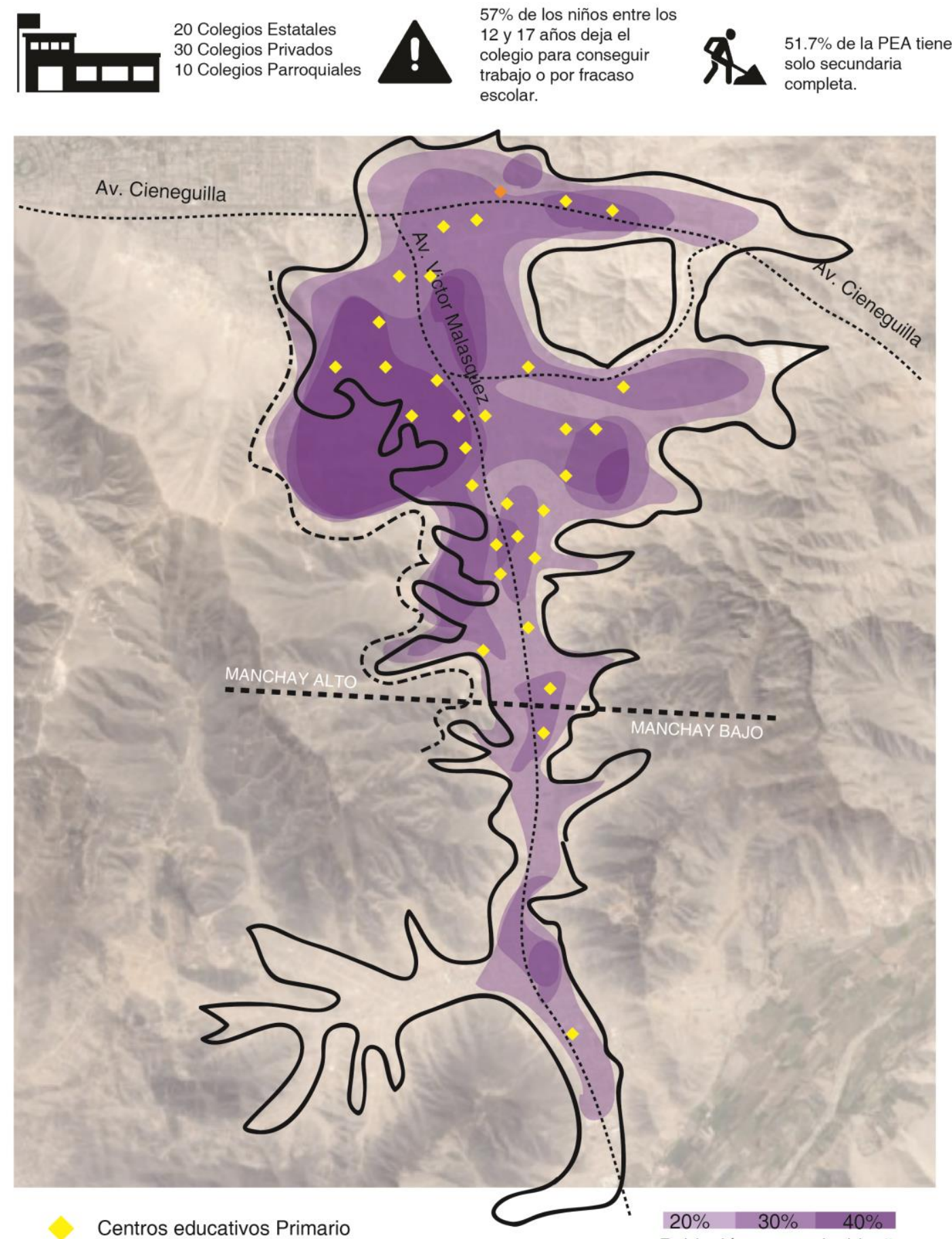

Población mayor de 11 años que únicamente ha alcanzado la educación primaria

Fuentes: INEI 2016, (Municipalidad-de-Pachacámac, 2010), (Ministerio-de-Desarrollo-e-InclusiónSocial-(MIDIS), 2016)

Mapas: Google Earth Pro 2016.

Íconos: recuperados de https://thenounproject.com

Gráfica: Elaboración propia (Lima, 2016) 
Figura 6.8

Mapa ubicación de parques públicos y zonas industriales en Manchay

6. MANCHAY_Áreas verdes_Área industrial
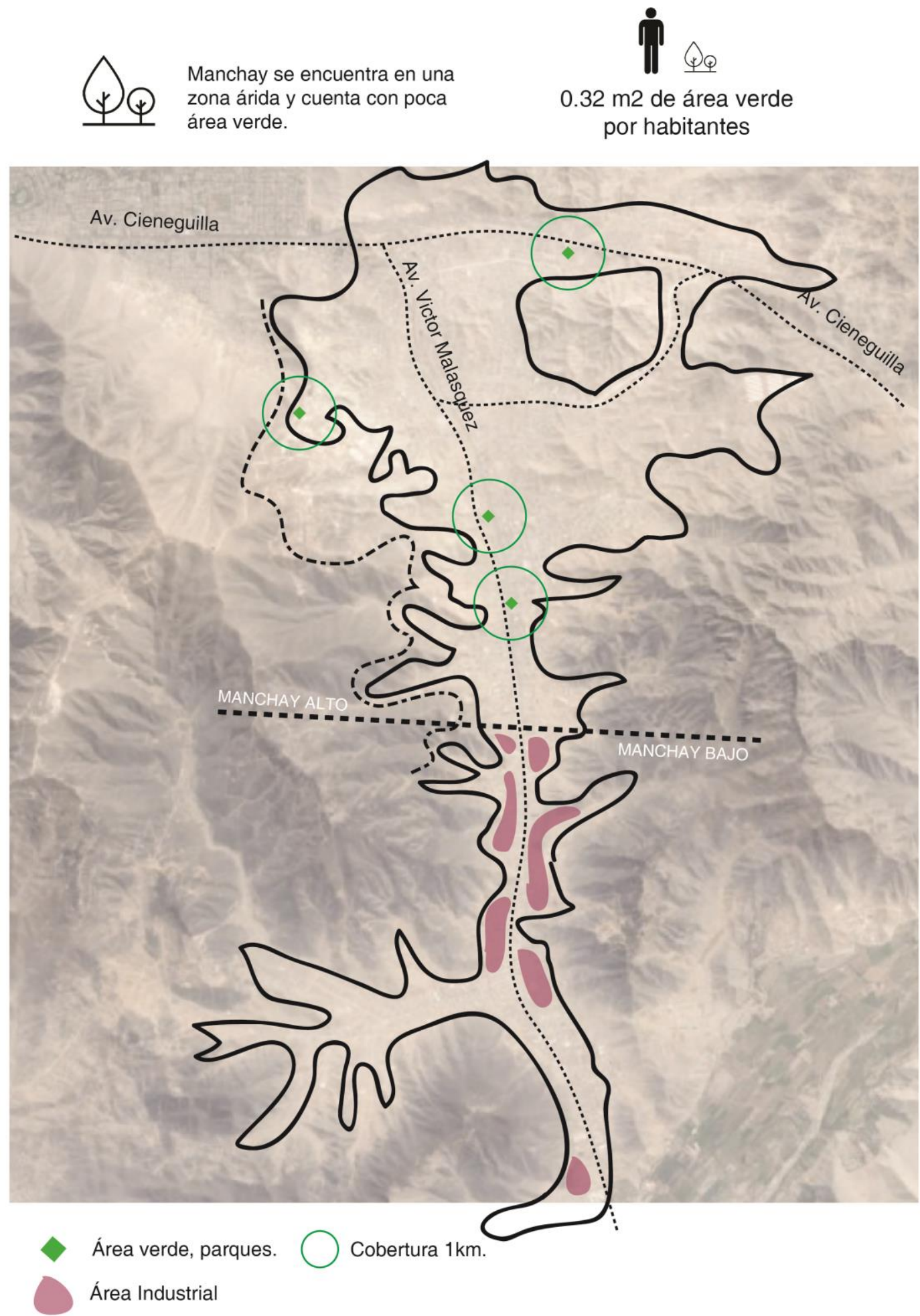

Fuentes: INEI 2016, (Municipalidad-de-Pachacámac, 2010), (Ministerio-de-Desarrollo-e-InclusiónSocial-(MIDIS), 2016)

Mapas: Google Earth Pro 2016.

Íconos: recuperados de https://thenounproject.com

Gráfica: Elaboración propia (2016) 
Figura 6. 9

Mapa ubicación de equipamiento urbano en Manchay

\section{MANCHAY_Equipamento Urbano}

- No cuenta con una estación de bomberos.

- No cuenta con centros comerciales.

- Falta de Espacios Públicos.

- Falta de Hospitales para cubrir la demanda.
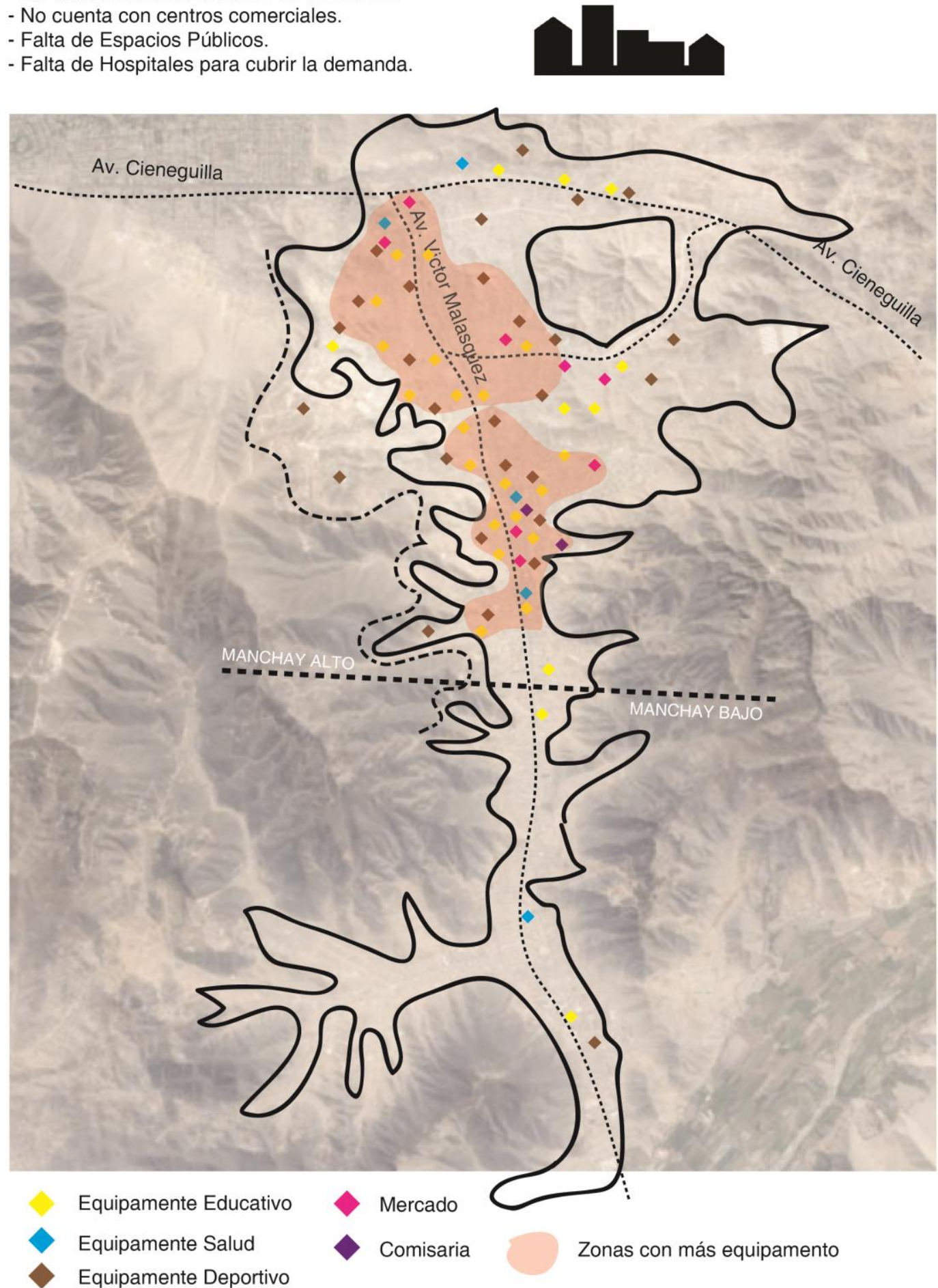

Fuentes: INEI 2016, (Municipalidad-de-Pachacámac, 2010), (Ministerio-de-Desarrollo-e-InclusiónSocial-(MIDIS), 2016)

Mapas: Google Earth Pro 2016.

Íconos: recuperados de https://thenounproject.com

Gráfica: Elaboración propia ( 2016) 
Figura 6. 10

Mapa de zonas de riesgo en Manchay

\section{MANCHAY_Riesgos}

Manchay se encuentra en una zona de alto peligro sísmico, en las partes bajas de las quebradas, debido a la intervención del terreno y a la precariedad de la construcción de las viviendas.
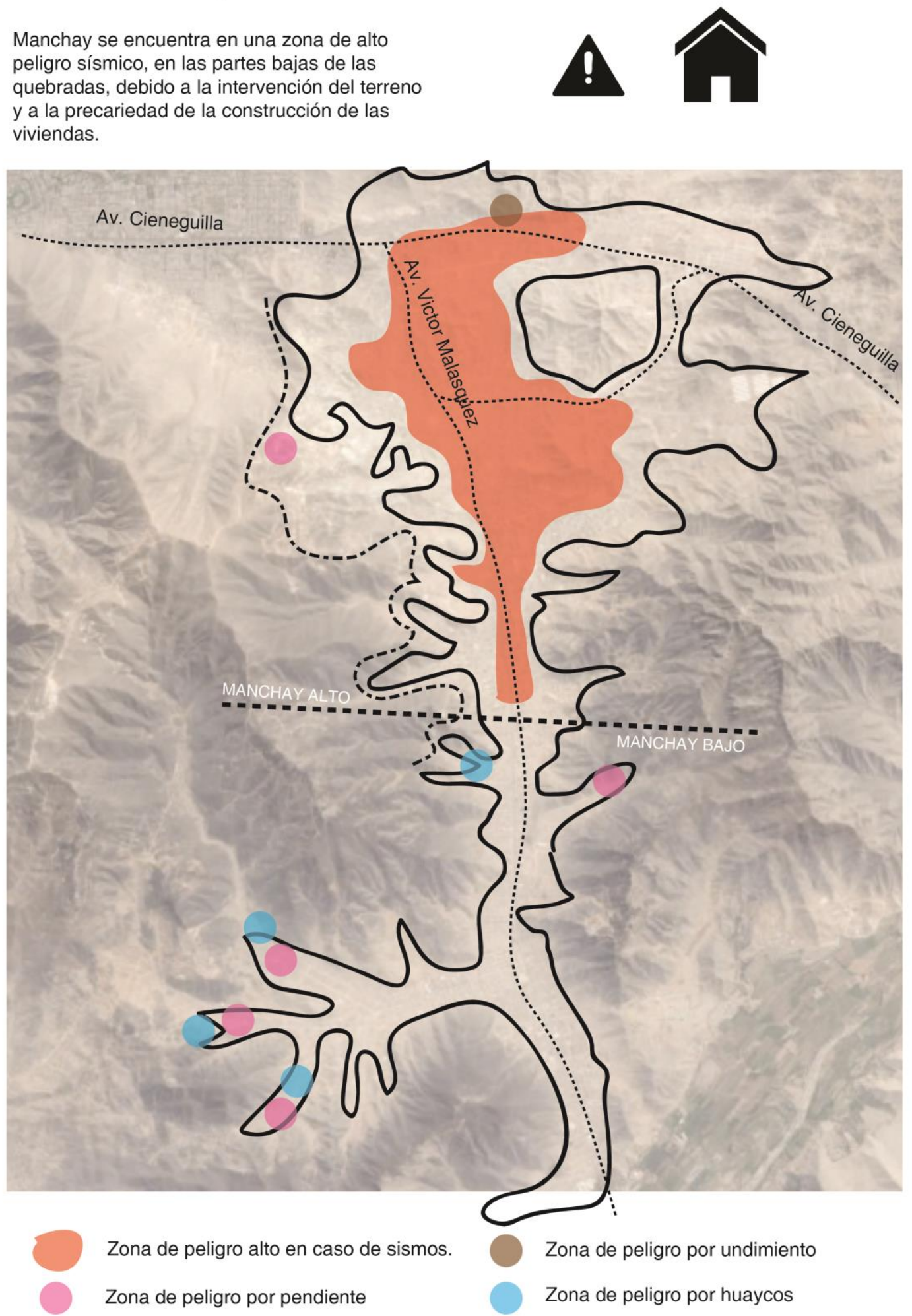

Fuentes: INEI 2016, (Municipalidad-de-Pachacámac, 2010), (Ministerio-de-Desarrollo-e-InclusiónSocial-(MIDIS), 2016)

Mapas: Google Earth Pro 2016.

Íconos: recuperados de https://thenounproject.com

Gráfica: Elaboración propia (2016) 
Figura 6. 11

Mapa resumen de criterios

8. MANCHAY_Resumen

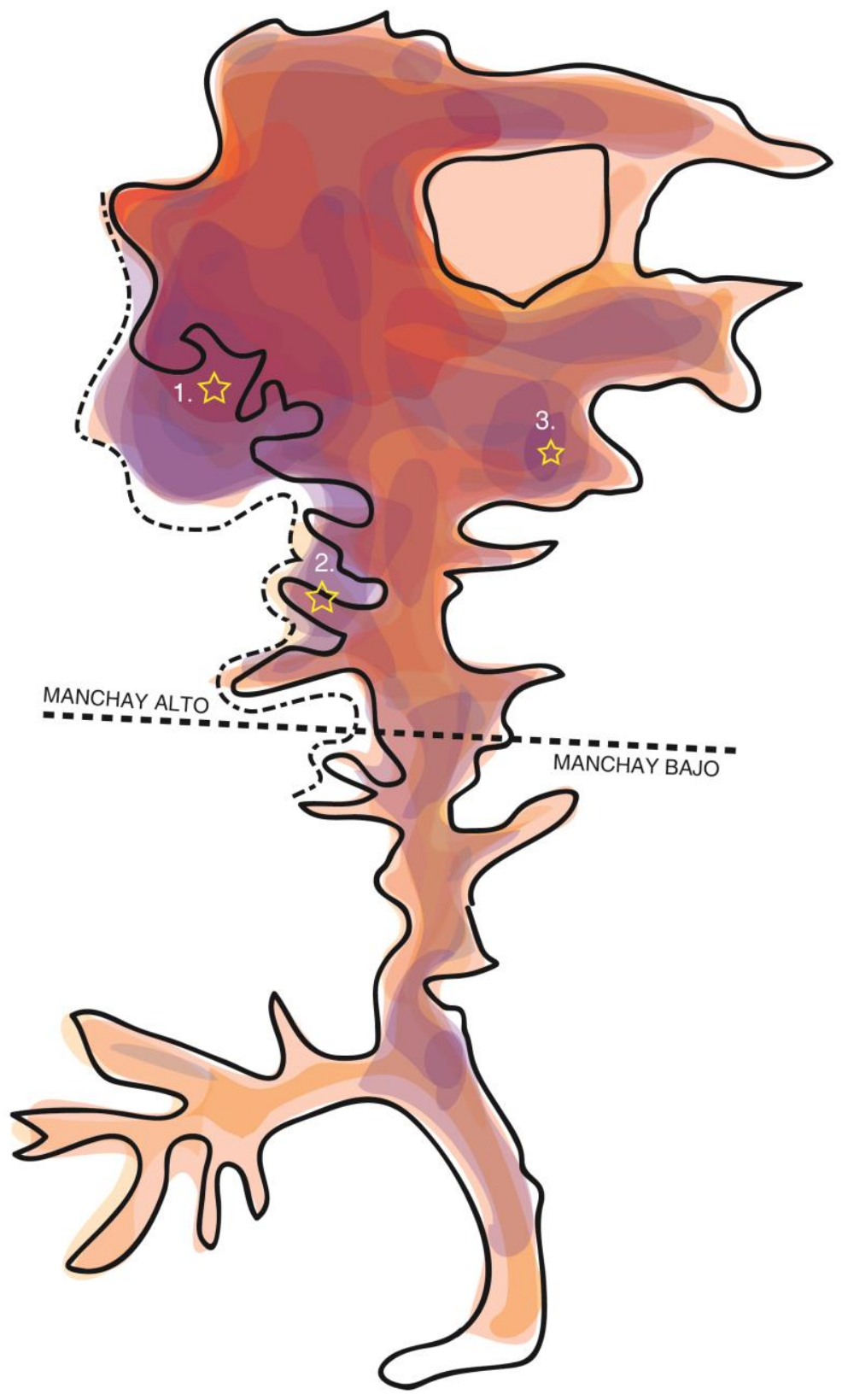

1. Corazón de Jesus

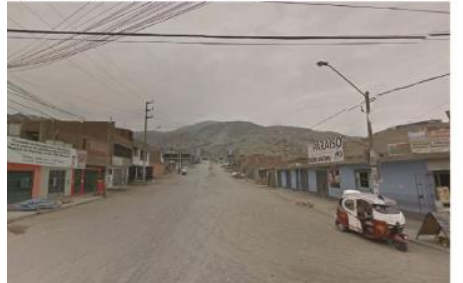

2. Huertos de Manchay Sector Central

3. Huertos de Manchay Sector K

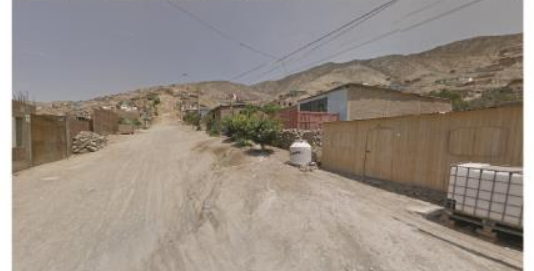

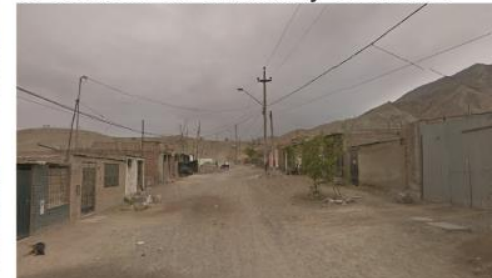

Fuentes: INEI 2016, (Municipalidad-de-Pachacámac, 2010), (Ministerio-de-Desarrollo-e-InclusiónSocial-(MIDIS), 2016)

Mapas: Google Earth Pro 2016.

Íconos: recuperados de https://thenounproject.com

Gráfica: Elaboración propia (2016) 
Figura 6. 12

Comparación de terrenos potenciales
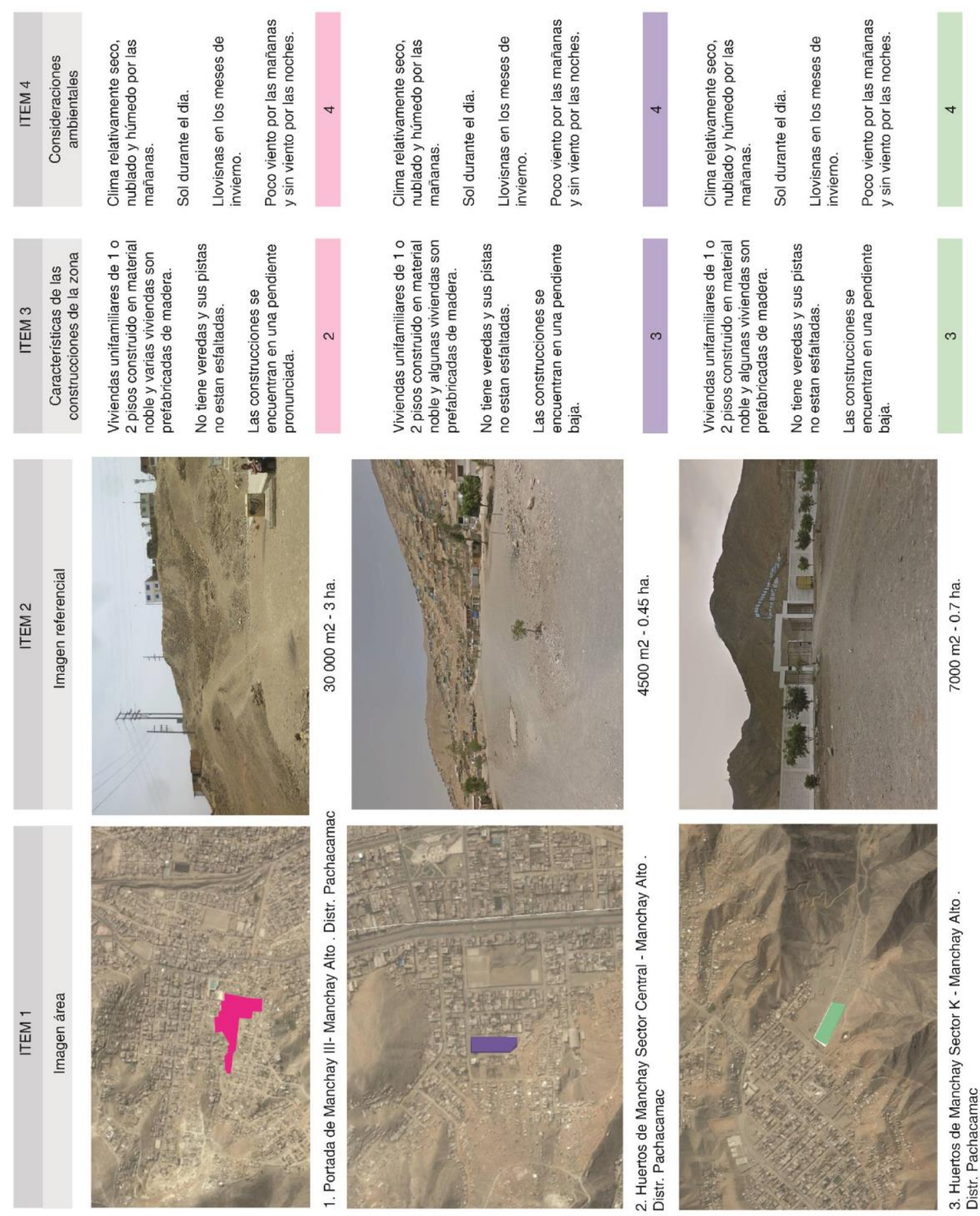

เ оนәมرว।

乙 оนәมرよ

$\varepsilon$ оиәндә

Mapas: Google Earth Pro 2016.

Gráfica: Elaboración propia (2016) 

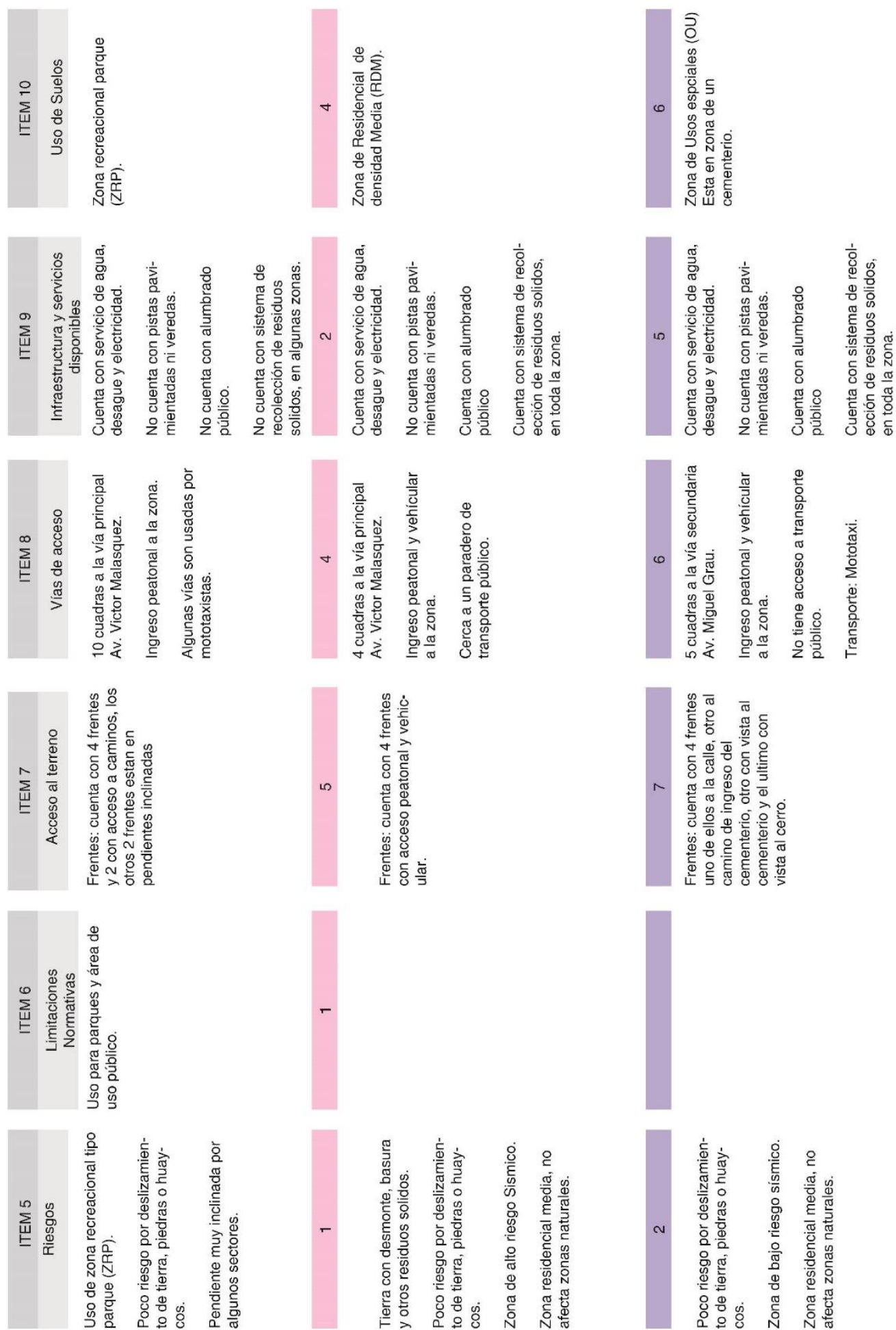

Mapas: Google Earth Pro 2016.

Gráfica: Elaboración propia (2016) 


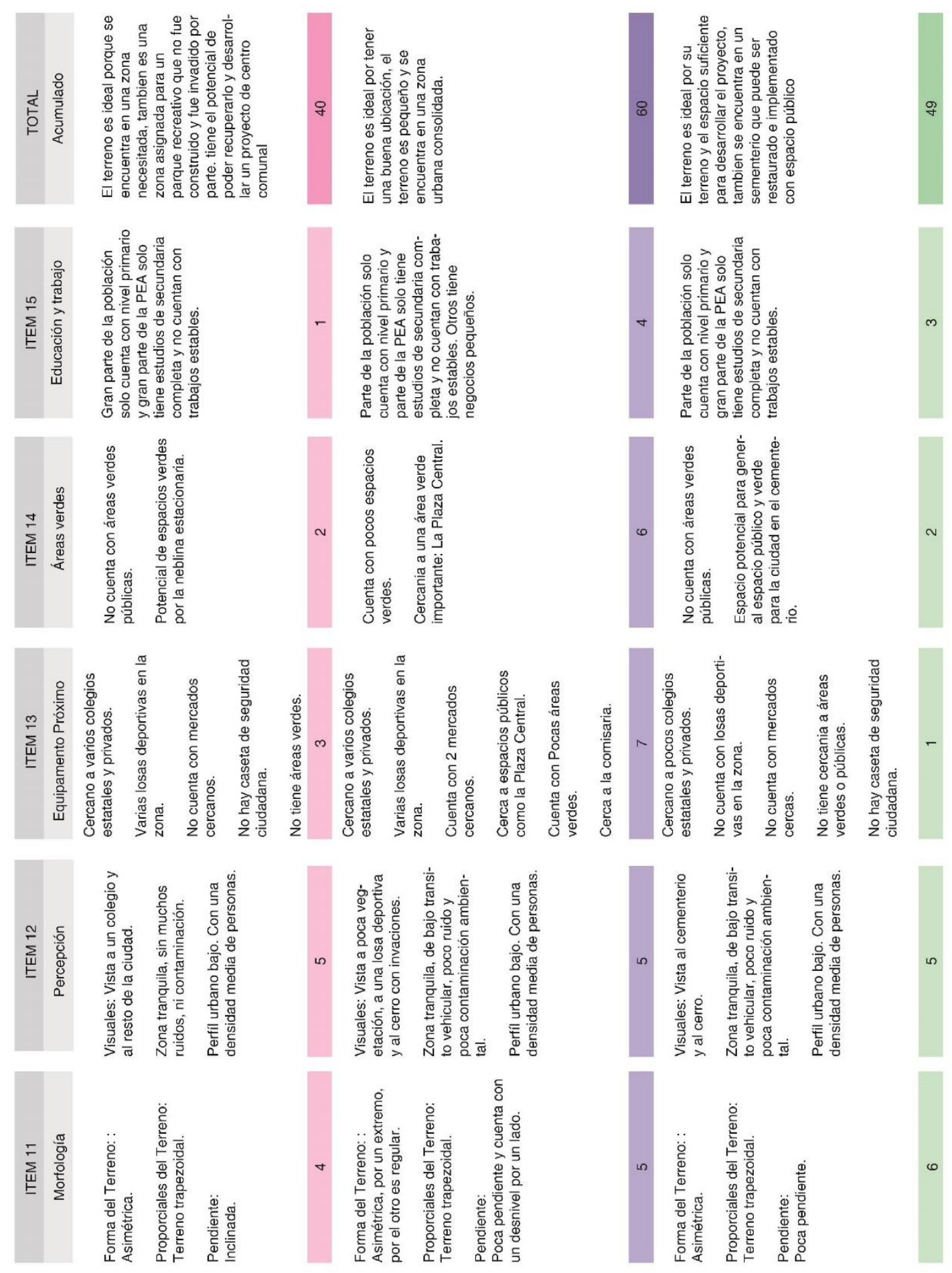

Mapas: Google Earth Pro 2016.

Gráfica: Elaboración propia (2016) 


\subsection{Red de equipamiento y radio de influencia}

Actualmente en la zona de Manchay es considerada una zona en proceso de consolidación debido a la falta de equipamiento urbano así como vías de acceso y sistema de servicios básicos como el agua y desagüe. Sus espacios públicos no cuentan con el equipamiento adecuado para satisfacer a la ciudadanía, como áreas recreativas, espacios de sombra, espacios para sentarse o estar, áreas verdes etc.

Los centros comunitarios que son apoyadas por ONGs como RuwaSunchis son espacios en estado de precariedad y no satisface a su población objetivo.

Así mismo se identificó que existe una organización por parte de los barrios de la zona, las madres son las más comprometidas para hacer actividades deportivas o de emprendimiento para sacar adelante a sus familias. El proyecto plantea proporcionar espacios para ellas y puedan seguir trabajando en sus proyectos en condiciones más adecuadas con mejores facilidades de espacios y servicios.

El proyecto de parque recreativo con centro comunal busca brindar un espacio público que aporte a la ciudad un adecuado espacio de esparcimiento y ocio, también espacios óptimos para las actividades comunitarias y pueda satisfacer al usuario objetivo que son los niños, jóvenes y madres en estado de vulnerabilidad y la población en general.

El radio de influencia que se propone será a nivel distrital pero enfocado en la zona de la quebrada de Manchay Alto y Bajo, ya que concentra la mayor parte de la población del distrito es la menos consolidada con equipamiento urbano y áreas verdes públicas. Las personas beneficiarias del proyecto serían más de 8000 jóvenes y menores de edad que se encuentran en estado de vulnerabilidad por haber dejado los estudios o piensan dejarlo en algún momento y un total de 2500 familias de los distintos sectores de Manchay que tendrían acceso a los distintos talleres y el espacio público. 
6.3 Variables del lugar 


\subsection{Conclusiones parciales}

- El terreno para el proyecto sale del resultados del análisis previo del lugar y se ubica en la zona de San Pablo Mirador tiene un área de casi 30000 m2, se encuentra en pendiente y tiene un alto potencial por su ubicación en la ladera y que puede ser un hito importante para la ciudad, ya que puede verse desde distintos puntos. También tiene unas visuales muy buenas a la ciudad desde el terreno.

- Actualmente el terreno es un gran vacío urbano en la ciudad con una losa deportiva en la parte inferior. Tiene zonas usadas como basural o desmonte. Mucha gente pasa constantemente por el terreno, ellos mismos generaron sus propios senderos marcados en la tierra. A pesar de ser un gran vacío en medio de la trama urbana mucha gente no lo percibe.

- El terreno se encuentra en una zona de pendiente, solo cuentan con escaleras, en algunas zonas se encuentran en malas condiciones. Las vías vehiculares si están habilitadas desde su punto más bajo hasta el más alto, teniendo una pista que lo bordea.

- Los servicios básicos en la zona están habilitadas: luz, agua y desagüe. Pero el terreno en si no tiene.

- Por parte de la municipalidad de Pachacamac no se generan obras de viabilidad y de servicios, la municipalidad de Lima se está encargando de ello.

- La zonificación asignada por la Municipalidad es de ZRP (Zona de recreación pública) por lo que puede ser transformado en un parque urbano y tiene compatibilidad con centro comunal. De esta manera se podrá desarrollar el proyecto y generar un nuevo gran espacio público para la comunidad con distintos espacios de encuentro, de sombra y de recreación.

- El proyecto tendrá también como objetivo mejorar la accesibilidad de la zona, generando nuevos y mejores accesos mediante rampas y escaleras que formarán parte de un sistema de caminos integrados al paisaje.

- El programa arquitectónico que se planteará va ir enfocado a la educación de los niños, al emprendimiento de los jóvenes y al empoderamiento de las mujeres. Para combatir contra la deserción escolar, generar nuevas oportunidad de empleabilidad de emprendimiento para los jóvenes y mujeres de la zona. 
- Una de las ventajas de la zona es la organización de la comunidad, existen grupos de madres y jóvenes que gracias a la ONG Ruwa Sunchis pueden desarrollar actividades en conjunto para apoyarse entre sí y generar ingreso a las familias gracias al trabajo de las madres tejedoras que ofrecen productos a distintas empresas.

- A nivel de diseño el terreno tiene una mayor longitud de este a oeste, los ambientes tendrán iluminación natural con vanos con dirección norte sur así mismo ayudará también con la ventilación que va de sur a norte.

- La tierra de Manchay es fértil, muchas familias de la zona tienen huertos en sus jardines, otros cuentan con árboles frutales y lo aprovechan para su consumo diario o para generar un pequeño ingreso. Para el proyecto del parque se contará con especies de árboles, plantas y arbustos que requieran poco consumo de agua y que requieran poco mantenimiento teniendo mucha resistencia a las plagas y al asoleamiento. 


\section{CAPÍTULO VII: CONCLUSIONES FINALES DE LA INVESTIGACIÓN}

- Lima es una ciudad en constante cambio y expansión sin planificación, los motivos por el cual la gente sigue llegando a la ciudad son diversas, principalmente búsqueda mejores ofertas laborales y de educación y huir de la violencia. Manchay es uno de los tantos lugares en la periferia de Lima donde las personas se establecieron proveniente del interior del país, durante los años 60 migraron y se establecieron por temas laborales a causa del auge de la construcción de Lima Este, posterior a ello durante los años 80 las personas llegaban ahí a causa del miedo y la violencia generada por el terrorismo. Manchay "nació" a causa de este miedo, y sus primeros pobladores se establecieron en los cerros sin servicios básicos, ni vías que los conecten. En el año 2000 la Municipalidad de Lima reconoció a Manchay como la zona más pobre de Lima y empezaron los trabajos de habilitación urbana y de consolidación. Han pasado 18 años desde el inicio de la consolidación de Manchay con el resto de la ciudad, pero aún falta mucho trabajo por hacer a nivel social y urbano.

- En Manchay el 35\% niños entre 12 y 17 años deja los estudios por múltiples motivos, ya sea por problemas económicos, porque tienen que apoyar a sus familias, falta de motivación y de conocimiento del valor de una educación básica de calidad. Un indicador alto en Manchay son los jóvenes entre los 18 y 25 años que no estudian ni trabajan, ya sea por no tener una educación básica, técnica o superior, también por no estar capacitados para entrar y presentarse al mundo laboral. Otro grupo social vulnerable con las mujeres, en su mayoría son madres jóvenes, que se dedican al hogar y al cuidado de los hijos, pero también son parte de un grupo muy afectado por la violencia de género y el machismo por parte de sus parejas o inclusive de su familia.

- El proyecto plantea el diseño de espacios donde se puedan desarrollar programas sociales, para reducir todos los indicadores mencionados anteriormente y poder ayudar a estas poblaciones vulnerables, así mismo diseñar espacios de integración y recreación para la comunidad de Portada de Manchay III y San Pablo Mirador, que son las zonas donde se encuentra el terreno propuesto gracias a un análisis de la zona donde se consideraron varios indicadores que identificaron el déficit de 
servicios y equipamiento, también identificando problemáticas en la zona que deber ser atendidos.

- Los programas sociales que formarán parte del programa arquitectónico son de carácter educativo, cultural y de emprendimiento. Serán espacios que apoyen a los colegios de la zona, brindaran talleres para niños y jóvenes, también se motivará a las iniciativas de emprendimiento mediante capacitaciones en trabajos manuales y técnicos.

- El terreno elegido se encuentra en la ladera de un cerro en la zona de San Pablo Mirador, cuenta con $28332 \mathrm{~m} 2$. Actualmente hay una losa deportiva y tiene varios problemas como invasiones, acumulación de desmonte y basura. El lugar escogido tiene un gran potencial por estar en medio de una trama urbana y por su ubicación en ladera está expuesta a una mirada panorámica de la ciudad convirtiéndolo en un hito potencial al tener el proyecto desarrollado.

- La accesibilidad peatonal a la zona es complicada e insegura, las escaleras están mal diseñadas y no existen rampas para discapacitados, actualmente se están desarrollando proyectos de asfaltado de pistas y señalización. Uno de los objetivos con el proyecto es mejorar la accesibilidad de la zona a través de una red de caminos con rampas y escaleras, proponer distintos espacios de estar y de encuentro que se integren con la arquitectura y el paisaje.

- La pendiente que presenta el terreno va a ser utilizado como una fortaleza para diseñar una arquitectura que se adecue a la pendiente, mejorando su accesibilidad y generar distintas plataformas a desnivel, la pendiente también va ser trabajada proponiendo plataformas de ocio y recreación para los niños y familias en general. Podrá ser ideal para un sistema de regadío en pendiente.

- Los servicios básicos de luz, agua y desagüe están presentes en la zona, por lo que pensar en estrategias para obtener recursos como el agua no será tan complicado. De todas maneras al plantear un parque con áreas verdes, se necesitará un espacio donde almacenar agua para su mantenimiento, se planteará estrategias pasivas para purificar y reutilizar el agua de regadío o de algunos servicios para optimizarlo. También se propondrán distintas especies de plantas, arbustos y árboles que consuman poca agua, requieran poco mantenimiento y que sean resistentes a la radiación constante. Se ubicarán de tal manera que puedan ofrecer distintos espacios de sombras para los caminos y espacios de estar. El tratamiento 
de paisaje busca mejorar las condiciones de confort tanto al exterior como al interior, también poder transmitir un lugar de tranquilidad y de conexión con la naturaleza, cambiar la percepción del usuario con su medio inmediato.

- El proyecto de parque recreativo con centro comunal busca ser un espacio de integración y fortalecimiento social que pueda expandirse y mantenerse en el tiempo, proyectado en etapas para luego seguir en expansión. Sus espacios también serán flexibles para distintas actividades y usuarios. El proyecto puede tener una inversión costo-beneficio teniendo el apoyo de entidades tanto públicas como privadas para la construcción, tener el apoyo de voluntarios en los primeros momentos para que poco a poco el centro pueda mantenerse económicamente, para ello con ayuda de la comunidad y los talleres técnicos puedan producirse productos que puedan ser ofrecidos al mercado. Actualmente la ONG Ruwasunchis tienen talleres con madres tejedoras, donde ellas mismas hacer tejidos manuales y son ofrecidas a empresas o a marcas que las representen, ellas mismas logran obtener un ingreso para sus familias y parte del ingreso obtenido puede ser asignado para el mantenimiento de las instalaciones.

- Las familias que viven en Portadas de Manchay III y San Pablo Mirador tienen buena relación, comparten actividades y desarrollan talleres juntos gracias a la participación de Ruwasunchis y de la misma agrupación de vecinos. Actualmente la asociación de vecinos de San Pablo Mirador se encuentra construyendo un centro comunal que le pertenece a los vecinos de la zona y que tendrá ambientes de usos múltiples para juntas vecinales y para eventos sociales.

- Con el proyecto Parque recreativo y Centro Comunal Mirador de Manchay se busca proponer una iniciativa arquitectónica articulada en ladera para una de las poblaciones más vulnerables de Manchay, a través de espacio públicos y espacios para programas sociales, el objetivo es plantear desde el espacio una base para lograr en el tiempo una sociedad más justa, equitativa y organizada.

- Con el estudio in situ de la población de Manchay se podrían desarrollar de forma efectiva programas sociales como talleres educativos $\mathrm{y}$ proyectos de emprendimiento gracias a que ya existe la iniciativa por parte de los vecinos solo que no cuentan con la infraestructura adecuada para desarrollarlas adecuadamente, necesitan espacios más amplios, ventilados, iluminados, áreas 
verdes y mejores espacios de recreación o desarrollo de actividades deportivas que también son de gran ayuda para la integración barrial.

- El proyecto de parque recreativo busca generar estos nuevos espacios de ocio que tanto requiere la población, donde los niños puedan aprender jugando y las familias puedan relacionarse con el resto de la ciudad y no tengan que recorrer largas distancias para acudir a un buen espacio de encuentro. Estos espacios serán pensados para que su uso cambie en el tiempo, espacios flexibles y adaptables a la necesidad del momento, asimismo se abrirán hacia otros espacios para albergar más usuarios o cambiar el uso.

- Las teorías planteadas en el capítulo 3 aporta un panorama de los modelos que sigue este proyecto en cuanto a nivel de diseño y como se planea abordar frente a un contexto como Manchay. En primer lugar la arquitectura debe integrarse a su terreno en pendiente, y ubicar los caminos de la manera más eficiente para el recorrido peatonal ya sea mediante rampas o escaleras. Respetar el perfil urbano de la ciudad manteniendo una altura adecuada. Una manera de llegar a un diseño con un programa adecuado para la población objetivo es comunicación directa con ellos, el desarrollo de talleres de diseño participativo, la observación de la población con su entorno inmediato así como la relación entre vecinos.

- Existe la oportunidad de usar un vacío urbano dentro de la trama de la ciudad que corre el riesgo de ser invadido a usado como basural. Generar un gran espacio público para otorgar protagonismo a la zona, darle valor y hacerlo parte de la comunidad será uno de los objetivos proyectados. El diseño del paisaje al igual que la arquitectura buscarán ser un punto de atracción en la zona por su contraste natural que hace falta.

- Con el estudio de casos existentes a un contexto tanto físico como social a la de Manchay, se puede analizar mejor la manera en cómo fueron planteadas, diseñadas y ejecutadas. Uno de los referentes más cercanos son la de los Parque Biblioteca de Medellín, que mediante un diseño participativo, inversión públicoprivada y participación ciudadana lograren grandes metas para el desarrollo social, educativo, productivo y cultural de la zona. 


\section{CAPITULO VIII: PROYECTO}

\subsection{Proyecto}

\subsubsection{Toma de partida y estrategias proyectuales}

El proyecto busca integrarse a la trama urbana existe por lo que nace primero del alineamiento del espacio público, este es delimitado por la prolongación de los ejes de las manzanas que colindan con el terreno tanto en la parte superior como inferior, el espacio público están sobre plataformas alineadas a esos ejes que se nivelan sobre unos metros de las viviendas y al mismo tiempo son usadas como un sistema de prevención y contención de tierra.

Figura 8. 1

Plano de alineamiento del espacio público.

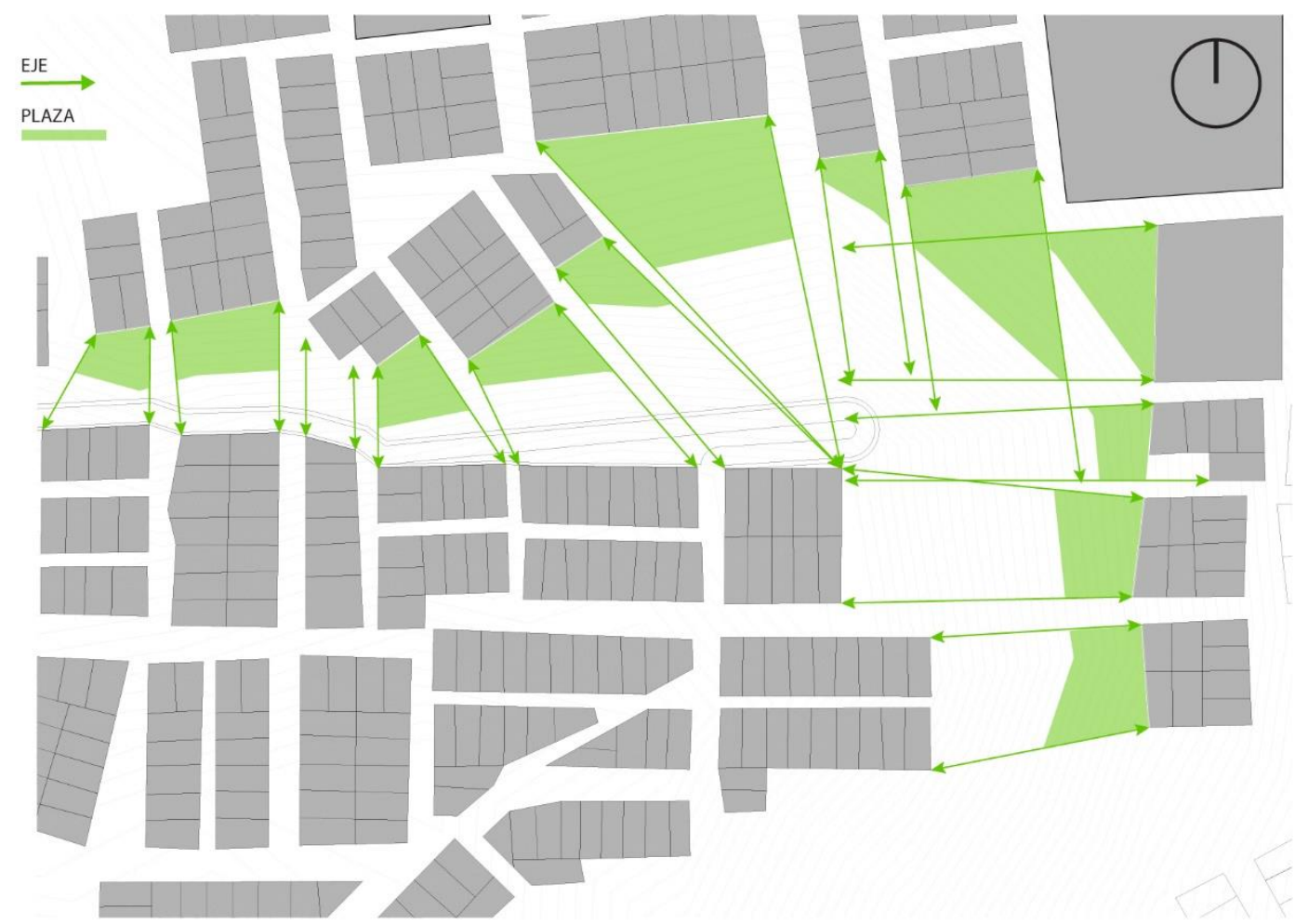

Fuente: Elaboración propia (2018).

Luego de delimitar las plataformas se trazan los caminos de conexión de la parte inferior a la superior del terreno mediante escaleras y rampas, algunas de las escaleras 
existentes serán reconstruidas debido a que no cuentan con descansos y se considerará algunas de las sendas trazadas por los pobladores, un sistema de rampas podrá ser posible para un recorrido más agradable y accesible desde el punto más bajo.

Figura 8. 2

Plano de trazado de caminos

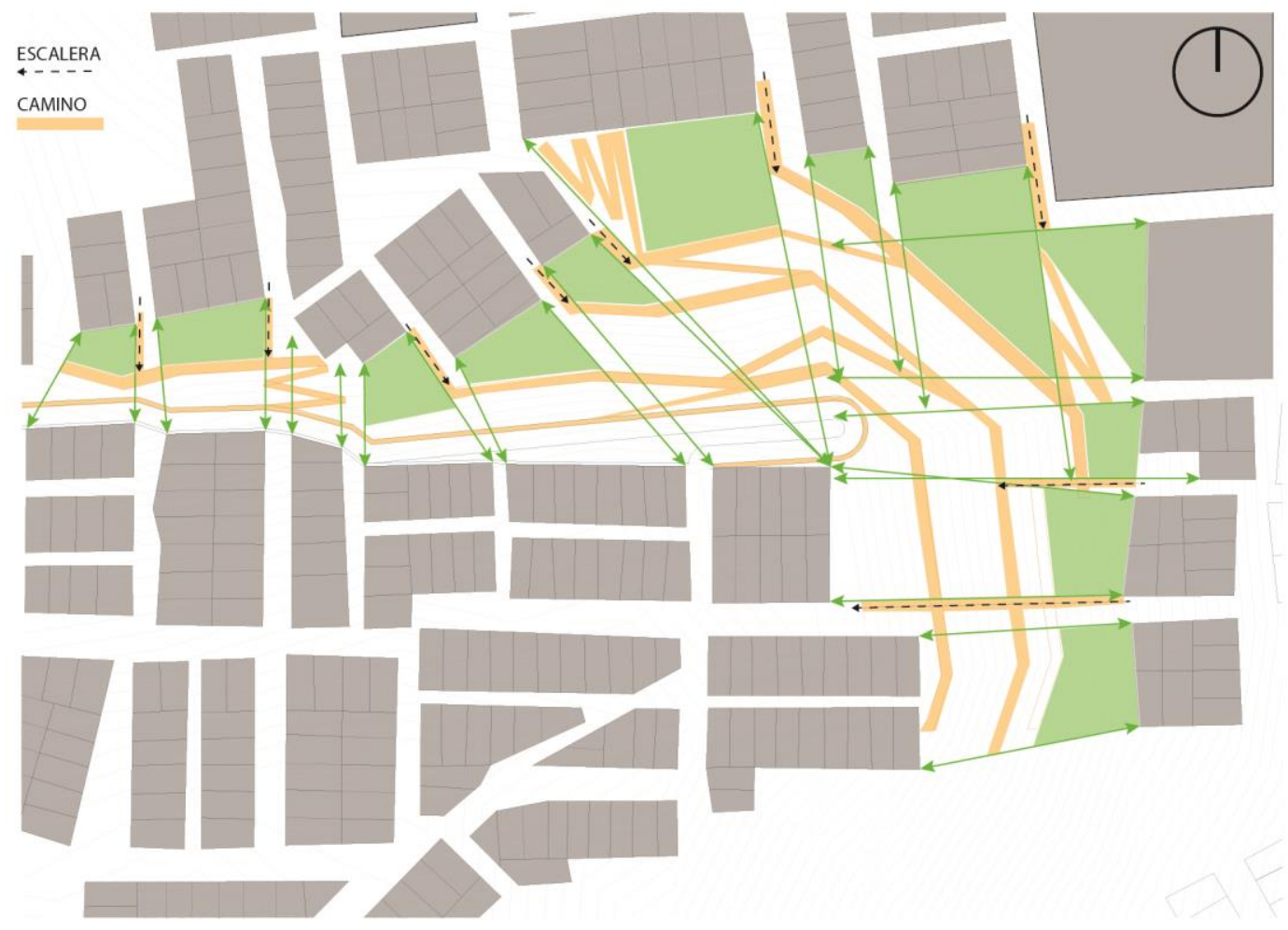

Fuente: Elaboración propia (2018).

Después de trazar los caminos estos mismos delimitaran las zonas para los volúmenes arquitectónicos a idea de "manzanas" dentro del terreno como una continuación a la idea de barrio donde los caminos te conectan como todo el programa y el espacio público propuesto. Cabe resaltar que la idea de barrio para ellos, según las conversaciones con la gente de la zona, son sus interacciones del día a día en las calles, como cuando van a dejar a sus hijos al nido, cuando van a la bodega, cuando van a visitar algún familiar o amigo, para ir al mercado, cuando los niños salen a las calles a jugar o cuando tienen que salir las madres al taller de bordado. Esas conexiones que se generan constantemente les permiten hablar y relacionarse entre ellos, transmitiendo una sensación de seguridad en el barrio, por lo que muchos niños pequeños regresan solos del colegio. El uso de espacios públicos como las losas deportivas apoya a la integración entre niños, jóvenes y adultos. 
Figura 8. 3

Plano de ubicación del programa

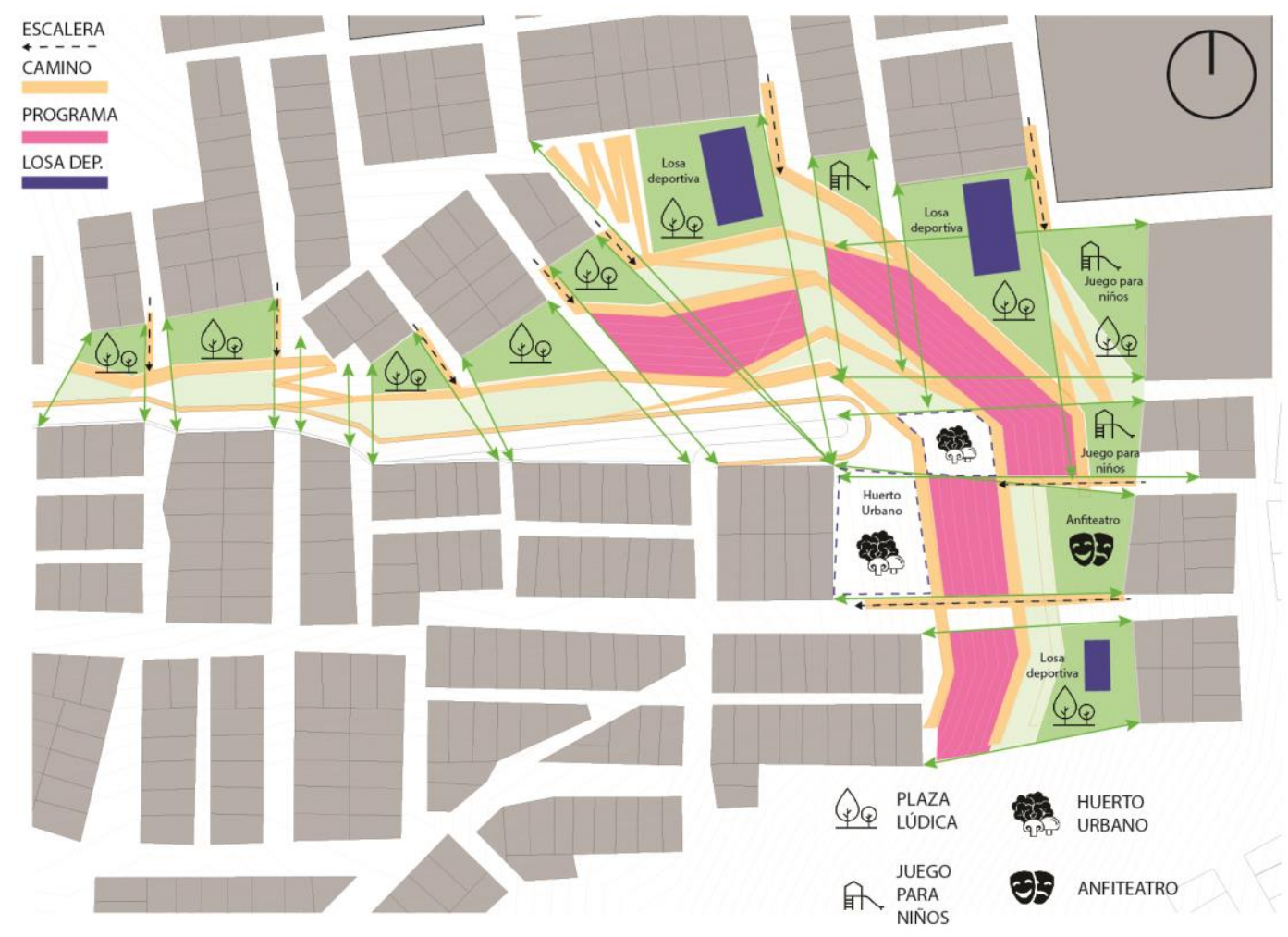

Fuente: Elaboración propia (2018).

Finalmente para definir los volúmenes arquitectónicos, estos mantienen una proporción similar a la de los lotes. La arquitectura será integrada a los caminos y al espacio público, por ellos los caminos se integran formando espacios de encuentro sobre la superficie de los volúmenes que se encontraran semi-enterrados en la ladera para integrarse a la topografía, así mismo los volúmenes podrán funcionar de manera independiente como vivienda en un barrio, pero compartirán espacios comunes para realizar talleres o actividades de integración social, educativas o culturales. Los volúmenes estarán ubicados en una cota media de la pendiente del terreno para que sea apreciado desde distintos puntos de la ciudad así mismo la arquitectura pueda estar rodeada por un ambiente natural. 
Figura 8. 4

Plano de ubicación de volúmenes arquitectónicos

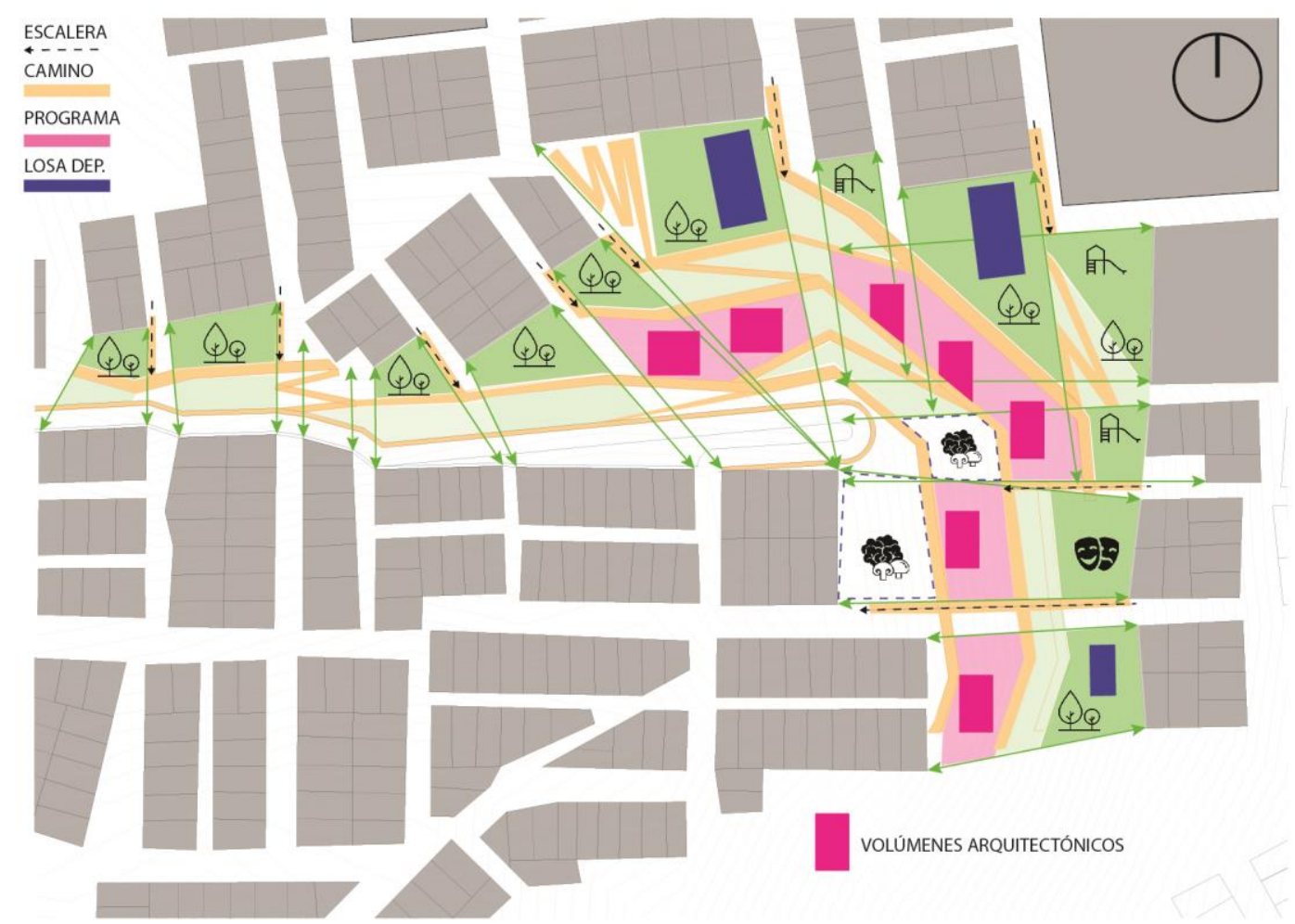

Fuente: Elaboración propia (2018).

Entre las estrategias proyectuales se consideraron varias ideas iniciales para aplicar al proyecto, de las cuales algunas fueron descartadas y otras evolucionaron con el desarrollo del proyecto, estas ideas surgieron de las potencialidades y problemáticas que se pudieron reconocer en el lugar. Las estrategias que se plantean se agrupan para afrontar una necesidad. 
Figura 8.5

Potencialidades y problemas del lugar

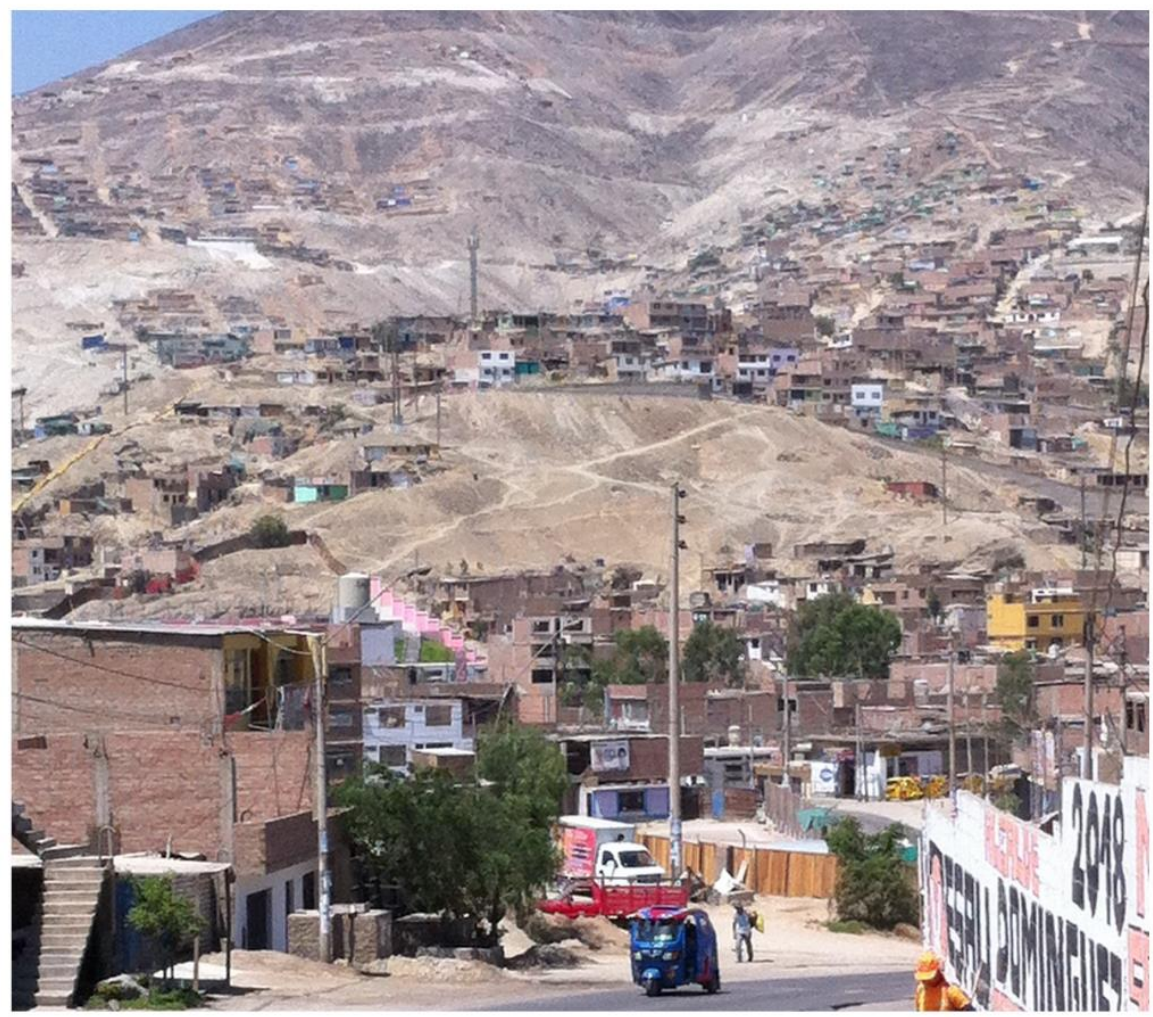

POTENCIALIDADES:

- Uso de la pendiente para diseño y distribución de recursos como el agua.

- La zona se encuentra saneado con servicios básicos como agua, luz, desague.

- Acceso por la parte superior o inferior del terreno.

- Un vacío en medio de una trama urbana existente.

- Tierra fértil para cultivo y crecimiento de vegetación.

- Una vida barrial activa por niños, jóvenes y adultos.

- Oportunidad de emprendimiento por parte de un grupo de madres quienen tienen un taller de bordado apoyadas por la ONG Ruwasunchis

- Existe la iniciativa de integración con la comunidad gracias al deporte y talleres.

- Existe una comunidad organizada, dispuesta a trabajar en conjunto para mejorar sus condiciones económicas y sociales.

- Existe un acceso vehicular por la parte superior del terreno.

- La comunidad hace uso del terreno para trasladarse de un punto a otro, generando senderos.

- Cuenta con una losa deportiva, en una porción de terreno previamente nivelado.

\section{PROBLEMAS:}

- El terreno se encuentra en abandono, poco a poco es invadido, usado como basural o acopio de desmonte, la falta de escaleras o rampas dificulta el desplazamiento dentro del terreno. La falta de sombra hace agotador pasar por ahí.

Fuente: Elaboración propia (2018). 
Figura 8.6

Estrategias de diseño 01

\section{ESTRATEGIAS DE DISEÑO}

1. Para intervenir y adaptarse a un entorno natural en ladera de cerro.

1.1. Aprovechar la pendiente para generar distintos niveles para usos y relaciones espaciales.
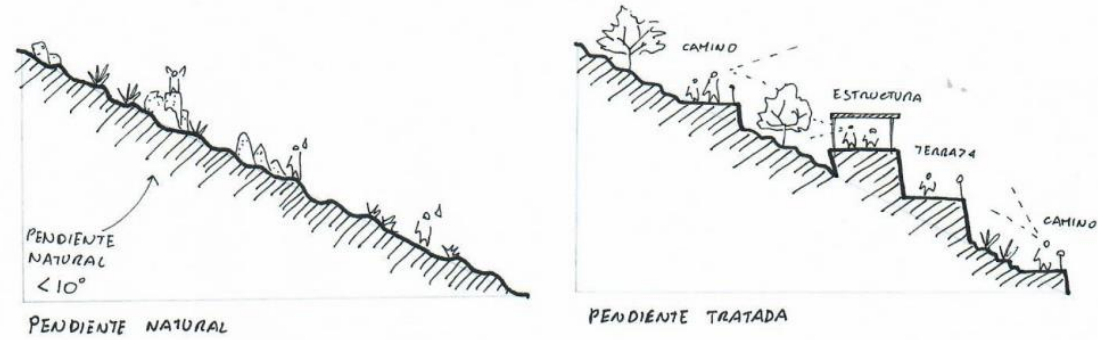

1.2. Usar la ladera para proponer una red de caminos que genere un recorrido por el terreno y el proyecto. También para conectar distintos puntos de trama urbana existente.

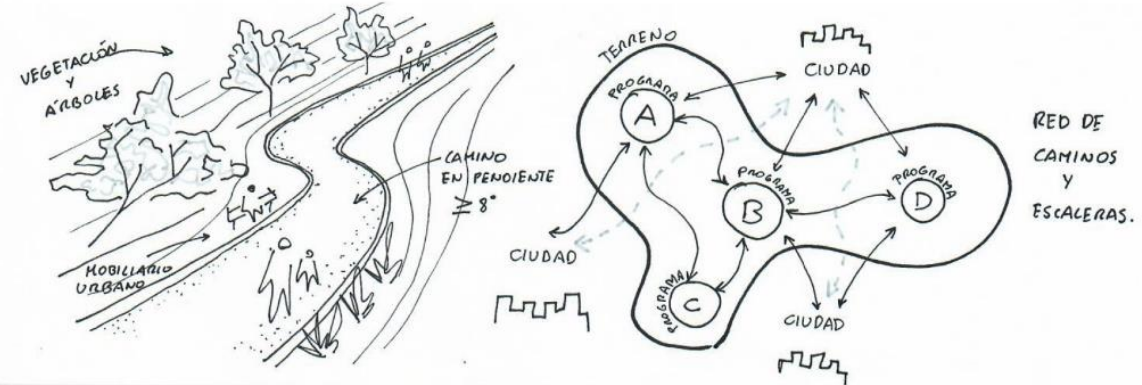

1.3. Emplear sistemas de canales de agua en pendiente para distribuirlo en el terreno e irrigar nuevas áreas verdes propuestas.
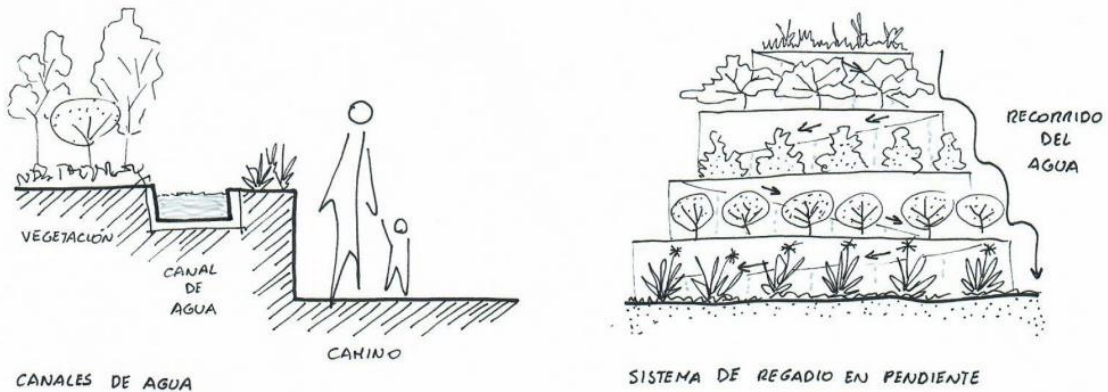

1.4. Arborizar y ofrecer áreas verdes con especies vegetales aptas a la zona en ladera para generar un nuevo ecosistema en la ciudad para aves e insectos.

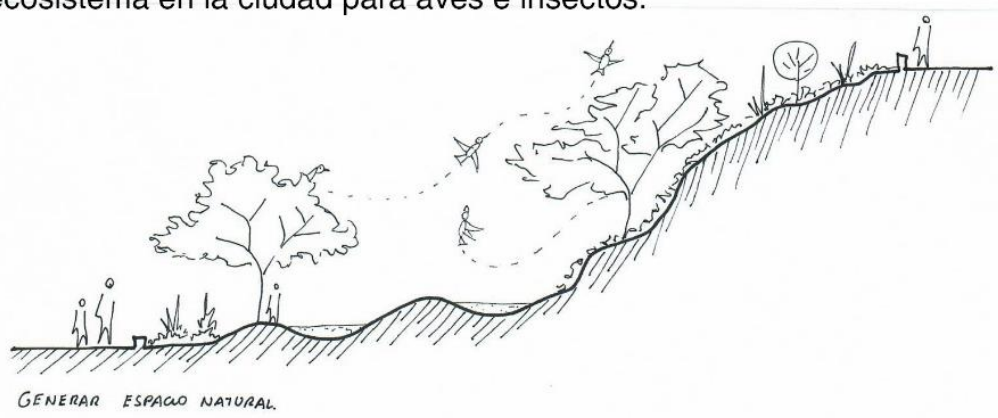

Fuente: Elaboración propia (2018). 
Figura 8.7

Estrategias de diseño 02

1.5. Usar los desniveles del terreno para ofrecer nuevos espacios de juego y aprendizaje.

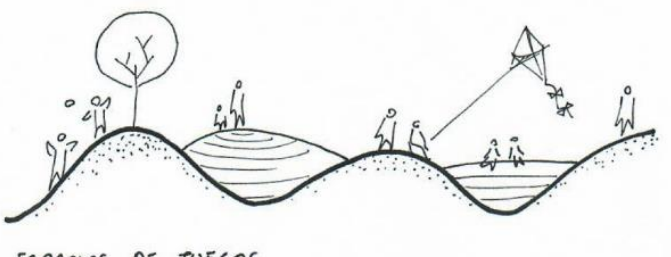

ESPACLOS DE JUEGOS

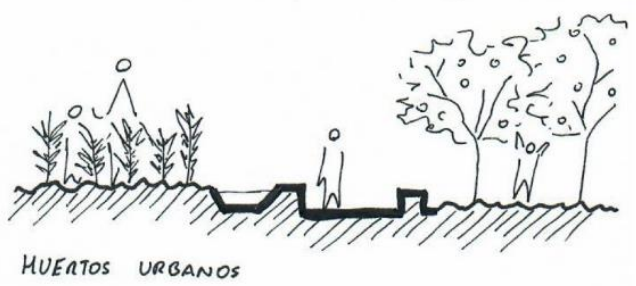

1.6. Integrar la pendiente al diseño de paisaje con distintas plataformas naturales.

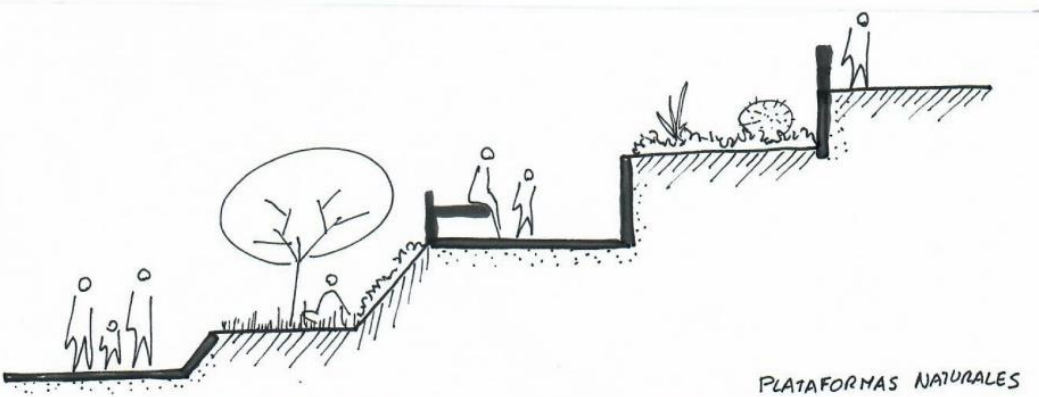

1.7. Transformar la ladera en una zona de juegos para niños con lomas, pendientes y espacios de sombra.

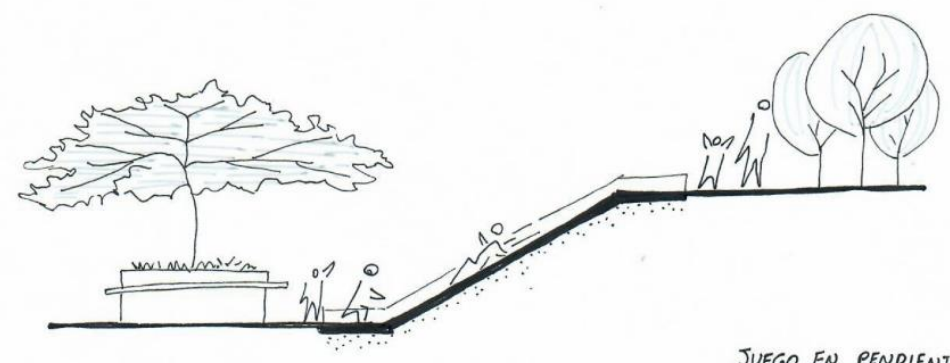

1.8. Formar plazas semienterradas y proporcionar espacios de sombra usando elementos naturales, en caminos, plazas, espacios de encuentro.

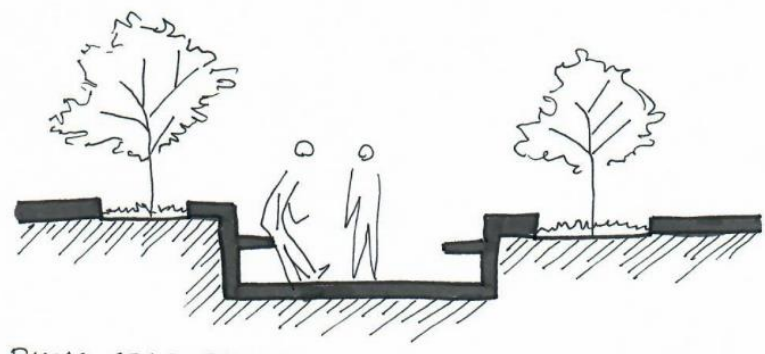

PLAZAS SEMIENTERTADAS.

Fuente: Elaboración propia (2018). 
Figura 8.8

Estrategias de diseño 03

\section{ESTRATEGIAS DE DISEÑO}

2. Para intervenir y adaptarse a un entorno urbano para fortalecer la idea de barrio.

2.1. Seguir la trama urbana existente para orientar el programa y espacio público.

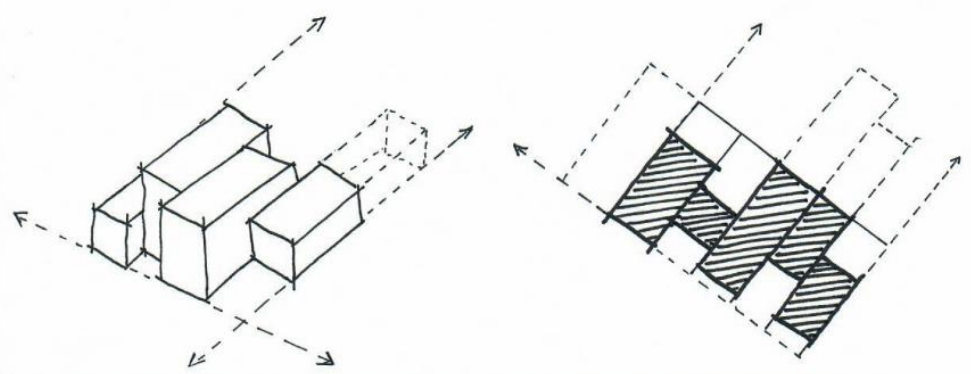

2.2. Respetar el perfil urbano existente, no superar la altura de 2 niveles construidos.

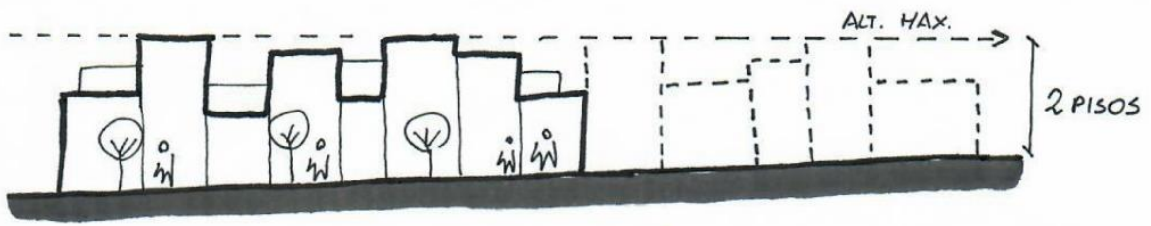

2.3. Generar nuevos espacios de encuentro y ocio para la ciudad y la comunidad.

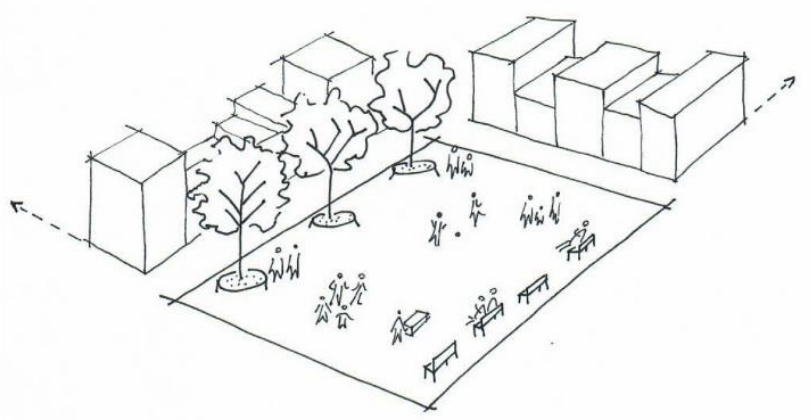

2.4. Recuperar y mejorar las sendas existentes para unir caminos dentro de la trama urbana.

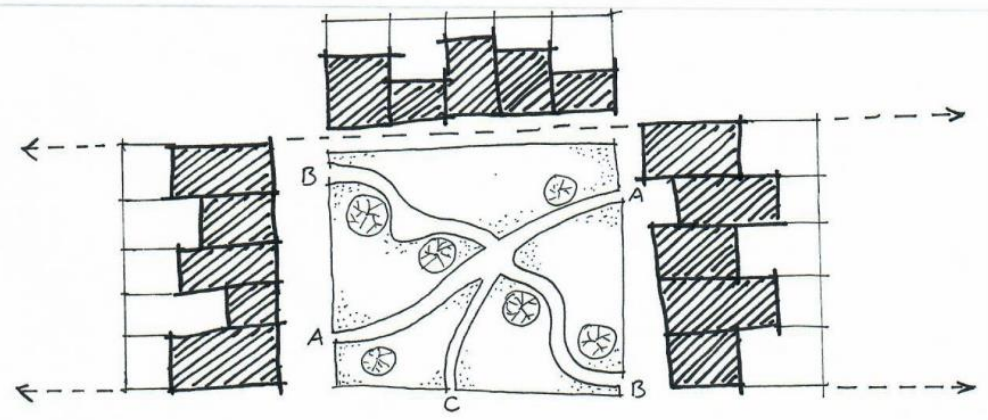

Fuente: Elaboración propia (2018). 
Figura 8.9

Estrategias de diseño 04

2.5. Mejorar la accesibilidad de la zona con nuevas escaleras y rampas.

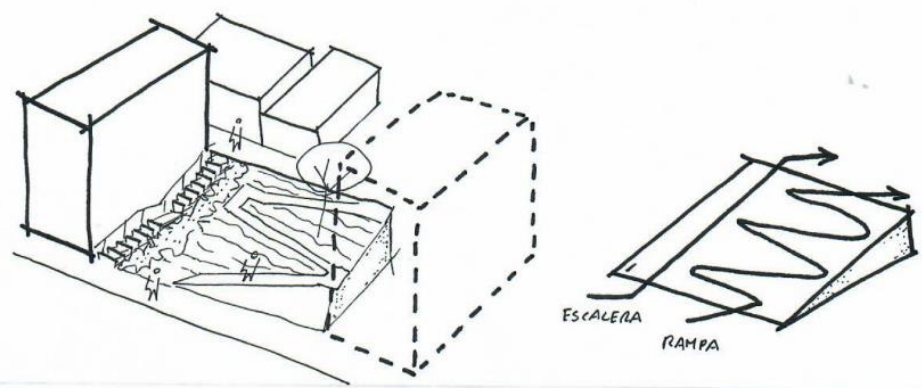

2.6. Activar un vacio urbano con programa educativo, cultural y social.

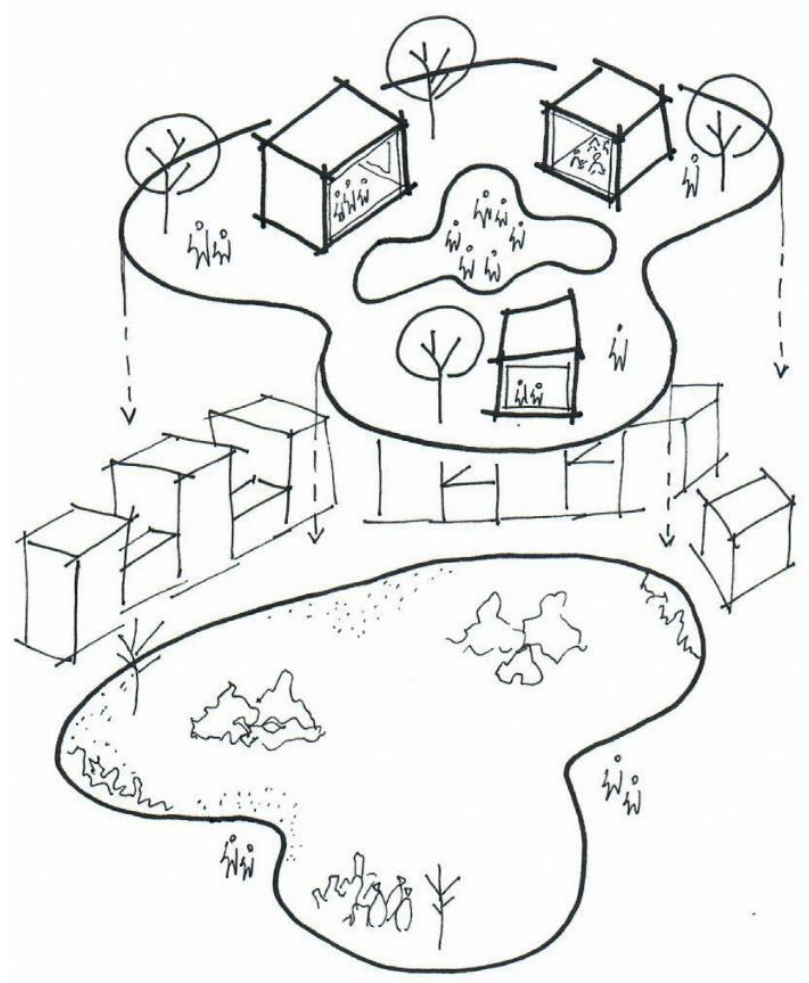

Fuente: Elaboración propia (2018). 
Figura 8.10

Estrategias de diseño 05

\section{ESTRATEGIAS DE DISEÑO}

3. Para desarrolar una identidad con la comunidad

3.1. Diseñar una arquitectura con apoyo de la comunidad con niños, jovenes y adultos. También escucharlos para entender mejor sus problemáticas y costumbres.

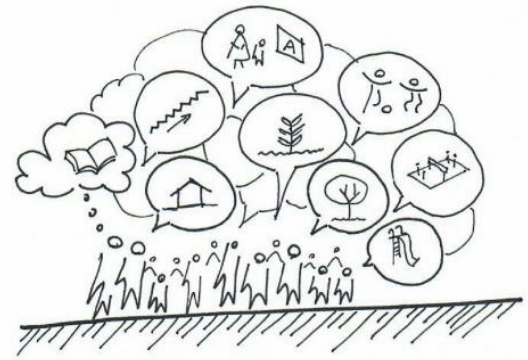

3.2. Diseñar plazas de encuentro entre familias y vecinos. Pueden tener usos específicos o multiples como recreativos y culturales.

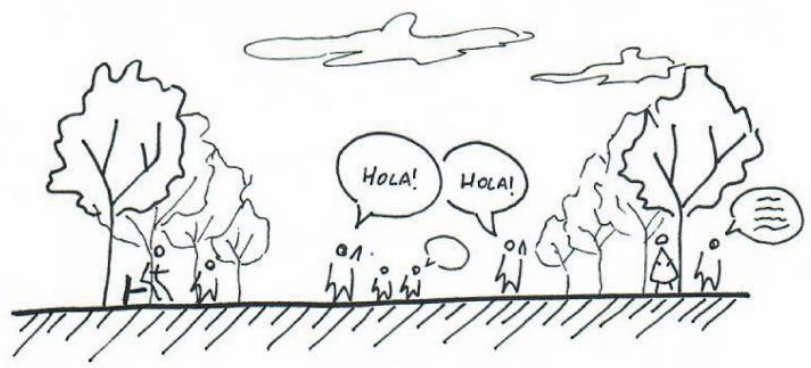

3.3. Desarrollar y mejorar los espacios para el deporte. Lograr una integración barrial entre jóvenes, adultos, hombres y mujeres.

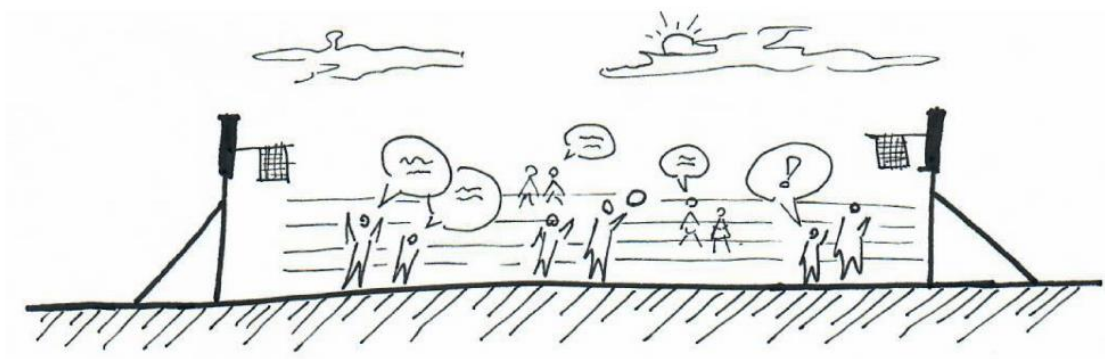

3.4. Diseñar espacios de ocio al aire libre, generando distinas situaciones espaciales donde los niños puedan jugar, descubrir y esconderse.

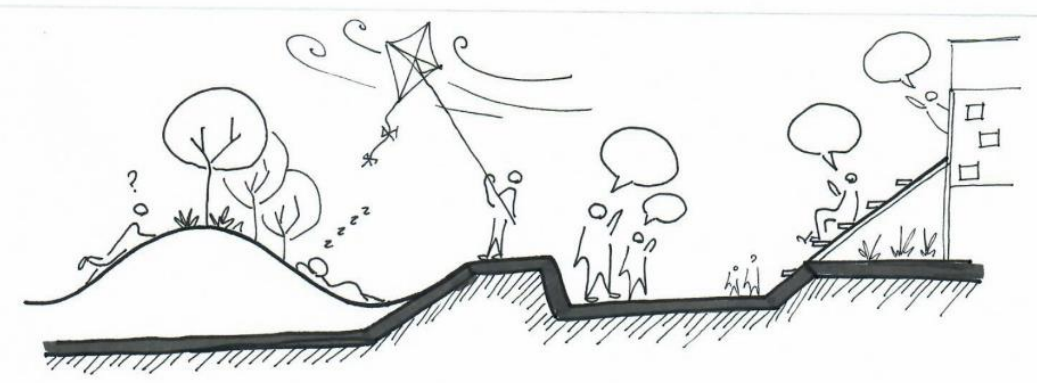

Fuente: Elaboración propia (2018). 
Figura 8.11

Estrategias de diseño 06

3.5. Proponer espacios colectivos sociales como huertos urbanos comunales, donde se pueda aprender y aprovechar del consumo de la comunidad.

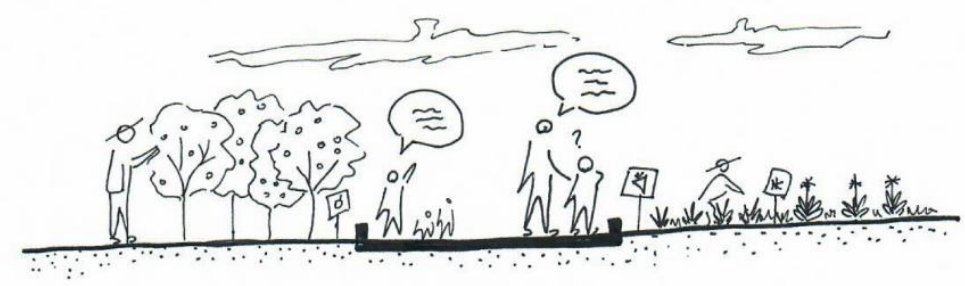

3.6. Diseñar espacios que apoyen a la educación de los jóvenes y niños de la zona.

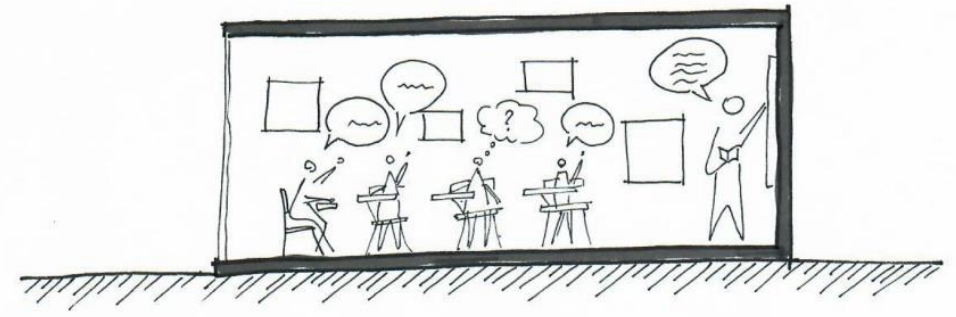

3.7. Diseñar espacios comunales para talleres culturales, educativos y recreativos.

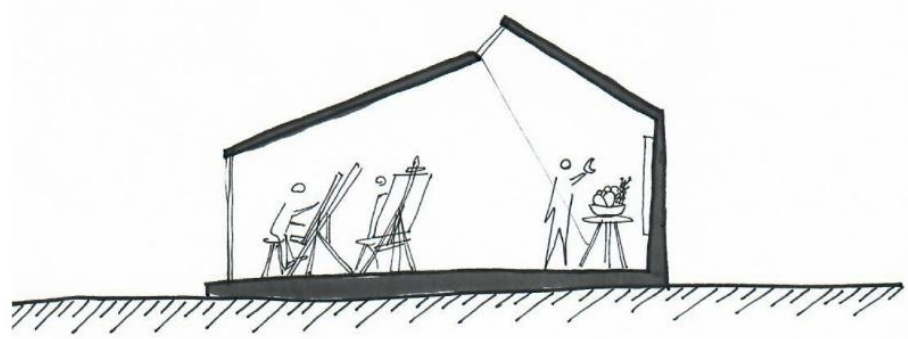

3.8. Diseñar espacios para talleres técnicos que promuevan el emprendimiento, mediante productos y clases de capacitaciones que los prepare e informe sobre la vida laboral.

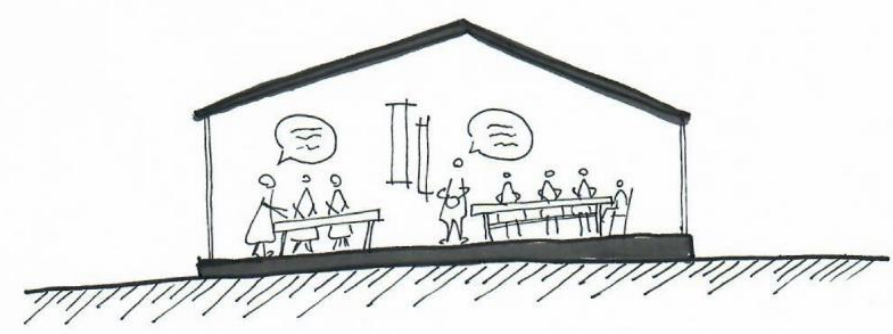

Fuente: Elaboración propia (2018). 
Figura 8.12

Estrategias de diseño 07

\section{ESTRATEGIAS DE DISEÑO}

4. Para diseño de arquitectura

4.1. Tener volúmenes semienterrados para aprovechar el aislamiento térmico natural de la tierra.

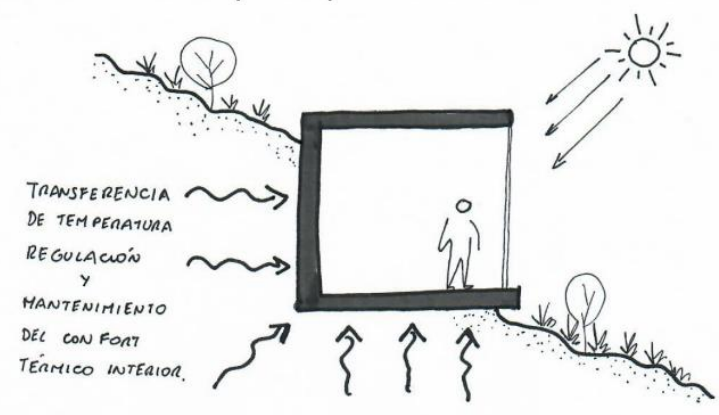

4.2. Orientar los volúmenes con mayor fachada con orientación Norte-Sur para reducir la exposición directa del sol y mejorar el confort térmico.

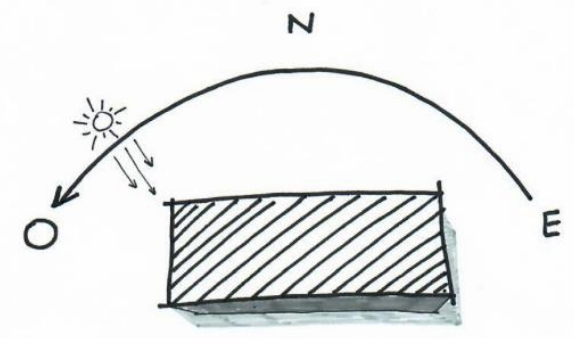

4.3. Orientar los vanos con dirección al Sur para aprovechar el recorrido del viento que va de Sur a Norte. Ventilar los espacios de manera natural con ventilación cruzada.

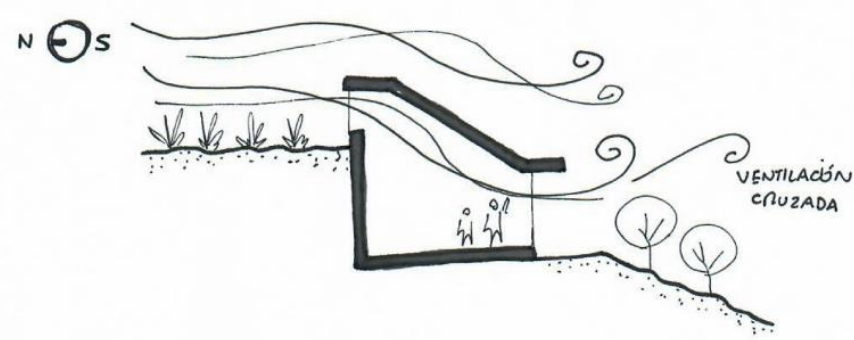

4.4. Usar la pendiente para colocar volúmenes uno sobre otros con desfases para generar terrazas.

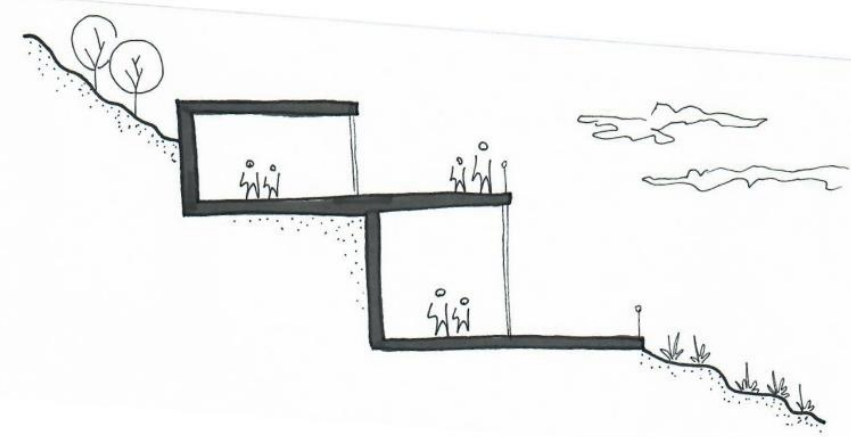

Fuente: Elaboración propia (2018). 
Figura 8.13

Estrategias de diseño 08

4.5. Tener patios interiores para mejorar la ventilación y la iluminación natural, además de ser una extensión de los espacios interiores. Los árboles regulan el asoleamiento y entrada de viento.

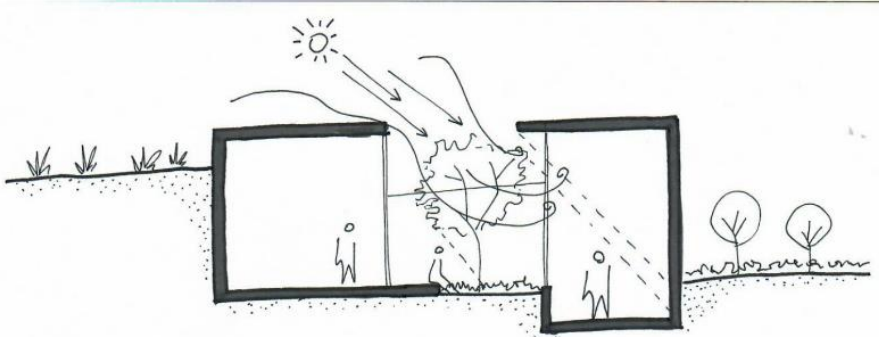

4.6. Tener acceso y uso de los techos para generar espacio público o más programa.

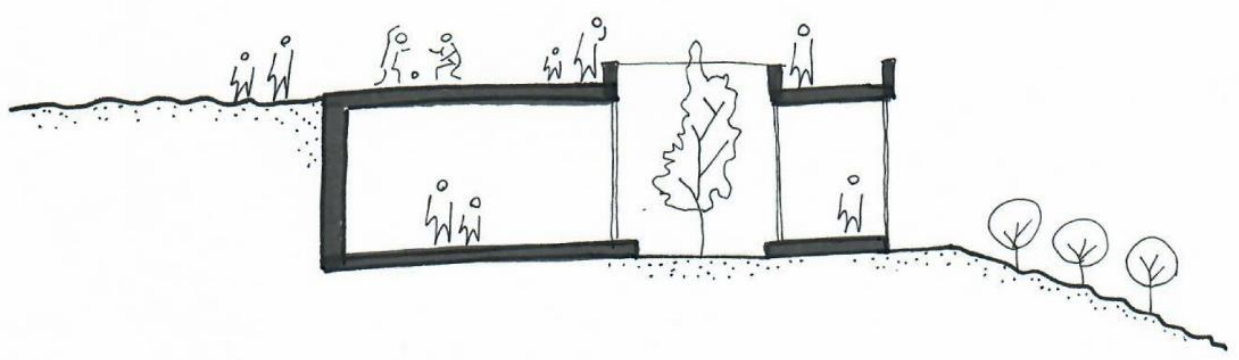

4.7. Desarrollar un sistema de terrazas y jardines con distintas relaciones espaciales.

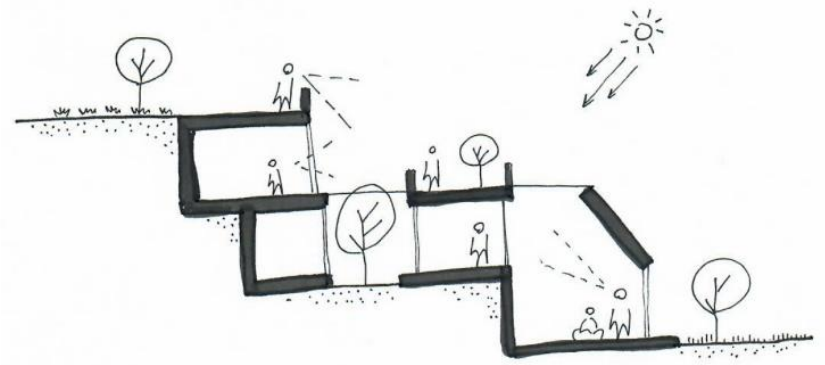

4.8. Proponer algunos ingresos por la parte superior de los volúmenes mediante puentes o mismo techo.

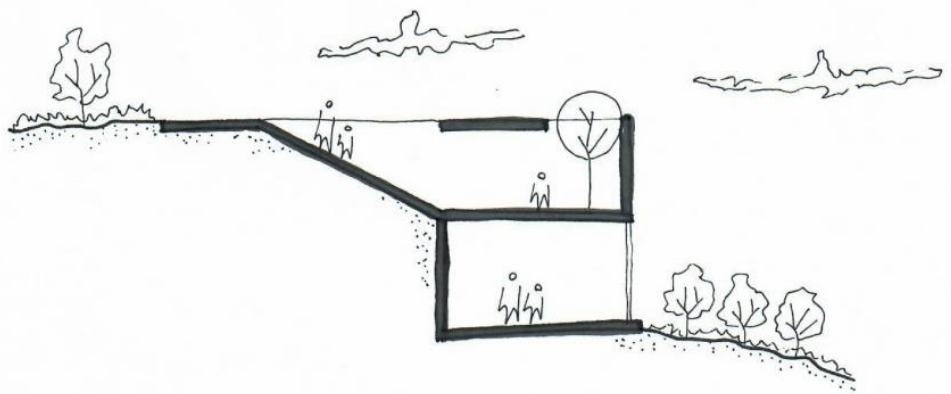

Fuente: Elaboración propia (2018). 


\subsubsection{Diseño participativo}

Para obtener una información más precisa sobre la zona, la población y conocer más sobre la realidad en la que viven se realizaron unos talleres de diseño participativo el día 13 de mayo del 2018 con los niños y madres de la zona cercana al terreno, con finalidad de conocer cuales serías sus espacios ideales para el aprendizaje y trabajar en comunidad. Así mismo se les pidió plasmar en el diseño los elementos que les gustaría en su espacio público ideal. Este trabajo se pudo realizar gracias al apoyo de los voluntarios de Ruwasunchis, quienes me apoyaron a realizar la dinámica. Para el día del trabajo asistieron 25 niños de entre 5 y 10 años a quienes pedimos que plasmaran con dibujos o algún tipo de expresión gráfica sus espacios ideales para estudiar, aprender, tener talleres y divertise.

Figura 8.14

Taller de diseño participativo con los niños de Manchay

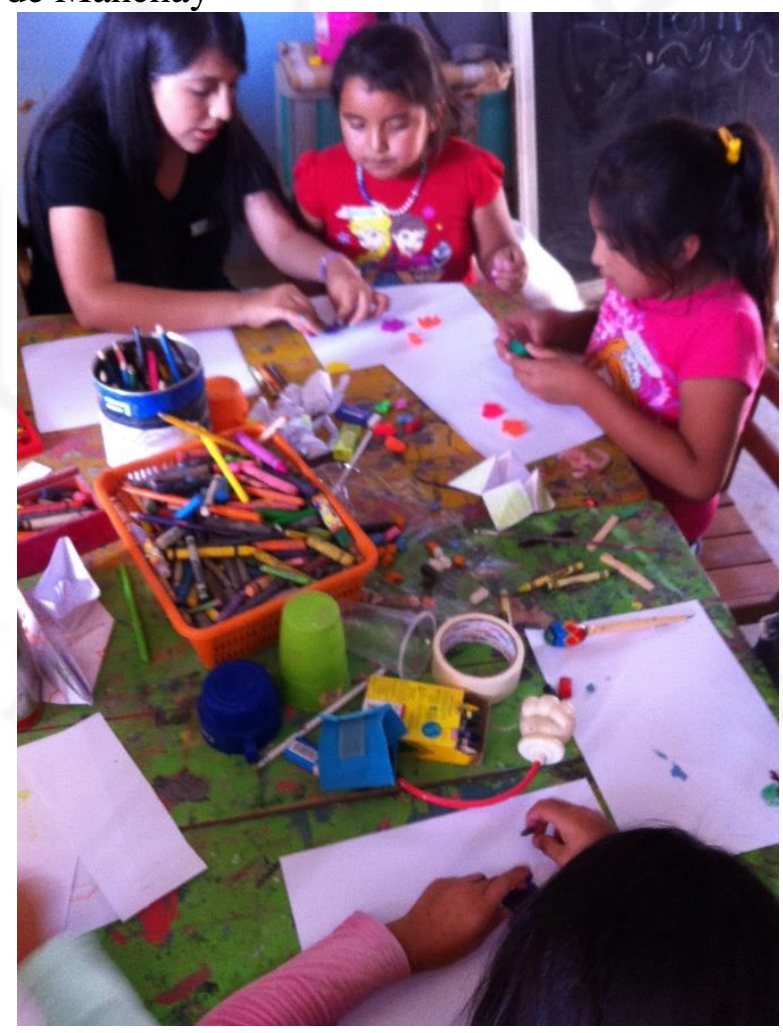

Fuente: Elaboración propia (2018). 
Figura 8.15

Taller de diseño participativo con los niños de Manchay

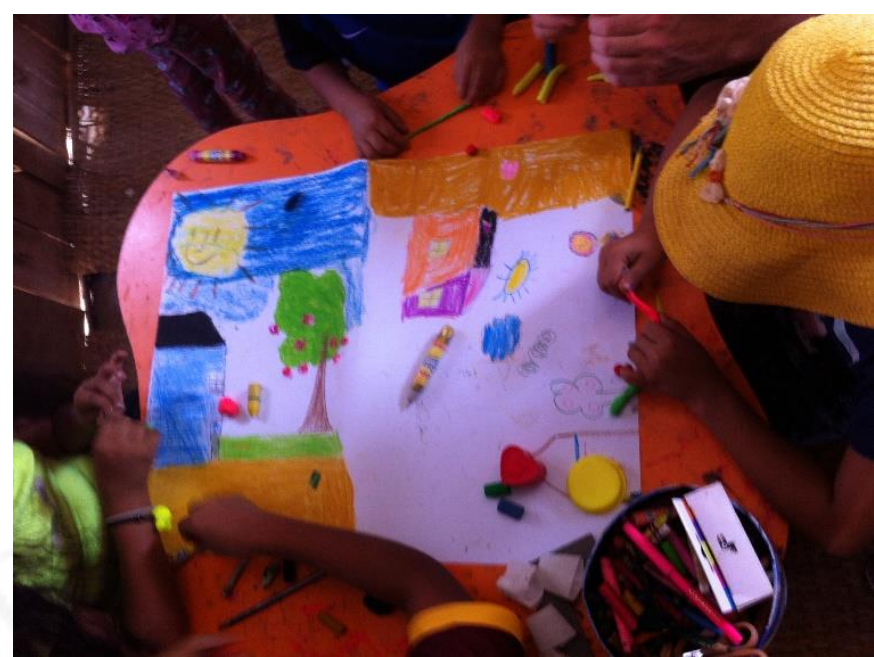

Fuente: Elaboración propia (2018).

Figura 8.16

Taller de diseño participativo con los niños de Manchay

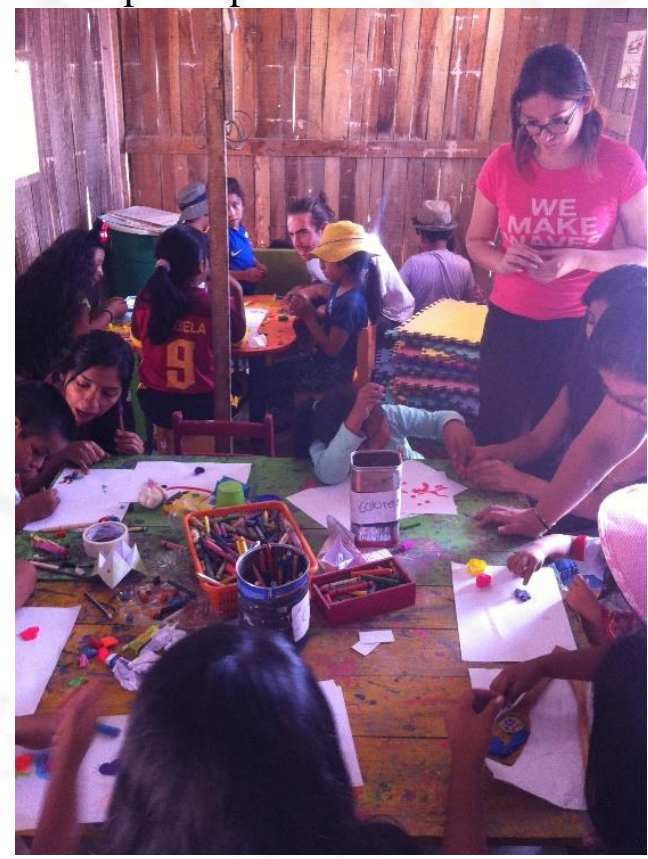

Fuente: Elaboración propia (2018). 
Figura 8.17

Taller de diseño participativo con los niños de Manchay

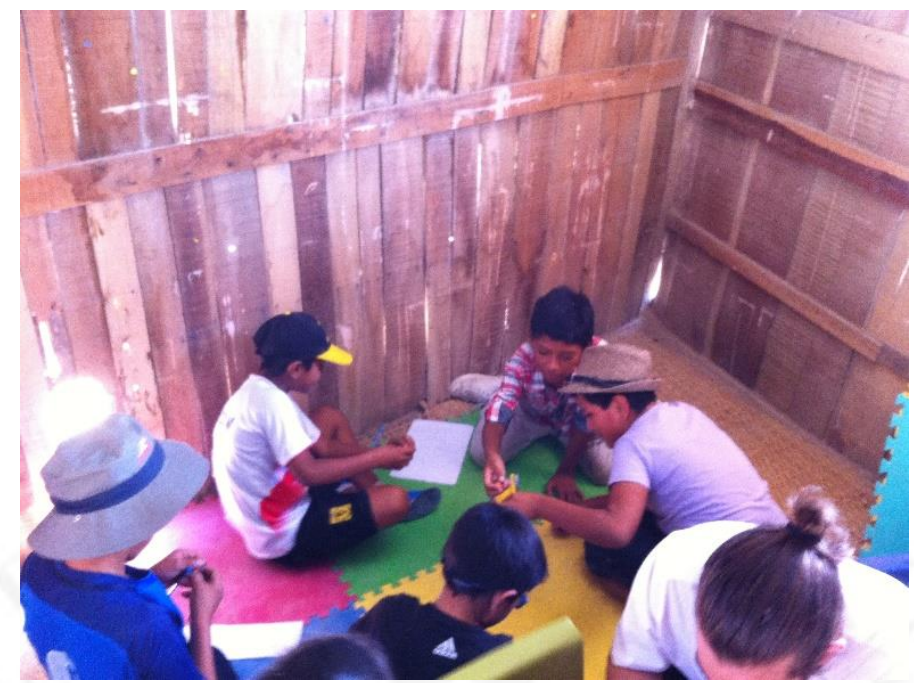

Fuente: Elaboración propia (2018).

Resultados:

Figura 8.18

Taller de diseño participativo con los niños de Manchay

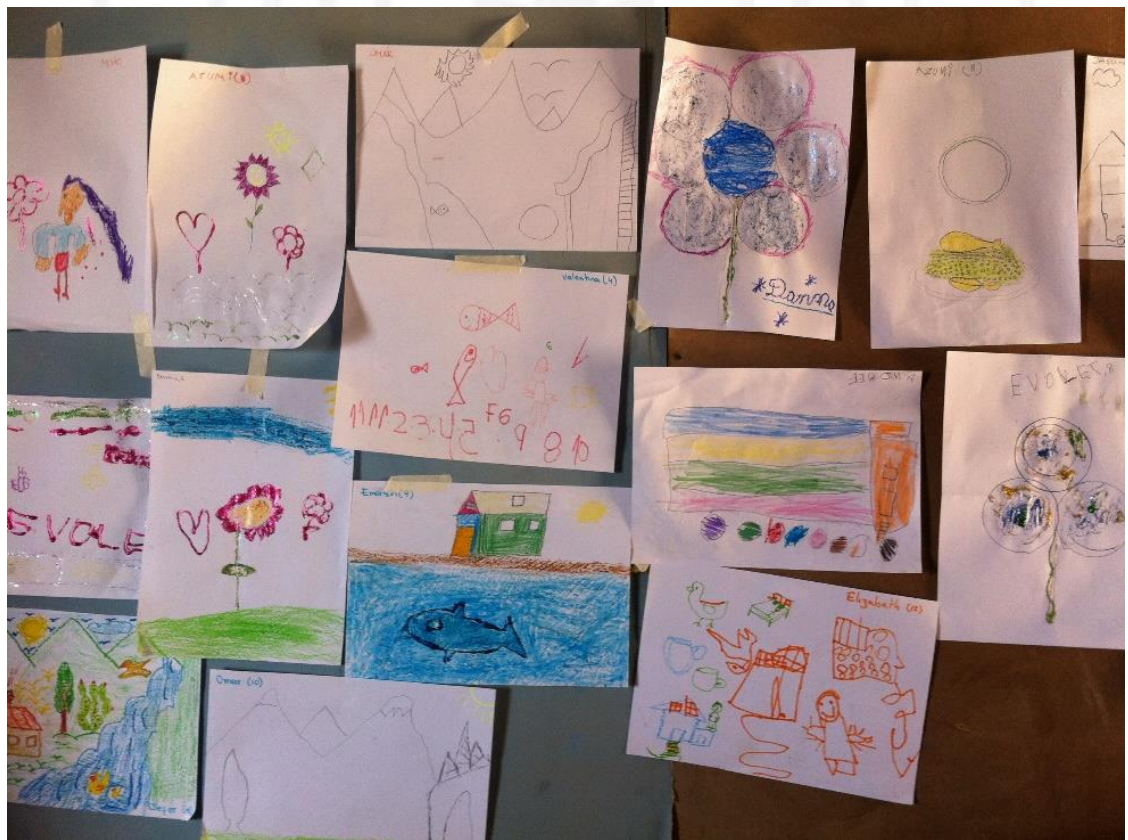

Fuente: Elaboración propia (2018). 
Figura 8.19

Taller de diseño participativo con los niños de Manchay

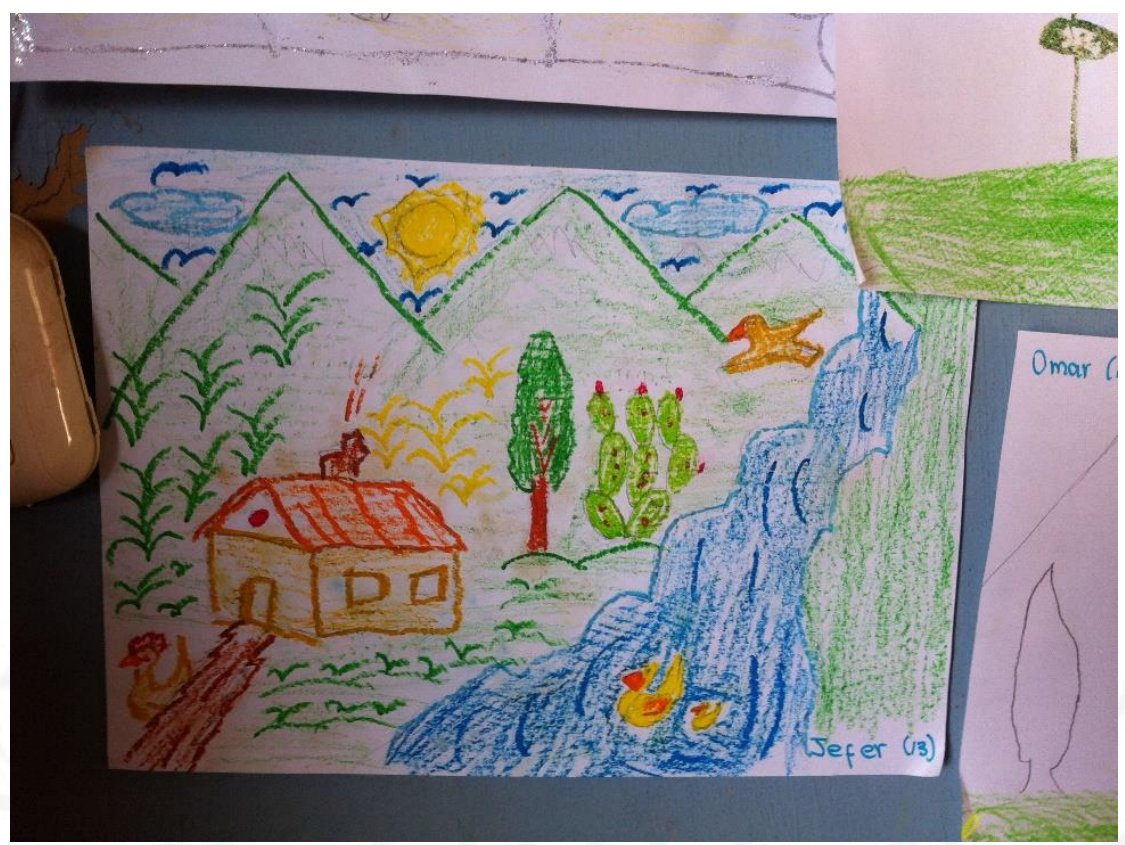

Fuente: Elavoración propia (2018).

El trabajo con los niños fue estimulante, muchos dibujaban una casa como su lugar ideal para estudiar ya que reflejaba un lugar más seguro para ellos, incluso muchos dibujaron vegetación porque consideran que es lo que falta en sus escuelas, también informaban que en sus casas tenían una pequeña huerta donde les gustaba pasar el rato. Entre sus espacios ideales para aprender, les gustaría tener más libertad para explorar nuevos lugares.

Una semana después del taller con los niños se realizó un ejercicio parecido con las madres del taller de tejedoras el día domingo 20 de mayo del 2018, a ellas se les asigno la tarea de plasmar como seria su espacio de trabajo ideal, como sería la ciudad ideal para ellas y sus hijos y como les gustaría que mejoran las cosas en su zona. Este taller de diseño participativo fue también apoyado por algunos voluntarios de Ruwasunchis. 
Figura 8.20

Taller de diseño participativo con las madres de Manchay

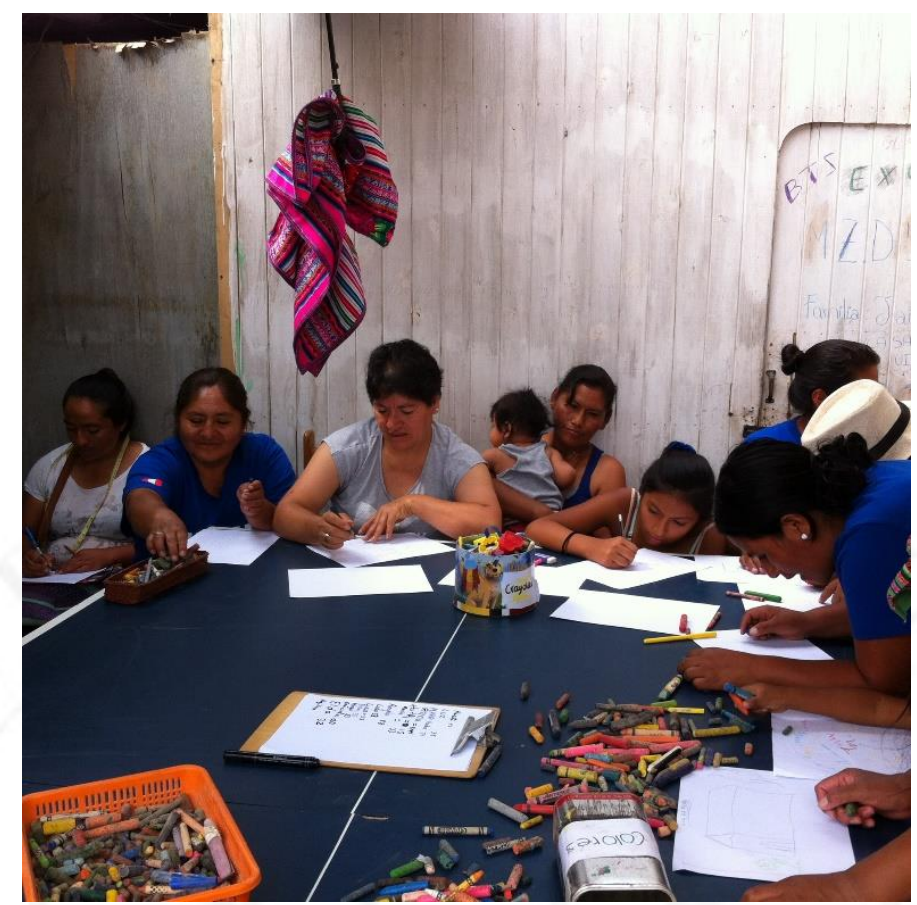

Fuente: Elaboración propia (2018).

Figura 8.21

Taller de diseño participativo con las madres de Manchay

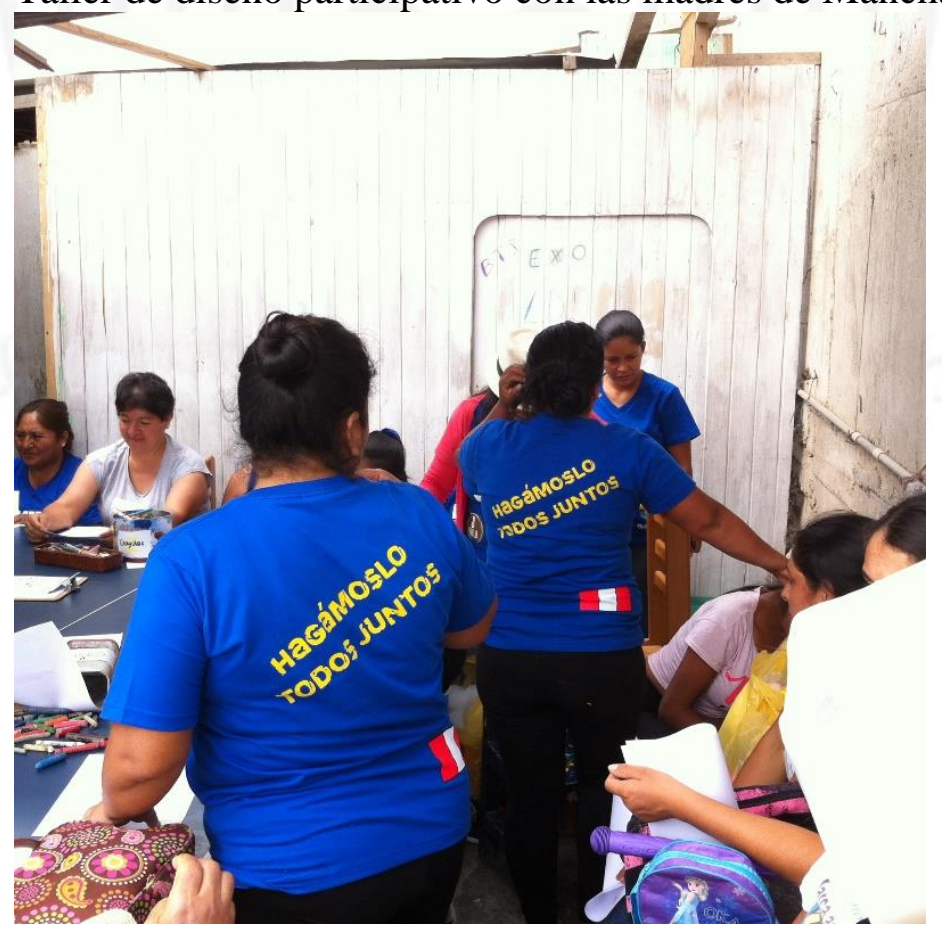

Fuente: Elaboración propia (2018). 
Figura 8.22

Taller de diseño participativo con las madres de Manchay

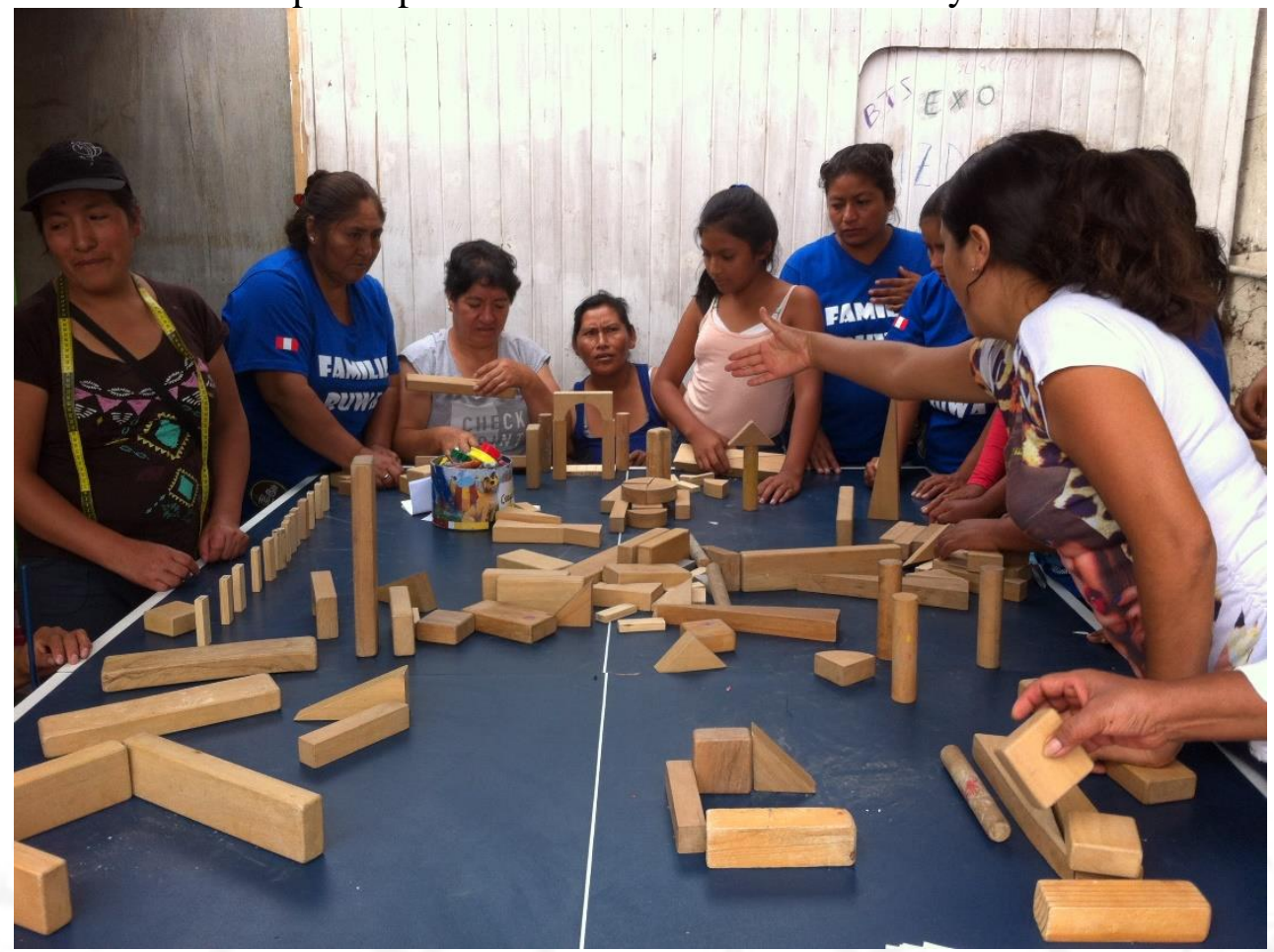

Fuente: Elaboración propia (2018).

Figura 8.23

Taller de diseño participativo con las madres de Manchay

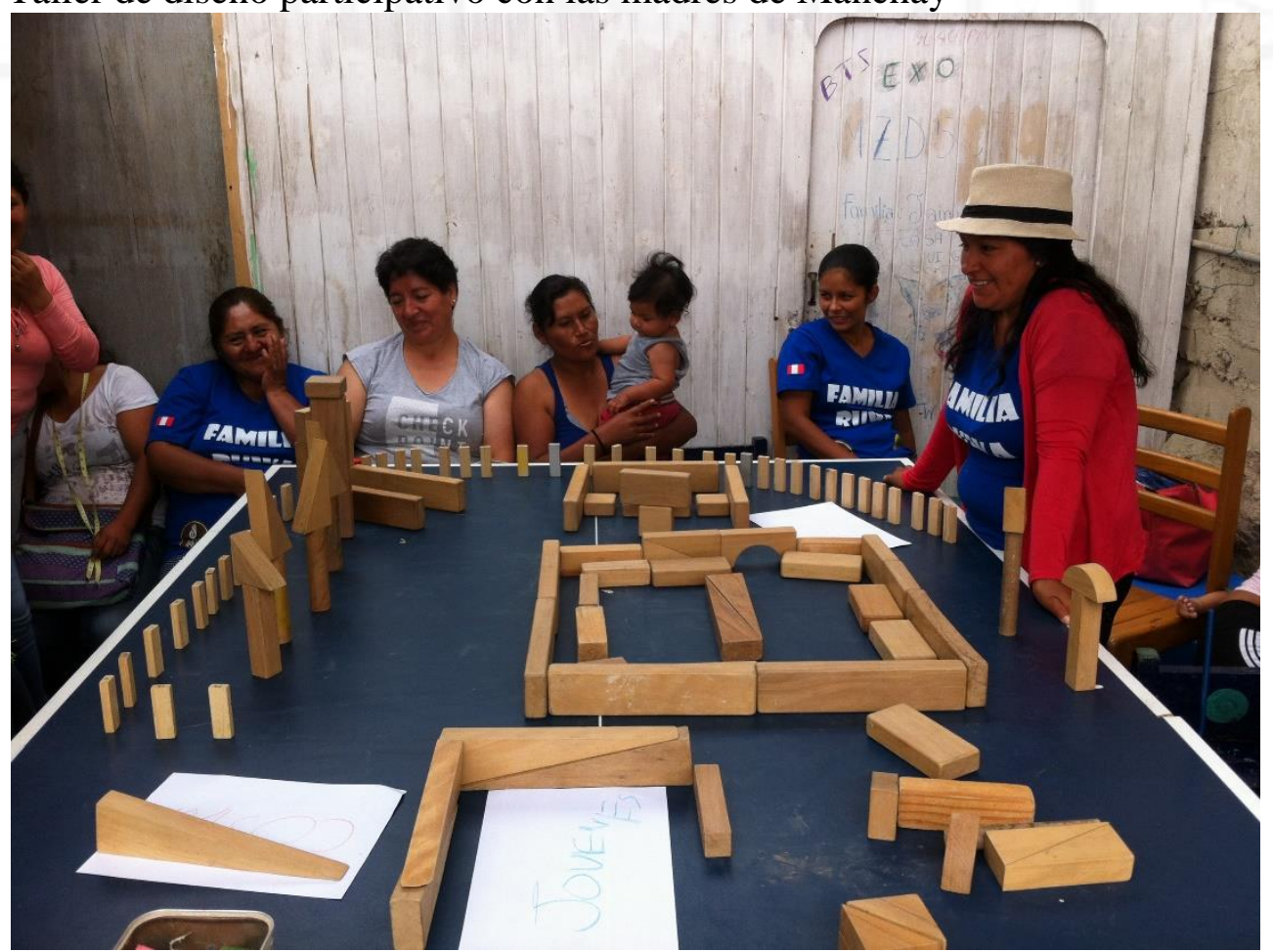

Fuente: Elaboración propia (2018). 
Figura 8.24

Taller de diseño participativo con las madres de Manchay

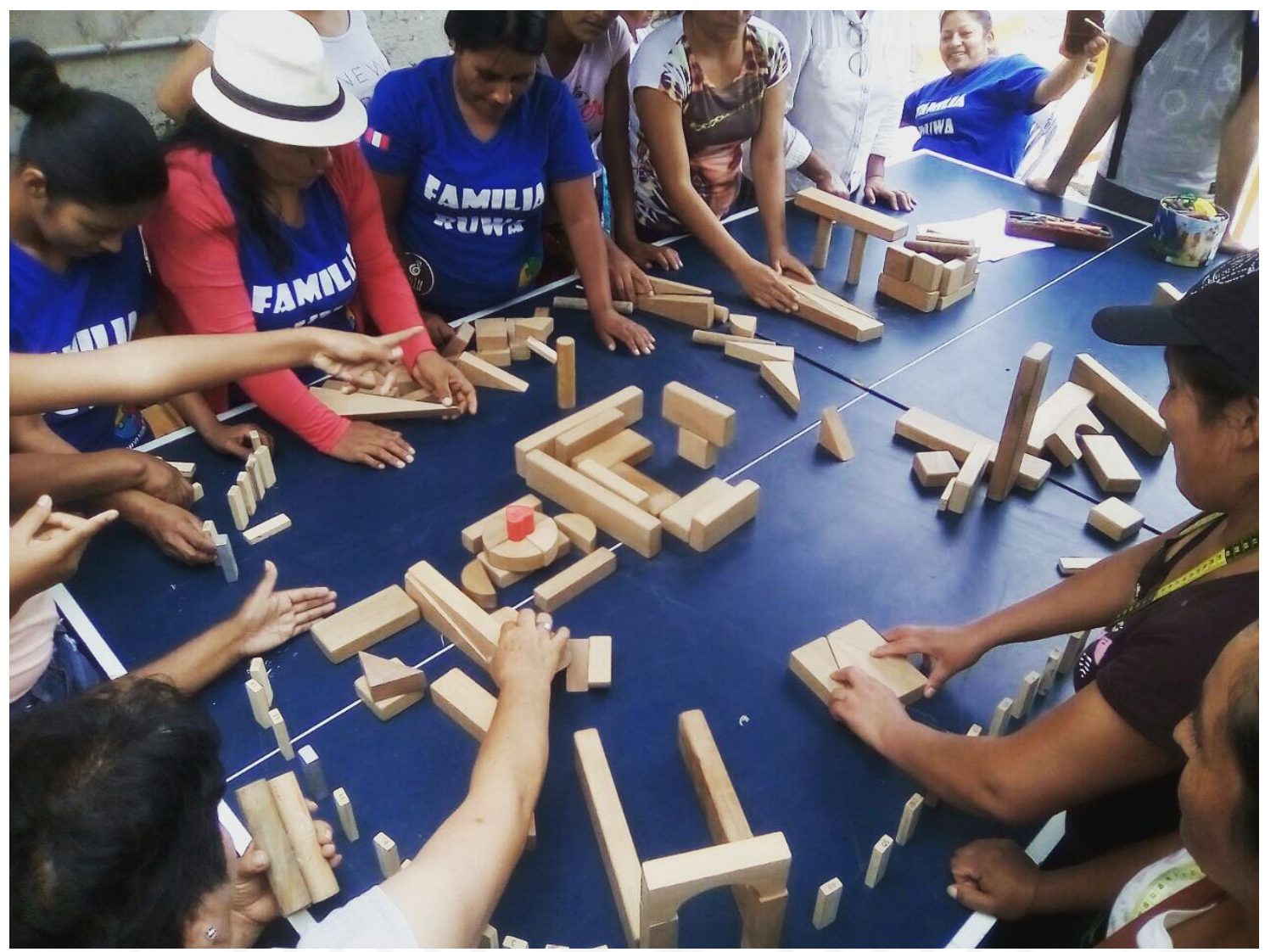

Fuente: Elaboración propia (2018).

El resultado del taller de las madres fue el esperado, se mostraban algo tímidas en los primeros momentos de la actividad de dibujo, pero finalmente lograron explayarse y plasmaron sus ideas mediante dibujos que luego fueron explicados. En su totalidad buscar espacios amplios, con buena iluminación, ventilación y una gran mesa de trabajo para poder desarrollar sus productos. También la relación con la naturaleza es importante ya que muchas madres provienen de provincia y extrañan la naturaleza de donde son originarias, ellas proponen la idea de huertos comunitarios, áreas verde con sombra para estar cuando salen a pasear y proponen espacios de juegos para sus hijos.

La segunda actividad fue armar en conjunto su centro comunal ideal, para ello se les dio unas piezas de madera para que crearan una maqueta o composición de la distribución y espacios necesarios para su comunidad. Como resultado fue satisfactorio, todas participaron y debatían que sería lo mejor para ellas y sus familias. Teniendo como prioridad mantener los talleres ofrecidos para los niños y jóvenes, propusieron espacios de estudio para sus hijos ya que muchas no tienen internet en casa y más espacios 
deportivos y de recreación ya que consideran que es la manera más efectiva de integrarse como barrio.

\subsubsection{Programa arquitectónico}

Para el tema del programa arquitectónico se optó por diseñar volúmenes que funcionan de manera independiente con un programa específico y cuentan con espacios flexibles donde pueden ampliarse o cambiar de uso a través del tiempo. El proyecto se encuentra desarrollado en su totalidad pero está pensado para su crecimiento en el tiempo y está dividido por 3 etapas. En una primera etapa se construyen 3 volúmenes arquitectónicos junto con 5 plazas y el recorrido principal que conecta la parte interior y superior del terreno mediante rampas y escaleras. En una segunda etapa se agregan 2 volúmenes más juntos con 5 plazas, además conectarse con los caminos y rampas de la primera etapa, finalmente la tercera etapa cuenta con 2 volúmenes y 2 plazas que se conectan al sistema de caminos propuestos anteriormente. A continuación se mostrara el programa arquitectónico de los volúmenes propuestos, juntos con sus áreas y aforo, posteriormente se mostrará un resumen general de las etapas propuestas.

Figura 8.25

Etapas del proyecto

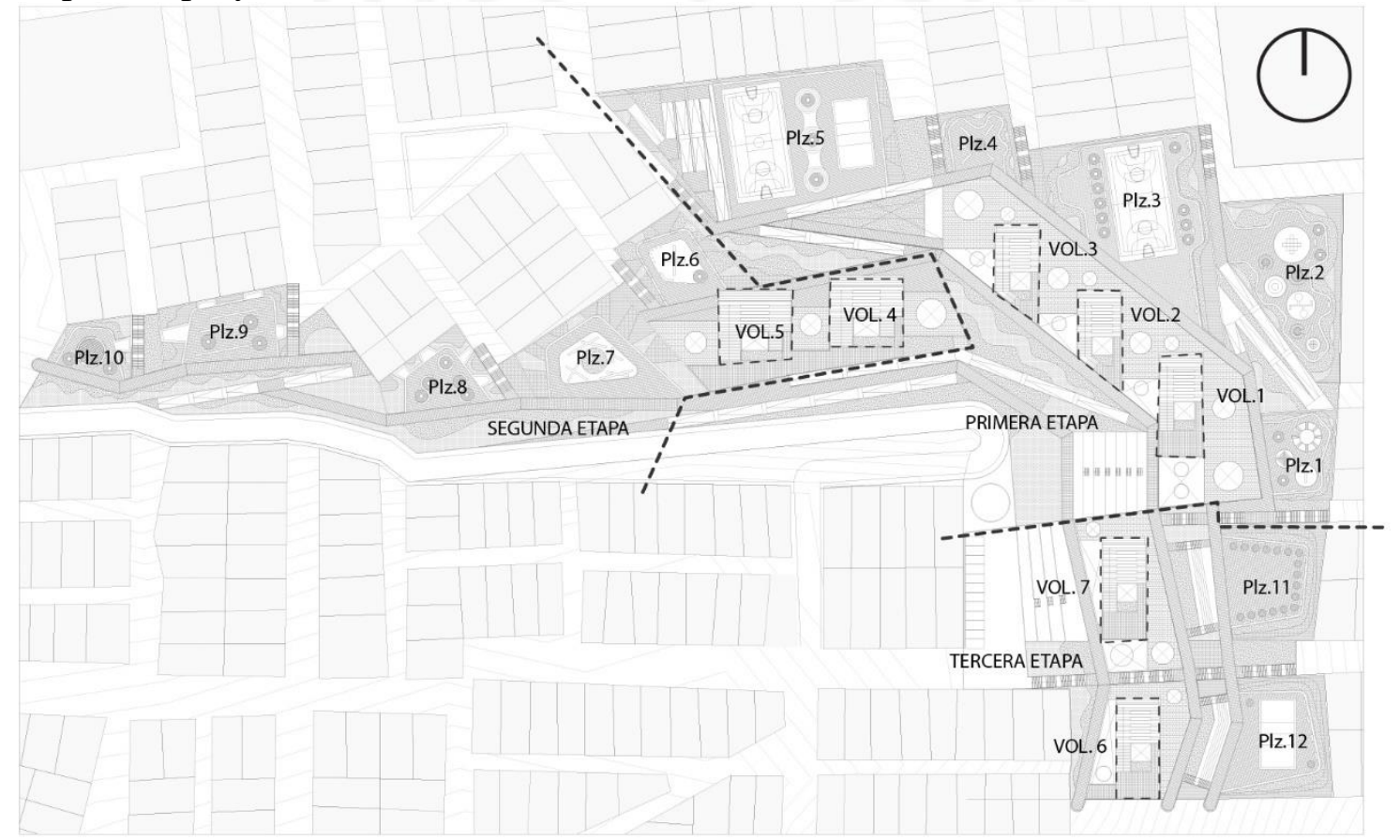

Fuente: Elaboración propia (2018) 
Tabla 8.1

Cuadro resumen del programa arquitectónico

\begin{tabular}{|l|r|r|}
\hline \multicolumn{2}{|c|}{ ETAPA 1.0 } & \multicolumn{1}{c|}{86.72} \\
\hline & \multicolumn{1}{|c|}{$\mathrm{m} 2$} & $\%$ \\
\hline Área del terreno & $24,569.69$ & 100.00 \\
\hline Área verde & $10,987.12$ & 44.72 \\
\hline Circulación & $6,330.14$ & 25.76 \\
\hline Área ocupada Arq. & $3,475.48$ & 14.15 \\
\hline Área plazas & $3,776.95$ & 15.37 \\
\hline
\end{tabular}

\begin{tabular}{|l|r|r|}
\hline \multicolumn{2}{|c|}{ ETAPA 2.0 } & 90.51 \\
\hline & $\mathrm{m} 2$ & $\%$ \\
\hline Área del terreno & $25,644.50$ & 100 \\
\hline Área verde & $8,344.04$ & 32.54 \\
\hline Circulación & $6,330.14$ & 24.68 \\
\hline Área ocupada Arq. & $5,412.79$ & 21.11 \\
\hline Área plazas & $5,557.53$ & 21.67 \\
\hline
\end{tabular}

\begin{tabular}{|l|r|r|}
\hline \multicolumn{2}{|c|}{ ETAPA 3.0 } & 100 \\
\hline & \multicolumn{1}{|c|}{$\mathrm{m} 2$} & $\%$ \\
\hline Área del terreno & $28,332.00$ & 100 \\
\hline Área verde & $8,273.91$ & 29.20 \\
\hline Circulación & $6,330.14$ & 22.34 \\
\hline Área ocupada Arq. & $7,183.97$ & 25.36 \\
\hline Área plazas & $6,543.98$ & 23.10 \\
\hline
\end{tabular}

Fuente: Elaboración propia (2019)

\begin{tabular}{|l|r|r|}
\multicolumn{1}{c}{} & $\mathrm{m} 2$ & $\%$ \\
\hline ARQUITECTURA & $2,986.60$ & 100.00 \\
\hline ÁREA CONSTRUIDA & & \\
\hline VOLUMEN 01* & 514.90 & 17.24 \\
\hline VOLUMEN 02* & 514.90 & 17.24 \\
\hline VOLUMEN 03* & 566.80 & 18.98 \\
\hline TERRAZA 1.0* & $1,390.00$ & 46.54 \\
\hline
\end{tabular}

\begin{tabular}{|l|r|r|}
\multicolumn{1}{c}{} & $\mathrm{m} 2$ & $\%$ \\
\hline ARQUITECTURA & $4,953.20$ & 100.00 \\
\hline ÁREA CONSTRUIDA & & \\
\hline VOLUMEN 01 & 514.90 & 10.40 \\
\hline VOLUMEN 02 & 514.90 & 10.40 \\
\hline VOLUMEN 03 & 566.80 & 11.44 \\
\hline TERRAZA 1.0 & $1,390.00$ & 28.06 \\
\hline VOLUMEN 04* & 808.30 & 16.32 \\
\hline VOLUMEN 05* & 808.30 & 16.32 \\
\hline TERRAZA 2.0* & 350.00 & 7.07 \\
\hline
\end{tabular}

\begin{tabular}{|l|r|r|}
\hline ARQUITECTURA & $6,576.80$ & 100.00 \\
\hline ÁREA CONSTRUIDA & & \\
\hline VOLUMEN 01 & 514.90 & 7.83 \\
\hline VOLUMEN 02 & 514.90 & 7.83 \\
\hline VOLUMEN 03 & 566.80 & 8.62 \\
\hline TERRAZA 1.0 & $1,390.00$ & 21.13 \\
\hline VOLUMEN 04 & 808.30 & 12.29 \\
\hline VOLUMEN 05 & 808.30 & 12.29 \\
\hline TERRAZA 2.0 & 350.00 & 5.32 \\
\hline VOLUMEN 06* & 566.80 & 8.62 \\
\hline VOLUMEN 07* & 566.80 & 8.62 \\
\hline TERRAZA 3.0* & 490.00 & 7.45 \\
\hline
\end{tabular}

*CONSTRUIDO EN ESA ETAPA 
Tabla 8.2

Áreas volumen 1: Taller de madres

PRIMERA ETAPA: ZONA DE MADRES Y NIÑOS

TOTAL M2:

1596.47

AFORO:

VOLUMEN 1: TALLER DE MADRES

TOTAL M2:

566.75

TOTAL AFORO:

199

PRIMER NIVEL

Ambiente

$\mathrm{m} 2$

$\%$

$\%$

$\mathrm{m} 2$

100

AFORO

RNE

1 COMEDOR

2 PATIO INTERIOR

3 SS.HH. PERSONAL

4 SS.HH. DISCP.

5 SS.HH. MUJ.

6 SS.HH. HOM.

7 ALMACEN

8 CURT. LIMP.

9 TALLER DE COCINA

$\%$

103.075

10 CIRCULACIÓN

$\begin{array}{rr}88.5 & 37.55 \\ 27.5 & 11.67 \\ 5.6 & 2.38 \\ 4 & 1.70 \\ 8.2 & 3.48 \\ 11.4 & 4.84 \\ 8.3 & 3.52 \\ 8.4 & 3.56 \\ 34.3 & 14.55 \\ 39.5 & 16.76\end{array}$

SEGUNDO NIVEL

Ambiente

me

\%

100

1 TALLER DE TEJEDORAS

$\mathrm{m} 2$

$\%$

36.07

2 SALA TALLER

3 OFC. PSICOLOGÍA

75.8

$45.1 \quad 21.46$

$12 \quad 5.71$

4 PIEL A PIEL

5 ALMACEN

28.35

13.49

9.6

4.57

6 OFC. COORDINACIÓN

7 CIRCULACIÓN

10.6

5.04

28.7

13.66

TERCER NIVEL

Ambiente

$\mathrm{m} 2$

120.9

m2

1 TALLER DE TEJEDORAS

2 CIRCULACIÓN

$\begin{array}{rr}92.9 & \\ 28 & 26.84 \\ & \end{array}$

AFORO

31

$313 \mathrm{~m} 2 \times$ pers

$$
\begin{array}{rl}
59 & 1.5 \mathrm{~m} 2 \mathrm{x} \text { pers } \\
28 & 1 \mathrm{~m} 2 \mathrm{x} \text { pers } \\
1 & 1 \text { pers } x \text { aparato } \\
1 & 1 \text { pers } x \text { aparato } \\
2 & 1 \text { pers } x \text { aparato } \\
2 & 1 \text { pers } x \text { aparato } \\
1 & 40 \mathrm{~m} 2 \times \text { pers } \\
1 & 1 \text { pers } x \text { aparato } \\
9 & 4 \mathrm{~m} 2 \times \text { pers }
\end{array}
$$

AFORO

65

RNE

$253 \mathrm{~m} 2 \times$ pers

$301.5 \mathrm{~m} 2 \times$ pers

$110 \mathrm{~m} 2 \times$ pers

$74 \mathrm{~m} 2 \times$ pers

$140 \mathrm{~m} 2 \times$ pers

$110 \mathrm{~m} 2 \times$ pers

Fuente: Elaboración propia (2018) 
Tabla 8.3

Áreas volumen 2: Taller de niños

PRIMER NIVEL
Ambiente
1 TALLER DE NIÑOS 1
2 PATIO INTERIOR
3 SS.HH. PERSONAL
4 SS.HH. DISCP.
5 SS.HH. MUJ.
6 SS.HH. HOM.
7 DEPÓSITO MATERIA.
8 CURT. LIMP.
9 CIRCULACIÓN

m2 $210.16^{\%}$ $\mathrm{m} 2$ $\%$

88.5

27.5

SEGUNDO NIVEL

Ambiente

1 TALLER DE NIÑOS 2

2 SALA TALLER

3 OFC. PSICOLOGÍA

4 DEPÓSITO

5 OFC. COORDINACIÓN

6 ARCHIVO

7 CIRCULACIÓN

\section{TERCER NIVEL}

Ambiente

1 TALLER DE NIÑOS 3

2 CIRCULACIÓN m2

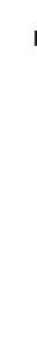

$\mathrm{m} 2$

$183.8^{\%}$

$\%$ $\%$

75.8

45.1

$\mathrm{m} 2$

$\mathrm{m} 2$

120.9

$92.9^{\%}$

28

41.24

24.54

6.53

3.86

5.77

2.45

15.61

AFORO

59

$253 \mathrm{~m} 2 \times$ pers

$301.5 \mathrm{~m} 2 \times$ pers

$110 \mathrm{~m} 2 \times$ pers

$140 \mathrm{~m} 2 \times$ pers

$110 \mathrm{~m} 2 \times$ pers

$140 \mathrm{~m} 2 \times$ pers

AFORO

31

$313 \mathrm{~m} 2 \times$ pers

$28 \quad 23.16$
100

76.84

23.16

RNE

$303 \mathrm{~m} 2 \times$ pers

11 pers $x$ aparato

11 pers $x$ aparato

1 pers $x$ aparato

pers $x$ aparato

$140 \mathrm{~m} 2 \mathrm{x}$ pers

11 pers $x$ aparato

RNE

RNE 
Tabla 8.4

Áreas volumen 3: Educación para niños

PRIMER NIVEL
Ambiente
1 MEDIATECA
2 ZONA LECTURA
3 PATIO INTERIOR
4 SS.HH. PERSONAL
5 SS.HH. DISCP.
6 SS.HH. MUJ.
7 SS.HH. HOM.
8 OFIC. ASESORIA
9 CURT. LIMP.
10 CIRCULACIÓN

$\mathrm{m} 2$

$$
210.16^{\%}
$$

m2

$\%$

59.85

28.65

27.5

5.6

4

8.2

10.9

15.82

10.14

39.5

SEGUNDO NIVEL

Ambiente

1 SALA DE ESTUDIOS

2 SALA TALLER

3 OFC. PSICOLOGÍA

4 DEPÓSITO

5 OFC. COORDINACIÓN

6 ARCHIVO

7 CIRCULACIÓN

TERCER NIVEL

Ambiente

1 BIBLIOTECA

2 CIRCULACIÓN m2

(1)

$\mathrm{m} 2$

$\%$

$\%$

75.8

45.1

41.24

24.54

12

7.1

6.53

3.86

10.6

5.77

$\begin{array}{rr}4.5 & 2.45 \\ 28.7 & 15.61\end{array}$

$\mathrm{m} 2$

$\%$

120.9

$\mathrm{m} 2$

100

92.9

76.84

28

23.16
AFORO RNE

95

$401.5 \mathrm{~m} 2 \times$ pers

$191.5 \mathrm{~m} 2 \times$ pers

$281 \mathrm{~m} 2 \mathrm{x}$ pers

11 pers $x$ aparato

11 pers $x$ aparato

21 pers $x$ aparato

21 pers $x$ aparato

$210 \mathrm{~m} 2 \mathrm{x}$ pers

11 pers $x$ aparato

AFORO

72

$382 \mathrm{~m} 2 \times$ pers

$301.5 \mathrm{~m} 2 \mathrm{x}$ pers

$110 \mathrm{~m} 2 \times$ pers

$140 \mathrm{~m} 2 \times$ pers

$110 \mathrm{~m} 2 \times$ pers

$140 \mathrm{~m} 2 \times$ pers

AFORO

23

$234 \mathrm{~m} 2 \times$ pers

Fuente: Elaboración propia (2018) 
Tabla 8.5

Áreas volumen 4: Educación para jóvenes

$\begin{array}{llr}\text { SEGUNDA ETAPA: ZONA DE JÓVENES } & \text { TOTAL M2: } & 1616.56 \\ & \text { AFORO: } & 481 \\ \text { VOLUMEN 4: EDUCACIÓN PARA JÓVENES } & & \\ & \text { TOTAL M2: } & 808.28 \\ & \text { TOTAL AFORO: } & 254.96\end{array}$

\begin{tabular}{|c|c|c|c|c|}
\hline \multirow[b]{2}{*}{ PRIMER NIVEL } & \multirow[t]{2}{*}{$\mathrm{m} 2$} & \multicolumn{2}{|c|}{$\%$} & \multirow{2}{*}{$\begin{array}{r}\text { AFORO } \\
84\end{array}$} \\
\hline & & 279.88 & 100 & \\
\hline Ambiente & $\mathrm{m} 2$ & $\%$ & & \\
\hline 1 SALONES DE ASESORÍA & & 104.76 & 37.43 & $353 \mathrm{~m} 2 \times$ pers \\
\hline 2 PATIO INTERIOR & & 33.95 & 12.13 & $341 \mathrm{~m} 2 \times$ pers \\
\hline 3 SALA DE VOLUNTARIOS & & 24.64 & 8.80 & $64 \mathrm{~m} 2 \times$ pers \\
\hline 4 SS.HH. PERSONAL & & 4.48 & 1.60 & 11 pers $x$ aparato \\
\hline 5 SS.HH. DISCP. & & 4 & 1.43 & 11 pers $x$ aparato \\
\hline 6 SS.HH. MUJERES & & 8.1 & 2.89 & 31 pers $x$ aparato \\
\hline 7 SS.HH. HOMBRES & & 13.73 & 4.91 & 31 pers $x$ aparato \\
\hline 8 DEPÓSITO & & 18.22 & 6.51 & $140 \mathrm{~m} 2 \times$ pers \\
\hline 9 CIRCULACIÓN & & 68 & 24.30 & \\
\hline
\end{tabular}

SEGUNDO NIVEL
Ambiente
1 MEDIATECA
2 SALA TALLER
3 OFIC. PSICOLOGÍA
4 SALA DE TERAPIA
5 OFIC. COORDINACIÓN
6 DEPÓSITO
7 CIRCULACIÓN

$\begin{array}{rrrrr}m 2 & \% & \text { AFORO } & \text { RNE } \\ & 252.08 & 100 & 103 & \end{array}$

TERCER NIVEL
Ambiente
1 BIBLIOTECA
2 SALA DE ESTUDIO (M)
3 CIRCULACIÓN

\begin{tabular}{|c|c|c|}
\hline $\mathrm{m} 2$ & & \\
\hline & 276.32 & 100 \\
\hline $\mathrm{m} 2$ & & \\
\hline & 162.21 & 58.70 \\
\hline & 81.54 & 29.51 \\
\hline & 32.57 & 11.7 \\
\hline
\end{tabular}
$701.5 \mathrm{~m} 2 \times$ pers $271.5 \mathrm{~m} 2 \times$ pers $110 \mathrm{~m} 2 \times$ pers $34 \mathrm{~m} 2 \times$ pers $110 \mathrm{~m} 2 \times$ pers $140 \mathrm{~m} 2 \times$ pers

$19.2-7.62$

$19.2-7.62$

$\begin{array}{rr}19.2 & 7.62 \\ 53.98 & 21.41\end{array}$

7 CIRCULACIÓN

$40.9 \quad 16.23$

$11.12 \quad 4.41$

4.41

21.41

AFORO

RNE

68

$364.5 \mathrm{~m} 2 \times$ pers. 321 pers $x$ asiento

Fuente: Elaboración propia (2018) 
Tabla 8.6

Áreas volumen 5: Taller de jóvenes

PRIMER NIVEL
Ambiente
1 SALONES DE ASESORÍA
2 PATIO INTERIOR
3 SALA DE VOLUNTARIOS
4 SS.HH. PERSONAL
5 SS.HH. DISCP.
6 SS.HH. MUJERES
7 SS.HH. HOMBRES
8 DEPÓSITO
9 CIRCULACIÓN

$\mathrm{m} 2$

$279.88^{\%}$

$\mathrm{m} 2$

$\%$

104.76

33.95

24.64

4.48

4

8.1

13.73

18.22

68

SEGUNDO NIVEL

Ambiente

1 TALLER DE JÓVENES

2 SALA TALLER

3 OFIC. PSICOLOGÍA

4 SALA DE TERAPIA

5 OFIC. COORDINACIÓN

6 DEPÓSITO

7 CIRCULACIÓN

TERCER NIVEL

Ambiente

1 SALA DE ESTUDIO

2 SALA DE ESTUDIO (M)

3 CIRCULACIÓN m2

$\mathrm{m} 2$

$252.08^{\%}$

$104.76^{\%}$

40.9

11.12

11.12

11

19.2

53.98

$\mathrm{m} 2$

276.32

$\mathrm{m} 2$

162.21

81.54

32.57
100

100

37.43

12.13

8.80

1.60

1.43

2.89

4.91

6.51

24.30

41.56

16.23

4.41

4.41

4.36

7.62

21.41

100

58.70

29.51

11.79

RNE

84

$353 \mathrm{~m} 2 \times$ pers

$341 \mathrm{~m} 2 \times$ pers

$64 \mathrm{~m} 2 \times$ pers

11 pers $x$ aparato

11 pers $x$ aparato

31 pers $x$ aparato

31 pers $x$ aparato

$140 \mathrm{~m} 2 \times$ pers

AFORO

RNE

59

$264 \mathrm{~m} 2 \times$ pers.

$271.5 \mathrm{~m} 2 \times$ pers

$110 \mathrm{~m} 2$ x pers.

$34 \mathrm{~m} 2 \times$ pers

$110 \mathrm{~m} 2$ x pers.

$140 \mathrm{~m} 2 \times$ pers

AFORO

RNE

83

511 pers $x$ asiento

321 pers $x$ asiento

Fuente: Elaboración propia (2018) 
Tabla 8.7

Áreas volumen 6: Taller de emprendimiento 01

PRIMER NIVEL
Ambiente
1 TALLER DE ENVASADO
2 PATIO INTERIOR
3 SS.HH. PERSONAL
4 SS.HH. DISCP.
5 SS.HH. MUJ.
6 SS.HH. HOM.
7 ALMACEN
8 CURT. LIMP.
9 TALLER DE PREPARADO
10 CIRCULACIÓN

$\mathrm{m} 2$<smiles>C1CCCCC1</smiles>
$\mathrm{m} 2$

235.7

$$
88.5
$$

27.5

5.6

SEGUNDO NIVEL

$$
\text { Ambiente }
$$

1 SALONES CAPACIT.

2 SALA TALLER

3 OFC. PSICOLOGÍA

4 SALA DE REUNIONES

5 ALMACEN

6 OFC. COORDINACIÓN

7 CIRCULACIÓN

TERCER NIVEL

Ambiente

1 TALLER CREATIVO

2 CIRCULACIÓN m2

m2<smiles>[124Sn]</smiles><smiles>C1CCCCC1</smiles>

75.8

45.1

12

28.35

9.6

10.6

28.7

m2

120.9

$\mathrm{m} 2$
100

37.55

11.67

2.38

1.70

3.48

4.84

3.52

3.56

14.55

16.76

100

36.07

21.46

5.71

13.49

4.57

5.04

13.66

100

76.84

23.16
RNE

71

$303 \mathrm{~m} 2 \times$ pers

$281 \mathrm{~m} 2 \mathrm{x}$ pers

11 pers $x$ aparato

11 pers $x$ aparato

21 pers $x$ aparato

21 pers $x$ aparato

$140 \mathrm{~m} 2 \times$ pers

11 pers $x$ aparato

$64 \mathrm{~m} 2 \times$ pers

AFORO

77

RNE

$253 \mathrm{~m} 2 \times$ pers

$301.5 \mathrm{~m} 2 \times$ pers

$110 \mathrm{~m} 2 \times$ pers

$191.5 \mathrm{~m} 2 \times$ pers

$140 \mathrm{~m} 2 \times$ pers

$110 \mathrm{~m} 2 \times$ pers

AFORO

23

$234 \mathrm{~m} 2 \times$ pers

Fuente: Elaboración propia (2018) 
Tabla 8.8

Áreas volumen 7: Taller de emprendimiento 02

PRIMER NIVEL
Ambiente
1 TALLER DE MÁQUINAS
2 PATIO INTERIOR
3 SS.HH. PERSONAL
4 SS.HH. DISCP.
5 SS.HH. MUJ.
6 SS.HH. HOM.
7 ALMACEN
8 CURT. LIMP.
9 TALLER DE ARMADO
10 CIRCULACIÓN

$\mathrm{m} 2$

$235.7 \%$
$\mathrm{m} 2$

88.5

27.5

m2

SEGUNDO NIVEL

Ambiente

1 SALONES CAPACIT.

2 SALA TALLER

3 OFC. PSICOLOGÍA

4 SALA DE REUNIONES

5 ALMACEN

6 OFC. COORDINACIÓN

7 CIRCULACIÓN

TERCER NIVEL

Ambiente

1 TALLER DE DISEÑO

2 CIRCULACIÓN

m

$210.15 \quad 100$

m2

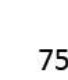

45.1

36.07

21.46

5.71

13.49

4.57

5.04

13.66

28.7

m2

120.9

$\mathrm{m} 2$

$\%$

92.9

28
AFORO

82

$303 \mathrm{~m} 2 \times$ pers

$281 \mathrm{~m} 2 \times$ pers

11 pers $x$ aparato

11 pers $x$ aparato

21 pers $x$ aparato

21 pers $x$ aparato

$140 \mathrm{~m} 2 \times$ pers

11 pers $x$ aparato

$1720 \mathrm{~m} 2 \times$ pers

AFORO

77

$253 \mathrm{~m} 2 \times$ pers.

$301.5 \mathrm{~m} 2$ x pers.

$110 \mathrm{~m} 2 \times$ pers.

$191.5 \mathrm{~m} 2 \times$ pers

$140 \mathrm{~m} 2 \times$ pers

$110 \mathrm{~m} 2 \times$ pers

AFORO

23

$234 \mathrm{~m} 2 \times$ pers

RNE

Fuente: Elaboración propia (2018) 


\subsubsection{Etapas del proyecto}

Tabla 8.9

Áreas Primera Etapa del proyecto

\begin{tabular}{|l|r|r|}
\hline \multicolumn{2}{|c|}{ ETAPA 1.0 } & \multicolumn{1}{c|}{86.72} \\
\hline & \multicolumn{1}{|c|}{$\mathrm{m} 2$} & \multicolumn{1}{c|}{$\%$} \\
\hline Área del terreno & $24,569.69$ & 100.00 \\
\hline Área verde & $10,987.12$ & 44.72 \\
\hline Circulación & $6,330.14$ & 25.76 \\
\hline Área ocupada Arq. & $3,475.48$ & 14.15 \\
\hline Área plazas & $3,776.95$ & 15.37 \\
\hline
\end{tabular}

\begin{tabular}{l}
\hline \multicolumn{2}{|c|}{ ETAPA 1.0} \\
\begin{tabular}{|l|r|r|}
\hline \multicolumn{2}{|c|}{$\mathrm{m} 2$} \\
\hline AREA VERDE & $10,987.12$ & \\
\hline & & 100 \\
\hline JARDIN PLAZAS* & $1,276.74$ & 11.62 \\
\hline HUERTOS URBANOS* & 442.00 & 4.02 \\
\hline PAISAJE* & $5,975.08$ & 54.38 \\
\hline VIVERO* & $3,293.30$ & 29.97 \\
\hline
\end{tabular}
\end{tabular}

\begin{tabular}{|c|c|c|}
\hline CIRCULACIÓN & $6,330.14$ & 100 \\
\hline \begin{tabular}{|l} 
ESCALERAS* \\
\end{tabular} & 660.35 & 10.43 \\
\hline \begin{tabular}{|l} 
RAMPAS* \\
\end{tabular} & $1,760.25$ & 27.81 \\
\hline CAMINOS* & $3,094.54$ & 48.89 \\
\hline ESTACIONAMIENTO* & 815.00 & 12.87 \\
\hline & $\mathrm{m} 2$ & $\%$ \\
\hline ÁREA OCUP. ARQ. & $3,475.48$ & 100 \\
\hline ETAPA 01* & $3,475.48$ & 100 \\
\hline
\end{tabular}

\begin{tabular}{|l|r|r|}
\multicolumn{2}{c}{} & \multicolumn{1}{c|}{$\mathrm{m} 2$} \\
\hline ÁREA PLAZAS & $3,776.95$ & 100.00 \\
\hline & & \\
\hline PLAZA 06* & $1,487.68$ & 39.39 \\
\hline PLAZA 07* & 183.43 & 4.86 \\
\hline PLAZA 08* & $1,163.31$ & 30.80 \\
\hline PLAZA 09* & 629.99 & 16.68 \\
\hline PLAZA 10* & 312.54 & 8.27 \\
\hline
\end{tabular}

\begin{tabular}{|l|r|r|}
\hline ARQUITECTURA & $2,986.60$ & 100.00 \\
\hline ÁREA CONSTRUIDA & & \\
\hline VOLUMEN 01* & 514.90 & 17.24 \\
\hline VOLUMEN 02* & 514.90 & 17.24 \\
\hline VOLUMEN 03* & 566.80 & 18.98 \\
\hline TERRAZA 1.0* & $1,390.00$ & 46.54 \\
\hline
\end{tabular}

*CONStRUIDOS EN ESA ETAPA

Fuente: Elaboración propia (2019) 
Tabla 8.10

Áreas Segunda Etapa del proyecto

\begin{tabular}{|l|r|r|}
\hline \multicolumn{2}{|c|}{ ETAPA 2.0 } & 90.51 \\
\hline & \multicolumn{1}{|c|}{$\mathrm{m} 2$} & $\%$ \\
\hline Área del terreno & $25,644.50$ & 100 \\
\hline Área verde & $8,344.04$ & 32.54 \\
\hline Circulación & $6,330.14$ & 24.68 \\
\hline Área ocupada Arq. & $5,412.79$ & 21.11 \\
\hline Área plazas & $5,557.53$ & 21.67 \\
\hline
\end{tabular}

\begin{tabular}{|c|c|c|}
\hline \multicolumn{2}{|c|}{ ETAPA 2.0} & \\
\hline & $\mathrm{m} 2$ & $\%$ \\
\hline AREA VERDE & $8,344.04$ & 100.00 \\
\hline \begin{tabular}{|l} 
JARDIN PLAZAS \\
\end{tabular} & $2,139.68$ & 25.64 \\
\hline \begin{tabular}{|l|} 
HUERTOS URBANOS \\
\end{tabular} & $1,301.19$ & 15.59 \\
\hline PAISAJE & $4,903.17$ & 58.76 \\
\hline VIVERO & & 0.00 \\
\hline
\end{tabular}

\begin{tabular}{|l|r|r|}
\hline CIRCULACIÓN & $6,330.14$ & 100.00 \\
\hline & & \\
\hline ESCALERAS & 660.35 & 10.43 \\
\hline RAMPAS & $1,760.25$ & 27.81 \\
\hline CAMINOS & $3,094.54$ & 48.89 \\
\hline ESTACIONAMIENTO & \multicolumn{1}{|c|}{815.00} & 12.87 \\
\hline
\end{tabular}

\begin{tabular}{|l|r|r|}
\hline ÁREA OCUP. ARQ. & $5,412.79$ & 100.00 \\
\hline & & \\
\hline ETAPA 01 & $3,475.48$ & 64.21 \\
\hline ETAPA 02* & $1,937.31$ & 35.79 \\
\hline
\end{tabular}

\begin{tabular}{|l|r|r|}
\multicolumn{1}{c}{} & \multicolumn{1}{c|}{$\mathrm{m} 2$} \\
\hline Á́REA PLAZAS & $5,557.53$ & 100.00 \\
\hline & & \\
\hline PLAZA 01* & 192.38 & 3.46 \\
\hline PLAZA 02 & $*$ \\
\hline PLAZA 03* & 437.48 & 7.87 \\
\hline PLAZA 04* & 302.18 & 5.44 \\
\hline PLAZA 05* & 536.48 & 9.65 \\
\hline PLAZA 06 & 312.06 & 5.62 \\
\hline PLAZA 07 & $1,487.68$ & 26.77 \\
\hline PLAZA 08 & 183.43 & 3.30 \\
\hline PLAZA 09 & $1,163.31$ & 20.93 \\
\hline PLAZA 10 & 629.99 & 11.34 \\
\hline
\end{tabular}

\begin{tabular}{|l|r|r|}
\multicolumn{1}{c}{} & \multicolumn{1}{c|}{$\mathrm{m} 2$} \\
\hline ARQUITECTURA & $4,953.20$ & 100.00 \\
\hline ÁREA CONSTRUIDA & & \\
\hline VOLUMEN 01 & 514.90 & 10.40 \\
\hline VOLUMEN 02 & 514.90 & 10.40 \\
\hline VOLUMEN 03 & 566.80 & 11.44 \\
\hline TERRAZA 1.0 & $1,390.00$ & 28.06 \\
\hline VOLUMEN 04* & 808.30 & 16.32 \\
\hline VOLUMEN 05* & 808.30 & 16.32 \\
\hline TERRAZA 2.0* & 350.00 & 7.07 \\
\hline
\end{tabular}

\section{*CONSTRUIDO EN ESA ETAPA}

Fuente: Elaboración propia (2019) 
Tabla 8.11

Áreas Tercera Etapa del proyecto

\begin{tabular}{|c|c|c|}
\hline \multicolumn{2}{|c|}{ ETAPA 3.0} & 100 \\
\hline & $\mathrm{m} 2$ & $\%$ \\
\hline Área del terreno & $28,332.00$ & 100 \\
\hline Área verde & $8,273.91$ & 29.20 \\
\hline Circulación & $6,330.14$ & 22.34 \\
\hline Área ocupada Arq. & $7,183.97$ & 25.36 \\
\hline Área plazas & $6,543.98$ & 23.10 \\
\hline \multicolumn{3}{|c|}{ ETAPA 3.0} \\
\hline & $\mathrm{m} 2$ & $\%$ \\
\hline AREA VERDE & $8,273.91$ & 100.00 \\
\hline JARDIN PLAZAS & $2,741.56$ & 33.13 \\
\hline HUERTOS URBANOS & 908.56 & 10.98 \\
\hline PAISAJE & $4,623.79$ & 55.88 \\
\hline
\end{tabular}

\begin{tabular}{|l|r|r|}
\multicolumn{1}{c}{} & \multicolumn{1}{c}{$\mathrm{m} 2$} & \multicolumn{1}{c|}{$\%$} \\
\hline CIRCULACIÓN & $6,330.14$ & 100.00 \\
\hline & & \\
\hline ESCALERAS & 660.35 & 10.43 \\
\hline RAMPAS & $1,760.25$ & 27.81 \\
\hline CAMINOS & $3,094.54$ & 48.89 \\
\hline ESTACIONAMIENTO & 815.00 & 12.87 \\
\hline \multicolumn{2}{|c|}{$\mathrm{m} 2$} & $\%$ \\
\hline
\end{tabular}

\begin{tabular}{|l|c|r|}
\hline ÁREA OCUP. ARQ. & $7,183.97$ & 100.00 \\
\hline & & \\
\hline ETAPA 01 & $3,475.48$ & 48.38 \\
\hline ETAPA 02 & $1,937.31$ & 26.97 \\
\hline ETAPA 03* & $1,771.18$ & 24.65 \\
\hline \multicolumn{3}{|c|}{$\mathrm{m} 2$} \\
\hline
\end{tabular}

\begin{tabular}{|c|c|c|}
\hline ÁREA PLAZAS & $6,543.98$ & 100.00 \\
\hline PLAZA 01 & 192.38 & 2.94 \\
\hline PLAZA 02 & 437.48 & 6.69 \\
\hline PLAZA 03 & 302.18 & 4.62 \\
\hline PLAZA 04 & 536.48 & 8.20 \\
\hline PLAZA 05 & 312.06 & 4.77 \\
\hline PLAZA 06 & $1,487.68$ & 22.73 \\
\hline PLAZA 07 & 183.43 & 2.80 \\
\hline PLAZA 08 & $1,163.31$ & 17.78 \\
\hline PLAZA 09 & 629.99 & 9.63 \\
\hline PLAZA 10 & 312.54 & 4.78 \\
\hline PLAZA 11* & 471.80 & 7.21 \\
\hline PLAZA 12* & 514.65 & 7.86 \\
\hline
\end{tabular}

\begin{tabular}{|l|r|r|}
\multicolumn{1}{c}{} & $\mathrm{m} 2$ & \multicolumn{1}{c|}{$\%$} \\
\hline ARQUITECTURA & $6,576.80$ & 100.00 \\
\hline ÁREA CONSTRUIDA & & \\
\hline VOLUMEN 01 & 514.90 & 7.83 \\
\hline VOLUMEN 02 & 514.90 & 7.83 \\
\hline VOLUMEN 03 & 566.80 & 8.62 \\
\hline TERRAZA 1.0 & $1,390.00$ & 21.13 \\
\hline VOLUMEN 04 & 808.30 & 12.29 \\
\hline VOLUMEN 05 & 808.30 & 12.29 \\
\hline TERRAZA 2.0 & 350.00 & 5.32 \\
\hline VOLUMEN 06* & 566.80 & 8.62 \\
\hline VOLUMEN 07* & 566.80 & 8.62 \\
\hline TERRAZA 3.0* & 490.00 & 7.45 \\
\hline
\end{tabular}

*CONSTRUIDO EN ESA ETAPA

Fuente: Elaboración propia (2019) 


\subsubsection{Cálculo de usuarios}

Para el cálculo de usuarios se consideraron las normal del Reglamente Nacional de Edificaciones (RNE, 2015), considerando el aforo para centros comunales y espacios afines a centros educativos y talleres. Como se vio anteriormente en los cuadros del programa arquitectónico el aforo fue calculado por ambiente, luego un cálculo por volumen y finalmente por etapa.

1. Primera Etapa: aforo 4413 personas

- Volumen 1 Taller de madres: aforo 199 personas

- Volumen 2 Taller de niños: aforo 155 personas

- Volumen 3 Educación para niños: aforo 190 personas

- Terraza: aforo 1521 personas

- Planta libre: aforo 2347 personas

2. Segunda Etapa: aforo 1568 personas

- Volumen 4 Taller para jóvenes: aforo 255 personas

- volumen 5 Educación para jóvenes: aforo 226 personas

- Terraza: aforo 353 personas

- Planta libre: aforo 734 personas

3. Tercera Etapa: aforo 1860 personas

- Volumen 6 Taller de emprendimiento / productos: aforo172 personas

- Volumen 7 Taller de emprendimiento / textil: aforo 183 personas

- Terraza: aforo 528 personas

- Planta libre: aforo 979 personas

Aforo total de volúmenes arquitectónicos: 1380 personas

Aforo total de terrazas: 2402 personas

Aforo total planta libre: 4059 personas

Aforo total proyecto construido: 7841 personas 


\subsubsection{Programa con cabida}

Figura 8.26

Área del proyecto

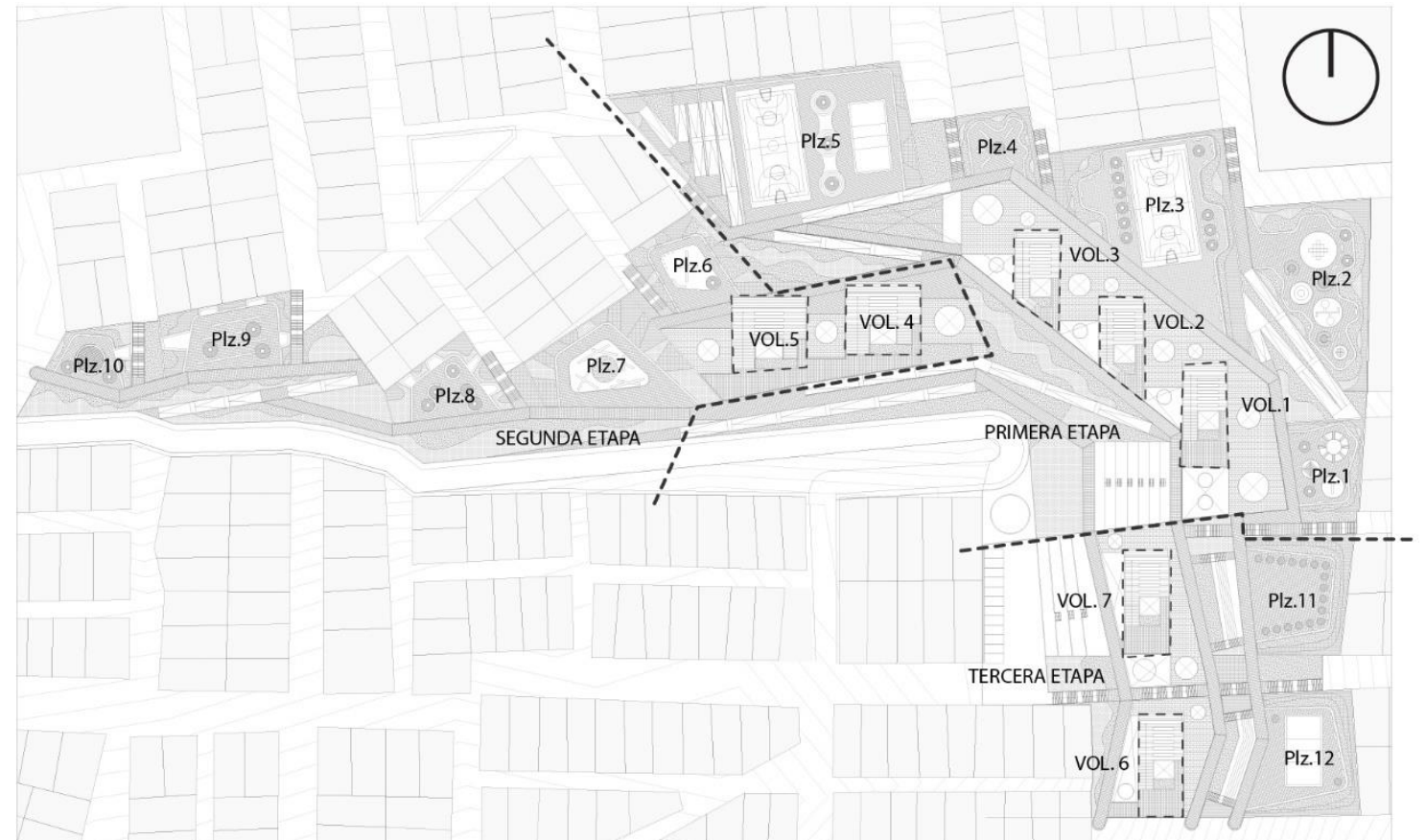

Fuente: Elaboración propia (2018).

El proyecto tiene un área de $28200 \mathrm{~m} 2$ de los cuales el área ocupada es el $21.63 \%$ que representa $6101 \mathrm{~m} 2$, dando un espacio público con áreas verdes de 22099 m2 (78.37\%).

- Volumen 1 Taller de Madres: 566.8 m2 construidos

- Volumen 2 Taller de Niños: 514.9 m2 construidos

- Volumen 3 Educación para Niños: 514.9 m2 construidos

- Volumen 4 Taller de Jóvenes: 808.3 m2 construidos

- Volumen 5 Educación para jóvenes: $808.3 \mathrm{~m} 2$ construidos

- Volumen 6 Taller de Emprendimiento / Productos: $566.8 \mathrm{~m} 2$ construidos

- Volumen 7 Taller de Emprendimiento / textil: 566.8 m2 construidos

Total de área construida de programa arquitectónico: 4346.53 m2 construidos 


\subsubsection{Viabilidad}

El proyecto se construye por etapas a una proyección de 10 años en el tiempo, por lo que el costo final será la suma de todas las etapas propuestas. Considerando costos aproximados en la construcción de acuerdo al tipo de estructura, acabados, cimentaciones, movimiento de tierra, muros de contención, así mismo un costo menor será le asignará a las áreas públicas para su implementación.

La forma del financiamiento será por el Estado, quienes otorgar 20 millones soles para proyectos sociales, para el terreno se buscará la donación por parte de la Municipalidad de Pachacamac por ser un terreno con zonificación recreativa (ZRP) con la finalidad de intervenirlo por la mejora de la educación, emprendimiento y recreación de los vecinos de Manchay.

El dinero sería utilizado para la primera etapa del proyecto, y para el mantenimiento en el tiempo, las madres pueden pagar un costo general por alquiler del espacio mensual para que puedan desarrollar sus productos, así mismo se propondrá la creación de una cooperativa por barrios donde se les cobraría un monto mínimo como la de 1 sol por persona mensual para que puedan hacer uso de todos los servicios ofrecidos en el parque recreativo y centro comunal, ese dinero recaudado servirá para el mantenimiento de los espacios, pago de los servicios de agua, luz, internet y pagos para los trabajadores como profesionales, personal de seguridad, jardinería y para el pago de los equipos y materiales en general.

A continuación se mostrarán los cuadros con los costos aproximados para la construcción por etapas del proyecto. 
Tabla 8.12

Costos Primera Etapa del proyecto

\begin{tabular}{|l|r|r|}
\hline \multicolumn{2}{|c|}{ ETAPA 1.0 } & \multicolumn{1}{|c|}{86.72} \\
\hline & \multicolumn{1}{|c|}{$\mathrm{m} 2$} & $\%$ \\
\hline Área del terreno & $24,569.69$ & 100.00 \\
\hline Área verde & $10,987.12$ & 44.72 \\
\hline Circulación & $6,330.14$ & 25.76 \\
\hline Área ocupada Arq. & $3,475.48$ & 14.15 \\
\hline Área plazas & $3,776.95$ & 15.37 \\
\hline
\end{tabular}

\begin{tabular}{|c|c|}
\hline ETAPA 1.0 & \\
\hline \multicolumn{2}{|c|}{$\mathrm{m} 2$} \\
\hline
\end{tabular}

\begin{tabular}{|l|r|r|}
\hline AREA VERDE & $10,987.12$ & 100 \\
\hline & & \\
\hline JARDIN PLAZAS* & $1,276.74$ & 11.62 \\
\hline HUERTOS URBANOS* & 442.00 & 4.02 \\
\hline PAISAJE* & $5,975.08$ & 54.38 \\
\hline VIVERO* & $3,293.30$ & 29.97 \\
\hline
\end{tabular}

\begin{tabular}{|c|c|c|}
\hline \multicolumn{3}{|c|}{ COSTOS APROX. ETAPA 1.0 } \\
\hline \multicolumn{2}{|c|}{ ÁREA CONSTRUIDA DE ARQUITECTURA } \\
\hline $\mathrm{m} 2$ & $\$ \times \mathrm{m} 2$ & TOTAL \\
\hline $1,596.60$ & 600.00 & $957,960.00$ \\
\hline ÁREA CONSTRUIDA ESPACIO PÚBLICO \\
\hline $\mathrm{m} 2$ & $\$ \times \mathrm{m} 2$ & TOTAL \\
\hline $11,497.09$ & 200.00 & $2,299,418.00$ \\
\hline \multicolumn{3}{|c|}{ ÁREA VERDE } \\
\hline $\mathrm{m} 2$ & \$ $\times \mathrm{m} 2$ & TOTAL \\
\hline $10,987.12$ & 20.00 & $219,742.40$ \\
\hline
\end{tabular}

\begin{tabular}{|c|c|c|}
\hline \multicolumn{3}{|c|}{ TOTAL A INVERTIR } \\
\hline DOLARES & & $3,477,120.40$ \\
\hline SOLES** & S/ & $11,648,353.34$ \\
\hline
\end{tabular}

$* * \$ 1.00=\mathrm{S} / 3.35$

\begin{tabular}{|l|r|r|}
\hline CIRCULACIÓN & $6,330.14$ & 100 \\
\hline & & \\
\hline ESCALERAS* & 660.35 & 10.43 \\
\hline RAMPAS* & $1,760.25$ & 27.81 \\
\hline CAMINOS* & $3,094.54$ & 48.89 \\
\hline ESTACIONAMIENTO* & 815.00 & 12.87 \\
\hline
\end{tabular}

\begin{tabular}{|l|r|r|}
\hline ÁREA OCUP. ARQ. & $3,475.48$ & 100 \\
\hline & & \\
\hline ETAPA 01* & & 100 \\
\hline
\end{tabular}

\begin{tabular}{|l|r|r|}
\multicolumn{2}{c}{} & $\mathrm{m} 2$ \\
\hline ÁREA PLAZAS & $3,776.95$ & 100.00 \\
\hline & & \\
\hline PLAZA 06* & $1,487.68$ & 39.39 \\
\hline PLAZA 07* & 183.43 & 4.86 \\
\hline PLAZA 08* & $1,163.31$ & 30.80 \\
\hline PLAZA 09* & 629.99 & 16.68 \\
\hline PLAZA 10* & 312.54 & 8.27 \\
\hline
\end{tabular}

\begin{tabular}{|l|r|r|}
\hline ARQUITECTURA & $2,986.60$ & 100.00 \\
\hline ÁREA CONSTRUIDA & & \\
\hline VOLUMEN 01* & 514.90 & 17.24 \\
\hline VOLUMEN 02* & 514.90 & 17.24 \\
\hline VOLUMEN 03* & 566.80 & 18.98 \\
\hline TERRAZA 1.0* & $1,390.00$ & 46.54 \\
\hline
\end{tabular}

*CONSTRUIDOS EN ESA ETAPA

Fuente: Elaboración propia (2019) 
Tabla 8.13

Costos Segunda Etapa del proyecto

\begin{tabular}{|l|r|r|}
\hline \multicolumn{2}{|c|}{ ETAPA 2.0 } & \multicolumn{1}{|c|}{90.51} \\
\hline & \multicolumn{1}{c|}{$\mathrm{m} 2$} & $\%$ \\
\hline Área del terreno & $25,644.50$ & 100 \\
\hline Área verde & $8,344.04$ & 32.54 \\
\hline Circulación & $6,330.14$ & 24.68 \\
\hline Área ocupada Arq. & $5,412.79$ & 21.11 \\
\hline Área plazas & $5,557.53$ & 21.67 \\
\hline
\end{tabular}

\begin{tabular}{l}
\hline \multicolumn{2}{|c|}{ ETAPA 2.0} \\
\begin{tabular}{|l|r|r|}
\hline \multicolumn{2}{|c|}{$\mathrm{m} 2$} \\
\hline AREA VERDE & $8,344.04$ & 100.00 \\
\hline & & \\
\hline JARDIN PLAZAS & $2,139.68$ & 25.64 \\
\hline HUERTOS URBANOS & $1,301.19$ & 15.59 \\
\hline PAISAJE & $4,903.17$ & 58.76 \\
\hline VIVERO & & 0.00 \\
\hline
\end{tabular}
\end{tabular}

\begin{tabular}{|c|c|c|}
\hline \multicolumn{3}{|c|}{ COSTOS APROX. ETAPA 2.0} \\
\hline \multicolumn{2}{|c|}{ ÁREA CONSTRUIDA DE ARQUITECTURA } \\
\hline $\mathrm{m} 2$ & $\$ \times \mathrm{m} 2$ & TOTAL \\
\hline $1,616.60$ & 600.00 & $969,960.00$ \\
\hline ÁREA CONSTRUIDA ESPACIO PÚBLICO \\
\hline $\mathrm{m} 2$ & $\$ \times \mathrm{m} 2$ & TOTAL \\
\hline $2,130.58$ & 200.00 & $426,116.00$ \\
\hline \multicolumn{3}{|c|}{ ÁREA VERDE } \\
\hline $\mathrm{m} 2$ & $\$ \times \mathrm{m} 2$ & TOTAL \\
\hline $2,390.00$ & 20.00 & $47,800.00$ \\
\hline
\end{tabular}

\begin{tabular}{|l|r|}
\hline \multicolumn{2}{|c|}{ TOTAL A INVERTIR } \\
\hline DOLARES & $1,443,876.00$ \\
\hline SOLES** & $\mathrm{S} / 4,836,984.60$ \\
\hline
\end{tabular}

** $\$ 1.00=\mathrm{S} / 3.35$

\begin{tabular}{|l|r|r|}
\hline CIRCULACIÓN & $6,330.14$ & 100.00 \\
\hline & & \\
\hline ESCALERAS & 660.35 & 10.43 \\
\hline RAMPAS & $1,760.25$ & 27.81 \\
\hline CAMINOS & $3,094.54$ & 48.89 \\
\hline ESTACIONAMIENTO & 815.00 & 12.87 \\
\hline
\end{tabular}

\begin{tabular}{|l|r|r|}
\hline ÁREA OCUP. ARQ. & $5,412.79$ & 100.00 \\
\hline & & \\
\hline ETAPA 01 & $3,475.48$ & 64.21 \\
\hline ETAPA 02* & $1,937.31$ & 35.79 \\
\hline
\end{tabular}

$\mathrm{m} 2 \%$

\begin{tabular}{|l|r|r|}
\multicolumn{1}{c}{} & \multicolumn{1}{c}{$\mathrm{m} 2$} \\
\hline & $5,557.53$ & 100.00 \\
\hline ÁREA PLAZAS & & \\
\hline PLAZA 01* & 192.38 & 3.46 \\
\hline PLAZA 02* & 437.48 & 7.87 \\
\hline PLAZA 03* & 302.18 & 5.44 \\
\hline PLAZA 04* & 536.48 & 9.65 \\
\hline PLAZA 05* & 312.06 & 5.62 \\
\hline PLAZA 06 & $1,487.68$ & 26.77 \\
\hline PLAZA 07 & 183.43 & 3.30 \\
\hline PLAZA 08 & $1,163.31$ & 20.93 \\
\hline PLAZA 09 & 629.99 & 11.34 \\
\hline PLAZA 10 & 312.54 & 5.62 \\
\hline
\end{tabular}

\begin{tabular}{|l|r|r|}
\hline ARQUITECTURA & $4,953.20$ & 100.00 \\
\hline ÁREA CONSTRUIDA & & \\
\hline VOLUMEN 01 & 514.90 & 10.40 \\
\hline VOLUMEN 02 & 514.90 & 10.40 \\
\hline VOLUMEN 03 & 566.80 & 11.44 \\
\hline TERRAZA 1.0 & $1,390.00$ & 28.06 \\
\hline VOLUMEN 04* & 808.30 & 16.32 \\
\hline VOLUMEN 05* & 808.30 & 16.32 \\
\hline TERRAZA 2.0* & 350.00 & 7.07 \\
\hline
\end{tabular}

\section{*CONSTRUIDO EN ESA ETAPA}

Fuente: Elaboración propia (2019) 
Tabla 8.14

Costos Tercera Etapa del proyecto

\begin{tabular}{|l|r|r|}
\hline \multicolumn{2}{|c|}{ ETAPA 3.0 } & 100 \\
\hline & \multicolumn{1}{|c|}{$\mathrm{m} 2$} & $\%$ \\
\hline Área del terreno & $28,332.00$ & 100 \\
\hline Área verde & $8,273.91$ & 29.20 \\
\hline Circulación & $6,330.14$ & 22.34 \\
\hline Área ocupada Arq. & $7,183.97$ & 25.36 \\
\hline Área plazas & $6,543.98$ & 23.10 \\
\hline
\end{tabular}

\begin{tabular}{|c|c|c|}
\hline \multicolumn{2}{|c|}{ ETAPA 3.0} & \\
\hline & $\mathrm{m} 2$ & $\%$ \\
\hline AREA VERDE & $8,273.91$ & 100.00 \\
\hline JARDIN PLAZAS & $2,741.56$ & 33.13 \\
\hline HUERTOS URBANOS & 908.56 & 10.98 \\
\hline PAISAJE & $4,623.79$ & 55.88 \\
\hline
\end{tabular}

\begin{tabular}{|c|c|c|}
\hline \multicolumn{3}{|c|}{ COSTOS APROX. ETAPA 3.0 } \\
\hline \multicolumn{2}{|c|}{ ÁREA CONSTRUIDA DE ARQUITECTURA } \\
\hline $\mathrm{m} 2$ & $\$ \times \mathrm{m} 2$ & TOTAL \\
\hline $1,133.60$ & 600.00 & $680,160.00$ \\
\hline \multicolumn{3}{|c|}{ ÁREA CONSTRUIDA ESPACIO PÚBLICO } \\
\hline $\mathrm{m} 2$ & \$ $\mathrm{m} 2$ & TOTAL \\
\hline $1,476.45$ & 200.00 & $295,290.00$ \\
\hline \multicolumn{3}{|c|}{ ÁREA VERDE } \\
\hline $\mathrm{m} 2$ & \$ $\mathrm{m} 2$ & TOTAL \\
\hline $1,602.99$ & 20.00 & $32,059.80$ \\
\hline
\end{tabular}

\begin{tabular}{|c|c|c|}
\hline \multicolumn{3}{|c|}{ TOTAL A INVERTIR } \\
\hline DOLARES & & $1,007,509.80$ \\
\hline SOLES** & $\mathrm{S} /$ & $3,375,157.83$ \\
\hline
\end{tabular}

$* * \$ 1.00=\mathrm{S} / 3.35$

\begin{tabular}{|l|r|r|}
\multicolumn{1}{c}{} & $\mathrm{m} 2$ & \multicolumn{1}{c}{$\%$} \\
\hline CIRCULACIÓN & $6,330.14$ & 100.00 \\
\hline & & \\
\hline ESCALERAS & 660.35 & 10.43 \\
\hline RAMPAS & $1,760.25$ & 27.81 \\
\hline CAMINOS & $3,094.54$ & 48.89 \\
\hline ESTACIONAMIENTO & 815.00 & 12.87 \\
\hline \multicolumn{3}{|c|}{$\mathrm{m} 2$} \\
\hline
\end{tabular}

\begin{tabular}{|l|c|c|}
\hline ÁREA OCUP. ARQ. & $7,183.97$ & 100.00 \\
\hline & & \\
\hline ETAPA 01 & $3,475.48$ & 48.38 \\
\hline ETAPA 02 & $1,937.31$ & 26.97 \\
\hline ETAPA 03* & $1,771.18$ & 24.65 \\
\hline \multicolumn{3}{|c|}{$\mathrm{m} 2$} \\
\hline
\end{tabular}

\begin{tabular}{|l|r|r|}
\hline ÁREA PLAZAS & $6,543.98$ & 100.00 \\
\hline & & \\
\hline PLAZA 01 & 192.38 & 2.94 \\
\hline PLAZA 02 & 437.48 & 6.69 \\
\hline PLAZA 03 & 302.18 & 4.62 \\
\hline PLAZA 04 & 536.48 & 8.20 \\
\hline PLAZA 05 & 312.06 & 4.77 \\
\hline PLAZA 06 & $1,487.68$ & 22.73 \\
\hline PLAZA 07 & 183.43 & 2.80 \\
\hline PLAZA 08 & $1,163.31$ & 17.78 \\
\hline PLAZA 09 & 629.99 & 9.63 \\
\hline PLAZA 10 & 312.54 & 4.78 \\
\hline PLAZA 11* & 471.80 & 7.21 \\
\hline PLAZA 12* & 514.65 & 7.86 \\
\hline
\end{tabular}

\begin{tabular}{|c|c|c|}
\hline \multicolumn{3}{|c|}{ COSTO APROX DEL PROYECTO } \\
\hline \multicolumn{2}{|c|}{ ÁREA CONSTRUIDA DE ARQUITECTURA } \\
\hline $\mathrm{m} 2$ & $\$ \times \mathrm{m} 2$ & TOTAL \\
\hline $4,346.80$ & 600.00 & $2,608,080.00$ \\
\hline ÁREA CONSTRUIDA ESPACIO PÚBLICO \\
\hline $\mathrm{m} 2$ & $\$ \times \mathrm{m} 2$ & TOTAL \\
\hline $15,104.12$ & 200.00 & $3,020,824.00$ \\
\hline \multicolumn{3}{|c|}{ ÁREA VERDE } \\
\hline m2 & \$ $\mathrm{m} 2$ & TOTAL \\
\hline $14,980.11$ & 20.00 & $299,602.20$ \\
\hline
\end{tabular}

\begin{tabular}{|c|c|c|}
\hline \multicolumn{3}{|c|}{ TOTAL A INVERTIR } \\
\hline DOLARES & & $5,928,506.20$ \\
\hline SOLES** & S/ & $19,860,495.77$ \\
\hline
\end{tabular}

$* * \$ 1.00=\mathrm{S} / 3.35$

\begin{tabular}{|l|r|r|}
\multicolumn{1}{c}{$\mathrm{m} 2$} & $\%$ \\
\hline ARQUITECTURA & $6,576.80$ & 100.00 \\
\hline ÁREA CONSTRUIDA & & \\
\hline VOLUMEN 01 & 514.90 & 7.83 \\
\hline VOLUMEN 02 & 514.90 & 7.83 \\
\hline VOLUMEN 03 & 566.80 & 8.62 \\
\hline TERRAZA 1.0 & $1,390.00$ & 21.13 \\
\hline VOLUMEN 04 & 808.30 & 12.29 \\
\hline VOLUMEN 05 & 808.30 & 12.29 \\
\hline TERRAZA 2.0 & 350.00 & 5.32 \\
\hline VOLUMEN 06* & 566.80 & 8.62 \\
\hline VOLUMEN 07* & 566.80 & 8.62 \\
\hline TERRAZA 3.0* & 490.00 & 7.45 \\
\hline
\end{tabular}

*CONSTRUIDO EN ESA ETAPA

Fuente: Elaboración propia (2019) 


\subsubsection{Estructuras}

A nivel de arquitectura el proyecto será construido mediante placas de concreto armado que serán conectadas con vigas chatas y losa aligerada para darle estabilidad. Usará un tipo de cimentación corrido que va a lo largo de todas las placas. Como es un proyecto en ladera, se le considerará muros de contención para soportar la tierra, y tendrá una junta de dilatación de 10 a 15 cm entre la placa y el muro.

\subsubsection{Instalaciones eléctricas}

Como se trabajan volúmenes independientes en el proyecto, cada uno contara con una subestación de energía que la conectará a la red pública de electricidad, así mismo cada volumen contará con su propio medidor y su pozo a tierra. No es necesario la implementación de un grupo electrógeno por el tipo de proyecto. El espacio público será iluminado con postes solares aprovechando la radiación de Manchay, ya que tiene un cielo más despejado y para evitar costos por instalación de cableado.

\subsubsection{Instalaciones sanitarias}

Como se propone un parque recreativo con áreas verdes, la manera en cómo irrigará es mediante un sistema de aspersores proveyendo aguas tratadas por un pozo de sedimentación propuesto en el nivel más alto del terreno y funcionará por gravedad, ese pozo de sedimentación usará la red pública de desagüe proveniente de la zona más alta, y servirá solo para la irrigación de las áreas verdes y huerto urbano. Los servicios higiénicos se abastecerán de la red pública de agua, cada volumen contará con su medidor independiente y tendrán una cisterna a un nivel superior a los servicios para que esta pueda funcionar por gravedad y no se requiera un cuarto de bombas. La red de agua potable vendrá por la parte superior y bajará a las cisternas.

\subsubsection{Gestión de proyectos}

El proyecto del Parque Recreativo y Centro Comunal Mirador de Manchay tendrá beneficios sociales por ofrecer espacios para reducir los niveles de deserción escolar, también será de apoyo para el emprendimiento de las madres y jóvenes de la zona de bajos recursos para que puedan tener opciones y visión de empresa para que puedan 
trabajar a futuro o ellos mismos hacer sus negocios. El proyecto también será beneficioso a nivel ambiental ya que se propone un parque público con áreas verdes, varias especies de árboles y espacios públicos de calidad que es lo que hace mucha falta a la zona de Manchay.

A nivel económico el proyecto será financiado por el Estado y apoyado por la Municipalidad de Pachacamac, para su mantenimiento en el tiempo se tiene pensado hacer una cobranza por alquiler de los espacios donde se hagan productos como el caso de los talleres de las madres tejedoras o en el caso de los talleres de emprendimiento, también se plantea la creación de una cooperativa de barrios donde se les cobrará un monto mensual mínimo por persona para hacer uso de todos los servicios ofrecidos y poder cubrir los gastos de mantenimiento y la paga las pensiones de los trabajadores como la seguridad, mantenimiento, asesorarías profesionales y cubrir gastos de materiales.

A nivel social Manchay no cuenta con espacios públicos de calidad, mucho menos áreas verdes o centros de recreación para niños con talleres educativos y culturales, por lo que la concurrencia al proyecto será constante por ser el primero de ese tipo en la zona, beneficiando a más de 60000 personas que viven en la quebrada de Manchay.

A nivel ambiental el proyecto busca reutilizar las aguas negras para tratarlas por medio de un pozo de sedimentación y poder usar esa agua para regar las áreas verdes y reducir el costo de consumo de agua potable, al mismo tiempo de ser un recurso que escasea en la zona, también se considera el uso de especies de plantas y árboles que consuman poca agua, sean resistentes al sol y a las plagas para que su mantenimiento sea el mínimo y su riego no sea constante. El parque será un gran aporte para generar un pequeño ecosistema atractivo para las personas y otros seres vivos.

La tecnología empleada en la construcción del proyecto será tradicional, usando concreto armado en las placas, losas aligeradas y cimentación corrida para estabilizarse en el terreno, el uso de muros de contención será de concreto armado para soportar las cargas de la ladera. No se aplicarán nuevas tecnologías que generen un costo mayor.

El proyecto será el primero en su tipo a nivel de espacio público, ofreciendo espacios lúdicos y de recreación para la comunidad, no existen parques o centros de ese tipo en Manchay y lo más cercano es el Parque Zonal Huascar en el distrito de Villa el Salvador a unos $20 \mathrm{~km}$ de distancia. Por la zona no existen centros comunitarios con 
buena implementación, como por ejemplo la ONG Ruwasunchis que trabaja a pocos metros del terreno, ellos cuenta con 2 locales comunales pero son espacios muy pequeños y están en estado de precariedad, por ello el proyecto también podría ofrecerles un espacio para que puedan desarrollar sus talleres con la comunidad.

\subsection{Panorama general del proyecto}

\subsubsection{Análisis FODA}

\section{Fortalezas:}

- Tiene una comunidad organizada dispuesta a trabajar y a emprender.

- La integración barrial esta lograda gracias al deporte y los talleres ofrecidos en la zona.

- El terreno se encuentra muy bien ubicado a vías con transporte público y tiene una gran visual a la ciudad.

\section{Oportunidades:}

- Un gran terreno para desarrollar espacio público con áreas verdes.

- Tiene potencial para ser un hito en la ciudad, la ladera es visible desde varios puntos en especial cuando uno entra por la avenida principal.

- La pendiente permitirá una mejor distribución del agua para el abastecimiento e irrigación.

\section{Debilidades:}

- Es un terreno en pendiente con una diferencia de 30 metros de altura con respecto a su punto más bajo.

- Es una ciudad que carece de agua por sectores.

\section{Amenazas:}

- Terreno en riesgo de ser invado o ser usado como basural.

- Por zonas la pendiente es muy pronunciada, difícil acceso. 


\subsubsection{Público objetivo}

El público a quien va dirigido el proyecto son los niños y jóvenes en etapa escolar que presentan vulnerabilidad por dejar el estudio a causa de factores externos y a las mujeres que desempeñan como amas de casa que puede ser parte de un grupo que emprenda con ayuda talleres que elaboren productos como tejidos . Por otro lado también se piensan apoyar a los grupos de madres, niños y jóvenes que se encuentran desarrollando taller creativos, dinámicos y de emprendimiento en la zona, que son monitoreados por la ONG Ruwasunchis pero que no cuentan con la infraestructura adecuada para desarrollar óptimamente los trabajos y actividades. En los siguientes cuadros se mostrara el crecimiento de la población a largo plazo para poder satisfacer la demanda en el tiempo, por ello el proyecto se fue trabajando por etapas ya que la línea de crecimiento es constante para los siguientes 10 años. 
Tabla 8.15

Inscripción de madres al programa de madres tejedoras

\begin{tabular}{|c|c|c|c|c|c|c|}
\hline \multicolumn{7}{|c|}{ MANCHAY } \\
\hline & pers. & $\%$ & & pers & $\%$ & \\
\hline \multirow[t]{2}{*}{ POBLACIÓN: } & 70,000 & 100 & Mujeres & 35,700 & & 51 \\
\hline & & & Hombres & 34,300 & & 49 \\
\hline Niños 0-5 & 8,890 & 12.7 & & & & \\
\hline Niños 6 -11 & 8,680 & 12.4 & & & & \\
\hline Jóvenes 12 -17 & 8,190 & 11.7 & & & & \\
\hline Adultos 18 - 36 & 24,150 & 34.5 mujeres & $12,316.50$ & & & \\
\hline Adultos 37 - 59 & 16,310 & 23.3 mujeres & $8,318.10$ & & & \\
\hline Mayores de 60 & 3,500 & 5 & 20,635 & & & \\
\hline Menores de edad & 25,760 & 36.8 & & & & \\
\hline
\end{tabular}

POBLACIÓN EN RIESGO:

\begin{tabular}{lll} 
& \multicolumn{2}{c}{$\%$} \\
Deserción escolar & 9,093 & 35.3 (57\% de jóvenes entre los 12 y 17 deja las estudios) \\
Amas de casa & 4,168 & 20.2 \\
Menores que trab. & 4,199 & 16.3
\end{tabular}

\section{OPORTUNIDADES}

1. REDUCIR LA DESERCIÓN ESCOLAR DE NIÑOS Y JÓVENES

2. GENERAR OPORTUNIDAD DE TRABAJO PARA JÓVENES Y ADULTOS

3. MEJORAR EL ESPACIO PÚBLICO

\section{MADRES TEJEDORAS 23-55años}

AÑo

MUJERES

$\begin{array}{rr}2013 & 10 \\ 2014 & 18 \\ 2015 & 26 \\ 2016 & 34 \\ 2017 & 42 \\ 2018 & 50 \\ 2019 & 58 \\ 2020 & 66 \\ 2021 & 74 \\ 2022 & 82 \\ 2023 & 90 \\ 2024 & 98 \\ 2025 & 106 \\ 2026 & 114 \\ 2027 & 122 \\ 2028 & 130\end{array}$

TALLER DE MADRES TEJEDORAS

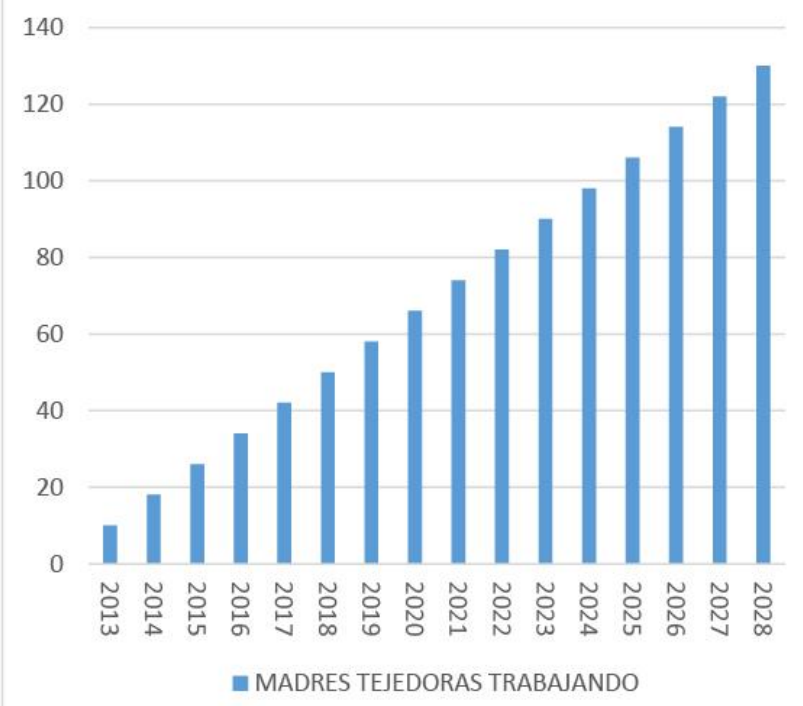

Fuente: ONG Ruwa Sunchis 
Tabla 8.16

Inscripción de niños a los talleres

TALLER DE NIÑOS 5-12años

AÑo NIÑOS TALLERES VOLUNTARIOS TURNOS M/T PERS X DIA

NIÑOS/AÑO

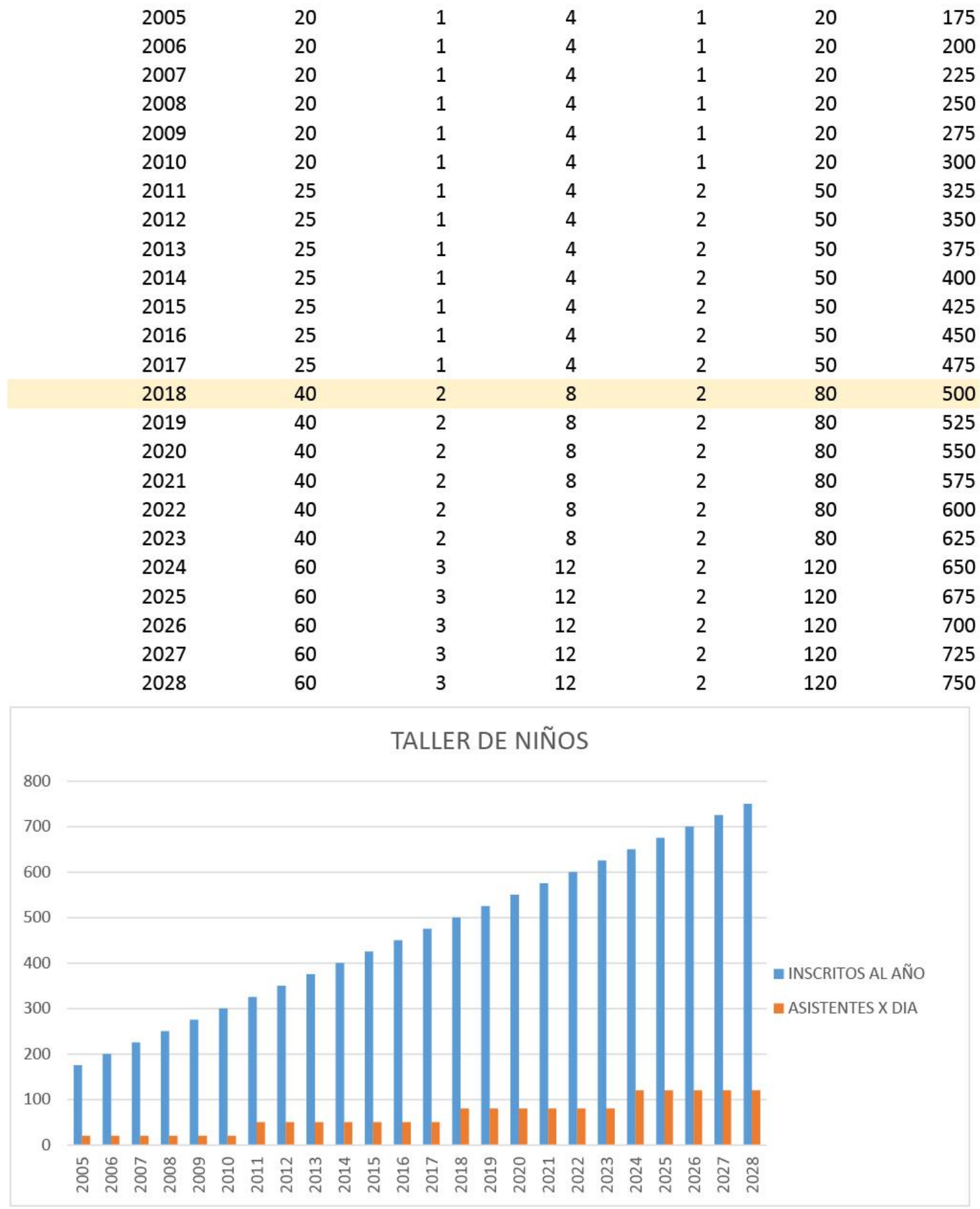

Fuente: ONG Ruwa Sunchis 
Tabla 8.17

Inscripción de jóvenes a los talleres

TALLER DE JÓVENES 13-17años

AÑo

JóVENES TALLERES VOLUNTARIOS TURNOS M/T PERS X DIA JÓVENES/AÑo

$\begin{array}{lll}2005 & 20 & 1 \\ 2006 & 20 & 1 \\ 2007 & 20 & 1 \\ 2008 & 20 & 1 \\ 2009 & 20 & 1 \\ 2010 & 20 & 1 \\ 2011 & 25 & 1 \\ 2012 & 25 & 1 \\ 2013 & 25 & 1 \\ 2014 & 25 & 1 \\ 2015 & 25 & 1 \\ 2016 & 25 & 1 \\ 2017 & 25 & 1 \\ 2018 & 40 & 2 \\ 2019 & 40 & 2 \\ 2020 & 40 & 2 \\ 2021 & 40 & 2 \\ 2022 & 40 & 2 \\ 2023 & 40 & 2 \\ 2024 & 60 & 3 \\ 2025 & 60 & 3 \\ 2026 & 60 & 3 \\ 2027 & 60 & 3 \\ 2028 & 60 & 3\end{array}$

$4 \quad 1$

$20 \quad 80$

(n)

$\begin{array}{llll}4 & 1 & 20 & 105\end{array}$

1 (1)

4

205

$50 \quad 230$

$\begin{array}{llll}4 & 2 & 50 & 230 \\ 4 & 2 & 50 & 255\end{array}$

1

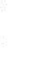

4

$50 \quad 280$

$50 \quad 305$

$50 \quad 330$

$50 \quad 355$

$50 \quad 380$

$80 \quad 405$

$80 \quad 430$

$80 \quad 455$

$80 \quad 480$

$80 \quad 505$

$80 \quad 530$

$120 \quad 555$

$120 \quad 580$

$120 \quad 605$

$120 \quad 630$

$120 \quad 655$

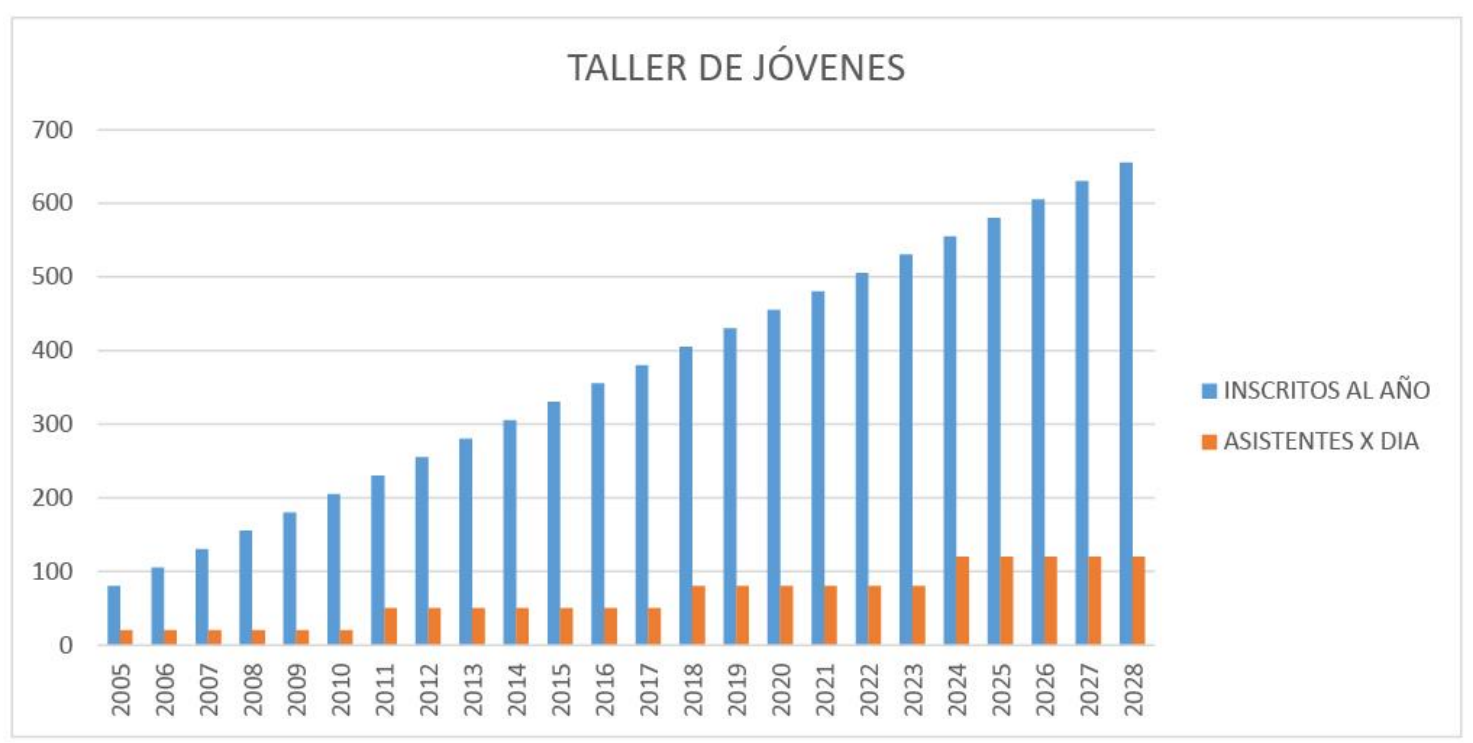

Fuente: ONG Ruwa Sunchis 


\section{REFERENCIAS}

Abad-Perez, A. (s.f.) Los franciscanos en América. Madrid: colección iglesiacatólica del nuevo mundo.

Aguilar Díaz, M.(2012) Antropología urbana y lugar: Recorridos conceptuales, en Giglia, A. y Signorelli, A. (eds.), Nuevas topografías de la cultura. México: Universidad Autónoma Metropolitana, Juan Pablos Editor, pp. 113-144.

Aguilar, A y López, F. (2016) Espacios de pobreza en la periferia urbana y suburbios interiores de la Ciudad de México. Las desventajas acumuladas: Espacios de pobreza y periferia urbana. EURE [en línea]. Santiago, 2016, enero, vol. 42, $\mathrm{N}^{\circ} 125$, pp. 5-29. [Consultado 20 febrero 2016]. Recuperado de: http://www.eure.cl/ index.php/eure/article/view/1566/849

Alfaro, D., y Diego, M. (2011) Una mirada a los programas sociales. Lima, Lima, Perú.

Altarmirano Enciso, A., \& Bueno Mendoza, A. (2011) El ayni y la minka: dos formas colectivas de trabajo de las sociedades pre-Chavín. Lima: Universidad Nacional Mayor de San Marcos.

Aramburu, F. (1993) Las ciencias sociales en la educación ambiental. Salamanca: Universidad de Salamanca.

Arrabal, M., Pérez, A., \& Salinas, J. (2000) Los Centros Universitarios Municipales: Centros Comunitarios Multipropósito al servicio de la educación. En R. Pérez, Redes multimedia y diseños virtuales (págs. 285-292) Oviedo: Universidad de Oviedo.

Arteaga, I. (2005) De periferia a ciudad consolidada Estrategias para la transformación de zonas urbanas marginales. Bitácora Urbano Territorial, 9(1) 98-111. Recuperado de http://www.redalyc.org/pdf/748/74800909.pdf

Arzobispado de Lima (14 de diciembre de 2009) Proyecto Manchay Verde. Notas informativas. Recuperado de http://www.arzobispadodelima.org/notas/2009/diciembre/141209a.html

ASEP (11 de Marzo 2019) La igualdad de género como acelerador del desarrollo empresarial en Perú. Recuperado de https://asep.pe/index.php/equidad-generoranking-par/

RPP (2 de agosto de 2016) Atrapanieblas: Solución revolucionaria para la falta de agua en Lima. Obtenido de http://rpp.pe/lima/actualidad/atrapanieblassolucion-revolucionaria-para-la-falta-de-agua-en-lima-noticia-988981

Augé, M. (2008) Los no lugares. Espacios para el anonimato. Barcelona: Gedisa editorial.

Azuela, A y Tomas, F. (1996) El acceso de los pobres al suelo Urbano, México. En La Regulación de las barriadas: El caso de Villa El Salvador (Perú) por: Castro M. \& Riofrio G. (p.45-88) 
Bähr, J. y Bordorf, A. (2012) La ciudad latinoamericana. La construcción de un modelo: Vigencia y perspectivas. Ur[b]es. Año II, número 2

Bellante, C. (11 de enero de 2015) Cazan nubes para calmar la sed en Lima (Perú) El Tiempo.

Benayas, J. (1992) Paisaje y Educación Ambiental. Madrid: MOPTMA.

Borja, J. (1998) Ciudadanía y espacio público. Urbanitats.

Botta, M. (7 de mayo 2014) Arquitectura y memoria. Pamplona, 16, 91-98. Recuperado de http://fresno.ulima.edu.pe/ss_bd00102.nsf/RecursoReferido?OpenForm\&id=P ROQUEST-41716\&url=/docview/1682442774? accountid=45277

Calderón-Cockburn, J. (2005) La ciudad ilegal. Lima en el siglo XX. Lima: Universidad Nacional Mayor de San Marcos.

Carevic, N. y Domínguez, L. (2012) Arquitectura y paisaje urbano como Globalización Específica. Contexto: revista de la Facultad de Arquitectura Universidad Autónoma de Nuevo Léon, (6), 87-109. Recuperado de https://dialnet.unirioja.es/servlet/articulo?codigo $=4156805$

CEDEZO-Centro. (21 de abril de 2010) CEDEZO Centro de Desarrollo Empresarial Zonal. Obtenido de http://www.cedezocentro.blogspot.pe/2010/04/cedezo.html

Cereceda, P. (2000) Los atrapanieblas, tecnología alternativa para el desarrollo rural. Medio Ambiente y Desarrollo, XVI(4), 51-56.

Clément, G. (2007) Manifiestos del Tercer Paisaje. Barcelona: Editorial Gustavo Gili

Collados-Alcaide, A. (2013) Laboratorios artísticos colaborativos. Espacios transfronterizos de producción cultural. Retrieved from http://search.proquest.com/docview/1664452704/7CDD800488464FB7PQ/26? accountid $=45277$

Collyns, D. (19 de Septiembre de 2012) Atrapanieblas en Perú para atrapar suministros de agua. The Guardian.

Comité Técnico del Pabellón de México. (30 de Noviembre de 2016) Centros comunitarios en México: una tipología para entender lo colectivo y su relación con el espacio. Recuperado de https://www.archdaily.pe/pe/800378/centros-comunitarios-en-mexico-unatipologia-para-entender-lo-colectivo-y-su-relacion-con-el-espacio

Cultura Viva Comunitaria (2018) Programa Cultural Viva Comunitaria. Recuperado de http://culturavivacomunitaria.munlima.gob.pe/index.php/programa-culturaviva-mml

De Solá Morales, I. (2002) Territorios. Barcelona: Editorial Gustavo Gili.

Dejtiar, F. (31 de Julio de 2017) 10 Ejemplos en la organización arquitectónica de proyectos comunitarios. Recuperado de https://www.archdaily.pe/pe/876775/10-ejemplos-en-la-organizacionarquitectonica-de-proyectos-comunitarios

Dolors, M., Ortiz, A., y Prats, M. (2014) Espacios públicos, género y diversidad. Barcelona: Icaria. 
Dorich, L. (1996) Al rescate de Lima, la evolución de Lima y sus planes de desarrollo urbano. Colegio de arquitectos del Perú.

Durantini-Villarino, C. (2014) Un espacio alternativo donde estar y aprender. Niños con experiencias de fracaso escolar construyendo su aula en un centro comunitario. Retrieved from http://web.b.ebscohost.com/ehost/detail/detail?vid=25\&sid=cd46b855-db2f$4 \mathrm{e} 8 \mathrm{e}-864 \mathrm{~b}-$ efc3f68d8bd4\%2540sessionmgr107\&hid=107\&bdata=Jmxhbmc9ZXMmc210Z T1laG9zdC1saXZl\#AN=102075407\&db=fua

Fernández, A. y Mozas, J. (2007) Civilities I. a+t Revista Independiente de arquitectura + tecnología, (9), 3. Recuperado de https://issuu.com/aplust/docs/civilitiesi_issuu

Férnandez-Güell. (2006) Planificación estratégica de ciudades. Barcelona: Reverté.

Gamboa, P. (2003) El sentido urbano del espacio público. Revista Bitácora Urbano Territorial, (1), pp.13-18. Recuperado de ttps://www.redalyc.org/pdf/748/74810703.pdf

García Espil, E. (2006) Hacer ciudad: la construcción de las metrópolis. Buenos Aires: Nobuko.

Gehl, J., Peñalosa, E., Pozueta, J., In Sainz, J., y Valcarce, M. T. (2015) La humanización del espacio urbano: La vida social entre los edificios. Barcelona: Editorial Reverté.

Gómez López, D. (2007) Ciudad y espacio público, perspectivas complementarias y nuevos desafios. Desafios.

Gómez Portilla, P. A., Cabarga Varona, A., \& Nogués Linares, S. (2014) La regeneración urbana integrada, una respuesta a la crisis urbana. Congreso Latinoamericano Sobre Patología de La Construcción, Tecnología de La Rehabilitación Y Gestión Del Patrimonio: REHABEND 2014, P. 247-254.

Gómez, A. (1993) Reflexiones acerca del contenido paisaje en los currícula de la enseñanza de la Enseñanza Obligatoria. Revista Interuniversitaria de Formación del Profesorado, (6), pp. 231 - 240.

Gurevich, R. (2017) Paisajes y visualidad: Geografías para mirar. Atelie Geográfica, 11(2), 6-18. Doi:10.5216/ag.v11i2.45923

Gutiérrez, A. C. (2016) Peruanos sin agua. Obtenido de http://www.lossinagua.org

Hamann, J. (2013) Lima: Espacio público, arte y ciudad. Lima: Pontificia Universidad Católica del Perú.

Harvey, D. (1989) Urbanismo y desigualdad social. Madrid.

Hernández-Díaz, J., Paredes-Carbonell, J. J., \& Marín Torrens, R. (2014) Cómo diseñar talleres para promover la salud en grupos comunitarios. Atención Primaria, 46(1), 40-47. http://doi.org/10.1016/j.aprim.2013.07.006

Instituto-de-la-Construcción-y-Gerencia-(ICG) (2006) Reglamento Nacional de Edificaciones. Obtenido de http://www.construccion.org.pe

Jacobs, J. (2013) Muerte y vida de las grandes ciudades. Madrid: Capitán Swing Libros. 
Jiménez, D., (2000) Laberintos urbanos en América Latina, Quito, Ecuador: Serie Pluriminor ABYA-YALA

Krier, L. (2013) La arquitectura de la comunidad: la modernidad tradicional y la ecología del urbanismo. Barcelona: Reverté.

Pontificia Universidad Católica del Perú (3 de diciembre de 2013) La neblina puede convertirse en una fuente de agua. Obtenido de http://www.pucp.edu.pe/climadecambios/index.php?tmpl=articulo\&id=1559

Lacasta, M. (11 de febrero 2013) Paisajes Transparentes. Axonométrica. Recuperado de https://axonometrica.wordpress.com/2013/02/11/paisajes-transparentes/

Los Custodios de la Creación (2018) Manchay Verde, un proyecto por el medio ambiente. Recuperado de https://custodiosdelacreacion.org/proyectos/manchay-verde/

Lozada, L. (2018) Espacio públicos no tan públicos. Politai: Revista de Ciencia Política, Año 9, primer semestre, n.16 pp. 75-109.

Ludeña, W. (2004) Lima: Con-cierto de-sierto barroco. ARQ, n. 57 Zonas áridas / Arid zones, Santiago, julio, p. $10-13$

Ludeña, W. (2006) Ciudad y Patrones de asentamiento. Estructura urbana y tipoligizacion para el caso de Lima. Eure: revista latinoamericana de estudios urbanos. Volumen 32 número 95.

Lynch, K. (2010) La imagen de la ciudad. Barcelona: Editorial Gustavo Gili

Marín Acosta, F. I. (2009) La arquitectura escolar del estructuralismo holandés en la obra de Hernan Hertzberger y Aldo Van Eyck. Revista Educación y Pedagogía, 21 (54), pp. 67 - 79.

Matos Mar, J. (1988) Desborde popular y crisis del Estado, el nuevo rostro del Perú en la década de 1980. Lima. Concytec.

Matos-Mar, J. (2011) Perú: Estado desbordado y sociedad nacional emergente. LIma: Universidad Ricardo Palma.

Matos-Mar, J., Potugal, J., y otros. (1964) El Valle de Lurín y el pueblo de Pachacamac. Cambios sociales y culturales. Lima: Universidad Nacional Mayor de San Marcos.

Ministerio de Cultura (2013) Puntos de Cultura. Recuperado de http://www.puntosdecultura.pe/programa

Ministerio de Desarrollo e Inclusión Social (MIDIS) (2016) Ministerio de Desarrollo e Inclusión Social. Obtenido de http://www.midis.gob.pe

Montaner, J. M. (2011) Arquitectura y política: ensayos para mundos alternativos. Barcelona: Gustavo Gili.

Montestruque, O. (2016) Memoria y lugar el recuerdo y olvido como forma de conservación de lo inmaterial. Limaq, (2) 143-158.

Moreno Molina, A. M. (2008) Urbanismo y medio ambiente : las claves jurídicas del planeamiento urbanístico sostenible. Valencia: Universidad Carlos III de Madrid.

Moya Pellitero, A. (2011) La percepción del paisaje urbano. Madrid: Biblioteca Nueva. 
Municipalidad-de-Lima. (2015) Municipalidad de Lima. Obtenido de http://www.munlima.gob.pe/index.php/servicios/social/demuna

Municipalidad-de-Pachacámac. (2010) Municipalidad de Pachacámac. Obtenido de http://www.munipachacamac.gob.pe/historia.htm

Navarro Arvizu, E. M.; Ochoa Jiménez, S.; Esparza García, I. G. (2014) Cultura Organizacional y Desempeño Individual en una Asociación Civil Mexicana. Retrieved from http://web.b.ebscohost.com/ehost/detail/detail?vid=39\&sid=cd46b855-db2f$4 \mathrm{e} 8 \mathrm{e}-864 \mathrm{~b}-$ efc3f68d8bd4\%2540sessionmgr107\&hid=107\&bdata=Jmxhbmc9ZXMmc210Z T1laG9zdC1saXZl\#AN=96717932\&db=fua

NESsT-Perú. (2016) NESsT-Perú. Obtenido de http://www.nesst.org

Novo, M. (1996) La Educación Ambiental formal y no formal. Iberoamericana de Educación, (11), pp. 75 - 102.

Ojeda, J. F., y Cano, N. (Noviembre de 2009) El paisaje en la memoria de los territorios.

Panfichi, A.. (2004) Mundos interiores. 1850 - 1950. Universidad del Pacifico. Lima

Pascal-Burga (2015) Espacio Cultural Urbano. Obtenido de http://www.espacioculturalurbano.net/

Peimbert, A. (2014) Espacios públicos, lugar y paisaje: proximidades y distancias para una analogía urbana. Contexto, 8(8) 51-68.

Peña, L. (2011) Las bibliotecas públicas de Medellín como motor de cambio social y urbano de la ciudad. Recuperado de http://bid.ub.edu/27/pena2.htm

Peruincuba. (2009) Peruincuba. Obtenido de http://www.peruincuba.net

PQS (6 de Noviembre 2017) Solo 3 programas del Estado apoyan el emprendimiento femenino en Perú. Recuperado de https://www.pqs.pe/economia/peruemprendimiento-femenino-apoyo-estado

Presidencia del Consejos de Ministros PCM (2015) Portal del Estado Peruano. Obtenido de http://www.peru.gob.pe

Protzel, J. (2011) Lima Imaginada. Lima, Universidad de Lima. Fondo Editorial.

Real Academia Española RAE (2016) Diccionario de la Real Academia Española. Obtenido de http://dle.rae.es

Regionales, R. M. (2015) Ciudades de periferia. Obtenido de https://www.uclg.org/es/organizacion/estructura/comisiones-grupos-detrabajo/ciudades-de-periferia

Rodriguez Tarduchy, M. J. (2011) Forma y ciudad: en los límites de la arquitectura y el urbanismo. Madrid: Cinter Divulgación Técnica SLL.

Ruwasunchis. (2016) Ruwasunchis. Obtenido de http://www.ruwasunchis.org

Santos, Á. (1992) Jesuitas en America. Madrid: Mapfre.

Servicio Nacional de Capacitación para la Industria de la Construcción SENCICO (2011) SENCICO. Obtenido de http://www.sencico.gob.pe 
SERPAR. (2017) SERPAR Servicios de Parques de Lima. Obtenido de http://www.serpar.gob.pe/

Sierra, K. (2004) Antecedentes e Historia de las Municipalidades en el Perú. Lima.

Social, M. (2017) Ministerio de Desarrollo e Inclusión Social. Obtenido de http://www.midis.gob.pe

Sosa, J. A. (1993) Contextualismo y Abstraccion: reflexiones sobre las interrelaciones espaciales entre suelo, paisaje y arquitectura (tesis doctoral). Universidad de las Palmas de Gran Canaria, Gran Canaria, España.

Soyentrepreneur. (25 de febrero de 2009) Entrepreneur. Obtenido de https://www.entrepreneur.com/article/261424

StarUp-Perú. (2015) StarUp Perú. Obtenido de http://www.start-up.pe

Vázquez Barquero, A. (2000) Desarrollo económico local y descentralización: aproximación a un marco conceptual.

Vega Centeno Bocángel, M. E. (1961) Estudio de la comunidad de Lurín, programa de un centro social comunal. Lima: PUCP.

World Vision Perú. (2015) World Vision Perú. Obtenido de http://www.visionmundial.org.pe 
ANEXOS 


\title{
ANEXOS 1: RNE A.010 Condiciones generales de Diseño
}

\author{
TITULO III.1 \\ ARQUITECTURA \\ NORMA A.010 CONDICIONES GENERALES DE DISEÑO \\ CAPITULO I \\ CARACTERISTICAS DE DISEÑO
}

Articulo 1.- La presente norma establece los criterios y requisitos minimos de diseño arquitectónico que deberán cumplir las edificaciones con la finalidad de garantizar lo estipulado en el Art. $5^{\circ}$ de la norma G.010 del TITULO I del presente reglamento.

Articulo 2.- Excepcionalmente los proyectistas, podrán proponer soluciones alternativas y/o innovadoras que satisfagan los criterios establecidos en el articulo tercero de la presente Norma, para lo cual la alternativa propuesta debe ser suficiente para alcanzar los objetivos de forma equivalente o superior a lo establecido en el presente reglamento.

En este caso el proyectista deberá fundamentar su propuesta mediante normativa NFPA $101 \mathrm{u}$ otras normas equivalentes reconocidas por la Autoridad Competente.

Articulo 3.- Las obras de edificación deberán tener calidad arquitectónica, la misma que se alcanza con una respuesta funcional y estética acorde con el propósito de la edificación, con el logro de condiciones de seguridad, con la resistencia estructural al fuego, con la eficiencia del proceso constructivo a emplearse y con el cumplimiento de la normativa vigente.

Las edificaciones responderán a los requisitos funcionales de las actividades que se realicen en ellas, en términos de dimensiones de los ambientes, relaciones entre ellos, circulaciones y condiciones de uso.

Se ejecutará con materiales, componentes y equipos de calidad que garanticen seguridad, durabilidad y estabilidad.

En las edificaciones se respetará el entorno inmediato, conformado por las edificaciones colindantes, en lo referente a altura, acceso y salida de vehiculos, integrándose a las caracteristicas de la zona de manera armónica.

En las edificaciones se propondrá soluciones técnicas apropiadas a las caracteristicas del clima, del paisaje, del suelo y del medio ambiente general.

En las edificaciones se tomará en cuenta el desarrollo futuro de la zona, en cuanto a vias públicas, servicios de la ciudad, renovación urbana y zonificación.

Articulo 4.- Los parámetros urbanísticos y edificatorios de los predios urbanos deben estar definidos en el Plan Urbano. Los Certificados de Parámetros deben consignar la siguiente información:

a) Zonificación.

b) Secciones de vias actuales y, en su caso, de vias previstas en el Plan Urbano de la localidad.

c) Usos del suelo permitidos.

d) Coeficiente de edificación.

e) porcentaje minimo de área libre.

f) Altura de edificación expresada en metros.

g) Retiros.

h) Área de lote normativo, aplicable a la subdivisión de lotes.

i) Densidad neta expresada en habitantes por hectárea o en área minima de las unidades que conformarán la edificación.

j) Exigencias de estacionamientos para cada uno de los usos permitidos.

k) Áreas de riesgo o de protección que pudieran afectarlo.

I) calificación de bien cultural inmueble, de ser el caso.

m) Condiciones particulares.

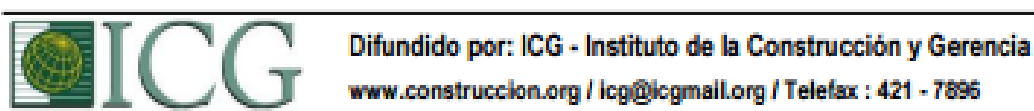




\section{ANEXOS 2: RNE A.040 Educación}

\begin{tabular}{|c|c|c|c|c|}
\hline 320658 & QNORMAS LEGALE & ES & \multicolumn{2}{|c|}{$\begin{array}{r}\text { ElPeruano } \\
\text { viernes } 9 \text { de junio de } 2006 \\
\end{array}$} \\
\hline & Centros de & \multirow{5}{*}{\begin{tabular}{|l} 
Centros de \\
Esucadin \\
Bdsica \\
Regular
\end{tabular}} & \multirow[t]{3}{*}{ Estucación hidal } & Cunas \\
\hline & Etucadion & & & Jandines \\
\hline & Bissica & & & Cuna Jandin \\
\hline & & & Educacion Primaria & Educacón Primaria \\
\hline & & & \multicolumn{2}{|c|}{ Estucación Seoundara Esucación Seoundara } \\
\hline & & $\begin{array}{l}\text { Centros de } \\
\text { Educzidon } \\
\text { Bisica } \\
\text { Alemativa }\end{array}$ & \multicolumn{2}{|c|}{$\begin{array}{l}\text { Centros Educativos de Esucadión Basica } \\
\text { Regular que erfatizan en la preparacón para el } \\
\text { trabajo y ed desamolo de capaciatades } \\
\text { empresariaks }\end{array}$} \\
\hline & & $\begin{array}{l}\text { Centros de } \\
\text { Esucadón } \\
\text { Bisica }\end{array}$ & \multicolumn{2}{|c|}{$\begin{array}{l}\text { Centros Esucativos para personas que fienen } \\
\text { un tipo de discapacidad que dficulte un } \\
\text { apiendizzie rezular }\end{array}$} \\
\hline & & Especial & \multicolumn{2}{|c|}{$\begin{array}{l}\text { Certros Educativos para nifos y addiescerties } \\
\text { superdotasos o con talertos especificos. }\end{array}$} \\
\hline & & & \multicolumn{2}{|c|}{ Centros de Educacion Teconiso Productiva } \\
\hline & & & \multicolumn{2}{|c|}{ Centros de Educacion Comuritaria } \\
\hline & & Universidar & & \\
\hline & Educzaion & \multicolumn{3}{|c|}{ Insthutos Superiores } \\
\hline & & \multicolumn{3}{|c|}{ Centros Superiores } \\
\hline & & \multicolumn{3}{|c|}{ Escuelas Superiores Miraves y Policiales } \\
\hline & & \multicolumn{3}{|c|}{$\begin{array}{c}\text { CAPITULO II } \\
\text { CONDICIONES DE HABITABILIDAD Y } \\
\text { FUNCIONALIDAD }\end{array}$} \\
\hline
\end{tabular}

Articulo 4.- Los criterios a seguir en la ejecución de edificaciones de uso educativo son:

a) Idoneidad de los espacios al uso previsto

b) Las medidas del cuerpo humano en sus diferentes edades.

c) Cantidad, dimensiones y distribución del mobiliario necesario para cumplit con la función establecida

d) Flexibilidad para la organización de las actividades educativas, tanto individuales como grupales.

Articulo 5. - Las edificaciones de uso educativo, se ubicarán en los lugares sefialados en el Plan Urbano, yjo considerando lo siguiente:

a) Acceso mediante vias que permitan el ingreso de vehiculos para la atención de emergencias.

c) Capacidad para obtener una dotación suficiente de servicios de energia y agua.

d) Necesidad de expansión futura.

f) Bajo nivel de riesgo en terminos de morfologia del suebo, o posibilidad de ocurrencia de desastres naturales. g) Impacto negativo del entorno en términos acústi. g) Impacto negativo del entorn

Articulo 6.-El disefio arquitectónico de los centros educativos tiene como objefivo crear ambientes propicios para el proceso de aprendizaje, cumpliendo con los siguientes

requisitos:

\section{NORMA A.040}

\section{EDUCACIÓN}

CAPITULO I

ASPECTOS GENERALES

Articulo 1.- Se denomina edificación de uso educativo a toda construcción destinada a prestar servicios de capacitación y educación, y sus actividades complementarias.

La presente norma establece las caracterisficas y requisitos que deben tener las edificaciones de uso educatrvo para lograr condiciones de habitabilidad y seguridad.

Esta norma se complementa con las que dicta el Mi. nisterio de Educación en concordancia con los objetivos y la Politica Nacional de Educación.

Articulo 2. Para el caso de las edificaciones para use de Universidades, estas deberán contar con la opinión fa vorable de ta Comision de Provectos de Infraestructura Fisica de las Universidades del Pais de la Asamblea Na. cional de Rectores.

Las demás edificaciones para uso educativo deberbn contar con la opirión favorable del Ministerio de Educación.

Articulo 3.- Están comprendidas dentro de los alcan ces de la presente norma los siguientes tipos de edifica. ciones: a) Para la orientación y el ascleamiento, se tomará en cuenta el clima predominante, el viento predominamte y el recocrido del sol en tas diferentes estacones, de manera de lograr que se maximice el confort.

b) El dimensionamiento de los espacios educativos es. tard basado en las medidas y proporciones del cuerpo hu. mano en sus diferentes edades y en el mobiliario a em. plearse.

c) La altura minima será de $2.50 \mathrm{~m}$

d) La ventilacion en los recintos educativos debe ser permanente, alta y cruzada.

e) El volumen de aire requerido dentro del aula serd de $4.5 \mathrm{mt} 3$ de aire por alumno.

f) La iluminacion natural de los recintos edueativos debe estar distribuida de manera uniforme.

g) El area de vanos para iluminación debera tener como minimo el $20 \%$ de la superficie del recinto.

h) La distancia entre la ventana única y la pared opues. ta a ella será como maximo 2.5 veces la altura del recinto. i) La iluminación artificial deberd tener los siguientes niveles, según el uso al que será destinado

$\begin{array}{lr}\text { Aulas } & 250 \text { luxes } \\ \text { Talleres } & 300 \text { luxes } \\ \text { Circulaciones } & 100 \text { luxes } \\ \text { Servicios higienicos } & 75 \text { luxes }\end{array}$


ElPenano

viernes 9 de junio do 2006

i) Las condiciones acústicas de los recirntos educativos son:

- Contral de interferencias sonoras entre los distintos ambientes o recintos. (Separación de zonas tranquilas, de zonas ruidosas)

- Aislamiento de ruidos recurrentes provenientes del exterior (Trafico, lluvia, granizo).

- Reducción de ruidos generados al interior del recinto (movimiento de mobiliario)

Articulo 7. - Las edificaciones de centros educativos ademats de lo establecido en la presente Norma deberán cumplir con lo establecido en las Norma A.010 *Condiciones Generales de Disenos y A.130 eRequisitos de Segu. ridadx del presente Reglamento.

Articulo 8. - Las circulaciones horizontales de uso obligado por los alumnos deben estar techadas.

Articulo 9. Para el calculo de las salidas de evacus cion, pasajes de circulación, ascensores y ancho y numero de escaleras, el nùmero de personas se calculará se. gün lo siguiente:

Auditorios

Salas de uso mulliple.

Salas de clase

Camsines, gimnasios

Amtiertes de uso administrativo $10.0 \mathrm{~mL} 2$ por persors

\section{CAPITULO III}

\section{CARACTERISTICAS DE LOS COMPONENTES}

Articulo 10. Los acabados deben cumplir con los siguientes requisitos:

a) La pintura debe ser lavable

b) Los interiores de los servicios higienicos y atreas himedas deberán estar cubiertas con materiales impermeables y de faci limpieza.

c) Los pisos serán de materiales antideslizantes, resistentes al transilo intenso $y$ al agua.

Articulo 11.- Las puertas de los recintos educafivos deben abrir hacia afuera sin interrumpir el transito en los pasadizos de circulación.

La apertura se hard hacia el mismo sentido de la evacuación de emergencia.

El ancho minimo del vano para puertas será de $1.00 \mathrm{~m}$ Las puertas que abran hacia pasajes de circulación transversales deberan girar 180 grados.

Todo ambiente donde se reaficen labores educativas con mas de 40 personas debera tener dos puertas distanciadas entre si para facil evacuación.

Articulo 12.- Las escaleras de los centros educativos deben cumplir con los siguientes requisitos minimos:

a) El ancho minimo será de $1.20 \mathrm{~m}$. entre los paramen. tos que conforman la escalera.

b) Deberán tener pasamanos a ambos lados.

c) El calculo del número y ancho de las escaleras se efectuard de acuerdo al numero de ocupartes.

d) Cada paso debe medir de 28 a $30 \mathrm{~cm}$. Cada contrapa. so debe medir de 16 a $17 \mathrm{~cm}$. de 16 .

El número maximo de contrapasos sin descanso serd

\section{CAPITULO IV \\ DOTACION DE SERVICIOS}

Articulo 13. - Los centros educativos deben contar con ambiemes desfinados a servicios hicienicos para uso de los alumnos, del personal docente, administrativo y del personal de servicio, debiendo contar con la siguierne dotación minima de aparatos:

Centros de educación inicial:

\begin{tabular}{|c|c|c|}
\hline $\begin{array}{l}\text { Número de alumnos } \\
\text { De } 0 \text { a } 30 \text { alumnos } \\
\text { De } 31 \text { a } 80 \text { slumnos } \\
\text { De } 81 \text { a } 120 \text { alumnos } \\
\text { Por cada } 50 \text { slumnos adicionales }\end{array}$ & $\begin{array}{l}\text { Hombres } \\
1 \mathrm{~L}, 1 u, 11 \\
2 \mathrm{~L}, 2 \mathrm{2u}, 21 \\
3 \mathrm{~L}, 3 \mathrm{3}, 31 \\
1 \mathrm{~L}, 1 \mathrm{u}, 11\end{array}$ & $\begin{array}{l}\text { Mujeres } \\
1 \mathrm{~L}, 11 \\
2 \mathrm{~L}, 21 \\
3 \mathrm{~L}, 3 \\
1 \mathrm{~L}, 11\end{array}$ \\
\hline urinario, I m Int & & \\
\hline
\end{tabular}

Centros de educación primaria, secundaria y su. perior:

\begin{tabular}{|c|c|}
\hline $\begin{array}{l}\text { Uumero de alumnos } \\
\text { De } 0 \text { a } 60 \text { alumnos } \\
\text { e } 61 \text { a } 140 \text { alumnos } \\
\text { e } 141 \text { a } 200 \text { alumnos } \\
\text { or cada } 60 \text { alumnos adicionsles }\end{array}$ & $\begin{array}{l}\text { Hombres } \\
1 \mathrm{~L}, 1 u, 11 \\
2 \mathrm{~L}, 2 u, 21 \\
3 \mathrm{~L}, 3 u, 31 \\
1 \mathrm{~L}, 1 u, 11\end{array}$ \\
\hline
\end{tabular}

L = lavalerio, un urinario, I = Inodero

Los lavatorios y urinarios pueden sustituirse por aparatos de mamposteria corridos recubiertos de material vi. driado, a razon de $0.60 \mathrm{~m}$. por posición.

Adicionalmente se deben proveer duchas en los loca. les educativos primarios y secundarios administrados por el estado a razón de 1 ducha cada 60 alumnos.

Deben proveerse servicios saritarios para el personal docente, administrativo y de servicio, de acuerdo con lo establecido para oficinas.

Articulo 14.- La dotación de aqua a garantizar para el disefto de los sistemas de suministro y almacenamiento son:

Education primaria

Education seandaria y superior

20 lts. $x$ alumno $x$ dia

25 lis. $x$ alumno $x$ dis 


\section{ANEXOS 3: RNE A.090 Servicios comunales}

Articulo 8.- Las edificaciones para servicios comunales deberdin contar con iluminacion natural o artificial sufi. ciente para garantizar la visibilidad de los bienes y la prestación de los servicios.

Articulo 9.: Las edificaciones para servicios comunales deberán contar con ventilación natural o artificial.

El durea minima de los vanos que abren deberá ser sL. perior al $10 \%$ del área del ambiente que ventilan.

Articulo 10. Las edificaciones para servicios comu.

\begin{tabular}{|c|}
\hline NORMA A.090 \\
\hline SERVICIOS COMUNALES \\
CAPITULOI \\
ASPECTOS GENERALES
\end{tabular}

Articulo 1.- Se denomina edificaciones para servicios comunales a aquellas destinadas a desarrollar actividades de servicios publicos complementarios a las tividades de servicios publicos complementarios a las
viviendas, en permanente relacion funcional con la coviviendas, en permanente relación funcional con la co-
munidad, con el fin de asegurar su seguridad, atender munidad, con el fin de asegurar su seguridad, atender
sus necesidades de servicios y facilita el desarrollo de la comunidad.

Articulo 2. Están comprendidas dentro de los alcances de la presente norma los siguiemtes fípos de edificaciones:

\section{Servicios de Seguridad y Vigilaneia:}

- Companias de Bomberos

- Comisarias policiales

- Estaciones para Serenazgo

Protección Social:

- Asilas

- Orfanatos

- Juzgados

Servicios de Culto:

- Templas

- Cementerios

Servicios culturales:

- Museos

- Galerias de arte

- Bibliotecas

- Salones Comunales

Gobierno

- Municipalidades

- Locales Institucionales

\section{CAPITULO II}

CONDICIONES DE HARITABILIDAD Y FUNCIONALIDAD

Articulo 3. Las edificaciones destinadas a prestar servicios comunales, se ubicaran en los lugares señalados en los Planes de Desarrollo Urbano, o en zonas compatibles con la zonificación vigente.

Articulo 4.- Los proyectos de edificaciones para servicios comunales, que supongan una concentración de público de mas de 500 personas deberán contar con un estudio de impacto vial que proponga una solución que resuelva el acceso y salida de vehiculos sin afectar el funcionamiento de las vias desde las que se accede.

Articulo 5. - Las proyectos deberan considerar una propuesta que posibilite futuras ampliaciones.

Articulo 6.- La edificaciones para servicios comuns. les deberán cumplir con lo establecido en la norma A. 120 Accesibilidad para personas con discapacidad.

Articulo 7. El ancho y número de escaleras será cal culado en función del numero de ocupantes.

Las edificaciones de tres pisos o mas y con plantas superiores a los $500.00 \mathrm{~m} 2$ deberán contar con una escalera de emergencia adicional a la escalera de uso general thicada de manera que permita una salida de evacuacion alternativa.

Las edificaciones de cuatro o mats pisos deberán contar con ascensores de pasajeros. nales deberán cumplir con las condiciones de seguridad establecidas en la Norma A.130 eRequisitos de seguri dads.

Articulo 11.- El calculo de las salidas de emergencia pasajes de circulacion de personas, ascensores y ancho y numero de escaleras se hara según la siguiente tabla de ocupacion:

$\begin{array}{ll}\text { Amtiertes para oficinas sdministrafivas } & 10.0 \mathrm{~m} 2 \text { por persona } \\ \text { Asilos y orfanatos } & 6.0 \mathrm{~m} 2 \text { por persona } \\ \text { Amtiertes de reurion } & 1.0 \mathrm{~m} 2 \text { por persona } \\ \text { Area de espectadores de pie } & 0,25 \mathrm{~m} 2 \text { por persona } \\ \text { Recintos para cullo } & 1.0 \mathrm{~m} 2 \text { por persona } \\ \text { Satas de exposicion } & 3.0 \mathrm{~m} 2 \text { por persona } \\ \text { Bitliotecas. Area de ibros } & 10.0 \mathrm{~m} 2 \text { por persona } \\ \text { Bitliotecas. Sslas de lectura } & 4.5 \mathrm{~m} 2 \text { por persona } \\ \text { Estacionsmientos de uso general } & 16.0 \mathrm{~m} 2 \text { por persona }\end{array}$

Los casos no expresamente mencionados considerafán el uso mas parecido

Articulo 12. El ancho de los vanos de acceso a am. bientes de uso del público sera calculado para permitir sis evacuación hasta una zona exterior segura.

Articulo 13.- Las edificaciones de uso mixto, en las que se presten servicios de salud, educación, recreación, etc. deberán sujetarse a lo establecido en la norma expresa pertinente en la seccion correspondieme.

\section{CAPITULO IV \\ DOTACION DE SERVICIOS}

Articulo 14. Los ambientes para servicios higiénicos deberăn contar con sumideros de dimensiones suficien tes como para permitir la evacuación de agua en caso de aniegos accidentales.

La distancia entre los servicios higienicos y el espacio mas lejano donde pueda existir una persona, no puede ser mayor de $30 \mathrm{~m}$. medidos horizontalmente, ni puede haber más de un piso entre ellos en sentido vertical.

Articulo 15. Las edificaciones para servicios comu. nales, estaran provistas de servicios saritarios para em. pleados, según el número requerido de acuerdo al uso:

\section{Nûmero de emplados}

De 1 a 6 empleados

De 7 a 25 emcleados

De 26 a 75 empleados

De 76 a 200 emplestos

Per cada 100 empleados adicionsles

\section{Hombres Mujertes}

$1 \mathrm{~L}, 1 \mathrm{u}, 1 \mathrm{I}$

IL $1 \mathrm{u}, 1 \mathrm{I} \quad \mathrm{tL}, 1 \mathrm{I}$

2L, 2u, 21 2L, 2

$3 \mathrm{~L}, 3 \mathrm{u}, 3 \mathrm{3} 3 \mathrm{~L}, 3 \mathrm{~S}$
En los casos que existan ambientes de uso por el pû. blico, se proveeran servicios higienicos para publico, de acuerdo con lo siguiente:

\section{Hombres Mujeres}

$\begin{array}{lll}\text { De } 0 \text { a } 100 \text { personas } & 1 L, 1 u, 11 & 1 L, 11 \\ \text { De } 101 \text { a } 200 \text { personas } & 2 L, 2 u, 2 \| & 2 L, 21\end{array}$

Por cada 100 personas adicionales $1 \mathrm{~L}, 1 \mathrm{u}, 1 \mathrm{H}$ - $1 \mathrm{~L}, 1$

Articulo 16. Los servicios higienicos para personas con discapacidad seran obligatorios a partir de la exigen cia de contar con tres artefactos por servicio, siendo uno cia de contar con tres artefactos por servicio, sien
de elos accesibles a personas con discapacidad.

En caso se proponga servicios separados exclusivos para personas con discapacidad sin diferenciacion de sexo, este deberá ser adicional al número de aparatos exigible según las tablas indicadas en los articulos prece. dentes.

Articulo 17.- Las edificaciones de servicios comuna. les deberán proveer estacionamientos de vehiculos dentro del predio sobre el que se edifica.

El nùmero minimo de estacionamientos serb el siguiente: 


\section{ANEXOS 4: RNE A.120 Accesibilidad para personas con discapacidad y de personas adultas mayores}

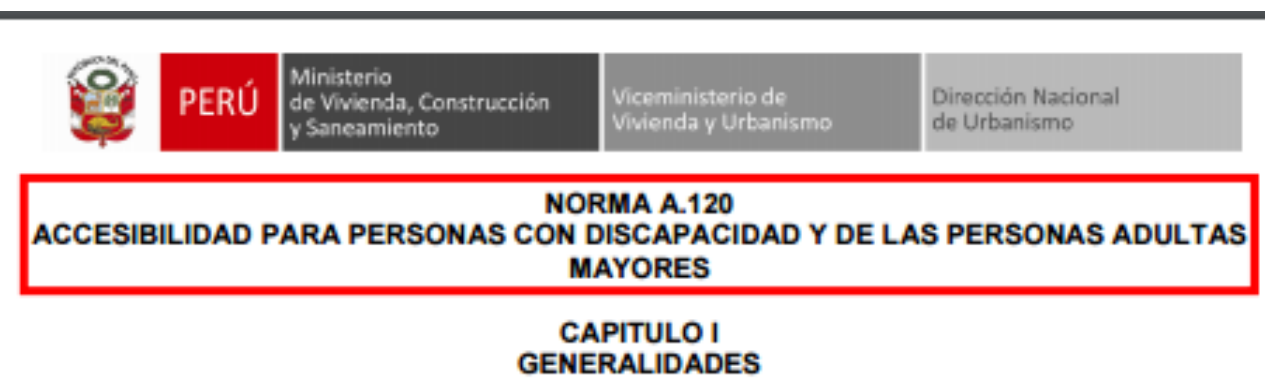

Articulo 1.- La presente Norma establece las condiciones y especificaciones técnicas de diseño para la elaboración de proyectos y ejecución de obras de edificación, y para la adecuación de las existentes donde sea posible, con el fin de hacerlas accesibles a las personas con discapacidad y/o adultas mayores.

Articulo 2.- La presente Norma será de aplicación obligatoria, para todas las edificaciones donde se presten servicios de atención al público, de propiedad pública o privada.

2. a.- Para las edificaciones de servicios públicos

2. b.- Las áreas de uso común de los Conjuntos Residenciales y Quintas, así como los vestibulos de ingreso de los Edificios Multifamiliares para los que se exija ascensor.

Articulo 3.- Para los efectos de la presente Norma se entiende por:

Persona con discapacidad: Aquella que, temporal o permanentemente, tiene una o más deficiencias de alguna de sus funciones fisicas, mentales ó sensoriales que implique la disminución o ausencia de la capacidad de realizar una actividad dentro de formas o márgenes considerados normales.

Persona Adulto Mayor: De acuerdo al articulo 2 de la Ley N 28803 de las Personas adultas mayores. Se entiende por Personas Adultas Mayores a todas aquellas que tengan 60 o más años de edad.

Accesibilidad: La condición de acceso que presta la infraestructura urbanistica y edificatoria para facilitar la movilidad y el desplazamiento autónomo de las personas, en condiciones de seguridad.

Ruta accesible: Ruta libre de barreras arquitectónicas que conectan los elementos y ambientes públicos accesibles dentro de una edificación.

Barreras arquitectónicas: Son aquellos impedimentos, trabas u obstáculos fisicos que limitan o impiden la libertad de movimiento de personas con discapacidad.

Señalización: Sistema de avisos que permite identificar los elementos y ambientes públicos accesibles dentro de una edificación, para orientación de los usuarios.

Señales de acceso: Simbolos convencionales utilizados para señalar la accesibilidad a edificaciones y ambientes.

Servicios de atención al público: Actividades en las que se brinde un servicio que pueda ser solicitado libremente por cualquier persona. Son servicios de atención al público, los servicios de salud, educativos, recreacionales, judiciales, de los gobiernos central, regional y local, de seguridad ciudadana, financieros, y de transporte.

\section{CAPITULO II}

\section{CONDICIONES GENERALES}

Articulo 4.- Se deberán crear ambientes y rutas accesibles que permitan el desplazamiento y la atención de las personas con discapacidad, en las mismas condiciones que el público en general.

Las disposiciones de esta Norma se aplican para dichos ambientes y rutas accesibles.

Articulo 5.- En las áreas de acceso a las edificaciones deberá cumplirse lo siguiente:

a) Los pisos de los accesos deberán estar fijos, uniformes y tener una superficie con materiales antideslizantes.

b) Los pasos y contrapasos de las gradas de escaleras, tendrán dimensiones uniformes.

c) El radio del redondeo de los cantos de las gradas no será mayor de $13 \mathrm{~mm}$.

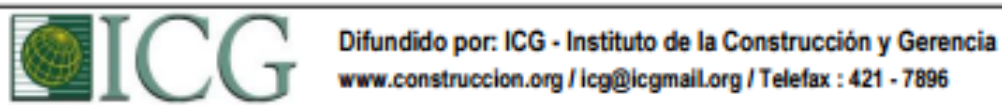




\section{ANEXOS 5: RNE A.130 Requisitos de Seguridad}

En los tipos de locales en donde se ubique mobiliari especifico para la actinidad a la cual sirve, como butacas, mesas, maquinaria (cines, teatros, estadios, restaurantes, hoteles, industrias), debera considerarse una persona por cada unidad de mobiliario.

La comprobarión del callalo del número de ocupan. tes (densidad), deberá estar basada en información estadisica para cada Leo de la edificacion, por lo que los pro. pietarios podran demostrar aforos dreerentes a los calcu. lados seg

E Ministerio de Vivienda en coordinadión con las Mu. nicipalidades y las Insthuciones interesadas efechuarin los estudios que permitan confirmar las densidades estable cidas para cada uso.

Articulo 4.-Sin importar el tipo de metodologia utiliza. do para calcular la cantidad de personas en fodas las áreas de una edificacion, para efectos de caloulo de cantidad de personas debe utilizarse la sumatoria de todas las perso nas (evaouantes). Cuando exista una misma area que ten:
ga distintos usos debera utilizarse para efectos de calcu. ga distintos usos debera utilizarse para efectos de

Ninguna edificacion puede albergar mayor cantidad de gente a la establecida en el aforo calculado.

\section{SUB-CAPITULO I}

\section{PUERTAS DE EVACUACIÓN}

Articulo 5.- Las salidas de emergencia deberán con tar con puertas de evacuación de apertura desde el inte rior accionadas por simple empuje. En los casos que por razones de proteccion de los bienes, las puertas de eva. cuación deban contar con cerraduras con llave, estas deberan tener un letrero iluminado y sefializado que indique beran tener un letrero iluminado y seflalizado que indique
asta puerta debera permanecer sin llave durante las horas de trabajo:

ras de trabajos.
Articulo 6.- Las puertas de evacuación pueden o no ser de tipo cortafuego, dependiendo su ubicación dentro del sistema de evacuacion. El giro de las puertas deben ser siempre en dirección del flujo de los evacuan tes, siempre y cuando el ambiente tenga mas de 50 personas.

Articulo 7.* La fuerza necesaria para destrabar el pes. tillo de una marija (cerradura) o barra artipánico será de 15 libras. La fuerza para empujar la puerta en cualquier caso no sera manor de 30 libras furem.

caso no sera mayor de 30 libras fuerza.
Articulo 8.. Dependiendo del planteamiento de evacuación, las puertas que se ubiquen dentro de una ruta o como parte de una ruta o sistema de evacuación podran contar con los siguientes dispositivos:

\section{NORMA A.130}

REQUISITOS DE SEGURIDAD

GENERALIDADES

Articulo 1.- Las edificaciones, de acuerdo con su uso y númern de ocupantes, deben cumplir con los requisitos de seguridad y prevencion de siniestros que tienen como objetivo salvaguardar las vidas humanas y preservar el patrimonio y la continudad de la edificación

\section{CAPITULO}

\section{SISTEMAS DE EVACUACIÓN}

Articulo 2. El presente capitulo desarrollara todos los conceptos y caloulos necesarios para asegurar un adecuado sistema de evacusaión dependiendo del tipo y uso de la edificadion. Estos son requisitos minimos que debe. ran ser aplicados a las edificaciones.

in ser aplicados a las edificaciones. minada cantidad de personas en funcion al uso, la cant. dad y forma de mobiliario ylo el area de uso disponible para personas. Cualquier edficación puede tener distintos usos y por io tanto variar la cantidad de personas y et riesgo en la misma edificacion siempre y cuando estos usos esten permitidos en la zonificadón establecida en el Plan Urbano.

E calculo de ocupantes de una edificación se hara según lo establecido para cada tipo en las normas espeA.090, A. 100 y A. 110 a) Brazo cierra puertas: Toda puerta que forme parte de un cerramiento contrafuego incluyendo ingresos a es. caleras de evacuacion, debera contar con un brazo cierra puertas apenbado para uso en puertas cortafuego

b) En caso se tengan puertas de doble hoja con cerra. jeria de un punto y cierra puertas independientes, debera considerarse un disposinvo de ordenamiento de cierre de puertas.

c) Marija o tirador: Las puertas que no requieran ba. re antiparico deberan conts con una cerradura de mari. ja. Las manijas para puertas de evacuacion deberan ser aprobadas y cerbificadas para uso de personas con disca. pacidad.

d) Barra antipánico Serán obligatorias, únicamente para carga de ocupantes mayor a 100 personas en cual. quier caso y en locales de reunion mayores de 50 perso. nas, locales de Salud y áreas de alio nesgo con mas de 5 personas. La altura de la barra en la puerta debera estar entre $30^{\circ}$ a $44^{\circ}$. Las barras antipanico requeridas en puer.
tas con resistencia al fuego deben tener una certiricación.

Articulo 9.- Cerraduras para salida retardada: Los dis. positivos de salida retardada pueden ser utilizados en cualquier lugar excepto: areas de reurión, centros educa. tivos y edificaciones de alto riesgo, siempre y cuando la edficación se encuentre totalmente equipada con un sistema de rociadoces y un sistema de deiecoión y alarms de incendio adioonálmente deberan cumplir cón las si. guientes condioiones:

a) De producirse una alarma de incendio o una per. dida de energia hacia el dispositivo, debe eliminarse el retardo. 


\section{ANEXOS 6: RNE EM.110 Confort térmico y lumínico con eficiencia energética.}

523070 NORMAS LEGALES BNow

Entre los beneficios directos mats saltantes de esta Norma se encuentran:

Beneficios Económicos

- Reducción de gastos de operación y mantenimiento para usuarios.

- Creación de valor agregado a la edificación.

- Mejora productividad de trabsiadores.

- Revaloracion de materiales locales.

\section{Beneficios Ambientales}

- Protección de hábitats naturales.

- Mejora de la calidad de aire y agua.

- Reduccion de residuos solidos.

- Conservación de recursos naturales.

- Disminución de emisiones de gases de efecto invernadero.

\section{Beneficios Sociales y en Salud}

- Mejora del ambiente térmico y luminico.

- Aumento del confort y salud de usuarios.

2 Objeto

- Establecer zonas del territorio de la República del Perú de acuerdo a criterios bioclimáticos para la construcción, indicando las caracteristicas de cada zona.

- Establecer linearnientos o parametros técnicos de disefio para el confort térmico y luminico con eficiencia energetica, para cada zona bioclimstica definida.

\section{Campo de Aplicación}

La presente noma se apica cotafivamente en el temilorio nscional a toda edificación nueva así como en la ampliación, remodedación, refacción yóo acondioionamiertode edficaciones existentes, siempre que esten induidas en las Modalidades B, C y D, de la Ley de Regulscion de Hatiftaciones Utbaras y de Edificaciones (Ley 29090 ) y sus modificatorias.

Para el caso del confort térmico, se excluye en la presente Norma a aquellos ambientes no habitables. Ver en el Capitulo 5. Glosario, la definición de "Ambiente no habitable".

\section{Marco Normativo}

La presente Norma se enmarca en la siguiente base legal existente.

\subsection{Base legal}

a) Constitución Politica del Perú (29.12.1993)

b) Decreto Supremo $\mathbb{N}^{\circ}$ 011.2008-VIMENDA (05.05.2006): Reglamento Nacional de Edificaciones (RNE)

c) Ley $\mathrm{N}^{2} 27345(01.09 .2000)$ : Ley de promoción del uso eficiente de la energia.

d) Decreto Supremo $\mathrm{N}^{\circ}$ 053-2007-EM (22.10.2007): Reglamento de la Ley de promoción del uso eficiente de la energia.

e) Decreto Supremo $N^{\circ} 034-2008$-EM (18.06.2008): Dictan medidas para el ahorro de energia en el sector público.

f) Decreto Supremo $N^{2}$ 009-2009-MINAM (14.05.2009): Mecidas de eco-eficiencia para el sector público.

g) Decreto Supremo $N^{2}$ 064-2010-EM (23.11.2010): Aprueban la Politica Energetica Nacional del Perú 2010 $-2040$

h) Ley N 29090 (24.09.2007): Ley de Regulación de Habilitaciones Urbanas y de Edificaciones.

Lapresente Norma ha tomado comodocumentos fuemte las siguientes referencias normativas internacionales.

4.2 Referencias normativas internacionales

a) Norma IRAM 11603 (Argentina): Acondicionamiemto termico de edifioios. Clasificacion bioambiental de la termico de edificios. Clasificacion

b) Norms IRAM 11604 (Avgertina): Aislamiento termico de edificios. Verificación de sus condiciones higrotermicas. de perdidas de calor. Clalculo y valores limile. Fetrero 2001. c) Norma IRAM 11625 (Argentina): Aistamiento térmicos de edficios. Verificación de sus condiciones higrotermicas. Verificación del fiesgo de condensación de vapor de agua superficial e intersticial en las pantas centrales de muros exteriores, pisos y techos de edificios en general Abril 2000.

d) Norma NCh 853-2007 (Chile): Acondicionamiento termico - Envolvente termica de edificios - Calcula de resistencias y transmitancias termicas. Mayo 2007.

e) Modificación a Decreto Supremo $N^{\circ} 47$, de Vivienda y Urbanismo, de 1992 , Ordenanza General de Urbanismo y Construcciones (Chile). Enero 2006.

f. Real Decreto $2429 / 79$ (Espafia), del 6 de julio de 1979, por el que se aprueba la Norma Bdsica de la Edificación NBE-CT-79, sobre Condiciones Termicas en los Edificios.

g) Documento basico HE (Espafia): Ahorro de energia. arzo 2006.

h) Código Tecrico de la Edificación - CTE (Espafta): Catslogo de elementos constnuctivos del CTE. Marzo 2010.

i) Norma UNE-EN ISO 10077-1: Caracteristicas i) Norma UNE-EN ISO 10077-1: Caracteristicas del coeficiente de transmision termica. Parte 1: Metodo del coeficiente de transm

f) Norma NOM =020-ÉNER-2011: Eficiencia energetica en edificaciones - Envolvente de edificios para uso habilacional. Agosto 2011 .

k) Código de edificación de vivienda (México). 2010.

i) Norma ASHRAE 55/1992 - Thermal environmental conditions for human occupancy.

\section{Glosario}

Para efectos de esta Norma, se establecen las siguientes definiciones de los conceptos fundamentales que en ella aparecen. Todas las magnitudes se expresan en las unidades del sistema imternacional (SI).

5.1. Ábaco psicométrico: Diagrama que se utiliza para representar las propiedades termodinamicas del aire hímedo y del efecto de la humedad atmosferica en los materiales y en el confort humano, también ufilizado par: para controlar las propiedades térmicas del aire húmedo.

5.2. Ambiente no acondicionado: Cualquier ambiemte no habitable donde no existen equipos de aire acondicionado para calefacción o refrigeración.

5.3. Ambiente habitable: Recinto interior destinado a la reurión o al uso de personas cuya densidad de ocupación y tiempo de estancia exigen unas condiciones acústicas, termicas y de salubridad adecuadas.

5.4. Ambiente no habitable: Para la presente Norma se incluye bajo este rubro al ambiente o espacio cerrado que no ha sido construido para ser ocupado por tiempo prolongado por seres humanos, tales como estacionamientos cerrados, tanques, cisternas, cuartos de mbquinas, cajas de ascensor, cuartos de bombas. cuartos de equipos electromecaricos y similares.

5.5. Azotea: El nivel accesible encima del techo del ultimo rivel techado. La azolea puede ser fore o tener construcciones de acuerdo con lo que establecen los planes urbanas.

5.6. Barrera de vapor: Parte o material que conforma un elemento constructivo a través del cual el vapor de aguas
no puede pasar. En la prbctica se definen generalmente no puede pasar. En la practica se definen generalmente
como barreras de vapor aquellos materiales cuya como barreras de vapor aquellos maferiales cuya
resistencia al vapor es superior a $10 \mathrm{MN}$ s/g, es decir, su resistencia al vapor es superior a $10 \mathrm{MN}$ s/g, es
permanencia al vapor es inferior al $0,1 \mathrm{~g} / \mathrm{MN}$.

5.7. Caja de persiana: Elemento constructivo que contiene en su imterior una persiana enrollable y que se empotra en un muro exterior. Representa un puente termico como consecuencia de la disminución del espesar del muro y de las filtraciones de aire a traves de la rendia del muro y de las filtraciones de aire a traves de la rendja de las persianas y las aberturas de manejo, sobre todo
cuando ta caja tiene conexión directa con la cámara de cuando ta caja tiene conexión directa con la camara de aire. Este elemento se 
